

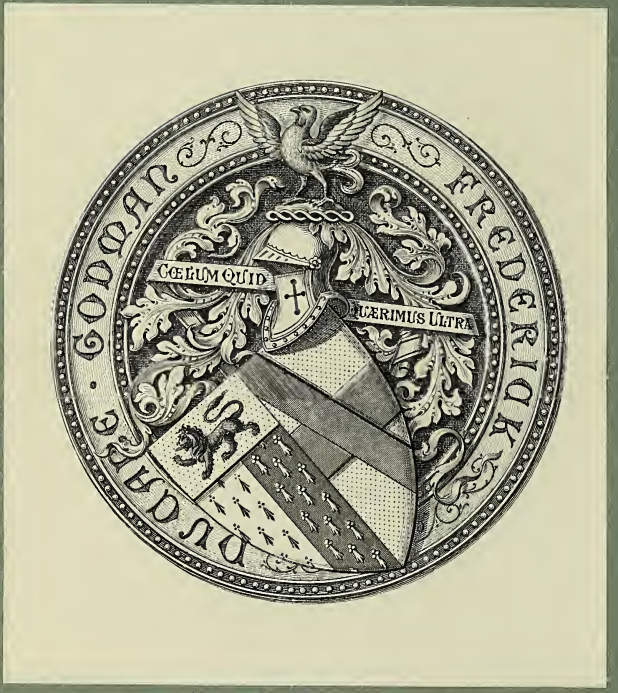









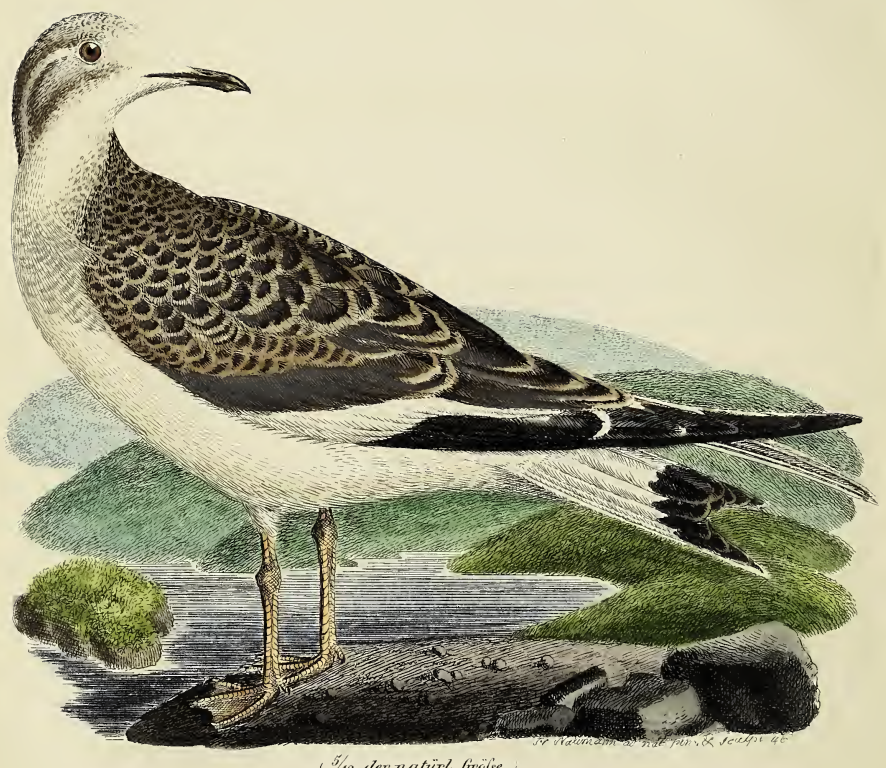

, 5/12 der mutrïrl (inofse.,

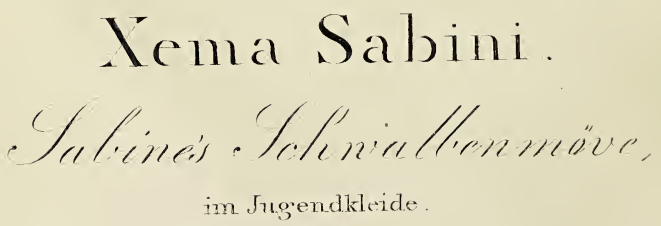




\title{
ORNITHOLOGISCHER BEITRAG
}

\author{
ZJ R \\ F A U N A GROE NLANDS \\ V $0 \mathrm{~N}$
}

CAR工

UEBERSETZT UND MIT EINEM ANHANG VERSEHEN

V 0 N

J. H. PAUTSEN, DR. MED.

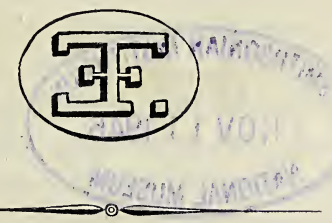

L E I P Z I G, E R N S T F L E I S G H ER. 1846. 


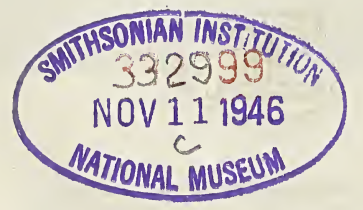




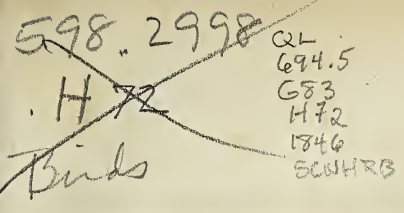

\section{Vorwort des Uebersetzers.}

Diese kleine Schrift wurde von dem Verfasser im Jahre 1840 an die Königl. dänische Gesellschaft der Wissenschaften eingesandt, von dieser mit der Silber-Medaille gekrönt, und für würdig erklärt, nach einigen Veränderungen, welche der Verfasser mit derselben bereitwillig vornahm, unter die Schriften der Gesellschaft aufgenommen zu werden. Da der Verfasser diese Aufnahme zu bewerkstelligen durch seinen Aufenthalt in Grönland verhindert wurde, zog er es vor, seine Schrift in der Zeitschrift für Naturwissenschaften Bd. IV. Heft 4. bekannt zu machen, aus welcher sie wiederum besonders abgedruckt wurde.

Obschon hierdurch der nächste Zweck erreicht, und dieselbe den Freunden der Ornithologie in Dänemark bekannt wurde, so hat sie doch, ausser diesem Kreise, eine so geringe Verbreitung erhalten, dass es mir selbst nicht gelingen wollte, dieselbe durch den Buchhandel zu erlangen.

Diese Abhandlung enthält aber, bei geringem Umfange, eine so grosse Menge gründlicher Untersuchungen, zuverlässiger Beobachtungen und neuer Thatsachen, dass die Kenntniss des Inhaltes gewiss jedem Ornithologen höchst wünschenswerth sein wird. Dieselbe schliesst sich den bekannten Schriften eines Faber, Boje und Graba an, und bildet gleichsam den Schlussstein zu diesem Cyclus von Beobachtungen, wodurch die Kenntniss von dem Vorkommen, der Ver- 
breitung und Lebensweise der nordischen (besonders nordwestlichen) Vögel unseres Weltheils bekannter und sicherer gestellt wird, als dies an den südlichen Gränzen desselben der Fall ist; wenn auch hier in neuerer Zeit (so durch die ausgezeichnete Schrift des Grafen v. d. Mühle über die Vögel Griechenlands) Bedeutendes geleistet wurde. Wie viele irrige Voraussetzungen über die Vögel Grönlands durch diese Arbeit berichtigt werden, brauche ich nicht näher anzuführen, ich bemerke nur hier die eine Thatsache, dass der grosse Ornitholog Temminck in seinem Manuel von dem Larus Sabini sagt: „,rés commun au Groenland, ou il niche etc.“, während unser Verfasser in $\mathbf{1 8}$ Jahren, bei allen Hülfsmitteln seiner Stellung, nur Ein junges Exemplar auftreiben konute.

Um das Hinderniss, welches die Sprache der grösseren Verbreitung dieser Schrift entgegen stellt, zu beseitigen, habe ich, nach Rücksprache mit dem Verfasser, die Uebersetzung in's Deutsche übernommen, und bitte um nachsichtige Beurtheilung. Eine Abbildung des in Grönland so seltenen Larus Sabini, welche ich im Jugendkleide von dort erhielt, wird dem Leser gewiss angenehm sein, zumal die ihm bekannte Meisterhand Naumana's es übernommen den Vogel zu zeichnen und zu stechen.

Ueber den Verfasser bemerke ich nichts, da sein Name bereits den meisten Ornithologen Deutschlands bekannt ist, aber die ausgezeichnete Gelegenheit, welche dem Verfasser, theils durch einen 18jährigen Aufenthalt, theils durch seine Stellung, zur Erweiterung der Naturgeschichte dieser starren Zone zu Theil wurde, muss hier hervorgehoben werden, und es verdient Anerkennung, dass die dänische Regierung bei Besetzung dieses Postens eine Wahl traf, welche ihr auch in andrer als amtlicher Beziehung zur Ehre gereicht.

Noch muss ich bemerken, dass ich die Schrift des Verfassers ganz unverändert wiedergegeben, obschon dieselbe ursprünglich für einen Leserkreis bestimmt war, der mit den 
in derselben vorkommenden Persönlichkeiten, so wie den Lokal - Verhältnissen des Landes, worüber sie handelt, bekannt ist. In dieser Beziehung führe ich an, dass dem hiermit weniger bekannten Leser der Gegensatz vielleicht auffallen wird, den man stets zwischen den Buchten (Fjorden) und den Inseln aussen vor findet. Dies rührt daher, dass das Innere Grönlands fast gänzlich unbekannt und unbewohnt ist. Nur die weite Küstenstrecke der Westseite Grönlands ist bekannt und bewohnt, und die Beobachtungen beziehen sich zum grössten Theıl nur auf diese. Diese Küste ist aber theils mit vielen, zum Theil tief in's Land sich erstreckenden Buchten (Fjorden) versehen, in oder an welchen die einzelnen Colonicen der Europäer oder Hütten der Grönländer liegen, während ein grosser Theil derselben mit einer Reihe zahlreicher Inseln besetzt ist. Die Communikation zwischen den verschiedenen Colonieen findet regelmässig zu Wasser statt, und nur ein kleiner Theil des Innern wird von den Grönländern, wenn sie sich auf die Rennthierjagden begeben, besucht; übrigens sind auch nur die Küstengegenden reich mit Vögeln versehen.

Die Communikation mit Europa, oder eigentlich mit dem Mutterlande Dänemark, findet nur durch die grönländische Handels - Compagnie in Kopenhagen statt, indem der Handel mit Grönland ein Monopol der Regierung ist, welches sie durch die erwähnte Compagnie ausübt. Kein Schiff irgend einer Nation, selbst kein dänisches, darf Grönland anders als im Nothfall besuchen. Ein Mal im Jahr besuchen die Königlichen Handelsschiffe sämmtliche verschiedene Colonieen, bringen die nöthigen Lebensbedürfnisse und Waaren dorthin, und führen die grönländischen Export-Artikel wieder nach Kopenhagen zurück *).

Wo in der Schrift schlechtweg vom Königl. Museum die

*) Grönland wird in 2 Inspektorate, Nord - und Südgrönland, getheilt; beiden hat unser Verfasser als oberster Beamter vorgestanden. 
Rede ist, bezieht sich dies auf das Königl. Museum zu Kopenhagen.

Einige Beobachtungen, welche vielleicht dem Leser von Interesse sein werden, habe ich als Anhang hinzugefügt. Sie waren theilweise für ein naturwissenschaftliches Journal bestimmt; da sie jedoch hauptsächlich von den in der Schrift vorkommenden Vögeln handeln, so glaubte ich, dieser Ort wäre zur Bekanntmachung eben so geeignet. Möchten sie nicht für ganz werthlos gehalten werden.

Apenrade, den Isten Februar 1846.

\section{Dr. Paulsen.}




\section{V $\mathbf{r}$ w $\mathbf{r}$ t.}

Die Fauna Grönlands ist früher, als die irgend eines andern, gleichen ungünstigen Verhältnissen unterworfenen, Landes bekannt geworden. Grönland ist so isolirt gelegen, dass man dort von allen litterarischen Hülfsmitteln, welche man nicht selbst mitbringt, entblösst ist, ja die Communikation mit der civilisirten Welt ist so dürftig, und beschränkt sich auf ein einziges Mal im Jahre, dass es zur reinen Unmöglichkeit wird, ein Buch zu leihen. Um so melir ist es anzuerkennen, dass mehrere der früheren Missionäre und selbst einige der dortigen Handels -Beamten einen so grossen Eifer für die Naturwissenschaften gezeigt haben, als dies wirklich der Fall ist.

Unter diesen vortrefflichen Männern zeichnet sich jedoch 0 tto Fabricius so sehr aus, dass er alle anderen in Schatten stellt, und jeder, der selbst nur wenig mit dem Lande und den Schwierigkeiten, dort Gegenstände aus den Naturreichen zu sammeln, bekannt ist, muss in Wahrheit über das erstaunen, was er geleistet. Später verstrich eine lange Zeit, in welcher die Naturwissenschaften in Grönland wenige Verehrer fanden, theils, weil die Fauna Groenlandica Fabrizii als ein abgeschlossenes Ganze, keiner Verbesserung fähig angesehen wurde, wobei man übersah, dass F a brizi u s nur an einer Colonie war, und sich nur wenige Jahre in Grönland aufgehalten hat; theils lag der Grund dieser Lauheit darin, 
dass sich damals auch in Dänemark kein besonderes Interesse für diese Wissenschaft zeigte.

Es ist zunächst der Eifer des Herrn Etatsrath Reinhardt für die Erweiterung des Königl. Museums in Kopenhagen, dem man es zu danken hat, dass das Interesse für Naturgeschichte hier im Lande wieder geweckt wurde, und dieser Gelehrte wurde durch mehrere günstige Umstände in diesem Bemühen unterstützt. Zuvörderst wurde das Land in den letzten Decennien von mehreren gebildeten Reisenden besucht, von denen einige die Naturgeschichte zu ihrem Hauptzweck gemacht hatten; dann gaben auch die gegenwärtig häufigen Reisen der Oberbeamten nach und von Grönland (welche in mehrerer Beziehung günstigen Einfluss äussern) den Naturforschern in Kopenhagen Gelegenheit, die Aufmerksamkeit jener auf naturhistorische Gegenstände zu lenken; endlich darf ich auch voraussetzen, dass mein Aufenthalt von 18 Jahren in Grönland (welches ich in dieser langen Zeit in keinem Sommer verlassen habe) einen günstigen Einfluss auf die Sammel-Lust geäussert hat, welche sich jetzt in dem Grade im Lande vorfindet, dass schwerlich auf der ausgedehnten Küstenstrecke von Julianehaab bis Upernevik irgend ein seltenes Säugethier, Vogel oder Fisch gefangen werden möchte, welche nicht für die Wissenschaft acquirirt würden.

Von meiner ersten Jugend an habe ich stets grosses Interesse für die Naturgeschichte empfunden; doch waren es hauptsächlich die Vögel, die mich besonders anzogen, und einer meiner liebsten Wünsche war es, ein Polarland zu besuchen, um Beobachtungen in dieser Richtung arizustellen. Dieser Wunsch wurde erfüllt, indem ich aus dem Fond ad usus publicos im Frühjahre 1822 Unterstützung zu einer Reise nach Grönland, um für das Königl. Museum zu sammeln, erhielt. Mein Aufenthalt dort verlängerte sich bis zum Herbst 1824, und in dem darauf folgenden Frühjahre wurde ich allergnädigst zum Inspektor über den Handel und Wall- 
fischfang in Nordgronland ernannt, von wo ich 1828 nach Südgrönland versetzt wurde. Für die Zwecke der Ornithologie sind an sich schon die Amtswohnungen der Inspektoren günstig gelegen, und dazu kommt noch, dass dies Amt häufige Reisen mit sich bringt, die immer in offenen Fahrzeugen längs der Küste unternommen werden.

Auf diese Weise habe ich wiederholt die ganze Küste von Julianehaab unter dem $60^{\circ}$ bis Upernevik unter dem $\mathbf{7 2}^{3 / 4}{ }^{0}$ N. B. bereist. Nach besten Kräften habe ich diese seltne Gelegenheit, welche mir zu Theil wurde, benutzt, um Grönlands Fauna, besonders die Ornithologie, zu studieren und ich hoffe, man werde mit dem, was ich als Sammler geleistet, zufrieden sein.

Seit 1832 habe ich mehrere Winter in Kopenhagen zugebracht, wo ich das Glück hatte, mich des freundschaftlichen und lehrreichen Umganges mit mehreren tüchtigen Naturforschern *) Dänemarks zu erfrenen, welches in hohem Grade mein Interesse für das Studium der Naturwissenschaften steigerte. Aber hierdurch erikannte ich auch sehr den Mangel, dass keiner, der sich längere Zeit in Grönland aufgehalten (allein mit Ausnahme von Fabri zius), seine Beobachtungen über das Vorkommen, die Verbreitung und Lebensweise der Thiere bekannt gemacht hat, so wie ich zugleich die Ueberzeugung erlangte, dass dasjenige, was durch Fabrizius geleistet wurde, uns schon zu wichtigen Schlüssen über die Veränderungen, die seit seiner Zeit in dem Vorkommen und der Verbreitung sowohl der höheren als niederen Thiere stattgefunden, berechtigt.

Die Leberzeugung dass der Standpunkt, welchen ge-

*) lch benutze diese Gelegenheit, öffentlich dem Herrn Etatsrath Reinh a rdt, Ritter etc. meinen wärmsten Dank für die wichtigen Aufklärungen auszusprechen, wodurch er mich in den Stand setzte, bedeutende Verbesserungen mit dieser $\mathbf{A b}$ handlung vorzunehmen. Gleichfalls danke ich Herrn Hage sehr für seine Bemerkungen, die an mehreren Stellen benutzt sind. 
genwärtig die Naturgeschichte im Kreise der Wissenschaften einnimmt, mehr als ein blosses Namens - Verzeichniss mit Beschreibung der Thiere erforderte (und dies ist doch alles, was unsere geehrten Gelehrten beim besten Willen und mit dèn besten Kräften daheim über Grönlands Thiere liefern können) und die Aufforderung, welche mir von mehreren Seiten zu Theil wurde, sind die Veranlassung, dass ich das Misstrauen in meine Kräfte überwand, und versuchen will, so gut. als dies meine Kräfte gestatten, diesen Mangel, in so fern er die Thierklasse, welche ich am besten kenne, betrifft, zu beseitigen. Sollte diese Abhandlung über die Vögel Grönlands, welche ich hiermit der 0effentlichkeit zu übergeben wage, eine wohlwollende Aufnahme bei Sachkundigen finden, so werde ich es mir zu einer angenehmen Pflicht machen, in einigermassen gleicher Art mehrere Thierklassen nach einander zu behandeln, zu welchem Zwecke ich in den letzteren Jahren fleissig die Materialien gesammelt habe.

Godthaab in Grönland im März 1840. 


\section{Von den Vögeln Grönlands.}

$\mathbf{S}_{0}$ viel mir bekannt, giebt es kein vollständiges Verzeichniss der in Grönland vorkommenden Vögel, daher ich der Meinung bin, ein solches werde hier an, seinem Platze sein.

Diejenigen Arten, welche als brütende Vögel in Grönland beobachtet wurden, sind ohne Abzeichen vor der Nummer aufgeführt. -

Dagegen bedeutet ein Stern (*) vor der Nummer, dass ich vermuthe, der Vogel brüte in Grönland, obschon dessen Brütplatz noch nicht entdeckt ist.

Zwei Sterne (**) zeigen an, dass der Vogel öfters in Grŏnland gefunden wurde, und daher zur Fauna dieses Landes gerechnet werden muss, obgleich ich nicht glaube, dass er daselbst brüte.

Die mit drei Sternen (***) bezeichneten Arten sind nur ein einziges Mal in Grönland getroffen, wesshalb ich ihr Vorkommen dort für zufällig ansehe. -

Ein Stern (*) hinter dem Namen der Species zeigt an, dass ich den Vogel selbst nicht in Grönland gesehen habe, dass er aber aufgenommen ist nach Etatsraths Reinhardts Ichthyologischen Beiträgen (Icht. B.) oder nach Fabricii Fauna Groenlandica. -

Eine Null $(0)$ endlich bedeutet, dass der Vogel früher dort gebrütet hat,. jetzt aber nicht mehr dort gefunden wird.

Mit einem $\mathbf{E}$ habe ich die europäischen, mit einem A die amerikanischen Vogelspecies versehen, welche in Grönland vorkommen. Z bezeichnet, dass der Vogel beiden Welttheilen gemeinschaftlich zukommt. Die eigentlichen Grönländischen Species, deren anderweitiges Vorkommen, als von dort ausgehend, angenommen werden muss; sind unter $\mathbf{G}$ verstanden, und endlich be- 
deutet ein grosses 0 , dass der Capt. Graah den Vogel auf der Ostküste Grönlands antraf. -

1. Aquila albicilla. Z.0.

* 2. - ossifraga. Z. 0 .

3. Falco islandicus. Z.0.

4. - peregrinus. $\mathrm{Z}$.

5. Strix nyctea. Z.0.

** 6. - brachyotus. Z.

7. Corvus corax (var. littoralis, mihi). G.0.

*** 8. Sylvia mexicana? A.

*** 9. Troglodytes palustris. A.

10. Saxicola oenanthe. E.

11. Anthus ludovicianus, Lichtenstein. Alauda rufa, Wilson. A.

*** 12. Alauda cornuta. A.

13. Emberiza nivalis. Z. 0.

14. - calcarata. Z.0.

* 15. Fringilla leucophrys. A.

16. Linota linaria. $\mathrm{Z}$.

17. - Hornemanni, mihi; canescens, auctorum. G.

*** 18. Hirundo americana. A.*

19. Tetrao Reinhardtii (Brehm. lagopus, auctor.). G.0.

20. Calidris arenaria. Z. O.

21. Charadrius hiaticula. Z.

** 22 . - pluvialis. $\mathrm{Z}$.

** 23. Vanellus melanogaster. Z.

*** $24 . \quad-\quad$ cristatus. E.*

25. Strepsilas collaris. Z.

** 26. Numenius phaeopus. E.

** 27. - hudsonius. A.

** 28. Tringa variabilis (T. alpina, Fauna Groenl.). *A.

** 29. Schinzii.

30 . - maritima. $\mathrm{Z}$.

31. - islandica. $\mathrm{Z}$.

** 32. Limosa melanura. Z.

** 33. Scolopax grisea. A. *

** 34. - gallinago, Z.*

*** 35. Rallus carolinus. A.

*** 36. Podiceps cornutus. Z.*

*** 37. - rubricollis. Z.*

38. Phalaropus hyperboreus. Z.o. 
39. Phalaropus platyrhynchus. Z.

40. Sterna arctica. Z. 0.

41. Xema Sabini. Z.

42. Larus glaucus. Z.O

43. - marinus. $\mathrm{Z}$.

44. - leucopterus. Z.G.

* 45. - eburneus. Z.

** 46. - brachytursus mihi. G.

47. - tridactylus. $\mathrm{Z}$.

** 48. Lestris catarractes. E.

49. - pomarina. $\mathrm{Z}$.

50. - parasitica (L. Schlepii Br.). Z. O.

51. - Buffonii:: E.

52. Procellaria glacialis. Z.0.

* 53. Thalassidroma Leachii. Z.

* 54. Puffinus cinereus. Z.

*** 55. - anglorum. Z.*

** 56. Cygnus melanorhynchus. E.

57. Anser hyperboreus. Z.

58. - albifrons. $\mathrm{Z}$.

** 59. - leucopsis. Z.

60. - bernicla. $\mathrm{Z}$.

61. Anas boschas. Z.

** 62. - acuta. Z.

** $63 . \quad$ - crecca. Z.

64. Clangula glacialis. Z.o.

65. - histrionica. Z.0

66. - Barrowii. A.

*** 67. - ? albeola. A.

68. Somateria mollissima. Z.0.

69. - spectabilis. Z.0.

** 70. - perspicillata. Z.0.

71. Mergus serrator. Z.

72. Carbo cormoranus. Z.0.

** 73. Sula alba. E.

74. Colymbus glacialis. Z.O.

75. - septentrionalis. Z.0.

76. Uria grylle. Z. 0.

* 77. - troile. $\mathrm{Z}$.

* 78. - leucopthalmos, Faber. (lacrymans, auctorum.) 
79. Uria Brünnichii. G.Z.O.

80. - alle. Z. 0 .

81. Mormon fratercula. $\mathrm{Z}$.

82. Alca torda. Z.

083. - impennis. $\mathrm{Z}$.

*** 84. Loxia leucoptera. Z. O. *

In den Jahren $1840-42$ sind die zufällig vorkommenden Vögel noch durch 3 amerikanische und eine europäische Art vermehrt worden:

*** 85. Muscicapa villica Lichtenstein. A.

*** 86. Sylvia (Sylvicola) coronata. A.

*** 87. Icterus frenatus Lichtenstein. A.

**** 88. Gallinula porzana. E.

Folgende mit einem Stern vor der Nummer versehene Arten, als :

Fringilla leucophrys,

Larus eburneus,

Puffinus cinereus,

Thalassidroma Leachii,

Uria troile,

- leucophthalmos

halte ich für nistend in Grönland selbst oder in unmittelbarer Nähe an dessen Küste, obgleich ihre Brüt-Plätze noch nicht auf gefunden sind :

1) weil man von diesen Arten Individuen in jedem Alter findet, und mit Ausnahme von Fringilla leucophrys und den 2 Uria-Arten in ziemlicher Menge, ja von Puffinus cinereus in grosser Menge;

2) weil man die alten Vŏgel in grosser Menge in der Brützeit antrifft, und man annehmen darf, dass die Vögel sich in dieser Zeit nicht weit vom Brütplatz entfernen. Dies ist zwar nicht der Fall mit Fringilla leucophrys und den Uria-Arten, aber ersteren schoss ich unter Verhältnissen, welche zienulich sicher schliessen liessen, dass der andere Gatte oder die Jungen in der Nähe waren, und von letzteren habe ich Uria troile einmal mit deutlichem Brutfleck erhalten.

Anders verhält es sich mit den vor der Nummer mit zwei Sternen bezeichneten Vögeln, welche mir aus folgenden Gründen nicht in Grönland zu nisten scheinen: 
1) Weil nur wenige Individuen dort angetroffen werden, worin alle übereinstimmen.

2) Einige wurden ausschliesslich nur während der Zugzeit bemerkt, z. B. die Arten von Anser etc.

3) Andre wurden nur auf dem Meere an den Küsten Grönlands gesehen, wie Lestris catarractes und Sula alba.

4) Andre wurden nur als junge Vögel gefunden, z. B. Anser hyperboreus.

5) Wiederum kommen andre zwar in verschiedenen Alterstrachten vor, z. B. Charadrius pluvialis, Vanellus melanogaster, Numenius phaeopus, aber an Orten und unter Verhältnissen*), die es unwahrscheinlich machen, dass die Erlegten brütende Vögel sein sollten. Dies trifft zu bei allen diesen Individuen, welche ich während der Brützeit erhielt und über deren Acquisition ich genaue Auskunft erhalten konnte; sie wurden nämlich unmittelbar bei den Colonieen, oder auf den alleräussersten Inseln erlegt, woraus man schliessen kann, dass sie nicht haben brüten wollen; ausserdem waren alle sehr scheu, während das Gegentheil an den Brütplätzen statt findet.

6) Endlich kann man sich mit ziemlicher Sicherheit auf die Aussagen der Grönländer verlassen, da sie die Vŏgel ihres Landes sehr gul kennen; und der Preis, den sie für seltne Vŏgel an den Colonien zu erwarten haben, erzeugt noch grŏssere Achtsamkeit bei Leuten, die für alles Lebende einen scharfen Blick haben, und deren Herumschweifen, sowohl bei ihrem gewöhnlichen Fang, als auf den Rennthierjagden ihnen die beste Gelegenheit darbietet, die Vögel, welche wirklich im Lande brüten, an den Brütplätzen aufzufinden. Hıerzu kommt, dass die Vegetation an den Bergseen, gleich wie die Anzahl der sich dort aufhaltenden Voggel, so unbedeutend ist, dass diejenigen, welche dort brüten, schwerlich der Aufmerksamkeit der Grönländer, selbst wenn diese geringer wäre, als ich mit Grund annehme, entgehen würde. Es bedarf kaum noch der Erinnerung, dass manche, selbst alte, Sumpfrögel, die nicht brüten oder frühzeitig in der Brützeit ihre Gatten verloren, weit von den Brütplätzen abzustreifen pflegen; das Vorkommen solcher Vögel in Grönland wäre somit sehr erklärlich. Ich will indessen nicht behaupten, dass nicht einzelne dieser Vögel, z. B.

*) Das Nähere darüber findet sich bei den einzelnen Arten. 
Tringa Schinzii*), die Scolopax-Arten, Vanellus melanogaster der Achtsamkeit der Grönländer entgangen sein konnten; warum sollte dies aber nicht ebensowohl mit Anthus und Calidris der Fall sein**); letzterer gehört offenbar zu den seltneren Vögeln Grönlands.

Folgende Vögel, deren Vorkommen in Grönland ich als zufällig bezeichnet habe, da von jedem derselben nur ein einziges Individuum bisher vorgekommen, möchten am passendsten zusammen, unter Angabe der Zeit wann, und des Ortes wo sie getroffen wurden, aufgezählt werden:

Alauda cornuta: Godthaab, October 1835.

Loxia leucoptera: Ostküste, Zeit unbekannt.

Vanellus cristatus: Fiskenaesset, Januar.

Troglodytes palustris: Fiskenaesset, October 1820.

Hirundo americana oder rufa: Juni 1830.

Rallus carolinus: Sunnertop, October 1822.

Podiceps cornutus: Nenortalik, November.

- rubricollis: Julianehaab, November 1839.

Puffinus anglorum: Julianehaab.

Clangula (?) albeola: Godthavn, October 1827.

Muscicapa villica (Licht.): Nenortalik, 24. Aug. 1840.

Sylvicola coronata: Fiskenaeset, 21. Mai 1841 und wiederum

1844 bei Frederickshaab nach schriftlicher Mittheilung des

Verfassers.

Icterus frenatus: Nenortalik, 2. September 1840.

Gallinula porzana: Goodthaab, 28. September 1841.***)

Werden diese 14 Arten von dem Verzeichniss abgezogen, so bleiben noch 74 Arten zurück, die zu Grönlands Fauna gehören, da sie ofter im oder am Lande angetroffen wurden. Von diesen

*) Ir. Schinzii brütet nach einer schriftlichen späteren Mittheilung des Verfassers an mich gewiss dort. Auch habe ich dieselbe wiederholt unter den Sendungen, die ieh von Grönland erhielt, sowohl alt als jung und selbst aus den nördlicheren Colonieen Grönlands erhalten.

Anmerkung des Uebersetzers.

**) In dicser Beziehung bedaure ich, dass mir die Gelegenheit fehlte, mehrere der Buchten Nord-Grönlands zu bereisen, welche im Ganzen am wenigsten von mir erforscht sind.

***) $\mathrm{Zu}$ diesen kommen noch Anthus pratensis, den ich im Herbste 1844, und Turdus iliacus, die ich im vorigen Jahre aus Grönland erhielt.

Anmerkung des Uebersetzers. 
sind 18 Arten nicht als brütend gefunden, und ferner muss Alca impennis abgezogen werden, welcher sicher nicht mehr im bekannten Theil des Landes nistet, so dass also 55 Vogelarten übrig bleiben, welche nach dem Vorstehenden in Grönland nisten.

Fabricius führt in seiner Fauna groenlandica 53 Arten auf, aber 2 von diesen: 1) Falco rusticulus und fuscus (unter einer Nummer aufgeführt) und 2) Anas glaucion sind bekanntlich nur junge Vögel andrer, in demselben Werke genannter, Arten, und 5 andre, Pelecanus cristatus, Larus cinereus, Ardea cinerea, Mergus merganser und Parus bicolor, welche Fabricius nicht selbst gesehen, sondern nach der Beschreibung der Grönländer aufgenommen hat, sind seitdem nicht in Grönland beobachtet, und müssen aus der Liste der grönländischen Vögel gestrichen werden; es bleiben also 45 Arten zurück, welche Fabricius bekannt waren, und die später wieder vorgekommen sind, obgleich nicht alle den in der Fauna groenlandica angeführten Namen entsprechen.

Grönland hat eine so bedeutende Ausdehnung und liegt so isolirt, dass man schon daraus schliessen kann, seine Fauna habe ihren eigenthümlichen Charakter, und dies zeigt sich auch an allen Thierklassen, die hier im Lande gefunden werden. Bei den Vögeln ist das besonders Hervortretende eine, wenn 'ich so sagen darf, boreale Tendenz. Diese zeigt sich nicht allein daran, dass die grösste Menge der im Lande vorkommenden Vögel beständig nordwärts strebt, dort nistet, und insofern sie aus Standvögeln besteht, sich nur ungern durch Eis oder Dunkelheit nach Süden drängen lässt, so dass es nicht allein, wie auch in andern borealen Ländern, weit mehr Individuen im Norden als im Süden giebt, sondern besonders daran, dass die eigentliche Brützone derselben bedeutend nördlicher in Grönland, als in andern Ländern beginnt. Daher kommt es, dass alle Vögel, deren Nester man in Südgrönland fand, auch in Nordgrönland (ausgenommen allein Clangula Barrowii*)) brüten, während unter den oben als

*) Doch ist die Nestzone dieses Vogels auch weit nördlicher in Grönland, als anderswo. Nach Richardson hört derselbe mit $57^{\circ}$ auf. Hier fängt sie erst mit $64^{0}$ an, und erstreckt sich ungefähr $1 / 2$ Breitengrad nördlicher. 
in Grönland brütend angeführten Vögeln 13 Arten von den 46, deren Nester wirklich gefunden wurden, nur in Nordgrönland, oder bestimmter: nördlich vom 66sten Breitengrad brüten und 3 andre, welche nicht südlich vom $63^{1 / 2^{\circ}}$ N. B. brüten. Nimmt man an, dass der 66 ste $^{\circ}$ N. B. Nord - und Süd-Grönland scheide, so hat Nord-G. 46, Süd-G. nur 33 Arten. Nichtsdestoweniger giebt es unter den Vögeln, die allein in Nordgrönland brüten, nicht wenig Arten, deren Brützone sich in andern Ländern weit südlicher erstreckt.

Betrachtet man die Vögelarten mit Rücksicht auf die Zahl der Individuen, so ist dies Phänomen noch mehr auffallend, da zur Brülzeit die Zahl der Individuen innerhalb der arktischen Zone ausserordentlich viel grösser ist, als in. Südgrönland. Nach meinen Beobachtungen nisten folgende Vögel hier nicht südlicher, als unter dem hinzugefügten Breitengrad, als:

\begin{tabular}{|c|c|c|c|c|c|}
\hline Linota Hornemanni ) & . & & & $75^{\circ}$ & \\
\hline $\begin{array}{l}\text { Anser bernicla } \\
\text { Lestris Buffonii }\end{array}$ & . & . & - & $70^{\circ}$ & - \\
\hline Procellaria glacialis & & & & $69^{\circ}$ & \\
\hline $\begin{array}{l}\text { Calidris arenaria } \\
\text { Tringa islandica }\end{array}$ & & & & 00 & \\
\hline $\begin{array}{l}\text { Phalaropus platyrhynchus } \\
\text { Uria alle }\end{array}$ & & . & • & $68^{\circ}$ & \\
\hline $\left.\begin{array}{l}\text { Anthus ludovicianus } \\
\text { Somateria spectabilis }\end{array}\right\}$ & & & & $67^{\circ}$ & - \\
\hline $\left.\begin{array}{l}\text { Uria Brünnichii } \\
\text { Carbo cormoranus }\end{array}\right\}$. & & & & $64^{\circ}$ & $\div$ \\
\hline Mormon fratercula. . & & & & $3 / 2^{0}$ & \\
\hline
\end{tabular}

Durch die Güte des Herrn Etatsrath Reinhardt sehe ich mich in den Stand gesetzt, eine Liste hinzuzufügen, wie weit nördlich einige boreale Voggel in Nordamerika brüten (nach Richardsons Beobachtungen):

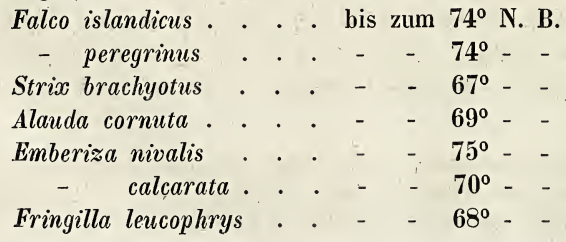


4 Arten Hirundo . . . bis zum $60-68^{\circ}$ N. B.

Tetrao rupestris . . . - - $77^{\circ}-$

Vanellus melanogaster . - - $70^{\circ}-$

Tringa alpina

- maritima

Sterna arctica

Phalarcopus hyperboreus

Larus leucopterus platyrhynchus

bis zım $75^{\circ}$ N. B.

- glaucus

Lestris pomarina

- parasitica

Obgleich nun aber manche Arten ganz im Süden des Landes brüten, z. B. Somateria mollissima, andere ziemlich südlich, als: Uria Brünnichii, Carbo cormoranus, so ist dies doch nur der Fall mit einer so unbedeutenden Zahl Individuen dieser Arten, dass die eigentliche Brützone für diese weit nördlicher zu setzen ist, und dies findet auch bei manchen andern Arten statt.

Die Ursachen zu der Thatsache, dass die Vögel in Grönland so weit nach Norden ihre Brütplätze suchen und überhaupt es vorziehen, im nördlichen Theile des Landes sich aufzuhalten, anzugeben, möchte wohl unmöglich sein, bis man bessere Kenntnisse über das Vorkommen der niedern Thierklassen hat, da man annehmen muss, dass die Nahrung eines der wesentlichsten Momente dabei ist. Allerdings kann auch die Lage des Landes darauf einen grossen Einfluss äussern. Nordgrönland liegt näher an Amerika, woher Grönland seine meisten Zugvŏgel bekommt, der Weg über das Meer ist also weniger lang. Ausserdem hat Nordgrönlands Clima mehr den Charakter eines borealen Festlandes, das Wetter im Sommer ist mehr beständig, die mittlere Wärme in den Sommer-Monaten höher als in Südgrönland, welches gänzlich den Charakter eines borealen Küstenlandes hat, mit viel Regen und Nebel.

Freilich fehlt ein Theil der Zugvögel, welche im Frühjahre sehr selten bei den Colonieen in Südgrönland angetroffen werden, dort nie im Herbste, z. B. Anthus, Anser albifrons und bernicla etc.; dies lässt sich aber leicht erklären, wenn man die Gestalt des Landes ansieht und sich erinnert, dass alle diese Vögel von und nach dem Festlande von Amerika ziehen; längs mit dessen Küsten ziehen die Vögel nach Norden, und gelangen so erst zu dem 
Breitengrade, wo sie ihre Brutplätze suchen, bevor sie quer über die Davisstrasse fliegen, wodurch der Weg über's Meer abgekürzt wird. Im Herbste folgen sie südwärts ziehend dagegen Grönlands Küsten, und indem sie den Flug über's Meer so lange als möglich aufschieben, sieht man dieselben an der ganzen Südküste. Bei Nenortalik, welches in der Nähe der Südspitze Grönlands liegt, sammeln sich daher die Vögel, sowohl von der West-als Ostküste, daher dieser Strich auch zur Herbstzugzeit am reichsten an Vögeln ist.

So reich Nordgrönland *) im Sommer an Vögeln ist, eben so arm ist es in dieser Beziehung im Winter. - In der Zeit, wo die Sonne unter dem Horizonte ist, sieht man von Landvögeln nur: Corvus Corax var. littoralis, Tetrao Reinhardtii, ausnahmsweise Falco islandicus und Strix nyctea; von Seevögeln nur: Uria Brynnichii, Alle und Grylle nebst jungen Vögeln der SomateriaArten. Aeusserst selten bemerkt man einen Larus, nie eine Procellaria, obgleich zuweilen das Meer nicht besonders mit Eis bedeckt ist. Weiter in dem Winter, in der kältesten Zeit, gegen Ende Februar und im März, sieht man auf den Felsen im Innern des Landes Emberiza nivalis und Linota Hornemanni stets in Schaaren, und dort findet man gewöhnlich auch viele Schneehühner. - Gegen Ausgang des April beginnt das Frühjahr, und sobald das Eis aufgeht, ist das Meer auch sogleich bedeckt imit Seevögeln, besonders Uria Briinnichii, Alle und Grylle. Der letztgenannte Vogel ist unter allen Seevögeln der letzte, welcher sich durch das Eis vertreiben lässt.

Nordgrŏnland besitzt zwar im Sommer eine weit grössere Anzahl Vögel, sowohl mit Rücksicht auf die Arten als auf die In dividuen, doch giebt es einzelne Vögel, welche Südgrŏnland eigenthümlich sind, und zwar folgende:

\section{Fringilla leucophrys, \\ Puffinus cinereus, Thalassidroma Leachii, \\ Uria troile, \\ Uria leucophthalmos,}

*) Indem ich von Nordgrönland spreche, beziehe icli mich besonders auf Godhavn $\left(69^{\circ} 14^{\prime}\right.$ N. Br. und $43^{1 / 2}$ W. L. von Greenwich), wo ich 3 Jahre mich aufhielt. 
Lestris catarhactes und

Cygnus melanorhynchus.

Als eigenthümlich für Nordgrönland betrachte ich alle die Vögel, deren Brützone sich nicht weiter südlich, als zum $66^{\circ} \mathrm{N}$. B. erstreckt; aber fast alle diese Vögel wandern entweder im Winter nach Südgrönland, oder werden doch dort in der Zugzeit gesehen.

Nur wenige der Vögel, die in Nord - und Südgrönland brüten, werden zur Brützeit häufiger in Süd-als Nordgrönland gefunden, diese sind:

Larus marinus,

- leucopterus,

- tridactylus,

Lestris parasitica,

Clangula histrionica,

Colymbus glacialis und

Corvus Corax var. littoralis.

Alle andern Species sind durchschnittlich weit zahlreicher in Nord - als Südgrönland.

Eine andre Eigenheit der borealen Vögel ist die constante Farben-Verschiedenheit an einer und derselben Art, welche, so weit mir bekannt, noch nicht gehörig beachtet ist. Diese Verschiedenheit dauert bei manchen Arten das ganze Leben hindurch, als bei Falco islandicus, Lestris parasitica und pomarina, Procellaria glacialis. Als eigenthümlich für Grönland führe ich an, dass dieselbe bei gewissen Arten nur in der Jugendtracht stattfindet, wie bei Larus glaucus und leucopterus, welche in zwei ganz verschiedenen Farbenkleidern die Jugendzeit durchmachen, doch so, dass, wenn sie brutfähig werden, sie die regelmässigen Farben der Art annehmen.

Als Besonderheit der Fauna Grönlands verdient noch die grosse Menge zufälliger Vögel einer Erwähnung, und, wenn man will, das Vorkommen einer Menge Arten, welche nicht jährlich eintreffen, obschon sie öfter gesehen wurden, und welche nie, oder sehr selten dort nisten. - Von erstern sind nemlich 14 Arten bemerkt, von letztern 18, also im Ganzen 32 Arten (von 84), welche nicht jährlich in Grönland eintreffen. Der Grund dieser Erscheinung. liegt wohl an verschiedenen Umständen. Der hauptsächlichste ist wohl, dass Grönlands Küsten stets mehr oder weniger mit Eis umgeben sind, und dass das Meer in weiter Entfernung vom Lande nie der Eisberge ermangelt; dazu kommt der 
Nebel, der oft längere Zeit anhält und die Vögel verwirrt, die auf den Eisschollen und Eisbergen Ruheplätze und Wasser, ja die Sumpfvögel selbst Nahrung vorfinden. Die geringe und niedrige Vegetation des Landes gewährt dem ankommenden Vogel keinen Schutz, so dass er bald entdeckt und von dem Sammler acquirirt wird. Hierzu kommt noch die genaue Kenntniss der Grönländer mit den Vögeln des Landes, wesshalb sie gleich auf einen ihnen unbekannten Vogel aufmerksam werden, und denselben erlegen, und der ziemlich hohe Preis, der für solchen ungewöhnlichen Vogel bezahlt wird, ermuntert sie, den Europäern den Fang zu bringen.

Endlich verdient als charakteristisch für die Fauna Grönlands die auffallende Armuth sowohl an Arten als Individuen der Grallatores, welche in andern Ländern der borealen Zone häufig brüten, bemerkt zu werden. -

Wie bekannt, besitzt Grönland einen Theil Zugvŏgel, welche sowohl in Europa als Amerika gefunden werden, und es möchte nicht ohne Interesse sein, zu erfahren, von welchem dieser grossen Continente Grönland seine Zugvŏgel erhält. Meine sechs Reisen nach Grönland machten es mir möglich, in dieser Beziehung einige Untersuchungen anzustellen, und, insofern diese ein einigermassen zuverlässiges Resultat geben, erhält Grönland nur 5 Arten seiner Zugvögel von Europa, nemlich:

\section{Saxicola oenanthe, \\ Falco peregrinus, \\ Strix brachyotus, \\ Numenius (phaeopus?) und \\ Cygnus melanorhynchus.}

Die Reise nach Grönland trifft gewöhnlich zur Zugzeit der Vögel ein, und der Weg geht über das Atlantische Meer, südlich von den Färöern und Island. Wenn man auf diesem Wege nach Westen die westlichste Spitze von Island passirt ist, so glaube ich annehmen zu dürfen, dass alle Vögel, die man dann antrifft, auf dem Wege nach Grönland sind. Auf allen diesen sechs Reisen sah und fing ich dort häufig Saxicola oenanthe, zwei mal erhielt ich Falco peregrinus, einmal Strix brachyotus und bemerkte zweimal einen Numenius und Cygnus, alle auf dem Zuge nach Grönland, wenn die genannten Bedingungen Grund genug geben, die Richtung des Zuges zu bestimmen. - Gelangt man dagegen westlich vom Cap Farvel (der Südspitze Grönlands) und hinein in die Davis-Strasse, so erscheinen ganz andere Zugvőgel.' Dann 
kommt Emberiza nivalis und calcarata, Anthus ludovicianus und Linota linaria (nie Hornemanni). gewöhnlich mit Nebel und Sadwind, oft-in grosser Menge am Bord der Schiffe. Gleichfalls sieht man kleine Schaaren Charadrius hiaticula*), und zuweilen grosse Schwärme der Phalaropus-Arten, theils fliegend, theils schwimmend zwischen dem Eise. Ich nehme an, dass diese Vögel auf dem Zuge von dem Festlande Amerikas nach Grönland begriffen sind. -

Grŏnlands Meer, ohne Zweifel eins der fischreichsten im Norden, ist gleichermaassen angefüllt mit Weichthieren, Crustaceen und andern Thieren der niedern Ordnungen. Hieraus lässt sich vielleicht schon der grösssere Vogel-Reichthum (an Individuen), woran die Küsten Grönlands die andrer Länder übertreffen, erklären. Da ein grosser Theil derselben gesellschaftlich leben, hat Grönlands Westküste eine Menge Vogelberge **), welche, da die Volksmenge unbedeutend und der Preis, welcher für Federn bezahlt wird, gering ist (jetzt werden sie nicht mehr aufgekauft), wenig gestört werden. Von den Vogelbergen sind vielleicht Inujuatub in dem Godthaaber Fjorde (Meerbusen) (hauptsächlich bewohnt von Larus tridactylus, leucopterus und glaucus) und Karsarsoak bei Upernevik (besonders besetzt mit Uria Brünnichii) die merkwürdigsten, wegen ihrer Ausdehnung und der unberechenbaren Menge Vögel, welche auf ihnen nisten***). Ich habe Gelegenheit gehabt, eine grosse Anzahl Vogelberge zu sehen, sie bieten alle mögliche Situationen dar: einige liegen weit hinein in die Meerbusen, z. B. Inujuatub gewiss 10 Meilen in dem Godthaaber Fjorde hinein, andere liegen an der offenen See, als Karsarsoak, Godhavn's Scharben - und Blaufelsen, besetzt mit Procellaria glacialis; sie sind gegen alle Himmelsgegenden gerichtet, und haben nur eine Eigenschaft gemeinschaftlich: nemlich die Leich-

*) Obgleich die Amerikan. Ornithologen das Vorkommen von Charadrius hiaticula in Amerika nicht zugeben, muss ich doch annehmen, dass wir den Vogel von dort erhalten; denn nicht allein habe ich denselben im Atlant. Meere gesehen, sondern auch oft auf dem Fluge quer über die Davisstrasse bemerkt. Gewiss ist es jedoch, dass alle die Individuen, welche ich erhielt, von der europäischen Art sind.

**) Doch giebt es nur wenige im südlichen Theil des Landes.

***) lch bin aufgefordert worden, die Vogelberge genauer zu beschreiben, und werde desshalb Materialien sammeln, um' eine solche Beschreibung in einer Zeitschrift zu geben. 
tigkeit, dem Vogel und den Jungen Nahrung während der Brutzeit zu verschaffen, besonders in der ersten Zeit, nachdem die Eier ausgebrütet. Die meisten Vogelberge, welche ich kenne, liegen nämlich ganz in der Nähe solcher Stellen, wo Mallotus arcticus ans Land kommt, um den Rogen zu streichen. Die übrigen liegen an Stellen, wo das Meer zur Brutzeit (zu andrer Zeit erinnere ich mich nicht, dort gewesen zu sein) gleichsam mit Crustuceen und Weichthieren (besonders Clio borealis und Limacina arctica) angefüllt ist. Bei Karsarsoak ist das Meer so mit Crustaceen angefüllt, dass man nicht durchs Wasser sehen kann, und die Excremente der Vŏgel beweisen hinreichend, dass jene ihre Nahrung ausmachen, wie ich auch keine andre in der Speiseröhre der erlegten fand. Ich nehme daher an, dass die Sorge für Nahrung das einzigste Motiv ist, welches auf die Wahl der Nistplätze an den sogenannten Vogelbergen influirt, insofern diese Felsen dann passende Localitäten dafür darbieten.

Das von Faber an den isländischen Vogelbergen beobachtete höchst interessante Phänomen, dass es dort immer auch ungepaarte Vögel giebt, und dass diese das Ausbrüten der Eier und die Ernährung der Jungen übernehmen, deren Versorger umkamen, habe ich nicht in Grönland entdecken können. Bei ganz kleinen Vogelbergen glaube ich beobachtet $\mathrm{zu}$ haben, dass es keine übercompleten Exemplare gebe; bei den grösseren macht die ungeheure Menge der Vögel es unmöglich, in dieser Beziehung eine Ansicht zu haben. Ich habe öfter die Vögel von einzelnen freiliegenden Nestern weggeschossen, in keinem Falle aber wurden die Eier bebrütet; aber ich habe nur Gelegenheit gehabt, diese Versuche mit Alca torda und mit Larus tridactylus anzustellen, welcher letztere indessen einer der Vögel ist, die Faber nennt. Dieser Mangel an Uebereinstimmung, wäre merkwürdig genug, da, wie bekannt, Landt dieselbe Bemerkung auf den Färöern gemacht hat, als Faber auf Island, wenn die Verhältnisse von diesen den grönländischen gleich wären, welches aber keinesweges der Fall ist. Ich habe schon früher bemerkt, dass die grönländischen Vogelberge wenig gestört werden, so dass die alten Vögel, Junge und Eier, welche hier von Menschen vernichtet werden, im Verhältniss zu der Menge der Vögel gleich Null zu rechnen sind. Wenn aber meine an den Vogelbergen hier angestellten Beobachtungen zu Schlüssen berechtigen können, dürfte es vielleicht nicht zu kühn sein, änzunehmen, dass der bedeutende Vogelfang auf 
Färröe und Island dies Vikariiren der ungepaarten Voggel sowohl nothwendig als möglich macht.

Faber führt in seinem Prodomus S. 108 an, dass, ungeachtet man auf Westmannöe jährlich wenigstens 20,000 Junge der Procellaria glacialis wegnimmt, doch die Zahl dieser Voggel an dieser Stelle zunimmt. $0 \mathrm{~b}$ diese Zunahme auch an den andern Vogelbergen stattfindet, wird nicht bemerkt, aber nach den Nachrichten, welche ich mir über die Ausfuhr der Federn aus Island habe verschaffen können, hat die Anzahl der Vögel nicht abgenommen.

Hier in Grönland, wo die Vögel und Vogelberge so wenig beunruhigt werden, kann man keine Zunahme bemerken, nur an einzelnen der kleinern Vogelberge findet sich die Zahl der Vögel zuweilen Veränderungen unterworfen, indem dieselben bei dem einen Vogelberge zunehmen, bei einem andern abnehmen.

Wie bekannt, wird der Eidervogel in Island geschont und gehegt, aber der Export der Dunen hat, so weit ich habe erfahren kŏnnen, nicht zugenommen, also auch nicht der Vogel selbst. Hier in Grönland wird der Eidervogel auf die schändlichste Art behandelt. Man nimmt nicht allein die Eier ohne Schonung weg, sondern fängt und schiesst auch die alten Vögel bei den Nestern, und verfolgt und fängt die kleinen Entchen, sobald sie ins Wasser kommen etc. Ausserdem wird nicht allein eine grosse Menge Eidervögel auf dem Zuge geschossen, sondern die Grönländer fangen auch eine Masse in den Monaten Januar bis April, da dieselben nicht selten in dieser Jahreszeit die Bedingung zur Existenz der Grönländer an mehrern Stellen Südgrönlands ausmachen, indem ihr Fleisch, nebst dem einiger Alken und Dorschen (Cottus bubalis, Seebull), die einzigen Nahrungsmittel derselben sind.

Trotzdem ist keine Abnahme zu bemerken, wenigstens wenn man nach der ungeheuren Anzahl, welche im Herbste manche Stellen der Meerbusen förmlich bedeckt, urtheilen will. Gleichfalls hat die Produktion der Dunen nicht abgenommen; dies sollte jedoch im allerletzten Jahre der Fall sein, welches indessen durch ganz andre Ursachen als die Abnahme der Vögel bewirkt ist *).

*) Leider muss ich jetzt (1842) berichten, dass die Menge der Eidervögel an Grönlands Küsten in den letzten Jahren bedeutend abgenommen; aber dies ist plötzlich geschehen, indem nach mehreren sehr feuchten Sommern, unter deren Einfluss die meisten Jungen umkamen, im Jahre 1836 ein sehr früher Winter mit 
Wenn sonach die Anzahl der in Grönland gewöhnlichen Vǒgel keinen bedeutenden Veränderungen unterworfen ist, so findet ein andres Verhältniss mit den Vögeln statt, welche hier nie in grosser Anzahl waren, sondern die nur Grönland besuchen.

So weiss man mit grosser Bestimmtheit, dass Alca impennis an mehreren Stellen 'gebrütet hat ${ }_{2}$ - jetzt kann derselbe als gănzlich verschwunden in Grönland angesehen werden. Aehnlich verhält es sich mit dem Schwan *), der jetzt nicht mehr in dem bekannten Theile Grönlands brütet. Charadrius pluvialis ist früher viel allgemeiner als jetzt gewesen, da er nicht allein von Fabrizius als brütender Vogel aufgeführt, sondern von andern auch als gemein genannt wird, während ich in 18 Jahren nur einige Exemplare gesehen habe.

Dagegen nehmen natürlich auch andre Vogelarten zu. Es ist fast unglaublich, dass ein so ausgezeichneter Beobachter, als Fabrizius, den Falco peregrinus **) und Anthus ludovicianus übersehen haben sollte, wenn diese Vögel denn damals, wie es jetzt der Fall ist, jährlich an den meisten Colonieen Südgrönlands, und namentlich bei Frederickshaab, wo Fabrizius wohnte, gesehen wurden.

Vanellus melanogaster und die Numenius-Arten waren vor 18 Jahren so sehr selten, dass ich in 3 Jahren nur ein Exemplar von Vanellus und einen Numenius erhielt, und auch keine Individuen weiter sah, obgleich ich damals häufiger die Fjorde besuchte als jetzt; aber in der spätern Zeit habe ich in jedem Jahre mehrere Exemplare gesehen. Gleichfalls meine ich, dass die $P$ halaropus-Arten und Tringa islandica im Zunehmen sind. Von andern Vögeln muss man annehmen, dass sie sich periodisch in grösserer Menge zeigen, darunter Strix brachyotus, welche ich im Jahre 1826 an mehreren Colonieen erhielt, die aber seitdem mir nicht vorgekommen. So ist auch Lestris Buffonii, wenigstens zur Zugzeit, ein solcher periodisch sich zeigender Vogel.

In der Fauna groenlandica des Fabrizius finden sich gewiss sehr gute Beobachtungen über Lebensweise und Vorkommen

ungewöhnlich früher Eisdecke eintrat, wodurch der Eidervogel zu Millionen in Nordgrönland unterging.

*) Ausführlicher hierüber bei dem Speciellen dieser Vögelarten.

**) Seitdem hat $\mathrm{H}$. H a ge mich aufmerksam gemacht, dass die Beschreibung von Fabrizius Falco rusticolus recht gut zum jungen Falco peregrinus passt. 
eines Theiles der Vŏgel Grönlands, und der Etatsrath Reinhardt hat, sowohl in seiner Zeitschrift für Naturwissenschaften, als in den Ichthyologischen Beiträgen gleichfalls über das Vorkommen derselben Aufklärungen gegeben; dennoch glaube ich, dass man bisher nirgends ausführliche Nachrichten über die Verbreitung der Vŏgel besitzt, sowie die Lebensweise mehrerer Arten von dem ausgezeichneten Beobachter Fabrizius nicht angeführt werden konnte, weil der Vogel sich im Sommer nicht bei der Colonie zeigte, wo Fabrizius wohnte. Ich wage es daher mit dem Versuche hervorzutreten, diese Lücken durch die Erfahrungen, welche ich mir erworben, auszufüllen.

\section{A qu i $\mathbf{a}$.}

\section{A Q U IL A A B I G ILLA}

ist im Sommer gleichhäufig in Nord- und Südgrönland, wohin im Winter alle ziehen, und im Frühjahre zu unbestimmter Zeit wieder nach Norden. Er horstet nicht selten auf zugänglichen Felsen, und legt 2 Eier spät im April. Er lebt sowohl von Seehunden, als Vögeln und Fischen, und da er zuweilen in SeehundsNetzen, welche nicht nahe an der Oberfläche des Wassers stehen, gefangen wird, taucht er auch: als Stosstaucher. Den Eidervogel fängt er, indem er sich vor Tagesanbruch auf einen Felsen oder eine Eisscholle in der Nähe des Tauchplatzes dieses Vogels setzt. Sobald eine Schaar dieser Vögel untergetaucht ist, fliegt derselbe über die Stelle hin, und sucht sich, wenn die Vögel heraufkommen, ein Männchen aus, wahrscheinlich, weil dessen weisse Farbe am besten im Wasser zu sehen ist, und indem er dasselbe verhindert, zum Athemholen hervorzukommen, ermattet der Adler es in dẹn Grade, dass es ihm leicht zur Beute wird. Uebrigens raubt er junge Voggel aus den Vogel-Felsen *) und nimmt vorlieb mit Aas jeder Sorte.

\section{A Q U I L A OS S IFRA GA.}

Unter diesem Namen glaube ich den Iangschwänzigen grösse-

*) Während die Larus-Arten zu Junujuatub Junge haben, sieht man täglich Adler und Falken über den Felsen schweben und ganz ruhig die Jungen aus den Nestern holen. 
ren Adler aufstellen zu müssen, welcher sich sowohl hier (in Dänemark?) als in Grönland findet, und sicher nicht A. leucocephala ist, welcher schwerlich in Grönland vorkommt, da man hier nie Adler mit vollkommen weissem Kopfe und Halse sieht. Erst in den letzteren Jahren bin ich auf den Unterschied zwischen diesen beiden Adler-Arten aufmerksam geworden, und bemerke nur, dass ich sicher bin, Aquila ossifraga horste in Grönland, da ich von dort sowohl junge als alte Individuen erhielt. In der Lebensweise stimmt er mit A. albicilla überein, und nach meinen Be obachtungen der letzten 2 Jahre. ist er eben so häufig in Nordals Süd-Grönland.

\section{F 21 co.}

\section{F A L G O IS L A N D I C US.}

Dieser ist der gemeinste Falke Grönlands und gleich häufig Im Süden und Norden. Er ist sehr verschieden an Farbe, vom Weissen mit einzelnen dunkeln Flecken, bis zum fast einfarbigen dunkeln Blaugrau. Ohne Zweifel hat das Alter einigen Einfluss auf diese Verschiedenheit, denn man findet fast keine weisse junge; allein es ist doch Unterschied in der Farbe, nicht allein bei den Nestjungen, sondern auch bei den brütenden Vögeln, von denen angenommen werden muss, dass sie dasjenige Kleid haben, welches sie durch's ganze Leben behalten.

Ich habe mehrere brütende Paare gesehen, von denen der eine Vogel hell war, der andre dunkel, und sowohl hellgefärbte als dunkle Männchen beim Neste erlegt. Nur ein einziges Mal erhielt ich ein Falkennest mit 4 Jungen, von denen das eine blaugrau, fast olıne Abzeichen, die andern dagegen sehr hell mit hellbraunen Streifen waren. Ferner habe ich viele junge Falken selbst erlegt, oder erlegt gesehen, welche dieselbe Farben - Verschiedenheit darboten, und unter den hellen sowohl Männchen als Weibchen gefunden. Die, freilich wenigen, Male, dass ich dergleichen Beobachtungen anstellen konnte, veranlassen mich zur Annahme, dass die weisse Farbe in Nordgrönland vorherrscht, wo das erwähnte Nest ausgenommen wurde, während in Südgrönland mehr dunkle Falken ausgebrütet werden. Mit diesem Punkte wäre ich also wohl im Reinen. Anders verhält es sich mit den schönen gelben Beinen 
und der gelben Wachshaut, welche einzelne, stets sehr helle, Falken haben; diese sind nicht nothwendig, um den Vogel brutfähig zu machen, ja ich muss gestehen, dass alle die Falken, welche ich beim Neste erhielt, mehr oder weniger hell blei-blane Wachshaut und Füsse besassen. Gleichwohl glaube ich nicht, dass der gelbbeinige Falke eine eigne Species ist, da ich durchaus keinen standhaften Unterschied in der Bildung des Schnabels oder der Zeichnung auffinden konnte. Vielleicht ist der Falke mit den gelben Beinen etwas kleiner, und die weisse Farbe etwas mehr rein; aber dies wäre auch der ganze Unterschied. Unter 14 alten Falken, die ich gegenwärtig in meiner Sammlung habe, ist nur einer mit den erwähnten gelben Füssen. *)

Die jungen Falken mausern, wie es scheint, ununterbrochen, den ganzen Winter hindurch, und gegen das Frühjahr wird keiner ohne Abzeichen gesehen. Ich besitze ein junges Weibchen, geschossen den 4. Jan. 1840, welches am Kopfe und Halse in starker Mauser begriffen ist, und durch die ausgewachsenen Federn an dieser Stelle ein weissgestreiftes Aussehen erhalten hat. Der Eierstock desselben war sehr ausgebildet, und da ich nach der Untersuchung der Fleischseite des Balges annehmen muss, dass der Vogel zum Frühjahre eine Zeichnung, wie bei den brutfähigen Vögeln, erhalten haben würde, scheint es mir nicht unwahrscheinlich, dass Falco islandicus schon im ersten Jahre, nachdem er ausgebrütet, sich fortpflanzt. **)

Der grönländische Falke legt im Juni 4 Eier von derselben Farbe, als die des Schneehuhns, aber doppelt so gross und mehr abgestumpft; er baut seinén Horst gewöhnlich auf unzugänglichen Felsen.

Er lebt in Grönland besonders von Schwimmvögeln, obschon er gerne Schneehühner raubt, und sucht seinen Horst in der Nähe der Vogelberge anzulegen, um mit Bequemlichkeit aus denselben die jungen Vögel holen zu können. Ich habe gesehen, wie er 2 junge Larus tridactylus auf einmal in seine Fänge nahm, und auf gleiche Weise 2 Tringa maritima, nemlich eine in jeder Klaue.

*) Durch Einsammlung einer grosseń Menge Falkén im Winter 1840-41 und 42 habe ich die Ueberzeugung erlangt, dass ein Theil, wenn nicht alle, die erwähnte hübsche gelbe Wachshaut erhalten, da ich mehrere Individuen gesehen habe, an denen der Uebergang von dem Bleiblauen deutlich $z$ sehen war.

**) Dieser Schluss des Verfassers möchte wohl gewagt sein, da der Vogel ja einige Jahre alt sein konnte.

A nm. d. U ebers. 
Seine Flugfertigkeit kann nicht besonders ausgezeichnet sein. Ich habe in mehreren Jahren Tauben gehalten, und nur 2 Junge verloren, welche der Falke im Sitzen nahm; gleichwohl wurden die alten Tauben im October und November fast täglich von den Falken gejagt, ohne eingeholt zu werden. Der Falke wurde oft geschossen, während er die Tauben bis zum Hause verfolgte. - Er ist nicht besonders scheu, und lässt sich leicht innerhalb Schussweite locken, wenn man ein Schneehuhn oder einen andern Vogel aufwirft.

Falco islandicus lebt im Sommer in der Tiefe der Buchten (Fjorde) und baut seinen IIorst am liebsten auf unzugånglichen Felsen, ganz nahe an den Vogelbergen. Im September fängt er an, sich an die Seeküsten zu begeben, in der Regel südwärts ziehend. Dieser Zug dauert bis in den November. Dann ist er nicht selten, und fliegt gerne bei den Wohnungen der Dänen umher, wo man ihn oft mit den Raben streiten sieht. Der Zug nach Norden im Frühjahre ist nicht so regelmässig, oder man sieht ihn dann nicht so häufig bei den Häusern der Europäer. Ausser diesem jährlichen Zuge hat der Falke in der Zeit, wo man ihn bei den Häusern sieht, einen täglichen Zug, indem er gewöhnlich Morgens südwärts und Abends gen Norden fliegt.

\section{F AL C O PEREGRIN U S}

ist nicht selten und horstet sowohl in Nord- als Südgrönland, unter andern selbst in der Nähe der Colonie Fiskenaesset. Er kommt in der zweiten Hälfte des Mai an und verlässt das Land im October; er verfolgt besonders Emberiza nivalis.

Obgleich ich nicht behaupten kann, dass der nordamerikanische Falco anatum sich in Grönland nicht vorfinde, bemerke ich nur, dass die Individuen, welche ich erhielt, vollkommen mit dem europäischen Falco peregrinus übereinstimmen. Hr. Hage, welcher sowohl aus der Benick'schen Sammlung, als von mir Exemplare vom alten und jungen Vogel erhielt, hat diese meine Meinung bestätigt. 


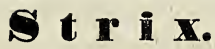

\section{S T R I X N Y G T E A.}

Diese Eule findet sich überall in ganz Grönland, von Upernevik bis Julianehaab, aber im Sommer häufiger im Norden, als im Süden. Ihr Nest ist zwar in Grönland nicht gefunden worden; ich habe jedoch zweimal in den ersten Tagen des Juni Junge derselben erhalten, welche unverkennbar nur wenige Tage das Nest verlassen hatten; es ist also gewiss, dass sie dort brüten. Die Jungen sind von viel dunklerer Färbung als die Alten. Ganz weisse Individuen habe ich nie gesehen.

Während der Vogel noch im Fleische ist, bilden einige wenige Federn auf beiden Seiten des Kopfes über dem Auge eine Art Horn *), so dass die in Temminck man. d'ornithol p. 83 als schlecht angegebene Rudbeck'sche Zeichnung gewiss nichts weniger als schlecht, sondern vollkommen naturgetreu ist.

Strix nyctea jagt sowohl am Tage, als am Abend, und scheint, wenigstens im Winter, am meisten des Abends thätig zu sein. Ich brachte einmal eine solche Eule dahin, mir fast eine Viertelmeile im Mondschein zu folgen, indem ich meine Mütze in die Luft warf; während ich aber ins Haus ging, meine Flinte zu holen, war sie fortgeflogen. Wenn sie gesättigt ist, ist sie sehr scheu, aber, während sie ihre Beute verzehrt, kann man sich ihr leicht nähern.

\section{S T R I X B R A C H Y O T U S.}

Ich habe diesen Vogel lebend hier im Lande nicht gesehen, aber auf der Ueberreise, wie auch von mehreren Colonieen in einem und demselben Jahre erhalten, jedoch nicht nördlicher als $65^{\circ} 30^{\prime}$. Die Wenigen, welche ich sah, waren alte Vögel im Mai geschossen.

Strix brachyotus scheint periodisch vorzukommen. So erhielt ich dieselbe 1826 von Julianehaab und dem Rikkertop, und habe sie später nicht wieder gesehen, bis zum Jahre 1842, wo ich Individuen von Fiskenaesset und Julianehaab erhielt; auch wurde in demsel-

*) Der Königl. Arzt an diesem Orte, Hr. Bloch, hat sowie ich diese Beobachtung gemacht, und ich hoffe, es könne diese Bildung noch an einem Balge bemerkt werden, den ich an das Museum geschickt habe. 
ben Jahre ein Exemplar an Bord der Brigg Egedesminde, im Mai, nahe an Grönlands Südspitze gefangen.

\section{C) V I.}

\section{C. CORAX VAR. LITTORALIS. Mihi*).}

Wenn ich auch nicht zugeben will, dass man allein nach der Ausmessung der absoluten Grösse eines Vögels die Verschiedenheit als Art bestimmen darf, so kann dies doch schwerlich auf die relativen Maasse ausgedehnt werden, und da diese, nach den geringen literärischen Hülfsmitteln, die mir zu Gebote stehen, beim Paben in Dänemark und Grönland verschieden sind, so könnte der grönländische Rabe wohl als eigne Art aufgeführt werden. Ich halte es indess für zureichend, denselben als constante Varietät anzuführen.

Nach Prof. Nilss ons Fauna Scandinaviae (das einzige Handbuch von denen, die ich besitze, welches die relativen Maasse angiebt) sind die Artzeichen von Corvus corax: Schwarz mit Purpurglanz, Schwanz stark abgerundet, Schnabel und Tarsus gleiche Länge, Länge 2 Fuss und darüber. - Dagegen möchten die Artkennzeichen von Corvus corax var. littoralis sein: schwarz mit Purpurglanz, Schwanz keilförmig, Schnabel 1/4 länger als Tarsus, welcher 2 bis $2^{1 / 2}$ Zoll beträgt, Länge $2^{\prime} 2^{\prime \prime}-2^{\prime} 3^{\prime \prime \prime}$. Die übrigen wichtigen Maasse sind: Länge $2^{\prime} 2^{\prime \prime}$, Flügelbreite $4^{\prime} 5^{1 / 2} 2^{\prime \prime}$, Schwanz $10^{\prime \prime} 6^{\prime \prime \prime}$, die mittelste Schwanzfeder länger als die äusserste $4^{\prime \prime}$, Länge des Kopfes vom ersten Halswirbel zur Schnabelwurzel 2" 2"', mit dem Schnabel 5" 6" Schnabel vom Mundwinkel zur Spitze in grader Linie $3^{\prime \prime}$. Höhe des Schnabels an den Nasenlöchern $1^{\prime \prime} 3^{\prime \prime \prime}$, Breite daselbst $1^{\prime \prime} 1 / z^{\prime \prime \prime}$.

Der grönländische Rabe weicht ausserdem sowohl im Habitus, als in der Lebensweise, vom dänischen Raben ab, welcher besonders im Sitzen sehr gedrungen aussieht, während der grönländische von schlanker flüchtiger Gestalt ist. Sein Schnabel scheint

*) Obgleich man mich aufmerksam gemacht hat, dass der europäische Rabe einen eben so grossen Schnabel als der grönländische hat, so scheint mir doch, als ob seine verschiedene Lebensweise und Aussehn ihm einen Platz als Varietät vindiciren. 
mir auch weniger stark, als der des dänischen Raben zu sein. In der Lebensart ist er von diesem ganz verschieden. Er ist nicht allein am wenigsten scheu von allen grönländischen Vögeln, sondern auch ein ausgemachter Küstenvogel, welcher, ungeachtet die Grönländer auf ihren Rennthierjagden im Gebirge grosse Mengen Fleisch liegen lassen, doch nur ausnahmsweise im Innern des Landes gesehen wird, während er sich sowohl im Winter als Sommer an den Küsten aufhält. Im Winter ist er ein vollkommner Küstenvogel, der sogar nicht selten grade in die Häuser geht, um dort zu stehlen. Ausserdem ist er ein vollständiger Raubvogel, welcher Schneehühner jagt und zuweilen fängt, und ein böser Räuber der Eier der kleinern Möven und der Eier und Jungen der Eidervögel. An meine Tauben schien er sich gewöhnt zu haben; nur in den ersten Tagen, wenn sie im Frühjahre ausflogen, wurden sie vom Raben verfolgt, später liess er sie unbeachtet.

Der Rabe sucht besonders seine Nahrung am Strande; diese besteht aus Fischen, Weichthieren und Muscheln, welche er aus der Höhe auf die Kilippen fallen lässt, um sie zu zerschellen. Ausserdem verzehrt er Aas und Abfall aus den Häusern der Dänen und Grönländer. Man sieht ihn nicht selten in grossen Schaaren von 100 und darüber auf den grönländischen Misthaufen sitzen; ausser der Brutzeit ist er sehr gesellig, wodurch er sich auffallend von dem europäischen Raben unterscheidet, welcher gewŏhnlich einzeln gesehen wird.

Er ist viel häufiger in Süd - als Nordgrönland, weil hier die grönländischen Hunde allen Abfall der Häuser, und Alles was sich bei niedrigem Wasserstande am Meerufer findet, verzehren. Die See tritt dort auch viel weniger zurück als in Südgrönland oder Mittelgrönland. - Er baut auf den Klippen, und hat schon Ende April Eier, die ganz denen des dänischen Raben gleichen.

\section{Saxicola Denanthe.}

Ich habe in der Einleitung zu beweisen gesucht, dass wir diesen Vogel aus Europa*) erhalten, und dass er wenigstens theil-

*) Wie bekannt hat Amerika nicht einmal das Genus Saxicola. 
weise die Reise nach Grönland über das atlantische Meer macht, ohne Island zu berühren. Der Vogel kommt ungefähr zur selbigen Zeit in Südgrönland, als in Island an, nemlich in den ersten Tagen des Mai.

Zu Godhavn kommt er einen Monat später an, und doch zuweilen zu früh, indem der Schnee noch Alles bedeckt, und die Wärme die Fliegen und Insekten, von denen er sich nährt, noch nicht hervorgelockt hat. Man trifft ihn weit in den Polarkreis hinein, bis zum $73^{\circ}$ und darüber hinaus. Im September zieht er in vollständiger Wintertracht fort.

\section{Anthus Iudovicianus. (Lichtenstein.)}

\section{A NTH U S R UFUS. (WILSON.)}

Dieser, der einzige Anthus*) Grönlands, ist in Etatsrath Reinhardt's Icht. B. unter dem Namen Anthus aquaticus mit der Bemerkung aufgeführt, dass der Vogel von dem europäischen verschieden sei, indem Reinhardt, Richardson und Bonaparte folgte, welche Alauda rufa $=$ Anthus aquaticus benannten. Später hat Bonaparte in seinem 1832 herausgegebenen Namensverzeichniss der europäischen und nordamerikanischen Vögel seine frühere Meinung dahin geändert, dass er die Art unter dem ersten der obengenannten Namen aufstellt.

Der Vogel weicht sowohl im Ganzen als in den einzelnen Dimensionen von Anthus aquaticus (obscurus Tem.) ab. Der grösste, den ich ausgemessen, betrug 5, $\left.5^{\prime \prime} *^{*}\right)$, der kleinste 5, $2^{\prime \prime}$, die meisten 5, 3"; die Breite 8" (während die Handbücher, welche ich besitze, Anthus aquaticus angeben: lang 6, 5", breit 11"). Der Nagel der Hinterzehe ist kürzer, als die Zeh, nemlich der

*) Ich habe schon früher bemerkt, dass ich ein Exemplar von Anthus pratensis aus Grönland 1844 im Herbst erhielt.

Anmerkung des Uebersetzers.

**) Diese Maasse sind nach Decimalen angegeben, da ich sie so in meinem Tagebuche aufgeführt habe und dieselben sich nicht genau auf Linien reduciren lassen. 
Zeh selbst 0, 27", der Nagel 0, 2" und nur wenig gebogen. Der Schwanz ist $2^{\prime \prime}$, der Tarsns 0, 7", der schwache Schnabel bis zum Mundwinkel 0, 52".

Es ist gleichfalls einiger Unterschied in der Farbe; soll derselbe jedoch in Worten wiedergegeben werden, so möchte vielleicht nur die Farbe des grönländischen Anthus mehr ungefleckt sein, als die des Anthus aquaticus (obscurus T.).

Bevor ich die erwähnte Abhandlung Reinhardt's kennen lernte, meinte ich, dieser Anthus sei unbeschrieben, und nannte denselben Anthus Reinhardtii, unter welchem Namen derselbe nach England gesandt ist. Sein grönländischer Name ist Kussecktarnak.

Auf dem Herbstzuge zeigt er sich bei allen Colonieen in Südgrönland, nistet jedoch nicht südlicher als in der Gegend von Holsteinborg, unter $66^{\circ} 50^{\prime}$, und soll an Nordgrönlands Meerbusen häufig 's sein. Das einzige Nest, welches ich gefunden, war in der Nähe von Godhavn, und enthielt im Anfange des Juli 4 Eier. Am Nestorte singt das Männchen mehr schrillernd als angenehm, indem dasselbe laut und durchdringend dieselbe Strofe wiederholt (welche quivit quivit quivit lautet), sich dabei in einer Spirallinie erhebend, und dann plötzlich grade niederstossend. Dieser Anthus ist kein Klippenvogel, wie nach Nilsson Anthus aquaticus, sondern hält sich im Sommer auf den Gras-Wiesen in der Nähe der Meerbusen, und zur Zugzeit bei den Häusern auf, wo er sich von Fliegenlarven nährt. Das Weibchen, welches ich beim Neste schoss, hatte Phalänen-Larven im Schlunde. An der Meeresküste habe ich denselben seine Nahrung suchend nie gesehen.

Seine Ankunft in Südgrönland findet in der Mitte des Mai statt, einen Monat später in Nordgrönland, und der Wegzug mit dem ersten Schneefall, also früher oder später im September.

\section{a m b e r i a.}

\section{E M B E R I Z A N I V A L I S}

ist sehr weit verbreitet über das ganze Land. Während auf Island die meisten überwintern, und nur wenige fortziehen, ist das Verhält- 
niss in Grönland umgekehrt, indem die meisten von da wegziehen, nur eine geringere Anzahl im Lande zurückbleibt, und von diesen noch mehr in Nord-als in Süd-Grönland, vermuthlich wegen des hier grössern Schneefalles. Während die Sonne unter dem Horizonte stelıt, habe ich denselben in Nord-Grönland nicht bemerkt. Die ankommenden Vŏgel zeigen sich zu Godtlaab in den ersten Tagen des April, zu Godhavn einen Monat später. Diese ankommenden Vögel, so auch diejenigen, welche ich auf der Herreise am Bord der Schiffe beobachtete, sind in voller Sommertracht, während die überwinternden Vŏgel hier im Süden gegen Ende des April oft noch in fast completer Wintertracht gefunden werden. Eine merkwürdige optische Täuschung ist es, dass die jungen Vögel, welche nach meiner Ansicht auswandern, grŏsser als die alten aussehen.

Diẹ jungen Vögel, deren Winteracht ganz verschieden von der Tracht derer, welche in Grŏnland überwintern, ist, haben die Rückenfedern, den Schwanz ind Schwungfedern von derselben Farbe, als im Sommer, doch alle Federn besetzt mit graubraunen Kanten, Kopf und Hinterhals grau mit bräunlichem Sclıein, auf der Mitte des Kopfes fast schwarz, Kehle, vordere Halsseite und Kropf bleich und aschgrau, am Kropfe ein rostbraunes Band. Die Seiten und der ganze Vogel sehen von unten weiss, mit aschoder braungrau angelaufen, aus, Schnabel gelb mit schwarzer Spitze. In dieser Tracht befinden sich alle die Vögel, welche Ende August, im September und October in Schaaren an den Colonieen und längs der Küste gesehen werden. Sie sind dann gewöhnlich sehr fett und wohlschmeckend. Wenn der Schnee del Boden ganz bedeckt, wandern sie aus. Als ich im October des Jahres 1834 Grönland verliess, sah ich Schaaren so gezeichneter Vögel nach Westen ziehen.

Sowohl Männchen als Weibchen überwirtern in Grönland. Bei dem Männchen sind dann die Federn am Kopfe, die im Sommer rein weiss sind, mit rostbraun gekantet; alle die Federn, welche im Sommer schwarz sind, haben dagegen breite weisse Säume, so dass der Vogel ein ganz weisses oder weissliches Aussehn erhält. Die Weibchen haben gleichfalls dieselben Farben als im Sommer, aber alle Federn mit breiten weissen Säumen, doch sehen diese nicht vŏllig so hell aus, als die Männchen. In dieser Tracht sieht man dieselben im Herbste nie an der Küste, wohl aber im Innern des Landes auf den Gebirgen. In sehr ge- 
linden (nie in harten) Wintern kommen sie in dieser Tracht einzeln an die Colonieen, werden aber desto häufiger von den Rennthier-Jägern im Innern des Landes gesehen, wo sie sich in Schaaren auf den Bergen umhertreiben.. Als ich 1826 im Februar über Land von Ritenbenk nach Omanak reiste, sahe. ich eine kleine Schaar $E$. nivalis nebst einer Schaar Linota Hornemanni auf den höchsten Gebirgen.

Emberiza nivalis nährt sich sowohl von Saamen und den Beeren von Empetrum nigrum und Vaccinium, als von Insekten und deren Larven, mit welchen sie vorzugsweise die Jungen füttert.

Der Uebergang zum Sommerkleide geschieht, selbst bei dem jungen Vogel, dessen Tracht ich beschrieben, allein durch $\mathrm{Ab}$ scheuern der Kanten, welches ich an Vögeln, die ich im Bauer überwinterte, beobachtet habe, obgleich diese immer etwas von der Zeichnung der jungen Vögel behalten und nie den rein weissen Kopf, welcher dem ausgefärbten Männchen eigenthümlich ist, bekommen.

\section{EMBERIZA CALCARATA}

ist allgemein im Innern der Meerbusen (Fjorde), sowohl in Südals Nordgrönland, doch sahe ich ihn nicht bei den nördlichsten Colonieen Omanak und Upernevik; die Fjorde dieser letzteren habe ich indess nicht bereist. Zu Godthaab kommt er an Anfangs Mai, einen Monat später zu Godhavn (ich bemerke, dass ich die Zeit der Ankunft der verschiedenen Vögel nach den ersten Tagen, an welchen ich die Vögel bemerkte, bestimmt habe). Der Zug, sowohl vom Lande weg als zum Lande, geschieht nicht zu einer Zeit; so sieht man z. B. bei Godthaab den ganzen Mai hindurch Emberiza calcarata ankommen. Er bleibt in Südgrönland bis Ausgang September, ja länger, wofern ihn der Schnee nicht vertreibt. Da man denselben nie auf den Schiffen sieht, bevor man in der Davisstrasse ist, so muss man annehmen, derselbe komme von Amerika nach Grönland.

Der grönländische Name: Narksamatak (Bewohner der Ebene) ist sehr bezeichnend, da der Vogel sich nur auf den Niederungen im Innern der Buchten aufhält, wo er sein Nest, wie die Lerchen, ins Gras oder zwischen Lichen-Arten baut. Seine 5 Eier von schmutziger Olivenfarbe mit braunen Flecken sind etwas kleiner als die der Emberiza nivalis. Der Gesang des Männchens, welchen es, entweder sich etwas in die Luft schwingend oder 
sich auf einem Zweige wiegend, hören lässt, ist sehr klar und melodisch, desshalb heisst er auch die grönländische Nachtigall.

Seine Nahrung besteht meist aus Saamen, und sucht derselbe nicht so sehr nach Insektenlarven an den Häusern der Grönländer als $\boldsymbol{E}$. nivalis.

In der Wintertracht gleichen alle Vögel dem Weibchen in der Sommertracht, nur sieht man an Männchen das Schwarze an den Kopffedern durchscheinen.

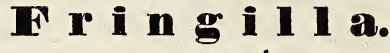

\section{F R I N G I L L A L E U G O P H R Y S}

Obschon ich diesen Vogel nur ein Mal*) in Grönland gesehen habe, glaube ich doch mit Grund anzunehmen, dass er im Innern des Landes nistet, da ich am 12. August das alte Männchen geschossen habe, welches im Königl. Museum aufgestellt ist, und abgezeichnet in den Icht. B. Tab. 1. fig. 2. Dies war 10-12 Meilen im Innern der Fjorde Amaraglik**); ich hörte hier seinen klaren Lockton, und vermuthete desshalb, dass er sein Weibchen oder Junge in der Nähe habe. Im Herbste desselben Jahres 1823 wurde wenigstens eine kleine Schaar bei Neuherrnhut bemerkt $\left(64^{\circ}, 10^{\prime}\right.$ N. B. $)$.

Einzelne Grönländer, denen ich die Zeichnung vorzeigte, erzählten mir, dass sie den Vogel im Innern von Amaraglik gesehen zu haben glaubten; allein ich habe, obschon ich gute Bezahlung anbot, später keinen erhalten. Vielleicht geht es mit diesem Vogel wie mit Clangula Barrowii, dass sein Aufenthalts-Ort sich auf eine sehr kleine Strecke des Landes beschränkt.

*) 1841 ist er im Herbste in der Nähe von Fiskenaesset geschossen.

**) In der Nähe von Godthaab. 


\section{I $\mathbf{m}$ o t a.}

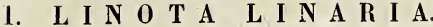

Dieser Vogel ist in Grönland sehr verbreitet, und kommt dort zur selben Zeit oder einige Tage später an, als $\boldsymbol{E}$. nivalis, aber stets in der ersten Hälfte des April. Dessen ungeachtet habe ich denselbén in den ersten Tagen des Juni am Bord der Schiffe gefangen, obgleich wir nicht nördlicher als Godthaab waren. $\mathbf{E r}$ kommt aus Amerika nach Grönland, welche Ansicht dadurch bestätigt wird, dass er in Island selten, aber häufig in Grönland ist.

Im Juni trifft man ihn im Innern der Fjorde bei seinem Neste, wo er ganz gegen die Natur andrer Vögel sehr wild ist, während er das ganze Jahr hindurch sonst sich äusserst dummdreist zeigt.

Das Männchen verliert in dieser Zeit seine schöne carmoisinrothe Brust, und ähnelt vollkommen dem Weibchen; er ist alsdann viel weniger prachtvoll, als in der Wintertracht. Derselbe baut ein kleines Nest in Birken, Ellern oder Weiden, und legt gewöhnlich 5 blauweisse Eier mit hellbraunen Flecken. Gegen Ende August und im September sieht man denselben in kleinen Schaaren bei den Colonieen. Das Männchen hat wieder seine schöne rothe Brust und sowohl Alte, als Junge sind äussert dummdreist. Die Individuen dieser Art, welche ich am Bord der Schiffe fing, wurden gleich völlig zahm, obgleich die Brütezeit, in welcher Zeit sich der Vogel selten an den Käfig gewöhnt, sehr nahe war; ja schon am. 2lsten Tage ihrer Gefangenschaft hüpften sie auf meine Hand, und kämpften selbst um Platz auf derselben, um den Hanfsaamen aufzulesen, obschon sie hinlänglich mit Grütz und Kernfutter versehen waren, hei welchem Futter ich sie Jahre lang erhalten habe. Ihre Nahrung besteht ausschliesslich aus Saamen und den Spitzen der Lichen-Arten. Im Anfang October verschwindet derselbe aus Grönland, und wird nie im Winter gesehen. In der Grösse variirt er sehr; in der Länge von $4^{3} / 4^{\prime \prime}$ $-5^{1 / 4} 4^{\prime \prime}$ und in der Breite von $7^{\prime \prime}$ bis $8^{\prime \prime}$. 
2. L. HORNEMANNI, Mihi*) L. GANESCENS, Auctorum.

Ich kann nicht annehmen, dass dieser Vogel, obschon er einige Aehnlichkeit mit Linota linaria hat, eine Abart dieser Species sein sollte, und zwar aus folgenden Gründen: Diese Art hat 1) einen stärkeren und viel breitern Schnabel, 2) ganz andre Farben in jedem Alter, 3) eine bedeutendere Grösse, 4) eine ganz andre Lockstimme, 5) eine andre Lebensweise als Linota linaria, der ausserdem immer das Land verlässt, während Linota Hornemanni Standvogel ist. 1824 sandte ich eine Sendung Vögel an Herrn T e mmin ck, unter dieser L. Hornemanni. Herr Justitiarius Boje, welcher bei dem Auspacken der Sendung zugegen war, hat mich versichert, dass sowohl er als Herr Temminck sogleich den Vogel als eigene Art erkannten**); da der Vogel indessen nicht in Temminck's Supplement angeführt ist, muss derselbe seine Meinung verändert haben, vielleicht weil er den jungen Vogel und das Nähere über die Lebensweise nicht kannte.

\section{Art-Kennzeichen:}

Der Schnahel stark, eben so breit als hoch, mehr als zur Hälfte bedeckt mit borstenartigen Federn, der Oberschnabel überragt den untern mit einer herabgebogenen Spitze. Länge $5^{3} / 4$ Zoll.

\section{Beschreibung:}

Das alte Männchen in vollständiger Wintertracht hat eine schwarzbraune Kehle, der Raum zwischen dem Schnabel und Auge von derselben Farbe, die borstenartigen Federn auf dem Schnabel dunkelgrau. Ueber den Augen läuft auf beiden Seiten ein weisser Strich, die hellgrauen rostgelb angelaufenen Ohrfedern bilden eine ohrähnliche Figur, um diese ein heller Streif, der Hals unter dem dunkeln Kehlfleck und an den Seiten rostgrau, diese letzteren gegen

*) Ich habe schon vor langer Zeit diese Linota als eigene Species erkannt, und nach dem secl. Etatsrath Ho rnemann genannt, welcher von Kindesbeinen an meine Lust für die Naturwissenschaften geweckt hat und welcher ohne Zweifel grosse Verdienste um den Eifer für diese Wissenschaft hat, welche sich vor 30 Jahren unter meinen Altersgenossen zeigte.

**) Bekanntlich ist im 3. und 4. Bande von T e m min cks Manuel d'Ornithologie dieser Leinfink unter dem Namen Fringilla borealis aufgeführt, vid.l. cit. III. $p .264$.

Anmerkung des Uebersetzers. 
den Kropf rosenroth angelaufen. Der Kropf und die Federn über dem Bürzel weiss und mit schönem Rosenroth angelaufen. Der übrige Theil des Rumpfes weiss, doch so, dass alle Federn gegen den Körper zu unten dunkelaschgrau sind, aber mit breiten weissen Säumen, welche den dunkeln Theil der Federn so decken, dass der Vogel völlig weıss aussieht. Hinter der carmoisinrothen Kaputze sind die Federn des Kopfes, Halses und Rückens grau in der Mitte, mit breiten weissen Säumen, welche dem Vogel das Ansehn geben, als wäre er in die Länge gestreift. Steuer- und Ruderfedern schwarzgrau mit breiten weissen Säumen. Auf den Flügeln 2 breite, weisse Streifen. Der gespaltene Schwanz und die ausgebreiteten Flügel sehen von unten so hellgrau aus, dass sie fast weiss erscheinen. Der Oberschnabel hornschwarz, der Unterschnabel gelb, die Beine schwarz, stark und mit stark gekrümmten Nägeln versehen.

Die Sommertracht unterscheidet sich vom Winterkleide nur dadurch, dass die Federn einen grossen Theil der weissen Säume durch die von Nilsson sogenannte „partielle Mauserung“ verlieren, durch welche auch das schöne Rosenroth am Halse und Kropfe verschwindet. Der ganze Schnabel ist hornschwarz, nur am Unterschnabel findet sich am Mundwinkel ein gelblicher Schein. Der Schnabel ist sehr stark, eben so breit als hoch. Der Oberschnabel ragt über den untern bedeutend hervor und ist von oben wenig eingedrückt. Länge $5^{3} / 4^{\prime \prime}$, Breite $8^{3} 4^{\prime \prime}$, Schwanz $2^{\prime \prime} 5^{\prime \prime \prime}$, Tarsus $71^{\prime \prime \prime}$.

Das alte Weibchen in der Wintertracht und das junge Männchen nach der ersten Mauser unterscheiden sich von dem alten Männchen in der Wintertracht nur dadurch, dass ihnen das Rosenroth am Kropfe und über dem Bürzel gänzlich fehlt, und dass sie weniger weiss sind, indem sich einzelne graue Streifen an den Seiten zeigen. Im Dunenklẹide sind die Jungen einfarbig grau, olnne Schwarz an der Kehle; der Schnabel bildet ein gleichseititiges Triangel, und der Vogel kann also nicht einmal in dieser Tracht, in welcher er doch am meisten dem jungen $L$. linaria gleicht, mit ihm verwechselt werden, da der Schnabel dieses stets von geringerer Breite als Höhe ist.

L. Hornemanni lebt im Sommer im höchsten Norden und nistet nicht südlicher, als unter dem 69sten Breitengrade. Er ist dann in Nordgrönland häufiger als $L$. linaria, welcher im hohen Norden selten wird, während L. Hornmanni selbst bei $73^{\circ} \mathrm{N}$. B. 
noch häufig vorkommt. Er baut sein Nest ebenso wie L. linaria ins Gebüsch und die Eier desselben gleichen ganz denen von $L$. linaria. Seine Lockstimme, welcher $L$. linaria nicht folgt, ist trillernd, und der des Seidenschwanzes nicht unähnlich. Er ist ein wirklicher Standvogel und hält sich im Winter in Schaaren auf den Gebirgen im Innern auf, doch von dem $66^{\circ} \mathrm{N}$. B. gegen Norden hin zahlreicher, als nach Süden. Im Februar 1826 sah ich mehrere Schaaren desselben auf den Gebirgen zwischen Ritenbenk und Omanak, und auf der Reise, welche der Kaufmann Kjeldson 1830 im stärksten Winter in's Inuere des Landes von Holsteinborg aus unternahm*), zeigten sich grosse Haufen dieses Vogels, der auch von den Rennthierjägern häufig gesehen wird, wenn. sie im Winter sich tief ins Land hinein wagen. In Südgrönland findet er sich im Sommer nie, und überhaupt selten. In sehr gelinden Wintern kann er jedoch zuweilen in ziemlich grosser Anzahl sich bei den Colonieen einfinden, wie im Winter 1828-29 und 1837-38 geschah. In den folgenden 2 Wintern wurde er nicht bei Godthaab gesehen, so wie man ihn in harten Wintern überhaupt nie an den Küsten bemerkt. Im Frühjahre und Herbste zeigen sich zuweilen einzelnè.

\section{T e t $\mathbf{r}$ a.}

Obschon mir Gelegenheit wurde, eine grosse Anzahl dieser Vögel zu untersuchen (die, so zu sagen, zu unserem täglichen Brodte gehören) und ich eine grosse Verschiedenheit in der Grösse und dem Bau des Schnabels und der Zehen gefunden habe, glaube ich doch, dass Grỏnland nicht mehr als eine Art besitzt. T. saliceti habe ich nie gefunden, obschon Temminck sie als grönländisch aufführt. Anführen muss ich jedoch, dass ich im Winter 1827-28 einige Schneehühner in Nord-Grönland erhielt, die so bedeutend kleinere Dimensionen hatten, dass ich nicht mit Sicherheit behaupten kann, dass diese nicht zu einer zweiten Art gehörten; ich nahm mir desshalb vor, sie in der Sommertracht aufzusuchen, um darüber Gewissheit zu erhalten, aber in demselben Jahre wurde ich nach Südgrönland versetzt, und verlor dadurch die Gelegenheit dazu.

*) Beschrieben in der dänischen Wochenschrift vom Dr. P ingel. 
Wenn auch das grönländische Schneehuhn nicht ganz oder vollkommen dem isländischen und norwegischen Felsen-Schneehuhne gleicht, so kann man, da die Abweichungen zu unbedeutend sind, doch schwerlich dasselbe als eigne Spezies aufstellen, und halte ich dasselbe für Tetrao lagopus, den Brehm'schen Namen hinzufügend.

\section{T. LAGOPUS, auctorum (REINHARDT II, Brehm.).}

Ich sehe mich ausser Stand gesetzt, eine genaue Beschreibung dieses Vogels zu geben, da dieselbe ohne sorgfältige Vergleichung mit dem isländischen und norwegischen Schneehuhn ungenügend sein würde, und beschrănke mich desshalb darauf, folgende Maasse anzugeben: Männchen: Ganze Länge 15“, Flügelbreite 25", Länge des Schwanzes 4" 7"', Tarsus 1" 3"', Kopf vom Halswirbel zum Schnabel $2^{\prime \prime} 1^{\prime \prime \prime}$, Schnabel in grader Linie vom Mundwinkel zur Spitze 9"', derselbe im Bogen von dem Anfang der Befiederung bis zur Spitze $4^{\prime \prime \prime}$. Die Maasse sind vom alten Männchen genommen; das Weibchen ist $13 \frac{1}{2} 2^{\prime \prime}$ lang, mit $231 / 2$ " Flügelbreite Es wäre wünschenswerth gewesen, dass Prof. Reinhardt das grönländische Schneehuhn in seinem Beitrag zur Naturgeschichte Grönlands abgezeichnet hätte.

In der Lebensweise gleicht das grönländische Schneehuhn durchaus dem isländischen, indem es sich den ganzen Sommer über im flachen Lande oder tiefen Gebirgsthälern aufhält, ja nicht wenige Paar nisten selbst auf den Inseln längs der offnen See. Dagegen finden sich auch einzelne Schneehühner brütend auf dem Gipfel mittelhoher Berge, wo man auch die meisten Schneehühner, welche nicht vereinzelt brüten, im Sommer antrifft. Schon in den letzten Tagen des April sieht man die Schneehühner gepaart, und das Männchen ist stets in der Nähe des Weibchens, bis die Eier ausgebrütet sind; dann zieht es fort in die höchsten Gebirge, wo es die wärmste Zeit des Sommers zubringt. Im Frühjahre sind die Schneehühner am Tage still; man sieht sie dann gegen Sonnenaufgang oft hin und her ziehen und auf Felsenspitzen sitzen. Das Männchen lässt jetzt oft sein schnurrendes arr $-r$ hören, welches das Weibchen mit seiner hellen Lockstimme beantwortet. Im Winter findet man das Schneehuhn, sobald es Tag wird, mit der Nahrung beschäftigt, und selten sieht man es, wenn es nicht aufgejagt wurde, vor Nachmittag fliegen, dann aber gewöhnlich in kleinen Schaaren ziehen, in der Regel von den 
Bergen herunter und gegen die See zu; gegen Abend zieht es zurück. Bei strenger Kälte gräbt es sich in den Schnee, wenn derselbe nur einigermassen weich ist.

Gegen den Herbst, wenn die Jungen vollständig ausgewachsen sind, ziehen die Schneehühner volkweise auf die Berge, wo sie sich den ganzen Winter über aufhalten; nur in sehr milden und schneearmen Wintern findet man dieselben auch überall in den Thälern. Ist sehr viel Schnee oder Eisschlag gefallen, dann streifen sie überall umher, kümmerlich ihre Nahrung suchend. Im Winter findet man dieselben sowohl im Innern der Buchten, als auf den Inseln. Obschon man das Schneehuhn einen Standvogel nennen kann, so wandert doch ein grosser Theil im Winter südwärts, am liebsten mit starkem Nordwinde; im Winter ist das Schneehuhn viel häufiger in Süd- als Nordgrönland, obgleich doch immer dort einige bleiben, selbst während die Sonne unter dem Horizonte ist.

Ich habe mehrmals bemerkt, dass das Schneehuhn nicht allein im Nothfall schwimmen kann*), sondern zuweilen selbst ohne solchen Grund schwimmt, und dies gar bei starker Kälte. Im September 1825 sah ich zum erstenmal ein Schneehuhn schwimmen; ich lag damals mit einer Galeasse auf der sogenannten Südostbucht, wir hatten einige Tage Nebel, und mehrere Schneehühner kamen auf's Schiff. - Eins dieser flog so gegen ein Segel, dass es ins Wasser fiel. Ich liess, da es fast stilles Wetter war, ein Boot aussetzen, in der. Meinung, es werde mir leicht zur Beute werden; aber mit grosser Leichtigkeit erhob es sich vom Wasser, und flog unbeschädigt davon. Im Winter darauf sah ich im December bei $10^{\circ}$ Kälte 2 Schneehühner von dem Udkigs Felsen bei Godhavn herabfliegen, und sich ganz ruhig auf's Wasser setzen. Gleichfalls habe ich Schneehühner in einem kleinen Gebirgswasser sich baden und auf selbigem herumschwimmen gesehen.

Die Mauserung des Schneehuhns bietet in Grönland einige merkwürdige Erscheinungen dar, indem dieser Vogel nicht allein in Südgrönland während des kurzen Sommers 3 mal mausert, sondern auch an den nördlichsten Orten, wo ich iln beobachtete, zwischen 72 und $73^{\circ} \mathrm{N}$. B., zum wenigsten das Männchen mit der Früljahrs-Mauserung nicht fertig wird, bevor die WinterMauserung im Herbste beginnt.

*) Herr Hage hat mir erzählt, dass er dasselbe beim gemeinen Rebhuhn beobachtet hat. 
Im April fängt das Weibchen an, seine Wintertracht mit der Sommertracht zu vertauschen, und hat vollständig ausgemausert, bevor es Eier legt. Das Männchen fängt später an zu mausern, mausert auch länger, so dass es gewŏhnlich erst im Juli in vollständiger Sommertracht erscheint, und dies selbst nur in Süd-Grönland. In Nord-Grönland geschieht diess noch später, und bei Upernevik (unter $72^{\circ} \mathrm{N}$. B.) habe ich die Männchen selbst im August in noch nicht vollständigem Sommerkleide gesehen, welches sie auch schwerlich ganz erhielten. Das Weibchen trägt die Sommertracht fast 3 Monate hindurch, denn im August findet man die meisten, wo nicht alle, brutfähigen Weibchen in voller Mauserung, durch welche sie ein völlig verschiedenes Aussehen bekommen, und es ist mŏglicherweise diese Mauserung, welche F a b e r zu der irrigen Annahme veranlasste, dass das Schneehuhn sein Winterkleid durch Abbleichen der Federn erhielte.

Durch diese Mauserung, welche vollständig ist (d. h. wo die Schwung - und eigentlichen Schwanzfedern auch gewechselt werden), behalten diese ihre gewöhnliche Farbe. Die Brust, welche während des Brütens völlig nackt war, wird weiss, alle übrigen Theile des Vogels, welche im Sommer bis dạhin schwarzbraune Federn mit breiten gelben Flecken und Bändern hatten, werden nun mit gelb-oder rothbraunen Federn bekleidet, welche ganz fein im Zickzack mit Schwarzgrau gezeichnet sind, so dass der Vogel in einiger Entfernung aussieht als wäre er einfarbig braungrau. Jede einzelne Feder hat indessen diese Färbung nur zur Hälfte ihrer Länge, indem der innere Theil weiss ist. Die Herbstmauser beginnt am Rücken, dann folgen die Seiten und zuletzt Hals und Kopf, dessen Federn braunröthlich sind. Ich habe noch nie einen Vogel gesehen, bei dem die erwähnte Mauserung am Kopfe fertig war*).

In wie weit das Männchen an dieser Mauserung Theil nimmt, habe ich bisher nicht entdecken können, da ich erst seit den letzten 2 Jahren diese Herbstmauserung des Weibchens kenne, und die Männchen in dieser Jahreszeit selten zu erhalten sind. Doch nehme ich an; dass diese Mauserung gleichfalls beim Männchen statt finde, ja selbst bei den Jungen desselben Jahres, worüber ich jedoch während meines erneueten Aufenthaltes hier in Grönland

*) Das zweifache Sommerkleid beobachtete auch Naumann (s. VI. S. 407 u. f.) am Schneehuhn der Schweizer-Alpen, u. a.

Anmerkung des Uebersetzers. 
Gewissheit zu erlangen suchen werde*). Von dieser Herbsttracht geht durch die gewöhnliche Mauserung das Schneehuhn über ins reine Winterkleid, welches es bereits im 0ctober vollständig trägt.

Das grönländische Schneehuhn ist sehr einfältig und wird leicht erlegt, es aber in der Gefangenschaft am Leben zu erhalten, hat mir nicht glücken wollen.

Ich habe nicht mehr als 12 Eier in einem Neste gefunden, doch hat man mir erzählt, dass dasselbe zuweilen bis gegen 16 Eier enthalte. Die kleinen Jungen habe ich in den ersten Tagen des Juli gesehen; sie sind im August ausgewachsen, doch ist es auffallend, von welcher verschiedenen Grösse man diese Jungen zur selben Zeit bei den verschiedenen Paaren findet. Das Schneehuhn nährt sich von den Blättern und Knospen der Gebüsche, aber im Winter machen die Beeren von Empetrum nigrum und den Vaccinium-Arten einen bedeutenden Theil seiner Nahrung aus.

Herr Justitiarius Boje hat mich mit der Stimme des norwegischen Schneehuhns bekannt gemacht; diese ist aber von der des grönländischen bedeutend verschieden. Das Männchen schreiet auch nicht wie das isländische: orrr! sondern deutlich arrr! und die Lockstimme des Weibchens hat keinesweges, wie die des isländischen, Aehnlichkeit mit der Stimme der Emberiza nivalis, sondern die Lockstimme derselben ist viel hŏher und klangvoller, doch weiss ich Nichts, mit dem ich dieselbe vergleichen könnte.

\section{Calidris aremaria}

gehört zu den seltnen Vögeln Grönlands, wird aber jedes Jahr auf Disco bemerkt, wo derselbe brütet. In Südgrönland habe ich den Vogel nicht selbst gesehen, aber bei Nenortalik ist er öfter geschossen, und ich glaube, dass er nicht südlicher, als unter dem $68^{\circ} \mathrm{N}$. B. brütet. Ich habe die Eier desselben nicht gesehen, sie sind mir aber beschrieben als von gleicher Farbe und Grösse, wie die der Tringa maritima; die 4 Jungen desselben im Dunenkleide fand ich auf einer kleinen Wiese etwas östlich von Godhavn im Monat Juli. Nach der Zeit, zu welcher er zu Nenortalik geschossen wird, zu urtheilen, verlässt er das Land Ende September.

*) Ich habe dem Königl. Museum Schneehuhn-Weibchen in dieser FederTracht übersandt. 


\section{C ha r a d r i u s.}

\section{G II A R A D R I U S II I A T I G U L A}

findet sich überall in Grönland, aber nirgends in Menge. Man sieht ihn bei Godthaab Anfangs Mai, trifft ilın aber im Herbste selten. Er hălt sich auf und sucht seine Nahrung bei kleinen Landseen und in Mooren. An solchen Stellen findet man das Nest zwischen kleinen Steinen und Grant.

\section{CHARADRIUS PL UVIALIS}

ist nach meinen Beobachtungen sehr selten. In 18 Jahren erhielt ich diesen Vogel nur 3 mal. Es wunderte mich daher, in den Icht. B. S. $11 \mathrm{zu}$ lesen, dass er an einzelnen Stellen in Schaaren gefunden würde. Ich glaube nicht, dass er im Lande brütet.

\section{Vanellus melanogaster}

gehört zu den Vögeln, deren Vorkommen nach meiner Ansicht im Zunehmen ist; ich habe ihn sowohl in Nord - als Südgrönland gesehen, doch gehört er bis dahin zu den seltneren Vögeln Grönlands. 1840 im September wurden 3 bei Nenortalik geschossen. Ich habe denselben im August bei Amaralik erlegt.

\section{Strepsilas collaris}

ist, ohne gerade gemein zu sein, doch auf den Inseln nicht selten, wo er sowohl in Süd - als Nordgrŏnland brütet. Er gehört zu den am spätesten ankommenden Vögeln, wird erst gegen Ende des Mai gesehen und verlässt das Land im September. Seine Nahrung bilden kleine Univalven, Bival en und Crustaceen. 


\section{N $\mathbf{m}$ e $\mathbf{n}$ i us.}

Es wurde in der Vorrede angeführt, dass man gegenwärtig Vögel dieses Genus häufiger, als vor 18 Jahren sieht. Wenn man dieselben in Grönland antrifft, sind sie ausserordentlich scheu, wesshalb man nur selten genau die Species erkennt. Dieser Umstand beweist übrigens auch, dass sie nicht in Grönland brüten, da dieselben zur Brutzeit sehr zahm sein sollen.

\section{NUMENIUS PHAEOPUS.}

Die Exemplare, welche ich erhielt, im Ganzen 5, waren zwischen Mai und September geschossen, und habe ich den Vogel sowohl von Nord - als Südgrönland erhalten.

\section{NUMENIUS HUDSONIUS}

ist zweifelsohne noch seltner, als der vorhergehende. Ich habe im Ganzen nur 3 Exemplare gesehen, nemlich von Julianehaab, Fiskenaesset und Godthaab.

\section{Tr i m a.}

\section{T R I N G A IS L A NoD I C A.}

Dieser Vogel ist in Süd-Grönland sehr selten, aber in NordGrönland wird derselbe oft angetroffen, und hat seine Brütplätze in den Buchten, wo er 4 Eier legen soll, die ich zwar nicht gesehen habe, aber dagegen mehrmals die Jungen desselben im Dunenkleide erhielt. Er muss in Nordgrönland gleich nach der Brütezeit sich auf die äussersten Inseln begeben, denn im Herbste habe ich ihn nie bei Godhavn bemerkt, dagegen bei Godthaab denselben in Wintertracht erhalten, und zwar im September. Erst im Juni kommt er im Sommerkleide zu Godhavn vor; kurz vor dieser Zeit sieht man ihn auf den äussersten Inseln unter $64^{\circ}$ in Südgrönland, wo er sich in der Zugzeit in jedem Frühjahre zu zeigen pflegt. Nach der Meinung der Grönländer, übereinstimmend mit meinen Beobachtungen, ist sein Erscheinen im Zunehmen; dieselben verwechseln ihn indessen zuweilen mit Phaluropus platyrhynchus und benennen ihn eben so: Kajok oder Kajordlik. 


\section{T R I N G A M A R I T I M A.}

Im Winter ist dieser Vogel sehr gemein so weit nach Norden, als das Meer nicht mit Eis bedeckt ist*). In dieser Jahreszeit hält er sich in grossen Schaaren zusammen, die desto zahlreicher werden, jemehr der Winter zunimmt und mehrere Vögel zwingt südwärts zu ziehen. Er nistet überall im Lande. Anfangs Juni verschwindet der Vogel von der Küste und zieht nach den Bergebenen, wo er sich kurze Zeit in kleinen Schaaren aufhält; bald darauf geht er paarweise an die Brütstellen, welche stets auf den Ebenen vom Meere $a b$, aber doch nie weit im Innern gefunden werden. Er legt 4 Eier, und ist um seine Jungen sehr besorgt. Zu keiner Jahreszeit ist er scheu, schwimmt nicht selten von einem Ufer zum andern, ja taucht selbst angeschossen. Seine Nahrung besteht aus kleinen Weichthieren mit Schaalen und Crustaceen, welche dem Fleische wahrscheinlich den nach meinem Dafürhalten unangenehmen Geschmack geben. Seine Frühjahrs Mauser findet Ende April statt, zu welcher Zeit sich der Vogel auf den Inseln in Haufen schaart, und die Paarzeit anfängt. In dieser Periode lässt er seine schrillernde Stimme ununterbrochen hören, besonders des Nachts.

\section{TR I NG A VAR I A B IL I S **).}

Ich sahe den Vogel nie in Grönland, führe ihn daher bloss auf Fabrizius und Reinhardt's Auctorität als grönländisch hier an.

\section{T R I N G S G H IN Z I I, Bonap. ***).}

Ich habe den Vogel selbst in Grönland nicht gesehen, und führe desshalb nur an, dass das Museum 3 Exemplare 1841 von

*) Es ist merkwürdig, dass Capt. Graah diesen Vogel nicht an der 0stküste von Grönland antraf; auch ist kein Name angegeben (Gra a h's Reise pag. 195), welcher vermuthen lässt, dass dieser Vogel gemeint sei.

**) Ich habe mehrmals den Vogel im Jugend - und Herbstkleide aus Grönland, jedoch nie im reinen Sommerkleide erhalten.

Anmerkung des Uebersetzers.

***) Nach schriftlicher Mittheilung des Herrn Verfassers vom vorigen Jahre brütet dieser Vogel sicher im Julianehaab-District, wo Capt. Holböl in den letzteren Jahren im August-Monat stets kleine Schaaren, junge und alte Vögel zusammen, angetroffen hat.

Anmerkung des Uebersetzers. 
Nenortalik erhielt (woher auch Herr Hage 1835 ein so junges Exemplar bekam, dass er annimmt, es müsse in Grönland ausgebrütet sein) und wiederum 1840 ein Individuum im Uebergange zur Wintertracht.

\section{Limosa melanura.}

Ich habe nur ein einziges Exemplar dieses Vogels erhalten, mit einer Kugel auf den Kok-Inseln, aussen vor Godthaab, erlegt.

\section{Scolopax grisea ?* $)$.}

Fast in allen Sommermonaten sahe ich eine Scolopax-Art bloss fliegend, konnte aber dieselbe nie schussrecht erhalten, da diese Vögel sehr scheu waren; jedoch dies nur in Südgrönland.

\section{Pha la ropus.}

Dies Genus enthält die niedlichsten Schwimmvögel, welche man sich denken kann. Sie schwimmen mit Grazie und Leichtigkeit, selbst in der aufgeregtesten see und unter den schwersten Stürmen, während welchen ich dieselben mitten in der Davisstrasse schwimmend angetroffen habe. Es ist bekannt, dass das Weibchen sowohl grösser als schöner ist, als das Männchen, und dass dieses Brütflecke hat, jenes nicht. Trotzdem behauptet Fa ber in seinem Prodromus, dass sowohl Weibchen als Männchen brüten und die Jungen begleiten. Dass ein Seevogel ohne Brütflecke brüten sollte, ist gegen alle Analogie, und ich war der Meinung, bis die erwähnte Schrift herauskam, dass das Weibchen nie brüte. Beide Arten sind in Grönland nicht selten, ich habe

*) Im Herbste 1845 erhielt ich eine Scolopax gallinago aus Südgrönland, und möchte es wohl zweifelhaft sein, ob die in Grönland vorkommenden Scolopax nicht der gewöhnlichen Heerschnepfe angehören, die man ja auch in Island und auf Ferroe häulig antrifft.

Anmerkung des Uebersetzers. 
viele Nester gefunden, aber nicht ein brütendes Weibchen; ja dies ist in der Nähe des Nestes so selten, besonders Ph. platyrhynchus, dass ich unter 11 dieser Vögel, welche ich in der Nähe 5, von mir aufgefundener Nester schoss, nur 1 Weibchen erhielt. Ich vermuthe daher, dass Faber (dem ich meine Beobachtungen über diese Vŏgel mittheilte und der mir sagte, dass Ph. hyperboraeus nur selten brüte) den Vogel auf dem Neste getroffen habe, grade als er sein letztes Ei legte; auf andre Weise kann ich mir diesen Mangel an.Uebereinstimmung nicht erklären.

\section{PH. H Y B ER B O R A E US}

kommt in den letzten Tagen des Mai an die Küste, schwimmit eine Zeit lang an den Inseln umher, und findet sich an den Brutplätzen zu Ende des Juni. Diese sind stets im Innern der Fjorde, am Ufer kleiner, in Thälern oder Mooren befindlicher Seen, nie an Gebirgs-Seen. Das Weibchen legt stets 4 Eier, die $10^{\prime \prime \prime}$ lang, hell olivengrün mit vielen braunen Flecken sind. Die Jungen laufen, wie die einer Tringa, im Grase umher und schwimmen nicht im Dunenkleide. In der Zeit, während welcher der Vogel sich hier aufhält, lebt er lauptsächlich von Insektenlarven, welche er in den kleinen Süsswasser-Seen fängt, oder aus dem Moose am Ufer hervorsucht. Jedoch zieht der alte Vogel am Abende hinaus auf die Fjorde, wo man ihn umherschwimmen und kleine Thiere verzehren sieht; zu welcher Thierklasse diese indessen gehören, habe ich, da sie sowohl sehr klein als gleich sehr zerdrückt sind, nie beobachten können.

Im August ziehen Alte und Junge hinaus zu den Inseln, wo sie in ungeheuren Schaaren umherschwimmen. Anfangs September sind sie in Wintertracht, und in dieser Zeit, in welcher sie selten an's Land kommen, sind sie so fett, dass es fast unthunlich ist, das Fell zum Ausstopfen abzustreifen. Am Ende des Septembers verlassen sie die Küsten ganz.

\section{PH. PLAT Y R H N CH U S}

ist der Vogel, welcher unter allen am spätesten in Grönland ankommt, nämlich Anfangs Juni. In diesem Monate sieht man ihn oft in der Davisstrasse und dann in grossen Schaaren; so traf es sich, als ich im Frühjahre 1835, 18 Tage hindurch, während der Hinreise nach Grŏnland, vom Eise eingeschlossen war. So 
lange wir vom Eise eingeschlossen waren, sahen wir stets diesen Vogel zwischen den Eisstücken herumschwimmen. In Südgrǒnland sieht man den Vogel äusserst selten, und nur auf dem Zuge nach Süden trifft man bei den äussersten Inseln oft kleine Schaaren an; aber in Nordgrönland, vom $68^{\circ}$ N. B. nach Norden, ist er sehr häufig und nistel dort fast auf allen Inseln, welche kleine T'eiche besitzen. Dagegen nistet er nie im Innern der Fjorde, und unterscheidet sich hierdurch von Ph. hyperboraeus, welcher nie auf den Inseln aussen vor der Küste brütet. Im Uebrigen gleichen beide Arten sich in der Lebensweise. Im August sind die Jungen flügge, und im September sieht man sie in Gesellschaft mit den Alten, sämmtlich in Wintertracht, bei den äussersten Inseln herumschwimmen, wo sie besonders die Scheeren aufsuchen, in deren Brandung sie sich sehr gern herumtummeln. In dieser Zeit kommen sie noch seltner an's Land, als Ph. hyperboraeus, und sind eben so fett. Sie verlassen die Küsten gegen Ende des September, und in dieser Zeit, besonders nach Sturm, trifft man kleine Haufen derselben aussen vor den Inseln in Südgrönland. Die Eier, stets 4, gleichen völlig denen der vorhergehenden Art, sind nur etwas grösser.

\section{Sterna arctica.}

Schon im April sieht man diese Meerschwalbe in der Davisstrasse, Anfangs Mai kommt dieselbe jedoch erst an die Küste, ungefähr gleichzeitig mit Phoca groenlandica. Sie ist sehr gemein gleich von Cap Farvel an bis Upernevik, mit Ausnahme der Strecke von Kangamiut $65^{\circ} 38^{\prime}$ bis Rummelpotten $67^{1 / 2^{\circ}}$. Auf dieser Küstenstrecke, die sehr mit Inseln versehen ist, und scheinbar einladende Brutplätze für Meerschwalben enthält, findet man sie nie, selbst nicht in der Zugzeit, so dass die Grönländer von Holsteinborg sie nur dem Namen nach kennen. Diese erwähnte Küstenstrecke, an welcher die Meerschwalbe nicht brütet, ist der Lieblings-Aufenthaltsort der Somateria mollissima, welche hier besonders nistet. Doch ist es keinesweges diese, welche die Sterna vertreibt, denn von dieser Küstenstrecke sowohl nord- als südwärts brütet die Sterna und der Eidervogel auf denselben Inseln in grösster Eintracht. Es wäre nicht ohne Interesse, den Meeres- 
grund auf dieser Strecke zu untersuchen, und da ich gegenwärtig im Besitz der nothwendigen Instrumente bin, werde ich dies bei erster Gelegenheit ausführen.

Die Meerschwalbe ist der einzige Vogel, welcher sich zuweilen an den Brütplätzen zeigt, ohne die Tracht der alten Vögel zu haben; aber diese jungen Vögel haben keine Brütflecke. Desshalb ist es auch nur der Geselligkeits -Trieb, welcher sie an die Brütplätze führt. Auch ich habe junge Vögel nur äusserst selten gesehen, und möchte lieber annehmen, eine verspätete Mauser habe die Schuld. Die Stirn ist dann weissgefleckt, der Schnabel sowohl als die Füsse schmutzig-carmoisinroth.

Die Meerschwalbe nistet sowohl auf den vor der Küste gelegenen Inseln, als in den Meerbusen und an den Süsswasserseen. Ihre liebste Nahrung sind kleine Fische und Themisto arctica, doch verzehrt sie auch viele Clionen. In den letzten (ersten?) Tagen des October verlässt sie die Küste, und wird bei Sturmwetter einzeln den ganzen Monat hindurch angetroffen.

\section{T a $\mathbf{r}$.}

Faber sagt im „Leben d. hochnordischen Vögel“ S. 85., dass Männchen und Weibchen dieses Genus gleich gross seien. Dies ist in Grönland nicht der Fall, wo das Männchen stets grösser als das Weibchen ist. Aber die Möven variiren an Grösse so sehr, dass man gewiss ein grosses Weibchen finden kann, welches eben so gross, als ein kleines Männchen derselben Art wäre, aber gewiss nicht mit diesem gepaart.

Alle die Möven, welche man in Grönland antrifft, so auch Sterna arctica, Lestris parasitica*) und pomarina sind Stosstaucher, da ich ohne Ausnahme alle diese Arten von den Grönländern in Schlingen, welche 2-3 Fuss unter die Oberfläche des Wassers gestellt werden, habe fangen sehen. Als Lockmittel braucht man entweder frische Mallotus arcticus oder man bildet einen Streifen aus Seehundspeck, wetcher sehr deutlich im Wasser zu sehen ist.

*) Lestris parasitica wird in Schlingen von den Grönländern in jedem Jahre, und recht häufig besonders im August gefangen. 
Es ist wohl schwer auszumachen, ob Larus marinus, glaucus und leucopterus theilweise vom Lande ziehen; ich bezweifle, dass die Erste dies thue, und möchte annehmen, dass von den zwei andern Arten auch nur sehr wenige im Winter die grönländische Westküste verlassen. Dagegen ist dies bestimmt der Fall mit den Möven dieser Arten, welche an der Ostküste leben, wo das Meer gewŏhnlich mit Eis bedecki ist; diese Möven ziehen vermuthlich nach dem nicht fernen Island, wo Faber Larus leucopterus im Winter antraf, aber nicht im Sommer; doch zweifle ich nicht, dass diese Möve zuweilen auch dort nistend vorkomme.

Die angeführten drei Arten ziehen dagegen längs der Küste im Herbste südlich, im Früljahre nördlich, aber die Zugzeit lässt sich nicht genau angeben, da sich dieselbe nach dem Belege mit Eis und dem Wetter richtet. Die Möven ziehen am liebsten im Sturm und gegen den Wind *). Ausser diesem jährlichen Zuge haben die Mlöven, wenigstens diejenigen, welche in den Fjorden sich aufhalten und brüten, einen täglichen $\mathrm{Zug}$, indem sie am Morgen theils längs der Küste, theils in der Mitte der Meerbusen in diese hineinziehen, und des Nachmittags oder Abends fast immer in der Mitte und oft sehr hoch in der Luft hinaușziehen. **)

\section{L. M A R I N U S.}

Aus dem grönländischen Larus marinus hat IIr. Brehm die Art Larus maximus gebildet, deren Art-Verschiedenheit gewiss aber auf sehr schwachem Grunde ruht; doch glaube ich anführen zu müssen, dass drei junge Grönländer, welche 1837 mit mir aus ihrer Heimath reisten, am Habitus den europäischen Larus marinus, welchen wir zuerst an den Hebríden und später an den dänischen Küsten sahen, durchaus nicht wieder erkennen konnten. Sie bemerkten mit Recht, dass nicht allein der Flug verschieden sei, sondern dass auch die Flügel dieser sowohl schmäler als spitzer seien, als die der grönländischen Mantelmöve.

Larus marinus ist im ganzen Lande gemein, doch häufiger in Süd-als Nordgrŏnland, am häufigsten vielleicht in der Mitte

*) Die Somateria-Arten ziehen am liebsten bei gutem Wetter und mit dem Winde.

**) Siehe bei Somateria mollissima. 
zwischen $63^{\circ}$ und $66^{\circ} \mathrm{N}$. Br. Diese Möve ist der bestimmteste Standvogel, den Grönland besitzt, denn ein Theil derselben bleibt das ganze Jahr hindurch in der Nähe der Inseln, wo sie brüten. Sie legt ihr Nest gewöhnlich auf Inseln aussen vor der Küste, oder auf ziemlich hohen Felsen an der Mündung der Meerbusen an. Trotzdem entfernt sie sich von allen Möven am wenigsten weit vom Lande, so dass die Schiffer es für ein sicheres Zeichen ansehen, dass das Land nur einige Meilen ențfernt sei, wenn $L a-$ rus marinus sich zeigt.

Obgleich sie selbst fischt und ein guter Stosstaucher ist, ist sie doch ein wahrer Raubvogel, da sie Eier und Junge stiehlt, wo sie nur ankommen kann. Sie nährt sich auch von Aas, aber da sie viel schener als Larus glaucus ist, findet sie sich nicht, wie diese, bei der Zerstückelung der gefangenen Wallfische ein. Anfangs Mai legt sie ihre Eier, und obgleich es am 6. Mai 1824 $12^{\circ}$ fror, hatte ich doch schon am 3. Mai die Eier derselben gefunden.

\section{L. G L A U G U S}

ist häufiger als die vorerwähnte Art, deren Grŏsse sie in einzelnen Individuen erreicht. Im Sommer ist sie zahlreicher in Nordals Südgrönland, wohin fast alle im Winter ziehen. Aus dieser Art hat Hr. Brehm 'seinen L. medius gebildet, von der man vorausgesetzt hat, dass sie sich in Grönland finden sollte; aber durch das Ausmessen einer grossen Anzahl dieser Vögel habe ich die Ueberzengung erlangt, dass es hier in Grönland nur eine Art giebt, die dahin gezählt werden kann, welche aber, was die Grösse betrifft, so sehr variirt, dass man gerne drei oder mehr Arten daraus bilden könnte. Das Mittel einer grossen Menge Ausmessungen giebt folgende Maasse:

Länge $2^{\prime} 5^{\prime \prime}$, Flügelbreite $5^{\prime} 6^{\prime \prime}$. Der grösste Vogel, den ich ausgemessen, ein Männchen, war $2^{\prime} 7^{1} / 2^{\prime \prime}$ lang und $6^{\prime}$ breit; der kleinste, ein Weibchen, war $\mathbf{1}^{\prime} 11^{\prime \prime}$ lang und zwischen den Flügeln $4^{\prime} 6^{\prime \prime}$. Dieser letzte nähert sich mit Rücksicht auf Grösse sehr dem Larus leucopterus, und kann nur dadurch von demselben geschieden werden, dass die Flügel nur ganz wenig den Schwanz überragen, während sie bei Larus leucopterus in zusammengelegter Lage über denselben 2 bis $2 \frac{1}{2}$ Zoll hinausreichen.

Larus glaucus und leucopterus haben das gemeinschaftlich, 
dass sie vom Neste an zwei ganz verschiedene Trachten durchmachen, oder, wenn man will, es giebt unter diesen zwei Arten, so lange die Vŏgel jung sind, zwei verschiedene Varietäten, welche dasselbe Kleid anziehen, sobald sie brutfähig werden. Diese Variation ist bei beiden Arten ganz gleich und die Beschreibung der einen Species gilt ebenso für die zweite. Wenn man in einem Neste Junge von dieser verschiedenen Zeichnung findet, so ist die eine, welche, ich mit Nr. 1 bezeichnen will, von der Färbung, in welcher die betreffende Mövenart im Nestkleide gewŏhnlich beschrieben wird; die andre, welche ich mit Nr. 2 bezeichnen will, ist von hellerer Färbung.

\section{N. 1.}

Am Halse mehrere Streifen im Zickzack; der Unterleib dunkelgraubraun; Rücken, Flügel und Schwanz weissgrau, auf welchem Grunde ein dunkles Graubraun und Lichtbraun Flecken und Bänder bilden.

Durch eine partielle Mauserung im ersten Herbste wird das Nestkleid fast gar nicht verändert.

Im ersten Frühjahre mausert der Vogel die Kopf- und Halsfedern, wodurch diese Theile dieselbe Farbe erhalten, welche Nr. 2 im Neste hatte; derselbe unterscheidet sich in diesem Alter von Nr. 2 durch den dunkelgraubraunen Unterleib.

Im zweiten Herbste mausert der Vogel alle Federn, und erhält dann den Schwanz, die Flügel und den Unterleib hellgrau mit bräunlichen Flecken und Strei-

\section{N. 2.}

Es fehlt überhaupt die dunkle graubraune Farbe, so dass die ganze Zeichnung einen sehr hellen Ton erhält, und derVogel dem ersten Augenschein nach einfarbig aussieht. Am Halse fehlt die Zeichnung fast gänzlich.*)

Ebenso.

Nach der ersten FrühjahrsMauserung wird Kopf und Hals einfarbig weissgrau, die übrigen Theile verändern sich nicht.

Im zweiten Herbst, wo alle Federn gewechselt werden, wird Nr. 2 überall schmutzigweiss, ausser am Kopf und Halse, wo er Nr. 1 gleicht, und am Unter-

*) 1824 brachte ich von Grönland zwei lebende junge Möven (Lar. glaucus) in dieser Farbentracht mit, welche von verschiedenen Ornithologen gesehen wurden. Bei meiner Zurückreise nach Grönland schenkte ich sie meinem Freunde dem Apotheker St ce nberg in Helsingör. 
fen, so dass der Vogel viel heller aussieht als im ersten Jahre. Am Kopfe und Halse ist diese Zeichnung fast völlig übereinstimmend mit der des alten Vogels in der Wintertracht, aber die Grundfarbe ist hellgrau, nicht wie beim alten weiss, der Schnabel hellfleischfarbig mit dunkler Spitze.

Im zweiten Frühjahre erhält Nr. 1 die Farbe des alten Vogels auf Kopf und Hals, aber das Weisse ist nicht so blendend als beim alten Vogel, das Uebrige bleibt unverändert.

Im dritten Herbste erhält der Vogel die Wintertracht des ausgefärbten Vogels. leibe, wo er einige bleichhellbraune Schmitze oder Streifen erhält.
Im zweiten Frühjahre wird der Vogel mit Ausnahme der erwähnten einzelnen Schmitze und Streifen einfarbig weiss, doch ist diese Farbe nicht von der blendenden Weisse, welche dem alten Vogel eigenthümlich ist, sondern das Weisse ist mit äusserst bleichem Grau angelaufen *). In diesem Kleide ist es Bennecke's Larus glacialis.

Im dritten Herbste erhält $\mathrm{Nr}$. 2 dieselben Farben, als der alte Vogel in Wintertracht, doch ist vielleicht das Mövenblau des Rükkens etwas weniges heller.

Die unter Nr. 2 beschriebene Varietät ist in Nordgrönland die häufigste **), während es von $\mathrm{Nr} .1$ am meisten im Süden giebt. Von 11 Jungen, die ich an einem Tage bei Godhavn erhielt, waren 8 wie Nr. 2, 3 wie Nr. 1 beschaffen. - In Südgrönland mag das Verhältniss umgekehrt wie.3-1 sein, so dass man am meisten von Nr. 1 findet.

Larus glaucus ist ein nicht völlig so schlimmer Räuber, als Larus marinus, aber doch ein kühner Eierdieb. Sie unterstützt die Lestris-Arten in der Bekämpfung der kleineren Arten, zwingt sie aber in der Regel, ihre Beute abzugeben. Sie ist sehr gie-

*) In dieser Farbentracht habe ich den Vogel an's Königl. Museum nach Hause gesandt, wo er sich aufgestellt vorfindet.

**) Wieder ein Beleg zu dem schon beim Falco islandicus bemerkten Vorwalten der weissen Farbe in höheren Breitegraden.

Anm. d. Uebers. 
rig nach Aas und desshalb beim Aufhauen der Wallfische sehr zudringlich, doch nicht so sehr als Procellaria glacialis. Sie fängt mehrere Arten Fische, z. B. Cyclopterus lumpus, Cottus bubalis etc., aber nährt sich im Nothfall auch von Seegras, und verzehrt eine Menge Beeren von Empetrum nigrum *), von denen die Excremente oft blau werden.

Sie brütet stets auf den Felsen, am liebsten in Gesellschaft mit andern Vögeln, doch sind einzelne Berge auch allein mit $\mathbf{L} a$ rus glaucus besetzt, wie Najartut, etwas südlich von Godthaab. Am meisten brütet sie in Gesellschaft mit Larus leucopterus und tridactylus. Larus glaucus duldet keinen Vogel über sich im Berge, und brütet daher in oberster Reihe, dann folgt Larus leucopterus, endlich Larus tridactylus in gleicher Höhe mit Alca torda, wenn dieser im Berge ist; zu unterst Uria grylle, die niemals in solchem Vogelberge fehlt.

Larus glaucus ist die einzige Möve, die man zuweilen, aber äusserst selten, im Winter in Nordgrönland antrifft; sonst hält sie sich in dieser Jahreszeit an den äussersten Inseln bis zum Februar auf, wo sie im Süden in die Buchten zu ziehen beginnt, dann tängt die Frühjahrs-Mauser an. Man sieht sie nicht selten sehr weit vom Lande ab.

\section{L. L E U G O P T E R U S.}

Es ist merkwürdig, dass ein so ausgezeichneter Beobachter, wie Fabrizius, diese so gewöhnliche Möve übersehen hat, um so mehr, da Glahn in seiner Recension der Cranz'schen Schrift Larus leucopterus mit dem grŏnländischen Namen Najangoak aufführt.

Diese Möve ist nach Larus tridactylus die häufigste im Lande, doch ist sie zu jeder Jahreszeit häufiger in Süd- als Nordgrönland, welches sie im Winter ganz verlässt.

Sie variirt bedeutend an Grösse, und kann daran allein nicht

*) Diese Beeren spıelen überhaupt eine wichtige Rolle in der Ernährung der Thiere in Grönland. Nach den Excrementen zu urtheilen, fressen fast alle Thiere und Vögel im Herbste diese Beeren, selbst der Fuchs. Auf den Inseln, wo die Wallrosse im Herbst ans Land gehen, sind alle Beeren bald verschwunden, also wahrscheinlich von den Wallrossen verzehrt. Die Grönländer essen die frischen Beeren unmässig, und bewahren sie in Thran eingemacht auf, als Desert im Winter. 
von Larus glaucus unterschieden werden, aber stets sind die Flügel länger als an dieser, und der Schnabel verhältnissmässig sowohl dünner als niedriger. Die Mittelgrösse ist in der Länge 1، $10^{\prime \prime}$, in der Flügelbreite $5^{\prime} 6^{\prime \prime}$. Sie erreicht aber zuweilen eine Länge von $2^{\prime} 1^{\prime \prime}$; wogegen unter den kleinsten mir eine vorgekommen, welche nur $1^{\prime} 7^{\prime \prime}$ maass.

In Grönland will man zwei Arten dieser langflügeligen Blau Möve unterscheiden, und behauptet, dass die kleinere auf den Inseln brüte, die grössere auf den Felsen. Ich kann das Factum nicht bestreiten, dass die Individuen, welche ich auf den Inseln und da fast immer nur in einzelnen Paaren brütend antraf, auffallend klein waren; aber die Maasse dieser und jener laufen so in einander, dass man daraut allein unmöglich irgend eine Artverschiedenheit gründen kann; ein andrer Unterschied, ausser dass die Flügel verhältnissmässig etwas länger scheinen, ist nicht bemerklich.

Schon im Vorhergehenden ist gesagt, dass Larus leucopterus dieselben verschiedenen Federtrachten in der Jugend durchmacht, als $L$. glaucus. Das Verhältniss zwischen der hellen und dunklen Varietät ist gleichfalls ein solches wie bei Larus glaucus.

Es ist sehr merkwürdig, dass man hie und da Individuen dieser Mövenart findet, welche dieselbe Zeichnung an den Flügelspitzen, jedoch von ganz blassgrauer Farbe haben, als Larus argentatus, während sie bei dieser schwarz ist. *) Dies hat schon Capt. Sabine bemerkt, und aus diesem Grunde wollte er Larus leucopterus nicht als eigne Art anerkennen. Ich habe drei so gezeichnete Exemplare erhalten. Es könnte also scheinen, als wenn diese Möve ein Albino von Larus argentatus sei, aber dieser Zweifel kann leicht gelöst werden, wenn man an lebenden Individuen und nicht an getrockneten Bälgen untersuchte, ob bei Larus argentatus die Flügel in der Ruhe den Schwanz eben so weit überragen, als bei Larus leucopterus, welches sie nach Temminck nicht sollen. **)

Larus leucopterus (wie schon bei $L$. glaucus erwähnt) baut gewöhnlich in den Vogelbergen, doch habe ich nie einen Berg mit dieser Mŏve allein besetzt gesehen. Dagegen findet man sie zuweilen einzeln oder in ganz kleinen Vereinen auf den Inseln

*) Etwas Aehnliches zeigt Larus glaucescens, gegenüber von L. glaucus und marinus. S. N a u man $\mathrm{n}, \mathrm{X}$. S. 351. A n m. d. Uebers.

**) Larus argentatus möchte ausserdem stets einen stärkern gedrungenern Kölper und kräftigeren Schnabel haben.

Anm. d. Uebers. 
brütend*); auf diesen bauet dieselbe, nicht wie in den Vogelbergen, am steilen Ufer, sondern auf der Oberfläche. Ihre Eier, 3, 2, 4 an der Zahl, sind von gleicher Grösse und Farbe, als die der Larus argentatus und möchten schwer von diesen zu unter scheiden sein. Sie legt Eier vom 10. bis 16. Juni.

Ihre liebste Nahrung ist Mallotus arcticus, doch verzehrt sie auch viele Gadus agilis (Reinh.), nimmt aber auch mit selbigem Futter vorlieb, als L. glaucus. In Nordgrönland habe ich sie im Winter nie bemerkt, dagegen siebt man sie weit hinaus in die Davisstrasse, aber nicht im atlantischen Meere.

\section{L. T R I D A C T Y L U S.}

Wer noch nie einen Vogelberg, besetzt mit dieser Vogelart, sah, kann sich eben so wenig einen Begriff von der eigenthümlichen Schönheit, als von der Menge dieser Vögel machen. Man könnte einen solchen Mövenberg vielleicht mit einem gigantischen Taubenschlage, besetzt mit Millionen gleichgefärbter Tauben, ver gleichen. Der Berg Inujuatuk ist eine Viertel Meile lang, und der ganzen Länge nach, mehr oder minder stark, mit verschiedenen Mövenarten besetzt, und dies bis zu. einer Höhe, dass man die obersten Vögel nur als kleine weisse Punkte erkennen kann. $\mathrm{Zu}$ den Zeiten, als ich den Berg besuchte, habe ich stets mehrere Adler und Falken, die unter den Mövenjungen fouragirten, angetroffen, und diese Räuber haben auch ihre Horste ganz in der Nähe des Vogelberges.

In der Zeit, wenn Larus tridactylus Eier und kleine Junge hat, ist der Meerbusen hier im Godthaaber Distrikt, in der Nähe der Vogelberge, gleichsam angefüllt mit Massen von Mallotus arcticus und die Seehunde, welche diesen Fisch von unten verfolgen, verhelfen den Vögeln zu einem leichtern Fang. So wie die Jungen der Letztern heranwachsen, und längere Zeit Futter und mütterliche Erwärmung entbehren können, muss jenes weiter weg gesucht werden, und gegen Ende Juli sieht man Schwärme dieser Vögel, nach der Richtung zu urtheilen, von Inujuatuk (10 Meilen weiter landeinwärts von Godthaab) kommend, aus und mit Futter einziehen, besonders Morgens und Abends.

L. tridactylus ist unser erstes Frühjahrszeichen. Zwischen

*) Es wurde schon bemerkt, dass diese Individuen stets sehr klein sind. 
dem 8. und 20. März kommt diese Mŏve in Schaaren an, oft mit strenger Kälte und östlichem Winde. Sie zieht gleich an die Vogelberge, wo sogleich ihr betäubendes Geschrei erschallt, und zeigt sich besonders unruhig und stark schreiend, wenn die Brut. plätze mit starkem Schnee bedeckt sind. Im November verlässt sie die Fjorde, hält sich aber zum Theil in der Davisstrasse, wo man bei Sturm, besonders aus Süden, dieselbe oft an der Küste, und zuweilen in ziemlicher Anzahl antrifft. Sie ist ein Ocean-Vogel, welchen man überall im atlantischen Meere erblickt.

Ihre Nahrung besteht aus Fischen, besonders Mallotus arcticus *) und Gadus agilis (Reinh.), jedoch auch aus Crustaceen, besonders Themisto arctica.

\section{L. E B U P N E U S.}

Ich habe zu jeder Jahreszeit diese liebliche Möve erhalten, nur nicht im Monate April, und stets in derselben Farbentracht. Wenn dieselbe also auch eine doppelte Mauser hat, so verändert sie doch nicht die Farben. An den Exemplaren, welche ich im Februar und März erhielt, konnte ich keine Mauserung bemerken, freilich waren dies junge Vögel.

Während und nach schweren Stürmen, besonders im Herbste und Winter, zeigt sich Larus eburneus zuweilen in Menge, und ist dann sehr einfältig und leicht zu fangen. Es liegt am Tage, dass dieselbe nicht die Gefahr kennt, welche mit der Annäherung an das räuberischste aller Raubthiere, den Menschen, verbunden ist. So ist es notorisch, dass man dadurch, wenn man ein Stück Speck an eine Schnur bindet, und dies in's Wasser wirft, den Vogel oft so nahe an sich lockt, dass man ihn mit Händen greifen kann; ja ein Grönländer, welcher mir ein schönes Exemplar eines jungen Larus eburneus brachte, erzählte mir, er habe dasselbe dadurch an sich gelockt, dass er seine Zunge hervorstreckte und bewegte, worauf der Vogel so nahe herangekommen sei, dass er iln mit seinem Kajak**)-Ruder erschlagen habe. Alle die In-

*) Dieser Fisch findet sich an manchen Orten in ungeheurer Menge, und dient im Herbste und Winter den Seehunden und Vögeln zum bedeutendsten Theil der Nahrung. Der Zug desselben ist noch nicht hinlänglich beobachtet.

**) Kajak ist das Boot, welches die Grönländer auf der See gebrauchen. Sehr leicht gebaut, an beiden Enden spitz, ist es von oben dicht und hat nur in der 
dividuen, welche ich secirt habe, hatten das Futter in der Speiseröhre so verzehrt, dass ich nur erkennen konnte, dass Ueberreste von Fischen darunter seien.

Larus eburneus scheint sich mehr westlich in der Davisstrasse aufzuhalten, wo man sie stets, wenn man sich mehr der Küste Amerika's als Grönlands nähert, von den Schiffen aus erblickt.

\section{L. BRACHYTARSUS. Mihi.}

Diese seltne Möve steht in demselben Verhältniss zu Larus eburneus, als Sterna arctica zu St. hirundo, denn sie hat dieselben Farben als $\boldsymbol{L}$. eburneus, unterscheidet sich aber von dieser:

1) durch den sehr kurzen Tarsus, welcher nur 1 Zoll lang ist,

2) durch die Länge der Flügel, sowohl durch die absolute als relative,

3) durch die Bildung der Federn im Flügel und

4) durch die noch stärker ausgeschnittene Schwimmhaut.

\section{Art-Kennzeichen:}

Tarsus $1^{\prime \prime}$; die zusammengelegten Flügel reichen $2^{1 / 2} \mathbf{2}^{\prime \prime}$ über den Schwanz hinaus; Farbe: schneeweiss oder schneeweiss mit dunkelbraunen Flecken. Länge $1^{\prime} 5^{\prime \prime}-1^{\prime} 6^{\prime \prime}$.

Larus brachytarsus gleicht in der Zeichnung in jedem Alter L. eburneus, und ist gleich gross oder etwas kleiner.

Der Schnabel ist gelb mit dunkler Spitze. Die besonders langen Flügel unterscheiden sich von denen aller andern Mọ̆ven dadurch, dass die 4 ersten Schwungfedern derselben von ausserordentlicher Breite sind. Füsse und Schwimmhaut schwarz, letztere sehr stark ausgeschnitten.

Ich habe drei Exemplare dieser Möve besessen, deren Dimensionen fast ganz gleich waren, so dass ich eine vergleichende Zusammenstellung der Maasse dieșer beiden, einander so nahe stehenden, Möven geben kann.

Mitte ein Loch, in welches der Grönländer sich hinein setzt, und eine am Rande desselben befindliche Fellbekleidung um seinen Leib befestigt; es kann also kein Wasser hineindringen und dasselbe nicht sinken; doch verliert mancher Grönländer sein Leben durch Umschlagen desselben.

Anm. d. Uebers. 
L. brachytarsus.

Lãnge . . . . . . 1' $5^{\prime \prime}-1^{\prime} 6^{\prime \prime}$

Flügelbreite . . . . . $3^{\prime} 4^{\prime \prime}$

Aeusserstes Flügelglied m. d. Vorderschwingen . . . . . $1^{\prime} 2^{\prime \prime}$

Schwanz . . . . . $6^{\prime \prime} 2^{\prime \prime \prime}$

Tarsus . . . . . . $1^{\prime \prime}-1^{\prime \prime} 1^{\prime \prime \prime}$

Mittelzeh . . . . . $\mathbf{1}^{\prime \prime} 9^{\prime \prime \prime}$

Breite der äussersten Schwinge, 4" v.

der Spitze . . . . . . . $1^{\prime \prime} 3^{\prime \prime \prime}$

Die zusammengelegten Flügel überragen den Schwanz um ... 2" $2^{\prime \prime \prime}$ Schnabel v. Mundwinkel in graderLinie $1^{\prime \prime} 10^{\prime \prime \prime}$

L. eburneus.

$l^{\prime} 51 / 2^{\prime \prime}$

$3^{\prime} \mathbf{l}^{\prime \prime}$

I' $^{\prime \prime \prime}$

$6^{\prime \prime} 2^{1 / 2^{\prime \prime \prime}}$

$1^{\prime \prime} 5^{\prime \prime \prime}-1^{\prime \prime} 6^{\prime \prime \prime}$

$1^{\prime \prime} 9^{\prime \prime \prime}$

$1 "$

$1^{\prime \prime} 9^{\prime \prime \prime}$

$2^{\prime \prime}$

Von diesen drei Exemplaren waren zwei von Nordgrŏnland, das eine von Godthaab. In der Lebensweise scheint sie Larus eburneus zu gleichen. Leider sind alle diese Exemplare zu Grunde. gegangen, so dass nicht einmal das Königl. Museum eins von mir erhalten hat. In den letzteren Jahren habe ich mich bemüht, mehrere zu erhalten, aber bisher vergebens.

Anm. Larus Rossi habe ich nie gesehen und bin auch nicht im Stande gewesen, über selbige einige Nachricht oder Auskunft zu erhalten.

\section{$\mathbf{X}$ e m $\mathbf{S}$ a b i $\mathrm{n}$ i.}

lch habe nur ein verstümmeltes. Exemplar dieses Vogels, das Museum ein zweites von Major Fasting erhalten. Beide diese waren junge Vŏgel. Die Grönländer von Kangek, einem Aussenposten westlich von Godthaab, welche das erwähnte Exemplar überbrachten, erzählten, dass sie zuweilen den Vogel săhen, wenn sie weit in der See hinaus auf Fang gewesen. Obgleich Upernevik nur 35 Meilen südwärts von dessen Brutplatz liegt, kannten die dortigen Grönländer doch nicht den Vogel nach der Zeichnung, welche ich ihnen zeigte. *)

Unter allen bekannten Vögeln erstreckt sich die Brutzone dieser Möve gewiss am wenigsten südlich vom Pole.

*) Unsere Abbildung, vor dem Titel ist nach einem grönländíschen Exemplare entworfen.

A n m. d. Uebers. 


\section{I e t i is.}

Dieses Genus hat eine doppelte Mauser, durch welche die Farbe unbedeutend und nur am Unterhalse sich verändert; dies beweist ein Exemplar, welches ich im Anfange des März erhielt, und das in voller Mauserung stand, jedoch nur am Halse und Kopfe. Die Wintertracht ist am kenntlichsten an Lestris pomarina und zeigt sich dadurch, dass sie mehr oder fast nur blaugraue Federn am Unterhalse bekommt. Bei Lestris parasitica findet kaum eine Veränderung statt. Ich glaube, dass dies Genus gleich im näclısten Frühjahre ausgefärbt ist; denn nicht allein sieht man keine jungen Vŏgel nach Grönland kommen, sondern auch, weil ich bei meinen Reisen hierher den Vogel nur in dem Kleide, in welchem er hier an's Land kommt, gesehen habe. Es sind wahre Ocean = Vögel, die ich alle, mit Ausnahme von Lestris Buffonii, im Atlantischen Meere gesehen habe.

\section{L. CA T A R A C T E S}

muss mit eben so grossem Rechte zu den grönländischen Vögeln gerechnet werden als Sula alba. Zweimal habe ich den Vogel in der Nähe der Südküste von Grönland gesehen, und ohne Zweifel kommt er zuweilen zwischen die Inseln hinein.

\section{L. P 0 M A R INA *)}

ist die gewöhnlichste Lestris in Nord-Grönland. Sie kommt zu Godhavn in der Mitte oder gegen Ende Mai an, und zieht im September fort. Die Jungen sieht man, nachdem sie flügge sind, selten länger als 14 Tage an der Küste. Sie brütet stets in Gesellschaft, am südlichsten bei Bjornenaesset, etwas südlich von Egedesminde, nördlicher auf einer Ebene an der Lachself bei Godhavn und an andern Orten. Sie kann allerdings fischen**), aber lebt doch noch ausschliesslicher als Lestris parasitica von dem andern Vögeln abgejagten Raube; und dies kann sie um so leich-

*) Nach späterer Mittheilung des Verfassers hat $L$. pomarina angefangen, weiter nach Süden zu brüten, indem sie 1844 als brütender Vogel im Holsteinborger Distrikte angetroffen wurde.

Anm. des Uebers.

**) Ich habe sie in Mövenschlingen fangen sehen, welche. 3 Fuss unter der Oberfläche des Wassers standen. 
ter, da sie sowohl stärker als die genannte ist, als auch gewöhnlich im Vereine mit mehreren Arts-Genossen ihre Angriffe ausführt. In Südgrönland ist sie selten, und man sieht sie hier nur im Frühjahre an den Küsten und im Herbste auf dem Zuge. Die dunkle Varietät ist selbst in Nordgrönland selten, wird aber doch zuweilen angetroffen. Sie legt 2 Eier von derselben Farbe und Länge als $L$. parasitica, aber bedeutend stumpfer und dicker.

\section{L. PARASITICA (L. SGHLEPII. Brehm.).}

Brehm hat die grönländische $L$. parasitica als eine von der isländischen verschiedene Art aufgestellt. Faber, welcher bei meiner. Heimreise von Grönland 1824 meine gesammelten Vögel musterte, erklärte beim ersten Anblick, dass die grönländische $L$. parasitica nicht mit der isländischen identisch sei. Ich sandte Herrn Temminck Männchen und Weibchen mit dieser Bemerkung; da er sie aber nicht als eigne Art aufgenommen hat, muss ich annehmen, dass Faber sich geirrt habe. Der Unterschied soll in dem bedeutend stärkeren Schnabel und in den grösseren Dimensionen des Vogels liegen. Da es auch dieses ist, welches $L$. parasitica von $L$. Buffonii unterscheidet, will ich die vergleichenden Ausmessungen dieser beiden Arten, von 2 frisch erlegten Vŏgeln (zwei Männchen) hergenommen, aufführen:

\section{L. parasitica.}

Ganze Länge mit den verlängerten Schwanzfedern

Ganze Länge ohne diese . . . . . . $\mathbf{1}^{\prime} \mathbf{5}^{\prime \prime}$

Tarsus . . . . . . . . . . . . $\mathbf{1}^{\prime \prime} 9^{\prime \prime \prime}$

Mittelzeh

Aeusserste Zeh

Innerste Zeh . . . . . . . . . . $1^{\prime \prime} 3^{\prime \prime \prime}$

Hinterzeh . . . . . . . . . . . $2^{\prime \prime \prime}$

Oberschnabél von den Federn bis zur Spitze

im Bogen gemessen . . . . . . $1^{\prime \prime}$

Länge des Schnabels vom Mundwinkel bis zur Spitze

Höhe des Schnabels über dem Nagel . . $\quad 5^{\prime \prime \prime}$

Breite des Schnabels an der Basis : . . 1"

Der Oberschnabel überragt den untern . 1/2"1

Länge des Kopfes . . . . . . . . $1^{\prime \prime} 9^{\prime \prime \prime}$

Breite des Kopfes über den Augen . . . I" 5 $^{\prime \prime \prime}$

L. Buffonii

$1^{\prime} 10^{\prime \prime}$

$1^{\prime} l^{\prime \prime}$

$1^{\prime \prime} 5^{\prime \prime \prime}$

I" $9^{\prime \prime \prime}$

$1^{\prime \prime} 3^{\prime \prime \prime}$

$11^{\prime \prime \prime}$

$31 / 2^{\prime \prime \prime}$

$10^{\prime \prime \prime}$

I" $9^{\prime \prime \prime}$

$4^{1 / 2} 2^{\prime \prime \prime}$

$7^{\prime \prime \prime}$

$11^{1 / 4 \prime \prime}$

$1^{\prime \prime} 5^{\prime \prime \prime}$

1" $2^{\prime \prime \prime}$ 
Da die grönländische $\boldsymbol{L}$. parasitica sich durchaus nicht von der europäischen an Farbe unterscheidet, wird man nach dieser Ausmessung allein zu urtheilen haben, ob die grönländische Lestris parasitica eine eigne Art sei.

L. parasitica ist häufiger in Süd - als Nordgrönland. Sie brütet stets auf Wiesen oder in Mooren, sowohl im Innern der Buchten als auf den Inseln, aber nie in Gesellschaft. Ihre 2 Eier sind ganz, wie Faber sie beschreibt, $3^{\prime \prime}$ lang $\left(2^{\prime \prime}\right.$ ?), sehr zugespitzt, von dunkelolivengrüner Farbe, mit vielen braunen Flecken. Die Jungen gleichen einander ganz im Neste, und die Varietäten zeigen sich erst beim Uebergange in's brutfähig machende Kleid des Vogels. Die dunkle Varietät, einfarbig dunkel blaubraun, ist nicht das Jugendkleid. Ich kann um so bestimmter dies behaupten, als ich in 3 Jahren dasselbe Paar, brütend auf einer Insel in der Nähe von Godthaab, beobachtet habe. Von diesem Paar war der eine Gatte dunkel, der andre hell. Im dritten Jahre schoss ich den hellen Vogel weg, welcher das Weibchen war; im vierten Jahre brachte das Männchen wiederum ein helles Weibchen, aber in diesem Jahre wurden beide alte Vögel gegen meinen Wunsch getödtet und der Platz nicht wieder besetzt. Man findet sowohl Männchen als Weibchen von der dunkeln Varietät.

In den ersten Tagen des Mai kommt $L$. parasitica an die Küste, scheint aber die Davisstrasse nie ganz zu verlassen, da in starken Stürmen einzelne zu den Colonieen selbst mitten im Winter kommen. Im Septẹmber verlassen die Alten die Küste, die jungen Vögel schon in der Mitte des August. Diese Art fischt viel selbst, und wird oft von den Grönländern in den für $L$. tridactylus ausgesetzten Schlingen gefangen.

\section{L. B U F F O N I I.}

Diese Lestris unterscheidet man, selbst in weiter Entfernung, von $L$. parasitica leicht an dem sehr hüpfenden Fluge, der ganz dem der Meerschwalben gleicht.

In Grönland ist dieser Vogel ein Bewohner des höchsten Nordens, und wird nur selten südlich vom $69^{\circ}$ N. B. gesehen. Der einzige Brütplatz, welchen ich kenne, ist auf einigen Inseln, einige Meilen südlich von Upernevik, auf circa $72^{\circ} 40^{\prime} \mathrm{N}$. Br. Als ich bei den Nestern war, waren nur mit Dunen bekleidete Junge darin. Im nächsten Jahre brachte man mir zwei von deren 
Eiern, welche dieselbe Farbe und Bau als die der L. pomarina hatten, aber fast $1 / 2^{\prime \prime}$ kürzer waren. Sie brütet in Gesellschaft, wie man dieselbe auch fast immer in Gesellschaft mit ihren ArtGenossen antrifft. Von den 3 Exemplaren, welche ich erhalten habe, ist eins geschossen am Brütplatze, eins zwischen Holsteinborg und Egedesminde und eins aus einer Schaar, welche sich in der Nähe von Godhavn niedergelassen hatte. Nach einer Mittheilung des jetzt verstorbenen Kaufmanns Merk werden öfter im Herbste Schaaren dieses Vogels an dem West-Eiland im Egedesminder Distrikt gesehen.

Ich habe nie bemerkt, dass $L$. Buffonii andre Vögel verfolgte; dagegen sahe ich selbige sehr eifrig mit dem Stosstauchen, wie die Sterna's, beschäftigt. Im Oesophagus fand ich Ueberreste von Fischen und Crustaceen. Ich habe keine dunkle Varietäl bemerkt. Der Tarsus war bei allen, welche ich untersuchte, hellblau, während das Knie, der Fuss und die Schwimmhaut schwarz waren.

\section{Procellaria und Puffinus.}

Mag man auch, um consequent zu sein, wegen des Unterschiedes im Bau des Schnabels*) genöthigt werden, diese Vögel in 2 Genera zu trennen, so herrscht doch zwischen ihnen eine so grosse natürliche Verwandtschaft, dass Faber gewiss sehr Unrecht daran thut, sie im System zu trennen. Wie bekannt begründete Faber diese Benennung allein auf den Umstand, dass er Puffinus Anglorum hat tauchen sehen, aber dies bei Procellaria glacialis nie bemerkt hat. Puffinus cinereus hat Faber nur in einem Individuum gesehen. Ich habe dagegen Puffinus Anglorum bei Grönland nie bemerkt; sollte ich aber Puffinus und Procellaria in 2 Genèra trennen, so würden meine Gründe den seinigen grade entgegengesetzt ausfallen, weil ich Puffinus cinereus nie, aber Procellaria glacialis sehr oft habe tauchen sehen. Doch muss ich sogleich hinzufügen, dass die Grönländer, welche oft Puffinus cinereus in grosser Anzahl fangen, berichten, derselbe

*) Müsste man nicht die 2 Phalaropus-Arten aus demselben Grunde trennen? So ist der Schnabel von Tringa islandica auch so verschieden von dem der $T$. maritima, dass man auch hier 2 Genera bilden könnte, u. d. m. 
tauche zuweilen. Faber hat im ,Leben der hochnordischen Vögel" S. 282 zu beweisen gesucht, dass Procellaria glacialis kein eigentlicher Taucher sei, obgleich er nach Wallisch-Aas untertauche, wenn er es sehen kann, und vergleicht diese Tauchfähigkeit mit der einer Taube, welche sich in's Wasser wirft, um dem Stosse des Falken zu entgehen. In wie weit man diese Gründe gelten lassen will, weiss ich nicht; aber ich habe oft Procellaria glacialis nach Futter tauchen sehen und jeder, der auf dem Atlantischen 0cean reist, kann dásselbe erfahren, wenn Windstille eintritt. Man braucht dann nur, wenn $\boldsymbol{P}$. glacialis in der Nähe ist, ein Stück Speck auszuwerfen, und ohne Zweifel wird der Vogel danach tauchen, um dasselbe zu erhaschen, bevor es sinkt. Ausserdem hat Herr Etatsrath Reinhardt in der Zeitschrift für Naturwissenschaften 3r Theil S. 60 anatomisch bewiesen, dass $\boldsymbol{P}$. glacialis ein Taucher sei.

\section{P R O GELLARIA GLA CIALIS.}

Man sieht diesen Vogel überall in der Davisstrasse, nur nicht ganz in der Nähe des Landes, denn in Südgrönland nähert er sich nur bei starkem Nebel der-Küste, und kommt zwischen die Inseln und auf die Fjorde, während er in Nordgrönland sich beständig an den Kủsten und in allen Buchten herumtreibt. Ja ich habe ihn mehrmals aus meinen Fenstern in der InspekteurWohnung zu Godhavn geschossen. Beim Aufhauen der Wallfische ist er sehr zudringlich so, dass man denselben zu Tausenden mit Rudern und Bootshaken todtschlagen kann. Er ist ein wahrer Ocean - Vogel, der gleich von Fairhill an auf dem ganzen Atlantischen Meere angetroffen wird.

Sein südlichster Brüteplatz findet sich einige Meilen nördlich von Godhavn; der einzige, welchen ich ausserdem kenne, ist in der Bucht von Omanak; an beiden findet sich eine grosse Menge brütender Vögel. Sein grosses weisses Ei ist"sehr wohlschmeckend, wie auch der Vogel in der Brütperiode.

Es giebt, wie bekannt, eine dunkle Varietät von Procellaria glacialis, welche mit Ausnahme eines dunkeln Fleckes am Auge und eines hellern am Flügel, einfarbig und sehr dunkel mövenblau ist *). Diese Varietät ist nicht sehr häufig, wird aber stets

*) Von den Grönländern wird diese Varietät Igarsuok d, i. Koch genannt, nach dem gewöhnlichen Aussehn des Schiffskoches. Der helle Fleck am Flügel wird nur bemerkt, wenn man den Flügel ausbreitet. 
unter den übrigen am Vogelberge bemerkt; in wie fern sie aber wechselseitig gepaart sind, kann ich nicht mit Bestimmtheit anführen. Am Gefieder kann man die flüggen Jungen nicht von den Alten unterscheiden.

Procellaria glacialis trägt seinen Namen nicht mit Recht, denn er scheut zum wenigsten die grösseren Eismassen. Während der langen Zeit, dass ich in den Jahren 1835 und 1837 mit dem Schiffe vom Eise in der Davisstrasse eingeschlossen war, wurde äusserst selten eine Procellaria benerkt, und die Schiffsführer halten es für ein sicheres Zeichen, dass sie in der Nähe des offnen Wassers sind, wenn sie, eingeschlossen im Eise, mehrere dieser Vögel sehen. In Nordgrönland findet man Procellaria glacialis im Winter nie, obschon das Meer zuweilen ziemlich frei vom Eise (bis in den Januar hinein) sein kann*).

\section{Thalassidroma Teachii.}

Auf der Reise nach Grŏnland sieht man stets diesen Vogel gleich von der Südspitze des Landes, bis man zwischen den $\mathbf{6 4}$ und $65^{\circ}$ kommt, wo er ganz aufhört. Ist man nicht zu weit von der Küste entfernt, also auf den reichen Fischbänken, so umschwärmt dieser Vogel gewöhnlich das Schiff in den hellen Sommernächten, besonders bei stillem und gutem Wetter, indem er beständig seine pfeifende Stimme, die dem Pfeifen der Mäuse gleicht, hören lässt. Bei den Kock-Inseln vor der Godthaab Bucht sieht man ihn am häufigsten, und es sollte mich nicht wundern, wenn man auf einer oder der andern dieser mehrerer hundert Inseln seine Brütplätze fände; denn er ist von Anfang des Mai bis Ende des August in der Davisstrasse anzutreffen. Als ich im October von Grönland abreiste, sahe ich keine Sturmschwalben in jener Strasse, aber ungewöhnlich viele im Atlanter-Meer, woraus ich schloss, dass sie im Winter die Küsten Grönlands verlassen.

Die Sturmschwalbe besitzt jene Fähigkeit, welcher sie den generischen Namen verdankt, nämlich auf den Wellen mit ausge.

*) Herr Brehm hat in der $0 \mathrm{rnis}$ die grönländische Procellaria als eigene Art aufgestellt, doch ist hierzu wohl kein Grund; was derselbe über den Nutzen des Vogels in der grönländischen Haushaltung anführt, ist vollkommen falsch. 
breiteten Flügeln zu laufen. Dies ist ein allerliebstes Schauspiel, wird aber vom Seemann nicht gern gesehen, weil er glaubt und, wie ich meine, nicht mit Unrecht, dass dies einen bevorstehenden Sturm bedeute.

\section{PUFFINUS CINEREUS. *) (PROCELLARIA PUFFINUS Tem.)}

Puffinus cinereus findet sich in grosser Menge in der Davisstrasse, gleich von der Südspitze Grönlands an, his $65^{1 / 2^{\circ}} \mathrm{N}$. Br.; hier scheint das Vorkommen desselben zu endigen; aber grade vom 63sten bis $65^{1 / 2^{\circ}}$ N. B., wo sich Grönlands fischreichste Bänke vorfinden, ist er am allerzahlreichsten. Tritt im August Nebel ein, so kommt er in solcher Menge in die Fjorde hinein, dass er, so zu sagen, das Meer bedeckt; aber kaum hebt sich der Nebel, so sind plötzlich alle wie durch Zauberei verschwunden. Es ist besonders vom 62. bis $65^{1 / 2^{\circ}} \mathrm{N}$. B., dass derselbe auf diese Weise an die Küste kommt, aber vorzüglich ist dies der Fall im Distrikt des Sukkertopp's (Zuckerhuts), wo er mehrfach in jedem Jahre vorkommt, ja selbst ohne Nebel sich dort am Abende zwischen den Inseln zeigt. Im Herbste, wo man ihn in der Regel fängt, ist er so ausserordentlich fett, dass es fast unmŏglich ist, das Fell zum Ausstopfen zu bereiten; dies ist der Grund, wesshalb das Museum nur 2 Exemplare dieses sonst gewöhnlichen Vogels erhalten hat.

Vom Anfange des Mai bis Ende September trifft man ihn in der Davisstrasse; desshalb nehme ich an, dass er seine bisher unbekannten Brütplätze hier, oder an der Ostküste des nördlichsten Amerika habe. Im October 1834 hatte er die Davisstrasse verlassen, wurde aber gleichwohl nicht im Atlanter-Meere bemerkt, wo dagegen Puffinus Anglorum, welcher, wie ich meine, nicht zu den grŏnländischen Vŏgeln gezählt werden kann, in grosser Menge gesehen wurde.

$\boldsymbol{P}$. cinereus gleicht im Habitus, wie in der Lebensweise, auffallend der Procellaria glacialis; freilich habe ich denselben nicht

*) Da Herr Etatsrath Reinhardt 1822 nur einen Puffinus von Grönland erhalten hatte, nemlich Puffinus Anglorum, nahm er an, dass dies Fabrizius Procellaria Puffinus sein müsste. Spätere Beobachtungen und der Umstand, dass man nur einmal Puffinus Anglorum von Grönland erhalten hat, beweisen, dass Fabrizius hinsichtlich der Ortsbestimmung Recht hatte. 
tauchen sehen; aber nach der Aussage der Grönländer taucht derselbe, doch nicht besser als $P$. glacialis. Dagegen ist dieser Vogel im Besitz einer andern Art Tauchfertigkeit. Wenn nämlich im Sturm, oder nach demselben, die See hoch geht, sieht man den Vogel beständig in Bewegung zwischen den hohen Wellen, deren Bewegungen er geschickt zu folgen weiss; wenn er nun in der Welle selbst seine Beute erblickt, fliegt er mit stille gehaltenen Flügeln durch die Woge, doch stets gegen dieselbe an, nie mit derselben.

Er scheut, wie Procellaria glacialis, die grossen Eismassen; während wir vom Eise eingeschlossen waren, habe ich ihn nie gesehen.

\section{Cygmus melanorhynchus *)}

gehŏrt nicht allein zu den grönländischen Vögeln, weil Capt. Graah ein Exemplar ganz südlich im Lande geschossen, und ich den Vogel nicht weit von der grönländischen Küste gesehen, sondern hauptsächlich, weil ich mit Grund annehme, dass der Schwan vor geraumer Zeit in Grönland gebrütet hat. Am Godthaaber Fjord ist eine Landstrecke, welche Kuksuk (der grönländische Name des Schwan's) heisst, wo derselbe nach der Tradition der Grönländer gebrütet haben soll. Diese Landstrecke ist angefüllt mit kleinen sumpfigen Seen und Bächen und hat eine für Grönland recht üppige Vegetation sowohl am Lande, als in den Seen.

Die Grönländer erzählen, dass der Schwan dort nistete, aber dadurch ausgerottet wurde, dass man in der Mauser-Periode, wenn der Vogel nicht fliegen konnte; denselben dort mit dem Kajak verfolgte. Den Verfolgungen mit diesen leicht zu rudernden Fahrzeugen zu entgehen, möchte auch, während der genannten Periode, für den Schwan unmöglich sein.

*) Der Verfasser schreibt mir, dass Cygnus melanorhynchus sich in mehreren Exemplaren im Julianehaaber Distrikt gezeigt habe.

Anmerkung des Uebersetzers. 


\section{A n $\mathbf{s}$ e}

\section{A N S R HYPERB OREUS.}

Man sieht diese Gans einzeln in der Herbst-Zugzeit, beson ders nach Sturm, und dann kommt dieselbe öfter nach Nord - als Süd-Grŏnland, obgleich ich dieselbe auch von Julianehaab erhielt. Es sind indessen nur junge Vögel, welche im Lande geschossen wurden, obschon kein Grund zu der Annahme vorhanden, als seien dieselben hier ausgebrütet, wenigstens nicht, so weit die Rennthierjäger in's Land hinein kamen.

\section{A N S ER A L B I FR ONS.}

Diese Gans ist nicht selten im Sommer in den Süsswasserseen und Strömen zwischen $66-681 / 2^{\circ}$, und wird in der Zugzeit nur südlich von dieser Breite gesehen. Nach den Aussagen der Grönländer legt sie 7-11 Eier und ist am Brütplatze wenig scheu. In der Mitte des Mai sieht man sie paarweise nach Norden ziehen, und im Herbste kommt sie in Schaaren sowohl auf die Inseln, als selbst an die Häuser der Colonieen (z. B. Jacobshavn), um zu weiden. In dieser Zeit ist sie zwar sehr scheu, wird aber doch nicht selten geschossen. Sowohl Alte als Junge werden leicht zahm und dem Menschen sehr zugethan. Vor einigen Jahren erhielt ich eine Junge, die nicht allein so zahm wurde, dass sie mir und meiner Familie überall wie ein Hund aus und ein folgte, sondern, wenn sie, wie dies ofter der Fall war, hoch in der Luft flog, augenblicklich herabkam, sobald man sie rief, und ihre Freude mit einem hellen gäck, gäck gäck zu erkennen gab. Uebrigens hatte sie sich sehr an eine rothe Kuh attachirt und folgte dieser, sobald sie nicht von ihren Bekannten unter den Menschen einige fand, welchen sie folgen konnte. Die Kuh schien auch viel Vorliebe für die Gans zu haben, und liess dieselbe stets auf ihrem Rücken schlafen, wenn sie im Stalle war, auch im Sommer sah man die Gans stets auf dem Rücken ihrer grossen Freundin stehen, wenn diese lag. Die Gans starb in ihrem dritten Jahre an einer Lungenkrankheit.

\section{A N S E L E U G OPSIS}

scheint regelmässig bei Julianehaab in der Herbst-Zugzeit vorzu- 
kommen, da ich sie in den letzten Jahren mehrmals von dort erhielt und dem Museum im Jahre 1837 zugestellt habe.

\section{A N SER BERNICLA}

erscheint als Zugvogel an der ganzen Westküste Grönlands, nistet aber erst nördlich von dem $73^{\circ} \mathrm{N}$. B. und brütet nach dem Berichte der englischen Reisenden bis weit gegen den Pol. Nach Godhavn kommt sie gewöhnlich zwischen dem 6ten und 12ten Juni, zieht dann in grossen Schaaren, in ungefähr 12 Tagen, und wird dann zuweilen in grosser Menge geschossen; in dieser Jahreszeit ist sie ziemlich mager. Im September sieht man sie nicht selten in ungeheuren Schaaren an den äussersten Inseln, aber besonders bei Norsoak am Nordende von Waigatt, wo dieselbe in dieser Jahreszeit zuweilen zahlreich erlegt wird. Im Herbste ist sie sehr wohlschmeckend, aber nicht sehr fett.

\section{A $\mathbf{a}$.}

\section{A N A S B O S G H A S}

ist die einzige in Grönland nistende Art dieser Enten-Familie, und nicht selten sowohl in Nord- als Süd-Grönland; sie baut ihr Nest stets an kleinen Süsswasserseen oder am Ufer der Ströme, führt aber nicht selten die Jungen gleich auf's Meerwasser, wo sie hauptsächlich von kleinen Schaalthieren leben; und ich habe öfter im Oesophagus dieser Jungen Turbo planorbis Fubr. gefun den, welche sonst schwierig genug aufzufinden ist.

Anas Boschas ist in Grönland derselben doppelten Mauser als bei uns (in Dänemark) unterworfen. Sie verlässt nie die Küsten Grŏnlands und lebt im Winter ganz wie eine Tauchente einzig von Crustaceen, nach welchen sie auf 2 bis 4 Faden Tiefe untertaucht. Gewöhnlich findet sich in ihrer Speiseröhre: Margarita helicina, Modiola und Tellinen, weniger häufig Amphipoden. $\mathrm{lhr}$ Fleisch hat im Winter einen sehr herben Geschmack, wahrscheinlich von ihrer Nahrung; doch ist sie in gelinden Wintern ausserordentlich fett.

Die Membran am Hinterzeh hat eine Breite von $3^{\prime \prime \prime}$, den Zeh eingerechnet. 


\section{A N A S A C U T A}

verirrt sich zuweilen nach Grönland. Ich habe sie von Fiskenaesset und Julianehaab erhalten, das Museum gleichfalls von Omanak.

\section{A N A S G R E C C A.}

Es verhält sich mit dieser Ente ganz wie mit A. acuta; sie wurde, durch Stürme verschlagen, sowohl in Süd- als Nord-Grönland angetroffen.

Beide diese Enten-Arten, so wie Clangula Barrowii, habe ich von den Grönländern untẹ dem Namen Kertlutok piarsuk erhalten, ụnter welchem Namen Fabrizius A. clangula anführt, so dass es scheint, als ob die Grönländer allen Enten-Arten, welche sie nicht kennen, diesen Namen, zusammengesetzt aus Kertlutok: „graue Ente“ und piarsuk: „etwas ähnliches“ beilegen.

\section{1 a $\mathbf{n g}$ u 1 a.}

\section{C L A N G U L A G L A G I A L I S}

ist häufig sowohl längs der ganzen Küste, als auf den Inseln und den Ufern im Innern der Fjorde. Sie legt 7-11 Eier an kleinen Süsswasserseen, führt aber die Jungen gleich auf's Meer. Ihre Nestdunen sind schwarz und sehr elastisch und werden für die vorzüglichsten von allen zur Füllung der Oberbetten gehalten. In der Mitte des Juni haben sie Eier. Das Männchen hält sich. während des Brütens zu dem Weibchen, verlässt es aber, wenn die Jungen ausgekrochen sind; dann fängt es an das Gefieder zu ändern und im August findet man den Vogel nicht mehr in der Sommertracht. Die jungen Vögel halten sich, gewöhnlich in Gesellschaft mit einander, zwischen den Inseln auf. Im Winter, wo Anas glacialis an der ganzen Küste von Südgrönland sehr häufig ist, sind die alten und jungen Vögel in demselben Haufen. Sie taucht besonders auf Sandgrund. Ihr Zug ist nicht regelmässig, wie der der Somateria.

Dies ist die einzige Ente in Grönland, deren Männchen die Sommertracht vor der Nestperiode anlegt, also gleichzeitig mit dem Weibchen. Sie taucht bis auf 8 Faden Tiefe und lebt be- 
sonders von Modiola faba, Margarita helicina, Tellinen, Mya arenaria und Amphipoden. Im dritten Sommer ist sie brutfähig.

Weder diese noch eine andre Art des Genus Clangula entfernt sich weit vom Lande, sie dienen daher auch als Kennzeichen von der Nähe des Landes, wenn man im Nebel auf selbiges zusegelt *).

\section{C L A NGULA HIS T RIONIGA}

ist in Nord - Grönland ein seltner Vogel, während sie zwischen dem 62 und $65^{\circ}$ N. B. sehr gemein ist. Das Nest dieser Ente findet sich stets am Ufer eines sehr reissenden Baches, und ist so gut unter Schirmpflanzen und Weiden versteckt, dass man es nur selten entdeckt. Die Jungen werden gleich in's Meer geführt, doch dauert ihr Aufenthalt in der Nähe der Brutstelle länger, als bei der vor hergehenden Art. Sie liebt aufgeregte See, und findet sich deshalb ausser der Brutzeit gewöhnlich bei den äussersten Inseln, wo sie mitten in der Brandung taucht; doch ist ihre Tauchfähigkeit geringer, als bei $C l$. glacialis, und sie taucht kaum tiefer, als in 6 Faden Wasser. Die Nahrung ist ähnlich der der vorhergehenden Art, doch vielleicht mehr ausschliesslich auf Amphipoden beschränkt.

Sie hat eine doppelte Mauserung. Die Frühjahrs-Mauser des Weibchens, wodurch keine Veränderung im Gefieder entsteht, fängt im April an, und ist beendet vor dem Eierlegen. Das Männchen, welches durch seine kurze Sommer-Mauser einfarbig blan wird, mausert Ende August. Keins der Individuen, welche ich in dieser Periode erhielt, hatte Schwungfedern; der Vogel kann also in dieser Zeit natürlich so wenig fliegen als A. boschas.

\section{G L A N G ULA BARR O W II.}

Mit den wenigen literarischen Hülfsmitteln, welche ich während meines ersten Aufenthaltes in Grönland mit mir führte, war es mir nicht möglich, diese Ente von Clangula vulgaris zu unterscheiden, obschon der Unterschied beim Zusammenhalten sehr

*) Herr Lector Steenstrup hat mich aufmerksam gemacht, dass es in Island 2 Formen dieser Art gebe; demzufolge habe ich eine Anzahl grönländischer Individuen untersucht, aber keinen derartigen Unterschied in der Grösse oder den Dimensionen gefunden. 
bedeutend ist. Nach Etatsrath Reinhardt besteht er in Folgendem,

1) in der grössern Ausbreitung der schwarzen Farbe des Kopfes am Halse herab,

2) dessen Schillern in's Blaue,

3) der triangulären Form des weissen Fleckes zwischen Auge und Schnabel bei $\mathbf{C l}$. Barrowii, welcher bei $C l$. vulgaris rund ist.

4) Die verlängerten Kopffedern erstrecken sich bei C. Barrowï weiter herab am Hinterhalse, wodurch der Schopf vollständiger, als bei $C l$. vulgaris wird.

Ausserdem ist der Schnabel derselben etwas hŏher und bréiter, und hierzu kommt noch, dass das Männchen der $\boldsymbol{C l}$. Barrowï grŏsser als das der $\boldsymbol{C l}$. vulgaris ist, während die Grŏsse beider Weibchen, nach den in den Handbüchern angegebenen Ausmessungen, sich gleich bleibt. Da ich nicht weiss, ob das Weibchen und junge Männchen in einer in Dänemark leicht zugānglichen Schrift beschrieben ist, erlaube ich mir, die Beschreibung dieser nebst einigen vergleichenden Ausmessungen mitzutheilen:

Länge . . . . . . . . $1^{\prime} 7^{\prime \prime} 6^{\prime \prime \prime} 1^{\prime} 6^{\prime \prime} 3^{\prime \prime \prime} 1^{\prime} 3^{\prime \prime}$ -

Flügelbreite . . . . . . $2^{\prime} 10^{\prime \prime}-2^{\prime} 8^{\prime \prime}-2^{\prime} 4^{\prime \prime}$ -

Des Schnabels Hŏhe an d. Basis - $1^{\prime \prime} 2^{\prime \prime \prime}-\quad-9^{\prime \prime \prime}-\quad-10^{\prime \prime \prime}$

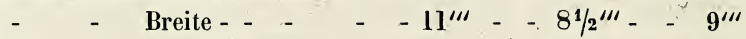

- $\quad$ - Länge v. Mund-

winkel . . . . . . - $2^{\prime \prime}-\quad-1^{\prime \prime} 6^{\prime \prime \prime}-1^{\prime \prime} 8^{\prime \prime \prime}$

Des Schnabels Bogen von den - $1^{\prime \prime} 6^{1 / 2^{\prime \prime \prime}}-1^{\prime \prime} 4^{\prime \prime \prime}-1^{\prime \prime} 3^{1 / 2} \mathbf{2}^{\prime \prime \prime}$

Stirnfedern

Tarsus . . . . . . . - $1^{\prime \prime} 9^{\prime \prime \prime}-1^{\prime \prime} 5^{\prime \prime \prime}-1^{\prime \prime} 6^{\prime \prime \prime}$

Länge des Schwanzes . . - $4^{\prime \prime} 1^{\prime \prime \prime}-3^{\prime \prime} 5^{\prime \prime \prime}-3^{\prime \prime} 2^{\prime \prime \prime}$

Das alte Weibchen hat am Kopfe und obern Theile des Halses ein sehr tiefes Dunkelbraun ohne Glanz, der übrige Theil des Halses ist aschgrau mit wellenartigen Linien von weisser Farbe; der Kropf weiss, die Seiten hell aschgrau mit weisslichen Wellenlinien, der Unterleib aschgrau, gegen die Brust zu heller, gegen den Schwanz dunkler. Der Rücken ist dunkelaschgrau mit hellaschgrauen Querstreifen, Flügel und Schwanz so dunkelaschgrau, dass sie fast schwarz aussehen. Am vordersten Theil der Flügel sind einige Wellenlinien von hellem Aschgrau und in der Mitte ein rein weisser Spiegel. Tarsus und Zehen sind dunkelbraun; 
die Schwimmbaut schwarz, der Schnabel dunkel aschgrau mit einem breiten orangegelben Band auf der Mitte, die Iris gelb.

Das junge Männchen vom Jahr gleicht ziemlich dem Weib chen, es fehlt ibm aber der reine weisse Spiegel auf den Flügeln, wie auch das Braun am Kopf und Hals heller und glänzender als beim Weibchen ist. Die Nackenfedern sind schon lang und beginnen einen Schopf zu bilden. Unter dem Braun des Halses ist ein ziemlich schmales weisses Band. Der Kropf ist schön aschgrau mit wellenförmigen weissen Streifen. Brust und Unterleib weiss, die Seiten hell aschgrau mit wellenförmigen weissen Streifen. Der Rücken, die Flügel und der Schwanz von so dunklem Aschgrau, dass sie schwarz scheinen; gegen den Hals zu hat der Rücken einen Schein von hellem Aschgrau. Die Flügel haben keinen rein weissen Spiegel, sondern es bilden einige weisse $\mathrm{Fe}$ dern 3 unregelmässige weisse Bänder, und hinter diesen endigen sich mehrere Federn mit Weiss, wodurch ein Phomboid entsteht.

Der Schnabel ist schwarz an der Basis und Spitze, in der Mitte etwas heller; Iris grüngelb; die Füsse, nämlich Tarsus und Zehen, von vorne dunkel orangegelb, von hinten fast schwarz, die Schwimmhaut schwarz.

Die Abbildung des alten Männchens in den Ichthyol. Beiträgen ist sehr genau, nur der Hals von der Schnabelwurzel bis hin unter den weissen Fleck am Kopfe zu dick.

Clangula Barrowii ist ganz beschränkt auf den Godthaaber Busen, und kommt so selten südlich oder nördlich vom Godthaaber District vor, dass die Grönländer sie nicht kennen, ja nicht einmal zu benennen wissen, welches sowohl der von Fabrizius als Graah angeführte Name hinreichend beweist. Der richtige grönländische Name ist Niakortok "grossköpfige Ente," welcher besonders für das Männchen sehr bezeichnend ist, welches, wenn es schwimmt, allerdings einen auffallend grossen Kopf zu haben scheint. Sie hält sich besonders im Innern der Fjorde auf und verlässt dieselben nicht, bevor alle kleinen Buchten mit Eis belegt sind. Sie kann nicht auf tieferem Wasser tauchen, als Cl. histrionica, ja ihre Tauchfertigkeit ist wohl noch geringer. Ihre Nahrung besteht besonders aus Modiola faba, Margarita helicina und Amphipoden*).

*) Herr Missionär Jorgensen, welcher sich mehrere Jahre hindurch in Julianehaab aufhięt ${ }_{\text {w, }}$ und manchen wichtigen Beitrag zur grönländischen Fauna ge- 
Ausser der Brutzeit sieht man dieselbe in Familien, aber sie ist der scheueste Vogel unter allen in Grönland, so dass es ohne ganz besondere Vorsicht unmöglich ist, sich ihr auf Schussweite zu nähern. Meine Schützen jiflegten in mondhellen Abenden sich in der Nähe der Orte verborgen aufzustellen, wo der Vogel zu tauchen pflegt, und erhielten auf diese Art zuweilen einige. Im Frühjahre erscheint sie paarweise; sie fliegt dann sehr hoch, und es ist noch schwieriger, bei ihr zum Schuss zu kommen. Ich selbst habe sie oft gesehen, aber mich ihr nie so nähern kŏnnen, um sie zu schiessen. Der einzige bekannte Brütplatz ist im Grunde eines der tiefsten Arme. des Godthaaber Busens, auf einer Felsen-Insel, mitten in einem nicht unbedeutenden Wasserfall, welcher die Insel unzugänglich macht. In der Nähe dieses Ortes erhielt ich ein ziemlich erwachsenes. Junges in der ersten Hälfte des August. Nach der Aussage der Grönländer trifft man Cl. Barrowii nie in den Buchten nördlich oder südlich von dem BaalsRevier (dem Godthaaber Fjorde) an, so dass ihr Aufenthalts-Ort sich hier auf die Strecke zwischen $63^{\circ} 45^{\prime}$ und $64^{\circ} 30^{\prime}$ N. B. einschränkt.

Da ich den Vogel nie im Sommer erhalten konnte, kann ich nichts Bestimmteres über die Sommer-Mauserung angeben, als dass das Männchen seine Farben nicht vor der Brützeit ändert, und dass die langen Federn am Kopfe kürzer zu sein scheinen, als im Winter, welches ich durch den Tubus bemerkt zu haben glaube.

Anm. Clangula vulgaris habe ich nie in Grönland angetroffen, wo sie nach meiner Meinung nicht vorkommt.

\section{S $\mathbf{m}$ at e r a}

Die 2 Arten dieses Genus, $S$. mollissima und spectabilis, machen nicht allein an den 3 Colonieen, wo die Dunen ein wichtiger Handels-Artikel sind, den hauptsächlichsten Reichthum der Grönländer aus, sondern es besteht auch bei mehreren Colonieen in den Monaten Februar und März die einzige Nahrung derselben in dem Fleische dieser Vögel. Ausserdem tödten die Grönländer den Eidervogel zu jeder Jahreszeit und unter allen Verhältnis-:

geben, theilt mir mit, dass C. Barrowii auch zwischen Nenortalik und Sydpröven nistet, wo ihre Lebensweise gleich wie im Godthaaber Busen sich yerhält. 
sen, so dass es wirklich unbegreiflich ist, dass die Menge dieser Vŏgel nicht bedeutend abgenommen; wenigstens glaube ich nicht, dass, trotz solcher Misshandlung, diess der Fall ist, so lange Europäer in Grönland gewohnt haben. Der Handel mit den Dunen hat bis vor wenigen Jahren durchaus nicht abgenommen. Die grŏsste Quantität unreiner Dunen, welche von Südgrönland in einem Jahre abgesandt wurde, betrug 5807 Pfund. Nord-Gronland sandte wohl halb so viel zurück. Man rechnet die Dunen von 12 Nestern auf ein Pfund, also wurden 104,520 Vögel in dem genannten Jahre ihrer Dunen beraubt, und zugleich, wenigstens dem grŏssten Theile nach, auch ihrer Eier; denn äusserst selten lässt ein Grönländer diese liegen, wenn sie .auch schon halb ausgebrütet wären.

Dass der Eidervogel in solcher Menge gefangen wird, und zwar zu jeder Jahreszeit, hat mich in den Stand gesetzt, seiner Mauserungs - Geschichte sehr genau zu folgen, und ich erlaube mir darüber Folgendes festzustellen:

Erst wenn der Vogel das zur Fortpflanzung fähig machende Gefieder bekommen hat, wozu für beide Geschlechter gleich lange Zeit, nemlich 2 volle Jahre gehören, erst dann tritt die doppelte Mauser für beide ein, aber zu sehr verschiedener Zeit, indem das Weibchen schon im April in voller Mauserung ist, und dieselbe vor dem Eierlegen beendet hat, während das Männchen erst zu mausern beginnt, wenn es das Weibchen verlassen hat, welches nicht eher, als bis die Eier ausgebrütet sind, statt findet.

Die Sommer-Mauserung des Weibchens beschrånkt sich auf die Federn am Kopf, Hals und einem Theil des Rückens, welche Theile eine hellere Farbe, die bei recht alten Vŏgeln vollkommen hellgrau (Mausegrau) ist, erhalten, bei jüngern Vögeln aber mehr in's Hellbraune fällt. Wie es die ältern Vögel sind, welche durch diese Mauser die hellern Farben erhalten, so sind es auch diese, bei denen die Mauser zuerst beginnt; doch ist sie bei allen vor dem Eierlegen, also vor dem 12. Juni beendet. Im angeführ ten Kleide sieht man die Weibchen gewöhnlich bis in den August, wo die totale Wintermauser eintritt, durch welche der Vogel seine gewöhnliche Wintertracht erhält. Einzelne Weibchen mausern indessen viel früher, wovon später.

Die Sommer-Mauser des Männchens findet dagegen erst statt, nachdem dasselbe das .Weibchen verlassen, welches geschieht, wenn die Eier ausgebrütet sind; denn, wie bekannt, begleitet das 
Männchen nicht die Jungen, obschon es das brütende Weibchen nicht verlässt. Durch diese Mauser wird das Männchen nicht dem Weibchen gleich, sondern der Theil der Federn, welcher der Veränderung unterworfen ist, erhält eine Farbe, welche der des jungen Männchens gleicht, und einfarbig blaugrau*) ist. Durch diese Mauser, welche total ist und in erstaunenswerther Kürze zu Stande kommt, verändern die Flügel ihre Deckfedern und der Schwanz nicht die Farbe, während der ganze Vogel im Uebrigen mit den erwähnten blaugrauen Federn bedeckt wird ; ein Gefieder, welches dem Vogel oft ein wunderlich fremdartiges Aussehn giebt, indem man z. B. bei $S$. spectabilis den hübschen hellfarbigen Schnabel mit dem grossen apfelsinengelben Auswuchs sieht, und die zierlich gekrümmten Flügeldeckfedern, welche das alte Männchen charakterisiren, und das andere sonst helle Gefieder ganz jene blaugraue Farbe angenommen hat; doch sind die Federn am Kopf und der Kehle dunkler. In der Regel können die Männchen während dieser Mauser-Zeit fliegen.

Aber es sind nur wenige Tage, dass man das Männchen mit diesem Gefieder, vollständig ausgebildet und ohne Beimischung von ausfallenden, oder nachwachsenden Federn der Wintertracht antrifft, und im Anfange des October sind fast alle Mànnchen in vollständiger Wintertracht.

Aber eben so wenig als die Weibchen beginnen alle Männchen ihre Winter - Mauser zur angeführten Zeit.

Faber hat im „Leben d. hochnordischen Vögel" S. 101-105 geäussert, dass man während der Zeit, in welcher die Vögel regelmässig beim Neste sein sollten, oft alte Vögel weit von den Brütplätzen entfernt antrifft. Dies ist auch der Fall bei den $\boldsymbol{S}_{0-}$ materia-Arten; aber wenn ich meinen Beobachtungen trauen darf, kommt dies Phänomen hauptsächlich daher, dass diese Vögel nach der Paarung oder vielleicht nach dem Eierlegen ihren Gatten verloren. Diese Individuen paaren sich in demselben Jahre schwerlich auf's neue. sondern begeben sich gleich rom Nestplatze an die Orte, wo sie sich ausser der Brütezeit aufzuhalten pflegen.

Meine Gründe für diese Behauptung bestehen darin, dass diese Schaaren alter Vögel, in welchen jedes Geschlecht sich vom andern getrennt hält, und welche die Grönländer nach ihrer in der Regel

*) Sollte wohl heissen ,braungrau ?؛ Wie überhaupt an mehrern Stellen das ,blaa" des Originals die Bedeutung von „braun" zu haben scheint.

Anmerkung des Uebersetzers. 
sehr bezeichnenden Art "Schaaren von Wittwen und Wittwern" nennen, stets grösser werden. Man sieht also zu Anfang der Brüt-Periode nur wenige dieser ungepaarten Vögel, aber im Verlaufe der Zeit nehmen sie allmählig zu, sowohl mit Rücksicht auf die Zahl der Haufen, als der Individuen; doch will man beobachtet haben, dass es besonders die Haufen der Männchen sind, welche -im Juni und Juli (nie späler) zunehmen; und auch giebt es stets mehr sogenannte ungepaarte Männchen als Weibchen. Viel allmähliger vergrőssern sich die Haufen der Weibchen, und diese Zunahme dauert auch viel länger, als bei den männlichen Haufen, sehr erklärlich, durch Vögel, welche ihre Jungen verloren, und nach diesem Verluste sich in die Gesellschaft der Ungepaarten begaben.

Sollte diese Auseinandersetzung über das Vorkommen jener ungepaarten Vŏgel sich nicht bestätigen, obschon sie mir so viel Wahrscheinlichkeit, als diese Dinge nur haben können, für sich zu haben scheint, so ist es zum wenigsten gewiss, dass diese Schaaren einen grossen Theil des Sommers hindurch im Zunehmen sind, und dass die Vögel, sobald sie zu diesen Haufen hinzukommen, die ersterwähnte Mauserung beginnen, und man oft alle Nüancen dieser doppelten Mauserung in einem Haufen findet. Daher lässt es sich auch erklären, dass man zu jeder Jahreszeit Männchen im vollständigen Winterkleide antrifft; denn die Mauser findet bei den ungepaarten Vögeln mit derselben überraschenden Schnelligkeit statt, als bei den Vögeln, welche zur gewöhnlichen Zeit die Mauserung beginnen, und manche Vögel haben auf diese Weise ihren Feder-Wechsel beendet, ehe derselbe bei den brütenden Vögeln beginnt.

In einer andern Hinsicht ist die Sommer-Mauser bei Somateria verschieden von der, welcher das Sub-Genus Anas und zum Theil Clangula unterworfen ist, indem bei diesen die Vögel wäh. rend der Mauser nicht fliegen können, während Somateria*) nie seine Flugfähigkeit verliert.

Die jungen Vŏgel haben nicht diese doppelte Mauserung, aber

*) Ein altes Männchen der Somateria spectabilis erhielt ich vor reichlich einem Jahre aus Upernevik, in voller Sommer-Mauser begriffen. Bei diesem waren alle Schwungfedern ausgefallen und im Begriff, durch die nachwachsenden ersetzt $\mathrm{zu}$ werden, so dass es gewiss nicht fliegen konnte; es war angeblich im August erlegt und befindet sich gegenwärtig im Besitz des Prof. Naumann zu Ziebigk bei Köthen.

Anm. des Uebers. 
die jungen Männchen mausern fast ununterbrochen den ganzen Winter hindurch, so dass es äusserst schwierig ist, zwei junge Männchen von vollkommen gleicher Zeichnung zu bekommen; und dieser Umstand in Verbindung mit der, bis vor wenigen Jahren gänzlich unbeachteten, Sommermauser haben wahrscheinlich die Ornithologen zu der Annahme veranlasst, dass der Eidervogel viel längere Zeit bedürfe, um zur Fortpflanzung fähig zu werden, als dies wirklich der Fall ist.

Im Sommer bleichen die Federn der jungen Vögel $a b$, und zwar nicht durch eine partielle Mauser, wie bei Emberiza, sondern durch Einwirkung der Sonne und Luft. Sie erhalten dadurch ein helleres oder abgebleichtes Aussehen.

Durch die Untersuchung der Häute bei einer grossen Anzahl Individuen habe ich die Gewissheit erlangt, dass dies nicht durch Mauserung geschehe, und diese Ueberzeugung wird dadurch bestätigt, dass auch die Federn im Schwanze und den Flügeln auf diese Art abbleichen.

Um nicht später wieder von den jungen Vögeln reden zu müssen, bemerke ich hier, dass sie im Sommer sich in den Fjorden und zwischen den Inseln aufhalten, wo das Wasser nicht zu tief, höchstens 6-8 Faden ist, und hier ausserordentlich fett werden. Obschon man in Südgrönland am meisten Somateria mollissima findet, findet man doch auch in denselben Haufen Somateria spectabilis.

Indem ich eine grosse Anzahl junger Vögel beider Arten verglichen habe, bin ich zu völliger Gewissheit gelangt, dass sie beide 2 volle Jahre bedürfen, un völlig ausgewachsen zu werden, so dass die Jungen, welche im Jahre 1840 aus den Eiern krochen, im Herbste 1842 ausgewachsen sind und im 0ctober vollständige Wintertracht erhalten haben*). Diese Zeit ist für beide Geschlechter gleich. Die Weibchen sind im ersten Jahre ganz grau, ohne das weisse Band im Flügel zu haben, und erhalten im zweiten Jahre fast dieselbe Färbung als die alten Vögel, sind aber stets von diesen durch den Mangel des weissen Bandes im Flügel unterschieden.

Noch ein Phänomen habe ich in Betreff der Weibchen beider Arten anzuführen: nämlich, dass sie zuweilen eine Tracht erhal-

*) Doch will ich gerne einräumen, dass diese allgemeine Regel einige Ausnahmen, durch verspätete Mauser veranlasst, erleidet. 
ten, welche der des jungen Männchens im 2ten Jahre in so fern gleicht, dass sie mit einem breiten isabellfarbigen Bande am Kropfe geziert sind und zuweilen auch die Zeichnung des alten Männchens am Kopfe zu erhalten beginnen, während der Vogel im übrigen die braune Farbe des alten Weibchens mit weissen Bändern auf den Flügeln behält. Alle die Individuen, welche ich in dieser Tracht gesehen habe, waren bestimmt sehr alte Vögel, und bei einigen fand ich Verhärtungen im Eierstock, welches erwies, dass dieselben zur Fortpflanzung unfähig waren. Ich habe Vögel in dieser Zeichnung dem Königl. Museum zugestellt.

Die Somateria-Arten halten sich in der Regel längs der Küste auf, woran die Nahrung sie bindet, doch sieht man dieselben nicht ganz selten weit in der Davisstrasse hinaus. Wahrscheinlich wird man dort, wo sich diese Vögel gewöhnlich aufhalten, reiche Fischbänke vorfinden, da diese auch stets von Mollusken bewohnt sind, welche die vorzüglichste Nahrung der Somaterien ausmachen.

\section{S. M O L L I S S I M A}

ist gemein an der ganzen Küste Grönlands und brütet schon in einzelnen Paaren ganz im Süden, jedoch in ziemlicher Menge erst zwischen dem $63^{\circ}$ und $64^{\circ}$. Zwischen dem $65^{1} / 2^{\circ}$ und $69^{\circ} \mathrm{N}$. B. nimmt die Anzahl der brütenden Vögel noch mehr zu, und es ist in einem Theil dieser Gewässer, die ich unter Sterna arctica genannt habe, wo dieser Vogel (St. arctica) sich nicht findet, obgleich südlich und nördlich von denselben Sterna arctica und $S$. mollissima in gutem Vernehmen mit einander auf denselben Inseln brüten.

Vom $69^{\circ}$ bis $71^{\circ}$ sind fast keine Inseln und hier ist der Eidervogel wieder selten, aber im Uperneviker Distrikt zwischen $72^{\circ}$ und $73^{\circ} \mathrm{N}$. B. ist er wieder sehr häufig, und seine Brütplätze erstrecken sich so weit nördlich, als ich das Land kenne. Der Eidervogel beschränkt seine Brütplätze nicht auf die vor den Küsten liegenden Inseln, sondern findet sich auch brütend weit in den Buchten hinein, wenn diese nur flache Eilande haben; dagegen brütet er nie in Grönlands grossen Bergseen.

Ich habe schon früher darauf aufmerksam gemacht, dass man zuweilen Weibchen antrifft, welche Junge anführen, die zu verschiedenen Zeiten ausgebrütet sein müssen.

Ich zweifle keineswegs, dass $S$. mollissimu zuweilen sich 
sich mit $S$. spectabilis fruchtbar verpaart; denn man findet nicht allein öfters Weibchen, deren Schnabel Aehnlichkeit mit beiden Arten hat, sondern ich habe zuweilen auch Männchen von $S$. mollissima erhalten mit der schwarzen lanzettförmigen Zeichnung am Halse, welche das Männchen von spectabilis bezeichnet. Dem Museum habe ich ein solches Individuum zugestellt, ein zweites ist zur Zeit in meiner Sammlung.

Ausser dem täglichen Zuge, auf welchem S. mollissima Abends in die Buchten hinein und Morgens aus diesen heraus zieht, hat der Eidervogel auch einen jährlichen Zug, indem derselbe in den Monaten September und October südlich zieht, und im April und bis Ende Mai wieder zurückkehrt.

Die Bedeutung des täglichen Zuges habe ich nicht ergründen kŏnnen. Weder am Morgen noch am Abende hat der Vogel be. sonders viel im Kropfe, und was sich vorfindet sind Mollusken, welche sich gemeinschaftlich in den Buchten und dem Meere aussen vor diesen aufhalten. Auffallend erscheint es dagegen, dass die Möven des Morgens hinein- und Abends herausziehen, den Eidervögeln gerade entgegengesetzt.

Aưf dem jährlichen Zuge nach Süden fliegt der Vogel nicht in grossen Haufen, sammelt sich aber an gewissen Stellen in ungeheurer Menge. An diesen Stellen giebt es überflüssige Nahrung und der Vogel bedeckt dann oft das Meer im buchstäblichsten Sinne des Wortes. Ich übertreibe gewiss nicht, wenn ich behaupte, dass diese Schaaren oft aus mehreren Hunderttausenden bestehen. Diese Lieblings - Plätze sind hier im Godthaaber Distrikt solche, welche früh sich mit Eis belegen, und nur einige Faden Wasser über Lehm - oder Sandboden haben.

Auf dem Zuge nach Norden fliegen sie oft in ungeheuren Schaaren, und es ereignet sich dann zuweilen, dass man seine Flinte mehrmals abschiessen und laden kann, ehe die Schaar vorbeipassirt ist, so z. B. in dem sogenannten Sunde, einer schmalen Meerenge nördlich vom Godthaaber Fjord. Bei Fiskenaesset schoss der Kaufmann Heilmann einst 21 Eidervögel aus einer solchen Schaar auf einen Schuss, ich selbst 13 Stück.

Die Tauchfähigkeit desselben ist sehr ausgebildet, aber bei weitem nicht in dem Grade als bei der S. spectabilis, und ich glaube nicht, dass derselbe seine Nahrung in grösserer Tiefe als 25 Faden sucht. Die längste Zeit, welche ich ihn habe untertau- 
chen sehen, war 6 Minuten*), doch ist dies selten. Seine Nahrung besteht gewöhnlich aus Tellina-, Modiola-, Margarita-, Buccinum- und Defrancia-Arten. Ausserdem finden sich Krabben und Echini, seltner Amphipoden und nie Fisch-Ueberreste in seinem Oesophagus, aber wohl Fisch-Rogen**).

\section{S. S P E C T A B I L I S.}

Es ist auffallend, dass diese schöne Ente so selten in Island ist, während sie hier in Grönland sich über das ganze Land verbreitet, obgleich ihre eigentliche Brützone nördlicher liegt, als das Land von Europäern bewohnt wird. Im Winter ist sie sehr gemein, gleich vom Cap Farvel an bis Holsteinborg. Sie kommt nistend, obgleich sehr selten, vom 67sten Breitengrade an vor, aber in einiger Menge brütet sie erst unter dem $73^{\circ} \mathrm{N}$. B. Ihre Eier sind schmaler, aber von derselben Farbe und Länge als die der Somateria mollissima.

An einigen Männchen endigt sich das schöne Blaugrau des Kopfes mit einem sehr dunkeln Rande am Halse.

Den kammartigen Auswuchs am Schnabel findet mạn entwickelt das ganze Jahr hindurch, derselbe verliert jedoch an Umfang, wenn der Vogel mager ist, und nimmt $\mathrm{zu}$, wenn er fett wird. Da alle Seevögel gegen die Brützeit zu fett sind, ist folglich dieser Kamm beim Männchen der $S$. spectabilis auch zu jener Zeit sehr entwickelt; dass aber ein andres Verhältniss zwischen diesem Schmucke und der Brützeit sei, glaube ich nicht. Einer der grössten Kämme, welchen ich ausgemessen, betrug $1^{\prime \prime} 8^{\prime \prime \prime}$ in der Höhe über dem Schnabel, die grösste Breite war $1^{\prime \prime} 2^{\prime \prime \prime}$,

*) Diese Zeit stimmt vollkommen mit F ab er's Beobachtungen in Island überein, doch bedaure ich, dass die Tiefe der Tauchstelle nicht zugleich angeführt ist. Wo ich die Zeit angeführt habe, während welcher ich beobachtete, dass der Vogel unter Wasser war, ohne an die Oberfläche, um zu athmen, zu kommen, ist dies stets die höchste, welche ich überhaupt bemerkte. S. mollissima ist gewöhnlich nur 2-3 Minutẹn, S. spectabilis 4,5 bis 6 Minuten unter Wasser. Die längste Zeit, welche ein Haufe Seehunde, umstellt von Netzen, unter Wasser zubrachte, war 14 $\frac{1}{2}$ Minute, und bei dem einen der Wallfischfänge, dem ich beiwohnte, war das Thier $27^{1 / 2}$ Minute unter Wasser, seitdem es die erste Harpune erhalten.

**) Herr Missionär Jorgensen hat mir mitgetheilt, dass er bei Frederikshaab zuweilen Cottus bubalis in dem Magen des Eidervogels fand. 
am Schnabel war die Breite 9"'. Die Farbe desselben ist schön apfelsinengelb, die der Beine und des Tarsus schmutzig orangegelb.

In der Lebensweise gleicht dieselbe sehr der S. mollissima und hat so auch denselben Zug als diese, fängt aber später im Herbste nach Süden zu ziehen an; ebenso beginnt ihr jährlicher Frühjahrszug später, obgleich sie eine weitere Strecke nach Norden zu fliegen hat, vielleicht weil das Meer, so weit nördlich als sie brütet, früher nicht offen ist.

Man sieht sie nie in so grossen Haufen fliegen, als $S$. mollissima, aber sie liegt nicht selten in eben so grossen Haufen auf der See, jedoch nicht auf denselben Tauchplätzen, weil sie tieferes Wasser aufsucht. Sie zieht weiter seewärts hinaus, wesshalb sie, und weil sie in kleineren Haufen fliegt, weniger oft geschossen wird. Dagegen wird sie von den Grönländern im Kajak in viel grösserer Menge gefangen; denn da sie längere Zeit unter Wasser bleibt, kŏnnen sich jene leichter der Stelle nähern, wo sie wieder auftauchen wollen. Es ist erstaunlich, welche Menge von diesen Vŏgeln jährlich in Südgrŏnland gefangen wird.

Im Herbste werden die jungen Vŏgel nicht selten ein Opfer ihrer Unlust, weiter nach Süden zu ziehen, indem sie dadurch umkommen, weil das Meer sich überall mit Eis belegt. Ende Juli sieht man bei Godhavn ungepaarte Vögel; sie sind dann in voller Mauser. Hier im Süden ist es schwierig, das Männchen in der Mauserzeit zu erhalten.

Wunderbar ist der Instinkt, welcher den Vogel in den Stand setzt, die Plätze, wo er seine Nahrung suchen kann, aufzufinden. Auf diesen ist stets tiefes Wasser, wo man die alten Vögel selten auf weniger als 30 Faden Tiefe ihrer Nahrung nachgehen sieht. Solche Bänke liegen nur ausnahmsweise in der Nähe des Landes und sind öfters ziemlich schmal. Der Vogel muss dann, wo der Strom stark geht, wie in dem Godthaaber Fjorde, auf einer ganz andern Stelle untertauchen, wenn das Wasser bei der Ebbe fällt, als wenn es steigt, welches ich von den Fenstern meiner Wohnung jetzt gut bemerken kann, da ich genau die Lage und Ausdehnung der Bänke kenne. In der Fähigkeit, auf den Grund unterzutauchen, übertrifft S. spectabilis bei weitem alle anderen Vögel Grönlands, und bleibt auch am längsten unter Wasser. Sie taucht auf so tiefem Wasser, als ich nur hier in der Nähe Conchylien gefunden habe, nämlich bis 65 Faden oder 200 Ellen Tiefe. Um so tief zu tauchen, seine 
Nahrung aufzusuchen und wieder an die Oberfläche des Wassers zu gelangen, braucht der Vogel allerhöchst 9 Minuten (denn längere Zeit habe ich sein Verweilen unter Wasser nie beobachtet); aber gewŏhnlich bleibt er bei gleicher Tiefe nur 4, 5, 6 Minuten unten. Doch ist zu bemerken, dass nur die alten Vögel diese Tiefe suchen, die Jungen dagegen auf kaum grössere Tiefe als 90 Ellen zu tauchen pflegen.

Um unter dem Wasser sich vorwärts zu bewegen, braucht der Vogel seine. Flügel, und die wenigen Male, dass ich $S$. spectabilis seiner Nahrung nachgehen sah, führte er dies schwebend, nicht gehend aus.

In der erwähñten grösseren Tiefe finden sich gerade keine andren Conchylien, als unter niedrigem Wasserstande, nämlich besonders Trophon craticulatum, Turritella polaris, Pecten islandicus, Mitra groenlandica und einige kleine unbestimmte Arten. Dagegen finden sich auf dieser Tiefe eine Menge, Ascidien, von denen ich aber keine im Magen der $S$. spectabilis gefunden habe*). Ich begreife desshalb nicht, wesshalb der Vogel diese grosse Tiefe aufsucht, um so mehr, da es augenfällig ihn sehr anstrengt. Im Magen findet man ausserdem Krabben, Actinien, Ophiuren und bei jungen Vögeln Echinen und Amphipoden, nie Fischüberreste, wohl aber öfter Rogen.

\section{S. P E R S P I C I L L A T A}

zeigt sich zuweilen an der grönländischen Küste, doch habe ich nur 1 Exemplar, nemlich von dem Godthaaber Fjorde erhalten. Capt. Graah sah den Vogel an der 0stküste. Im Schlunde hatte mein Exemplar dieselben Conchylien, welche sich gewŏhnlich bei S. mollissima finden.

*) S. spectabilis ist der beste Wegzeiger, den man sich wünschen kann, wenn man Mollusken in tiefem Wasser suchen will; nur Schade, dass man diesen Wegzeiger nur im Winter hat, wo man keine Reisen längs der Küste machen kann, und es ausserdem keine angenehme Arbeit ist, mit dem Schleppnetz zu fischen bei $12-16^{\circ}$ Kälte. Im Sommer muss das Auge die Lage, das.Senkblei das Specielle an den Bänken angeben. Eine kleine Art Ascidia, welche eingehüllt ist durch eine Sandkruste, circa $1 / 2 "$ lang, und sich auf 15 Faden Tiefe im Sandboden vorfindet, habe ich zuweilen im Kropfe der S. mollissima angetroffen. 


\section{Mergus serrator}

brütet sowohl in Süd - als Nord-Grönland, und ist, ohne eigentlich irgendwo selten zu sein, nirgends häufig. Seine hauptsächlichste Nahrung besteht nach meinen Beobachtungen in verschiedenen Arten Fischen, besonders Blennius, ausserdem Amphipoden.

\section{Carbo cormoranus}

ist die einzige Scharbe, welche wir in Grönland besitzen. Ihr südlichster Brütplatz ist in dem Godthaaber Fjorde, wo nur einzelne Paare brüten; sie nistet übrigens so weit nach Norden, als ich gewesen bin. Ihre Nestplätze sind auf Felsenabsätzen, welche lothrecht gegen das Meer zu stehen, gewöhnlich ziemlich hoch oben, nur selten so weit unten, dass man den Vogel schiessen kann. In Nord - Grönland nistet sie an vielen Orten; an einigen in grosser Menge zusammen. Ihre Eier sind kaum grösser als die der Uria grylle und von unebner Oberfläche. Im Winter ist sie häufig in Südgrönland und hat ihre eignen Schlafstellen dort, welche von den Excrementen weiss gefärbt sind.

\section{\$ $\mathbf{l} \mathbf{a} \mathbf{a} \mathbf{1} \mathbf{b} \mathbf{a}$.}

Ich habe sie einzeln in der Davisstrasse gesehen, und einmal ist eine todt bei Godthaab angetrieben. Ein Exemplar erhielt das Museum von Egedesminde. Doch habe ich sie weder selbst hier gesehen, noch einige Auskunft über ihr Vorkonımen in Nordgrönland erhalten können. 1842 erhielt ich ein Exemplar von Julianehaab.

\section{1 y m b u s.}

Obgleich ich mir viel Mühe gegeben habe, die MauserungsGeschichte dieses Genus zı studieren, hat es mir doch nicht glücken 
wollen, einige Resultate zu erlangen; vielleicht weil die Arten desselben zu früh die Küsten verlassen, und im vollständigen Sommerkleide zurückkehren.

\section{G O L Y M B U S GLA CIA L IS}

ist viel häufiger im Süden des Landes als in Nordgrönland, wo der Vogel sehr selten vorkommt. Vielleicht ist der Umstand, dass die Bergseen, deren einziger befiederter Bewohner dieser Vogel ist, oft sehr spät aufthauen, die Ursache dieser Erscheinung; auch sind wohl die Bergseen im Süden fischreicher, als die in Nordgrönland. In der Mitte des Mai kommt er zu Godthaab an, und gegen Ende des October verlässt er Grönlands Küste. Ich habe beobachtet, dass er 8 Minuten unter Wasser war.

\section{C O L Y MB US SEP TENTRIONALIS}

ist allgemein im ganzen Lande, und findet sich sowohl in den kleineren Bergseen, als in den Seen auf den Inseln und in den Thälern, aber selten weit vom Meere ab, welches er öfter besucht, als $C$. glacialis. Er kommt im Anfange des Mai an und Anfangs November sieht man noch einzelne Individuen in den Buchten umherschwimmen.

\section{U $\mathbf{r}$ i}

Grönland besitzl alle die Arten dieses Genus, welche in Island vorkommen, aber bei weitem überwiegend der Zahl nach ist $U$. Brynnichii. Die grosse Anzahl Vŏgel der verschiedenen Arten dieses Genus, welche ich untersucht habe, haben mir die völlige Gewissheit verschafft, dass die Nahrung derselben sich auf Fische und Crustaceen beschränkt; noch nie habe ich in ihrem Magen eine Conchylie, weder Univalve noch Bivalve gefunden.

Die Vŏgel dieses Genus sind allerdings gute Taucher, aber keinesweges kann ich mit Faber (l. c. S. 259 u. 263) annehmen, dass Uria troile und Grylle da bis auf den Grund tauchen können, wo das Wasser 50 Faden Tiefe hält. Da F ab er durch seine genauen Untersuchungen sich ein grosses Vertrauen erworben, darf ich, ohne meine Gründe anzuführen, dieser Meinung nicht widersprechen. 
Ich meine, es sei sehr schwer zu bestimmen, wie tief ein Vogel tauche, wenn man nicht genau angeben kann, in welcher Tiefe er seine Nahrung findet. Dies kann man aber unmöglich wissen, wenn es sich um Fische oder Grustaceen handelt. Faber hat desshalb auch seinen Beweis, dass diese Vögel so tief tauchen sollten, daraus hergenommen, dass man sie zuweilen in dem Magen des Scymnus borealis findet, welcher sich selten in geringerer Tiefe als 50 Faden aufhält; aber es ist hinreichend bekannt, dass der Polarhai auch bis an die Oberfäche des Wassers kommt, um seine Nahrung aufzusuchen, welches man z. B. sieht, wenn ein Wallfisch gefangen ist, und unter dem Wasser stirbt. Sobald derselbe sich an die Oberfläche des Wassers hebt, wird man ihn bald von Haien umringt finden; auch werden diese zuweilen in Seehundsnetzen bei 3-4. Faden Tiefe gefangen. Desshalb kann auch die Tiefe, in welcher derselbe gewöhnlich sich findet, durchaus keinen Maasstab für die Tauchfähigkeit der Vögel, welche sich in seinem Magen vorfinden mögen, abgeben. Ich kann mittlerweile nur die Aufklärung über die Tauchfähigkeit des Genus Uria geben, dass Uria Brynnichii nie über 3 und Uria Grylle nicht über $2 \mathrm{Mi}-$ nuten unter Wasser geblieben ist, wenn ich sie beobachtet habe.

\section{UR I A GR Y L L E.}

Sie ist gemein sowohl in Süd- als Nord-Grönland, wo sie der letzte Vogel ist, welcher sich durch die Eisdecke zwingen lässt, südwärts zu ziehen.

Zwar ist sie ein geselliger Vogel, findet sich jedoch selten in grosser Anzahl zusammen. Zuweilen ereignet es sich indessen, dass sie sich im Winter, wenn die Fjorde, welche ihren Lieblings-Aufenthalt bilden (z. B. Fiskenaesset-Fjord) sich mit Eis belegen, in ungemein grosser Anzahl in den Oeffnungen zusammenfindet, welche der Strom einschneidet, wo man zuweilen Abends im Mondschein über 40 Stück mit einem Schusse tödten kann.

Man findet sie stets in der Nähe des Landes, und sie unterscheidet sich in dieser Hinsicht von den andern Arten des Genus Uria, welche wahre Oceanvögel sind, und sich überall im atlantischen Meere vorfinden.

Sind Faber's Beobachtungen richtig, betreffend die lange Zeit, welche Uria Grylle in Island (Prodromus S. 40) bedarf, um zeu- 
gungsfähig zu werden, so ist die isländische Art von der grŏnländischen verschieden, da letztere dazu nicht mehr als 2 Jahre bedarf.

Uria Grylle variirt besonders häuifg sowohl in der Grösse als im Bau des Schnabels, aber diese Verschiedenheiten laufen so in einander, dass ich für meine Person überzeugt bin, dass es nur eine Art in Grönland giebt. Ich habe sowohl eine ganz weisse Varietät gesehen, als eine, die võllig schwarz aussah, indem der weisse Spiegel fehlte.

\section{URIA TROILE.}

Sie ist selten, und hat so grosse Aehnlichkeit mit Uria Brünnichii, dass sie erst von mir hier bemerkt worden ist.

Da ich ein Mal Uria troile in vollständigem Sommerkleide mit fast nacktem Brutflecke erhalten habe, nehme ich an, dass sie zwischen U. Brünnichii brüte. Ich erhielt dieselbe zwar nur bei Godthaab, glaube aber den Grund davon darin zu finden, dass man dieselbe bei den andern Colonieen nicht genau beobachtet oder unbeachtet gelassen habe. Ich sandte 2 Individuen an's Königl. Museum ein.

\section{URIA LEUCOPHTHALMUS. (Faber, lacrymans Auct.)}

Ich habe nur 2 Mal diese Uria erhalten, welche in Grönland sehr selten sein muss.

\section{UR I A B R UEN N I G H I I}

ist zweifelsohne die zahlreichste unter allen Vögeln Grönlands; denn man trifft sie fast überall in der Davisstrasse, zu jeder Jahreszeit, selbst in der Brützeit, in grossen Schaaren weit von den Brütplätzen an. und ich glaube desshalb, sie brüte nicht im ersten Lebens - Jahre.

Ilır südlichster Brütplatz ist $2 \frac{1}{2}$ Neile im Westen vom Godthaaber Fjord, wo vielleicht ein hundert Paar brüten. Obgleich man mehrere Berge im Distrikt des Sukkertopps und in Nordgrọnland mit diesen Vögeln besetzt findet, ist doch Kassarsoak, eine Meile im Süden von Upernevik, der Platz, wo die meisten im Vereine brüten. Dieser Fels, gewiss $3 / 4$ Meilen lang und einer der höchsten in Grönland, ist besetzt mit Nestern, so weit man sehen kann, so dass die obersten Vögel wie Fliegen ausse- 
hen, wenn sie aus - und einfliegen. Ich kann wahrlich nur ein schwaches Bild von der Menge dieser Vögel geben. Die beste Vorstellung kann man sich vielleicht machen, wenn man sich den Felsen, so lange die Vögel nicht beunruhigt werden, als einen Bienenstock vorstellt, wenn die Bienen schwärmen. Fällt da ein Schuss, wodurch doch nur ein sehr kleiner Theil der Vögel auf. geschreckt wird, so wird im eigentlichsten Sinne des Wortes die Sonne vón ihnen verdunkelt, und die Zuschauer förmlich bedeckt von den Excrementen der Vögel. In kürzerer Zeit als einer Stunde habe ich selbst von diesen Lummen eine ganze Ladung für eine gewöhnliche Schiffsschaluppe geschossen, und mit einem Schuss wurden 22 Stück niedergestreckt; so sah ich auch, dass eine einzige Büchsenkugel 12 Stück tödtete.

Sie kommen bei diesem Felsen an, bevor das Eis aufgebrochen ist, und bringen dort die kurze Nacht schlafend zu. Dies giebt den Grönländern Gelegenheit, auf eine eigne Art die Vögel zu fangen. Sie begeben sich nämlich so still als möglich, gewöhnlich mehrere zusammen, unter den Berg; dort angekommen erschrecken sie die Vögel, indem sie plötzlich schreien und schiessen; die armen Vögel bedenken im Augenblicke nicht, dass unter ihnen das Meer noch mit Eis bedeckt ist, sondern stürzen sich köpflings herab und brechen meistens am Eise das Genick oder werden doch den Grönländern zur leichten Beute, die dann gewöhnlich ihre Schlitten mit den so gefangenen Vögeln beladen kŏnnen.

Nächst dem Seehunde macht Uria Brünnichii das Hauptnahrungsmittel der Grönländer in mehreren Colonieen in Südgrönland aus, und wenn dieser Vogel sich nicht in Menge einstellte, würde ofter, als jetzt der Fall ist, Hungersnoth unter diesen wenig kultivirten Menschen, denen man bis jetzt noch nicht beigebracht hat, anders als von einem Tage zum andern zu leben, eintreten. Sie werden zuweilen in solcher Menge gefangen, dass sie für eine grönländische Familie auf mehrere Tage ausreichen. Hauptsächlich wird er bei kaltem Wetter, wo der Vogel sehr ungern fliegt, dem Grönländer, welcher ihn aus seinem Kajak mit dem Pfeile erlegt, eine leichte Beute.

Die Nahrung derselben besteht sowohl in Fischen (besonders Mallotus arcticus und Gadus agilis) als in Crustaceen, mit denen man oft den Schlund angefüllt findet. In den bei Kassarsoak geschossenen Vögeln fand ich nur diese. 
Obschon man sie das ganze Jahr hindurch an den Küsten Südgrönlands antrifft, so ist es doch besonders im September, von wo an die Anzahl derselben fortwährend zunimmt, bis gegen den Mai, wo sie die Südküste verlassen, um sich an die Vogelberge zu begeben. Wie bereits erwähnt, bleibt indessen eine nicht geringe Anzahl zurück.

Uria Brünnichï variirt nicht selten in der Farbe: man findet einfarbig schwarze, andre von hell aschgrauer und auch blass rothgrauer Farbe. Die schwarze Varietät habe ich im Ganzen 3 Mal erhalten, 2 Exemplare bei Godthaab, eins am Sukkertopp; stets in Winter.

\section{UR I A A L L E}

gehört als brütender Vogel ausschliesslich Nordgrönland an, zieht aber nach Süden, wenn der Winter sich einstellt. An den Küsten Südgrönlands findet man dieselbe vom December bis in den April hinein, und in harten. Wintern in ungeheurer Menge.

Sowohl unsere eignen Grönlandsfahrer, als die englischen Wallfischfänger haben dem Vogel den Namen „Eisvogel" beigelegt, weil sein Vorkommen in Menge gewöhnlich die Nähe grosser Eismassen andeutet. Zweimal bin ich vom Eise eingeschlossen gewesen, und beide Mal sah ich zahllose Vögel dieser Art stets in grossen Haufen nach Norden ziehen. Auf den andern Ueberreisen sah ich nur wenige dieser Vögel und nur in kleinen Schaaren. Seine Nahrung besteht ziemlich ausschliesslich aus Amphipoden, doch finden sich zuweilen Ueberreste von Fischen im Magen.

Man findet dieselben Varietäten als bei Uria Brünnichii, mit Ausnahme der ganz schwarzen; die rothgraue ist nicht selten.

\section{Mormon fratercula}

ist nirgends in Grönland häufig und hat seinen südlichsten Brütplatz unter $63^{\circ} 30^{\prime}$. Er brütet stets auf Inseln in der Nähe der offnen See, und ist häufiger, je weiter man nach Norden kommt; doch habe ich ihn nicht bei Upernevik getroffen, und kann aus meinen Bemerkungen nicht ersehen, ob ich die Grönländer dort über sein Vorkommen befragt habe. Ich nehme mit $\mathrm{F}$ aber an, dass er sowohl, als Alca torda, schon im ersten Jahre ausgewachsen ist, nicht allein, weil man durchaus keine jungen Vögel an 
den Küsten antrifft, sondern weil man im Atlantischen Meere und der Davisstrasse im Frühjahre nie andre als alte Vögel dieser Art bemerkt. Seine Nahrung besteht nach den Untersuchungen aller Individuen, die ich geŏffnet, ausschliesslich aus Fischen, besonders Ammodytes dubius Reinh.

\section{A 1 a.}

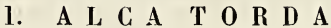

ist weder in Süd - noch Nordgrönland selten. Er ist ein Zugvogel, welcher in Südgrŏnland Ende April ankommt und die Küste im August verlässt, früher als irgend ein andrer Vogel, zugleich mit seinen Jungen, beide in der Sommertracht. Er ist der einzige mir bekannte Vogel, welcher die Küste vor der Mauser verlässt. Im August sieht man ihn in der Davisstrasse, und er hält sich auf Grönlands grossen und reichen Fischbänken auf. Seine Nester hat er in Gesellschaft mit Larus tridactylus und Uria Grylle. Seine Nahrung besteht während seines Aufenthaltes hier im Lande ausschliesslich aus Fischen und Crustaceen.

\section{A L C A I M P E N N I S}

ist an Grönlands Küsten seit 1815 nicht gefangen worden, wo Kaufmann Heilmann ein Exemplar bei Fiskenaesset erhielt.

Man hat mir erzählt, dass er im Norden des Sukkertopps gesehen worden sein soll; da ich aber 20 Thaler für ein Exemplar geboten habe, ohne eins zu bekommen, zweifle ich an der Richtigkeit der Aussage und fürchte, dass man den Vogel nicht mehr an den Küsten dieses Landes, wo er vor 80 Jahren nicht selten war, antreffen werde. Die Aussagen der Grönländer über seine früheren Brütplätze sind sehr verwirrt; indem einige ihm Brütplätze im Innern der Fjorde anweisen, behaupten andre, er trage die Eier unter den Flügeln, und wieder andre, er brüte an den alleräusserst gelegenen Inseln, was ich für das wahrscheinlichste halte. 
A I In a $\mathbf{n}$ g̈. 



\section{Aquila ossifiraga'}

Da diese Adler-Art, die von den meisten nordischen Naturforschern (so z. B. Nilsson ornith. suec. I. p. 14.) für eine eigne Species gehalten wird, sich selbst in den meisten Schriften bewährter Ornithologen (z. B. Sch legel, krit. Uebersicht der Vögel Europa's S. 28) keine rechte Anerkennung verschaffen kann, so ist es sehr zu bedauern, dass der Verfasser der vorstehenden Schrift nicht die Art-Kennzeichen genau angegeben, und durch vergleichende Ausmessungen an frischen Exemplaren beider Arten die Verschiedenheit dargethan hat; wenn gleich auch so das Urtheil eines so gründlichen Beobachters, der die beste Gelegenheit zu dergleichen Untersuchungen hatte, nicht zu übersehen ist. Ich habe unter den vielen alten und jungen Adlern, die ich von Grönland erhielt, bisher nur einen Balg eines $A$. ossifraga (junges Weibchen, das ich noch liegen habe) erhalten. Dasselbe ist durch ungewöhnliche Grössen-Verhältnisse, auch des Schnabels und der Fänge, einen sehr langen Schwanz (die mittlere Feder misst $1^{\prime} 2^{\prime} / 2^{\prime \prime}$, die äusserste $1^{\prime} 1^{\prime \prime}$ pariser Maass) und eine sehr dunkle Färbung (fast schwärzlich) des ganzen Gefieders ausgezeichnet. Es übertrifft an Grösse die alten Weibchen der gewöhnlichen Art, die ich aus Grönland erhielt; allein solche Bèstimmungen, von Bälgen hergenommen, haben allerdings keinen so grossen Werth, als vergleichende Ausmessungen frischer Vögel.

Anm. Es verdient vielleicht Erwähnung, dass ich den Uebergang vom Jugendkleide in's ausgefärbte bei einem gefargenen gewöhnlichen Seeadler beobachtet habe. Im vollständigen Jugendkleide wurde derselbe flügellahm geschossen und eingefangen. 
Im dritten Jahre nachher erhielt er bei guter Pflege und Kost und keinesweges geräumigem Bauer den weissen Schwanz und gelben Schnabel zu gleicher Zeit; es war ein Männchen.

\section{Aquila leucocephala.}

Es ist merkwürdig, wie schwierig es ist, die Resiltate einiger falschen Behauptungen und Beobachtungen aus der Wissenschaft wieder auszumerzen. Nach den gründlichen Untersuchungen Schlegel's, theils im Susemihl'schen Kupferwerk, theils in seiner Kritik, durfte es wohl als ausgemacht anzusehen sein, dass A. leucocephala in Europa nicht vorkomme. Hier erfahren wir nun gar bestimmt, dass er nicht einmal in dem Amerika so nahen Grönland angetroffen wird. Boje hat durch seine Bemerkungen in seinem Tagebuche wohl am meisten dazu beigetragen, diesen Vogel als europäisch festzuhalten. Sollte es sich vielleicht mit dem Unterschied zwischen Podiceps cornutus und arcticus auf ähnliche Weise verhalten? Schinz verwirft bereits die Verschiedenheit beider Arten, Naumann (IX. S. 756) kann keine festen Unterscheidungszeichen auffinden, Schlegel scheint die Versćhiedenheit $\mathrm{zu}$ bezweifeln, indem er den Podiceps arcticus auch cornutus arcticus nennt. Sieht man Boje's Reise S. 308 durch, auf dessen Auctorität hauptsächlich wohl die Art aufgestellt ist, so hat er dieselbe nach einem am 30. August geschossenen Weibchen aufgestellt, und zwar giebt er als Hauptunterscheidungszeichen den gänzlichen Mangel einer Haube an; konnte aber dieser Hochzeitsschmuck nicht schon an 30. August ausgefallen sein? zumal da angegeben wird (l. c. S. 309) dass die Oberbrust hell rostfarben, mit weissen Federstrahlen untermischt, gewesen sei, was wohl das beginnende Herbstkleid andeuten möchte. Das Männchen erhielt Boje nicht, und gleichfalls nicht die bei Brekeide bemerkten, zu dieser Art gezählten Vögel. Fernere Untersuchungen mögen hier entscheiden; mir hat es nicht glücken wollen an den Bälgen, die ich gesehen, einen dauerhaften Unterschied zu erkennen *).

*) Dass F aber ihn mit $P$. auritus verwechselte, würde doch auch wohl zu bedenken sein?

Anm. des Uebersetzers. 


\section{Aquila naevia.}

Da Schlegel (1. c. S. 25) zu neuen Untersuchungen über diese Art auffordert, so darf ich den, wenn gleich geringen, Beitrag, welchen ich geben kann, nicht vorenthalten. Der Schreiadler brütet bekanntlich in Schleswig-Holstein; es ist diess die Art, welche Schinz S. 120 Aquila pomarina nennt und Boje in der Isis beschrieben hat. 4 alte Exemplare, welche ich erhielt, gleichen vollständig dem im Susemihl'schen Kupferwerk Taf. 20 abgebildeten alten Vogel; sie waren grösstentheils im Frühjahre geschossen. Ein junges im September 1844 erhaltenes Exemplar aus Holstein gleicht genau dem an selbigem Orte Taf. 21 abgebildeten jungen Schreiadler. Im Mai des Jahres 1845 erhielt ich ein an demselben Neste geschossenes altes, wirklich gepaartes Paar. Das bedeutend grössere Weibchen mit grossem Brutfleck gleicht genau dem alten Vogel im erwähnten Werke, das zur selben Zeit am selben Orte geschossene Männchen, mit dem es gepaart gewesen, ist offenbar im Uebergange aus dem Jugendkleide in's Alterskleid und verdient eine nähere Beschreibung.

Von oben gesehen hat es so ziemlich dieselben Farben, als der im Susemihl'schen Werke abgebildete Vogel; Kopf, Oberrücken, Schulterfedern, Flügel wie beim alten Vogel, allein im Nacken findet sich noch der hellsemmelfarbige Fleck (an derselben Stelle als bei der alten männlichen Kornweihe) und die hintern Schwung- und Flügeldeckfedern sind noch sparsam mit tropfenförmigen semmelfarbigen Flecken versehen, zum Theil diese Flecken verschlissen. Die obern Deckfedern des Schwanzes fast einfarbig semmelgelb, diese Farbe und Flecken sich auf den Unterrücken hinauf erstreckend, und mit Braun gemischt bunt aussehend. Die Untertheile vom Halse an nach Brust und Bauch zunehmend mit tropfenartigen Flecken ähnlicher semmelgelber Farbe, die Unterschwanzdeckfedern einfarbig, etwas heller. Die Befiederung der Beine bunt: braun und semmelgelb. Die Hosen einfarbig gelblich. Schwanz einfarbig dunkel-schwarzbraun mit schwachem, von oben kaum bemerkbarem Saum. Es möchte sich wohl aus diesem ergeben, dass das Gefleckt- und Ungeflecktsein der Schreiadler keine Art-Verschiedenheit bedingt, sondern nur Alters - Verschiedenheit ist. Auch geht hieraus offenbar hervor, dass der Schreiadler zeugungsfähig wird, ehe er das Alterskleid ganz 
vollständig angelegt hat. Dazu bemerke ich noch, dass ein zuverlässiger, mit der heimischen Ornithologie vertrauter, Forstbeamter mir bestimmt versichert hat, dass er aus dem Neste ungefleckter Schreiadler ein geflecktes Junges selbst genommen und längere Zeit am Leben erhalten habe. $0 \mathrm{~b}$ es aber eine grössere, dem Aquila fulva näher stehende, Art giebt, die mehr einfarbig dunkel-kaffeebraun mit Goldglanz gefürbt ist, und sich vielleicht mehr östlich aufhält, mögen spätere Beobachtungen entscheiden; es scheint, als ob die Anmerkung in der kleinen Schrift des Grafen v. d. Mühle S. 19 u. 20 darauf hindeute. Alle alten Schreiadler, welche ich von hier erhielt und sah, waren sowohl im Herbst als Frühjahr ganz gleich gefärbt: Rücken, Schwanz, Schulterfedern dunkel mit Glanz, Flügel, besonders der obere Theil hell und matter gefärbt, Grösse bis auf den Geschlechtsunterschied bei allen ziemlich gleich, Schnabel und Zehen schwach.

\section{Falco islandicus.}

Die Bemerkungen des Verfassers im Vereine mit den gründlichen Untersuchungen Schlegel's in seiner Kritik möchten wohl hinreichen, den Falco candicans, islandicus und greenlandicus (Brehm) als eine und dieselbe Species wieder zu vereinigen. Ich haḅe eine ganze Reihe grönländischer Falken aus den verschiedenen Colonieen Grönlands unter den Händen gehabt, deren Musterung die Resultate dieser Naturforscher nur bestäligen. Das Vorwalten der weissen Farbe scheint theils ein Resultat des höheren Alters, hauptsächlich aber auch des Aufenthaltes in höheren Breitengraden zu sein; dagegen ist das Erscheinen der gelben Fänge und Wachshaut wohl allein ein Resultat des Alters. Solche gelbfüssige Falken erhält man nur selten aus Grönland; unter 10 weissen grönländischen Falken verschiedenen Geschlechts erhielt ich nur einen solchen, und dieser war nicht einmal so weiss als mehrere mit blauen Fängen und Wachshaut, die ich aus den nördlichsten Colonieen erhielt. So erhielt ich unter ancern aus Nordgrönland ein beim Nest geschossenes altes Weibchen, an dem Kopf, Schwanz und alle untern Theile, ausser einigen freien Streifen, rein weiss waren. Rücken und Flügel waren auf weissem Grunde mit einzelnen dunkeln Längsstreifen (nicht Querbinden 
oder herzförmigen Flecken) versehen; es war so frisch, als ich es im October erhielt, dass die lebhaft bleiblauen Fänge noch vollständig biegsam waren.

Es ist also gewiss, dass dieser Falke (wie ich auch bei $\boldsymbol{F}$. naevius bemerkte) nicht das vollständig ausgefärbte Kleid zu erhalten braucht, um fortpflanzungsfähig zu werden, und lässt sich auch ohne Annahme einer Artverschiedenheit erklären, warum auf Island wenig weisse Falken brüten.

\section{Falco peregrinus.}

Ich erhielt aus Grönland ein altes Männchen, bei dem der rein weisse Fleck am Halse sich sehr weit auf die Brust herab erstreckt, und besonders an den Seiten mit blassem Rosenroth angelaufen ist; der Kopf fast schwarz mit sehr breitem Backenstreif, an den untern Theilen nur sparsame herzförmige Flecken auf weisslichem und weissröthlichem Grunde. Er scheint sich dem Falco anatum zu nähern, obschon die Abtrennung dieser Art wohl auf schwachen Gründen beruhen mag.

\section{Cinclus aquaticus.}

Mit Rücksicht auf Schl e gel (l. c. S. 70) scheint mir die Bemerkung nicht überflüssig, dass alle Cinclus, die ich in der von mir bewohnten Gegend erhielt oder sah, zu der als Cinclus melanogaster aufgestellten Art (oder nach der Localität verschiedenen Varietät) gehörten, und ohne Rücksicht auf Alter, Geschlecht oder Jahreszeit stets einen einfarbigen Unterleib hatten. Schwanzfedern waren stets 12 vorhanden. Sie gleichen völlig einem alten Männchen, welches ich in diesen Tagen aus Lappland durch den Hrn. Prof. Naumann erhielt, nur sind an den hier erhaltenen, selbst im Herbste geschossenen, Exemplaren fast keine weisslichen FederSäume am Unterleibe zu bemerken, und sind dieselben vielleicht etwas grösser, doch täuscht dies bei Bälgen bekanntlich sehr. 
 \\ Sterna anglica.}

Wenn Temminck im Manuel Tom. IV. p.460 anführt, dass die Sterna aranea Wilson nach den Amerikan. Beobachtern von unserer Sterna anglica verschieden sei durch: „une légère différence dans les formes totales et une disparité trés-marquée dans leur genre de vie etc.", so kann ich dies zwar, was den ersten Unterschied betrifft, nicht bestimmt widerlegen, da mir zur Vergleichung Exemplare der amerikanischen Art abgehen; da aber dieser Unterschied légère sein soll, die zweite, von der Lebensart hergenommene, bedeutendere Verschiedenheit bei der hier vorkommenden Sterna anglica bestimmt wegfällt, so wird entweder Sterna anglica und aranea synonym sein, oder die hier vorkommende Sterna anglica gehört zu der amerikanischen Species, da sie nicht von Fischen lebt.

In der Nähe meines Wohnortes ist ein grosser See, welcher 2 Inseln enthält, auf deren einer Sterna anglica bisher jährlich in ziemlich grosser Anzahl brütete; und ich sehe mich daher in den Stand gesetzt, einige zuverlässige Nachrichten über selbige zu geben.

Sterna anglica stellt sich nach meinen Beobachtungen ziemlich früh am Brütplatze ein, da ich sie schon zu Ausgang April in Schaaren dort bemerkt habe, während Sterna hirundo und arctica hier erst in der ersten Hälfte des Mai sich zeigen. Sie macht bald Anstalten zum Brüten, und zu Anfang des Juni habe ich schon stark bebrütete Eier gefunden. Ihre Nester sind nicht so kunstlos wie die der hirundo und arctica, sondern bestehen aus einer mit trocknen Grashalmen reichlich belegten, und mit etwas erhöhter gleichfalls aus trocknem Grase bestehenden Rändern umgebenen Vertiefung, die sie gewöhnlich am Ufer über der Gränze anlegt, welche der höchste Wasserstand des Sees durch Aufspühlen von Schilfstückchen u. s. w. zurückgelassen. Auf dem Grante zwischen diesem Rande und dem Wasser, wo zuweilen die Sterna hirundo und Charadrius hiaticula (die einzeln diese Inseln bewohnen) ihre Nester anlegen, habe ich sie nie gefunden. Ich habe selbst eine Sterna anglica geschossen, welche im Schnabel einige trockne Grashalme zum Nestbau vom festen Lande zur Insel herüber trug. Federn habe ich nie in den Nestern bemerkt. Die Nester fand ich besonders an dem südlichen und westlichen 
Ufer, oft dicht zusammenstehend. In dieselben legt sie $\mathbf{2 - 4}$ Eier von so verschiedener Färbung und Form, dass ihre Beschreibung schwierig sein möchte, doch haben sie etwas Uebereinstimmendes, und sind überhaupt von Naumann gut beschrieben. In einem Neste fand ich 7 Stück, wahrscheinlich hatten 2 zusammen gelegt. Sie scheint auch am Tage zu brüten, denn zur Eierzeit sieht man stets eine ziemliche Menge auf der Insel sitzen, während eine noch grössere Anzahl über derselben schwebt. Năhert man sich aber derselben im Boote, so fliegen sie alle auf, und umgeben dasselbe mit ihrem einem Hohngelächter ähnelnden Geschrei, und nach dem ersten Schusse sind sie so scheu, dass selbst am Neste sie sich stets ausser Schussweite halten.

Obgleich der Meeresstrand kaum eine Meile von dem genannten See entfernt ist, so ist es doch eine grosse Seltenheit, dort eine zu erblicken, wăhrend ich sie 11/2 Meile weit vom Brütorte in's Land hinein hinter dem Pfluge habe gehen sehen. Der erwähnte See ist von baumlosen Ufern umgeben, die theils in trocknem, steinigem Ackerland, theils in Haide mit einigem Moorwasser bestehen.

Obschon der See fischreich ist, habe ich sie nie dort fischen sehen, und bei keiner der geöffneten Ueberreste von Fischen vorgefunden. Sehr häufig habe ich sie dagegen (auf meinen Berufsreisen) ihrer Nahrung nachgehen sehen und gefunden, dass sie dieselbe hauptsăchlich auf dem Lande sucht. Wenn im Frühjahre zur Buchwaizen-Saat gepflügt wird, so sieht man sie stets hinter dem Pfluge, vermischt mit Larus ridibundus, einhergehen und Engerlinge auflesen. $\mathrm{Zu}$ andern Zeiten sah ich sie über das trockne Land hinstreifen, plötzlich (wie die andern Sterna) rüttelnd stillhalten und sich jählings gegen das Land herabstürzen, dabei aber stets ganz nahe über der Bodenfläche sich in einem flachen Bogen wieder aufschwingen; ihren Flug muss sie also sehr in ihrer Gewalt haben. Sehr häufig habe ich sie auch gegen die stillen Moorwasser herabstürzen sehen, aber nie ins Wasser selbst; da nun diese Wasser keine Fische enthalten, müssen es wohl Insekten sein, welche sie erhascht. Auf dem See habe ich sie nie fischen sehen, obgleich derselbe fischreich ist, sondern stets beobachtet, dass sie vom Lande gerade über den See zum Brütplatz flog, und denselben auch so verliess; über der Insel sieht man aber stets eine grosse Schaar kreisen.

Die von mir geöffneten hatten sämmtlich den Schlund voll 
von Maikäferlarven, nur eine hatte eine grosse grüne zerstückelte Eidechse im 0esophagus.

Die zweite Insel war, als ich sie besuchte, von Larus ridibundus bewohnt, und war in solcher Menge von Eiern, nackten und ausgewachsenen Jungen bedeckt, dass ich, um nicht mit jedem Fusstritt mehrere zu vernichten, dieselbe schleunig verliess.

Leider muss ich hinzufügen, dass dieser interessante Brütplatz bald eingehen wird, da die Landleute den See, um Land zu gewinnen, etwas abgelassen und Knaben dadurch eine Fuhrt aufgefunden haben, wo sie zur Insel hin waten können. Im vorigen Frühjahre 1845 stellte sie sich zahlreich, wie gewöhnlich, ein, als ich aber zu Anfang August mich hinbegab, um wo möglich einige Vögel im Jugendkleid zu erhalten (während des Brütens hatte ich sie nicht stören wollen), fand ich nicht eine vor und erfuhr, dass ruchlose Knaben die ganze Brut zerstört hatten; unter andern hatte man am Ufer einen ganzen Haufen zerschlagener Eierschaalen gefunden. Ich habe die Jagdbeamten ersucht, diesem Unwesen wo möglich zu steuern.

\section{I $\mathbf{I}$. s.}

Der Verfasser der vorstehenden Schrift macht an verschiede. nen Orten auf den täglichen Zug aufmerksam, den man bei diesem Genus finde, ohne den Grund anzugeben. Bei den auf unsern Ostseehäfen sich aufhaltenden und überwinternden Möven (Larus marinus, argentatus, canus, ridibundus) findet genau dieselbe Erscheinung. statt; sie hat aber bestimmt nur ihren Grund darin, dass dieselben sich auf ihre Schlafstätten begeben, welche sie nicht in den Häfen haben, sondern vielleicht auf einzelnen Steinriffen, unbewohnten Inseln, oder schwimmend auf offner See. Dies abendliche Verlassen der Häfen theilen mit den Mŏven fast alle übrigen Winterseevoggel, und es hat etwas ganz Interessantes, gegen Abend am Ausgange der Fjorde dies zu beobachten. Da erscheint bald ein Zug Colymb. septentrionalis im schwerfälligen gerade ausgehenden Fluge, jeder für sich, vom nachfolgenden weit getrennt; bald dicht gedrängt mit läutendem Flügelschlag hoch in der Luft ein Haufe Anas clangula oder dicht an der Wasserfläche Anas glacialis mit melodischem Ruf. Wiederum streichen 
mit schwirrendem Fluge, dicht am Wasser hin, stets einzeln, Alca torda und Uria troile und endlich erscheint in unregelmässigen Haufen, gewöhnlich in der Mitte des Meerbusens, ziemlich hoch in der Luft die Mövenschaar bunt durcheinander, und in grosser Hast, während einzelne: am Ufer denselben Weg langsamer ziehend, vor dem Schlafengehen sich noch eine Mahlzeit zu erspähen suchen. Kaum aber haben alle den Hafen verlassen, so erscheinen wieder von aussen her (wo ich sie oft am Tage haufenweise auf offner See habe herumtreiben sehen) hereinziehend die Süsswasser-Enten, besonders Anas boschas, im Frühjahre Anas tadorna und mit heiserem Rufe der Reiher, die verlassenen Ufer einnehmend. Am Morgen ziehen mit den übrigen Wintervögeln die Móven wieder in die Häfen hinein, langsam dem Ufer folgend und unter beständigem Fischen. In der Mittagsstunde halten sie gewöhnlich auf irgend einem Sandriffe, alle Arten zusammensitzend, doch Larus marinus immer etwas gesondert, Ruhe. Da die $\boldsymbol{S}_{0-}$ materia-Arten ihre Futterplätze, wie wir gesehen haben, ziemlich weit hinaus in die See haben, so wäre es vielleicht möglich, dass ihr den Möven entgegengesetzter abendlicher Zug in Grönland dieselbe Bedeutung hätte, und dass sie in den Fjorden auf ruhigem Wasser etwa in der Mitte einen sicheren gemeinschaftlichen Schlafplatz fänden.

\section{Anas glacialis.}

Mit Beziehung auf die doppelte Mauser dieser Ente sehen wir In vorstehender Schrift den geehrten Verfasser auf die Seite Faber's und F. Boje's treten, der Meinung Naumann's in der Naturgeschichte Deutschlands XII. S. 225 entgegengesetzt. N aumann sagt, es liege ein Irrthum zu Grunde, wenn man behauptet hat, dass sie das Fortpflanzungs-Geschäft erst betrieben, wenn sie dạs braune Kleid völlig angelegt hätten, und Holböll sagt, diese Ente sei in Grönland die einzige, deren Männchen das Sommerkleid vor der Brütperiode anlege. Ohne über die Bedeutung des einen und andern Kleides zu streiten, erlaube ich mir meine Beobachtungen hier anzuführen, da diese Ente sich auf unserm Hafen vom October bis April, ja selbst Anfang Mai, und zwar in 
in grosser Menge, aufhält, nur nicht wenn derselbe, was jedoch selten der Fall ist, zufriert.

Wie bemerkt, kommt hier Anas glacialis im October an, und hält sich in grossen Haufen zuerst an den Sandbänken aussen vor dem Hafen auf, gegen das Frühjahr weiter hineinziehend. Diese Haufen sind aus Männchen und Weibchen gebildet und zuweilen auch aus Jungen, doch halten diese sich gern gleich anfangs gesondert, gewöhnlich näher dem Lande liegend *). Männchen und Weibchen sind den ganzen Winter über gepaart, welches man deutlich bemerkt, wenn ein Haufe auffliegt, wo man stets Männchen und Weibchen zusammen fliegen sieht. Trifft man ein einzelnes Paar, so fliegt das Männchen stets zuletzt auf, dem scheueren Weibchen folgend. Ungepaarte trifft man natürlich auch stets den ganzen Winter über an, und ich habe eben so oft an schönen Herbst - als Frühlingstagen mehrere Männchen ein Weibchen mit lautem Gesange verfolgen sehen. Im März beginnt durchweg die Mauser, und es scheint der Vogel während derselben gar nicht zu leiden, sondern ist stets munter; nie habe ich bemerken kŏnnen, dass die Flügelfedern ausgefallen waren, noch weniger, dass die Männchen in dieser Zeit nicht fliegen können, wie Naumann dies l. c. angiebt. Vor einigen Jahren hörte ich in der Stadt in den Ostertagen den lauten Gesang dieser Ente vom Hafen her; Nachmittags begab ich mich im Boote hinaus, und fand 2 grosse Schaaren, jede aus einigen Hunderten bestehend, bei ganz stillen Wetter; so weit ich sehen konnte, waren alle Männchen in der Mauserung. Sobald die Schaar bei Annäherung der Boote fortflog, fand ich auf der Stelle, wo sie gelegen, eine ganze Menge durch die Mauserung ausgefallener Federn des Winterkleides. Ein altes Männchen, welches ich schoss, hatte bereits das Sommerkleid theilweise an, unter andern waren die gekrümmten Schulterfedern schon durch dunkle ersetzt, und am Halse der Vogel in starker Mauser. Als ich nach mehreren Tagen mich wieder hinausbegab, waren alle fortgezogen, bis auf 4 Stück, 2 Paar, von denen ich wiederum ein Mănnchen schoss, das auch zum Theil das Sommerkleid angelegt hatte. Nicht ganz selten trifft man auch völlig ausgefärbte Vögel der Art im Sommerkleide

*) So wurden hier im December 1845 Hunderte von Anas glacialis gefangen, die fast' nur aus jungen Vögeln bestanden; ich sah selbst 14 Stück in einem Netze sitzen. 
hier an, aber die meisten begaben sich während der Mauserung mit ihren Weibchen fort. Dass man (S. Naumann l. c.) im Mai und selbst Anfangs Juni alte Männchen im Winterkleide sieht, will ich gerne einräumen, und ist sehr erklärlich, da die Mausernden*) stets gepaart nach Norden ziehen und so die ungepaarten Männchen, deren Mauser sich durch unbekannte Ursachen verspätete, zurückbleiben. Diese Erfahrungen werden auch durch Capt. Holb őll's Bemerkungen bestätigt, indem derselbe sagt, dass das Männchen die Sommertracht vor der Brützeit anlege, und hauptsächlich dadurch, dass nach seinen am Brütorte gesammelten Erfahrungen das Männchen gleich nach dem Ausbrüten der Eier (also schon im Juli) wieder die Wintertracht anlege und schon im August nicht mehr im Sommerkleide angetroffen werde. Es ist Schade, dass der Verfasser nicht bemerkt, ob bei dieser Sommermauser die Schwungfedern ausfallen, welches ich im Frühjahre nie habe finden können, vielmehr scheint mir die Frühjahrsmauser mehr mit der der Uria-, Alca- und Colymbus-Arten (s. unten) nebst Möven zu correspondiren, bei welchen erst in der Herbstmauser Schwung- und Schwanzfedern gewechselt werden.

\section{C $\mathbf{l}$ y m th s.}

Ich hatte gehofft, als ich die Holböll'sche Schrift zuerst in die Hand nahm, dass ich darin eine Bestätigung meiner Erfahrungen über die Mauser dieses Genus finden würde. Leider sagt der Verfasser aber, dass es ihm nicht geglückt sei, in dieser Beziehung einige Resultate erlangt zu haben**). Ich sehe mich daher genöthigt, mit meinen Beobachtungen ohne diese Stütze hervorzutreten, obgleich ich dies mit einigem Zagen thue, da ich einer so bedeutenden Auctorität, als Naumann ist, entgegentreten muss.

*) Dass die nordischen Seevögel ihre Reisen nicht ungewöhnlich während der Mauser vornehmen, werden wir später beim Colymbus septentrionalis bestātigt sehen.

**) Sollte dieser Umstand nicht selbst für meine Ansicht sprechen und die Colymbi ihr nordisches Vaterland im Prachtkleide verlassen, in dem sie dort ankommen? 
Naumann sagt XII. S. 386, dass" die Colymbi ihr Prachtkleid im August ablegen und in den Wintermonaten wieder anlegen, dass man namentlich in den Monaten October, November und December alte Vögel im Uebergange zum Prachtkleide fände.

Ich bin der Meinung, dass die Colymbi ihr Pracht- oder Sommerkleid im März und April anlegen und wieder mit dem unscheinbaren grauen oder Winterkleide in den Herbstmonaten, September bis Ausgang December vertauschen, eben so wie die Alken, Teisten und Lummen, nur etwas später, denen auch Naumann diese Mauserung beilegt; (s. 1. c. XII. 457, 468, 485, 514, $530,540,614$.)

Zuvörderst muss ich bemerken, dass meine Beobachtungen sich nur auf Colymb. arcticus und septentrionalis beziehen, da C. glacialis hier zu selten vorkommt, um Schlüsse ziehen zu können, und mache ich auch ausserdem darauf aufmerksam, dass einzelne entgegenstehende Beobachtungen nichts gegen die allgemeine Regel entscheiden. So erhielt ich in den ersten Tagen des Januar 1846 ein altes Männchen der Uria grylle im vollkommenen Sommerkleide und eben so von Alca torda einen alten Vogel mit halb vermauserter Kehle, während man oft zu Anfang März alte Alca torda schiesst, die noch einen rein weissen Vorderhals haben, und hier kann zwischen Alt und Jung keine Verwechselung stattinden; so erhielt ich ferner am 24 sten Decemher 1845 ein altes schönes Männchen der Larus fuscus *) im reinen Sommerkleide, da es doch bekannt genug ist, dass die Mòven 2 Mal jährlich, im Frühjahre und Herbste, mausern.

Was zuerst Colymbus septentrionalis betrifft, so beginnt die Herbstmauser, die vollständig ist, und durch welche die alten Vögel ihr Prachtkleid mit dem grauen unscheinbaren Herbstoder Winterkleide vertauschen, vielleicht bereits schon im August, dauert aber bestimmt bei einer nicht geringen Anzahl bis in den October und selbst November hinein und alte Vögel, die man in diesen Monaten mit noch vorhandenem zimmtbraunen

*) Ich halte die Bemerkung nicht für überflüssig, dass Larus fuscus hier zu den seltensten Erscheinungen gehört, Der erwähnte Vogel ist der einzige der Art, den ich in 8 Jahren gesehen oder erhalten habe. Ein Freund von mir, welcher bereits 20 Jahre und daräber sammelt, hat sie nie hier erhaltēn, - Larus marimus ist dagegen eine tăgliche Erscheinung. 
Kehlstrich antrift, sind im Uebergange in's graue und nicht in's Prachtkleid begriffen*), da der braune Kehlstrich am letzten verschwindet, wie er auch zuletzt im Frühjahre erscheint. Das Pracht - oder Sommerkleid zieht der alte Vogel erst wieder im März und April an, und begiebt sich während der Frühjahrsmauser wieder nach Norden zurück.

Es hat allerdings etwas Auffallendes, dass der Vogel grade während seiner Haupt-Herbstmauser wandert, allem die Beobachtungen, die ich darüber habe anstellen können, sind so zahlreich, dass ich darüber nicht im Zweifel sein kann. Der Colymbus septentrionalis gehört in unsern Ostseehäfen zu den allerge. wöhnlichsten Erscheinungen, und wird den ganzen Winter hindurch zu Hunderten geschossen und in Netzen gefangen, so dass ich den Vogel in jedem Monate und jeder Tracht, welche er in der Zeit seines Hierseins hat, dutzendweise habe untersuchen können.

Schon im September hört man gewöhnlich hoch in der Luft, besonders bei kaltem Wetter, die lautschallende Stimme des Vortrabs; im October, November und December nehmen die Schaaren zu, dann wird er, namentlich bei hartem Winter, selten (in gelinden überwintert ein grosser Theil) und im März und April kehrt die ganze Menge in raschem Zuge zurück.

Die alten Vŏgel, welche man im September und October, und einzelne davon, die man im November erhält, haben noch Spuren des Prachtkleides an sich, namentlich einen zimmtbraunen Streif an der Kehle, während die obern Theile alle das graue Winterkleid zeigen. Nur zwei mal erhielt ich früh im Herbste Vögel in fast vollständigem Prachtkleide, doch fing bei diesen auch schon die Mauserung auf den obern Theilen an. Einmal habe ich einen auf dem Kieler Hafen (im Vereine mit noch lebenden Zeugen) gejagt, der durchaus nicht fliegen wollte; wiederholt verwundet und auf seichtes Wasser gejagt, wusste er zuletzt vor dem schnellrudernden Boote keinen andern Ausweg, als auf's Land sich zu schieben, wo er lebend ergriffen wurde. Bei der Untersuchung zeigte es sich, dass es ein alter Vogel in der Mauserung war, der alle Schwungfedern abgeworfen hatte und nicht fliegen konnte; es war, wenn ich nicht irre, im October. Vom

*) Na umann I. c. S. 440 . 
December an bis in den Februar 'habe ich nur Vögel im reinen Winterkleide gesehen. Im December 1844 sah ich mehrere Tage einen grossen Haufen von gewiss 4-500 Stück unsern Hafen umkreisen, wie es schien, ungewiss, ob er weiter ziehen sollte; wenn mir die Schaar über den Kopf flog, konnte ich deutlich genug die weissen Hälse aller unterscheiden, da sie nie ge drängt, sondern stets weit aus einander fliegen; ich bemerkte nicht einen darunter mit dunkelm Halse. In diesen Tagen (Ende Januar 1846) sahe ich den Vogel täglich an den Stangen der Fischer hängen, neben den Fischen, mit denen er sich zugleich gefangen; noch heute den 26sten Januar musterte ich 3 Stück, von welchen einer gewiss ein sehr alter ungewöhnlich grosser Vogel war; alle hatten sie die rein weisse Kehle des Winterkleides. Wenn, wie Naumann l. c. 440 meint, das Prachtkleid bei den Alten in der Regel im Januar vollendet ist, müsste ich bei dieser Menge doch einen der Art in diesen Monaten antreffen. Erst im März sieht man alte Vögel und in der Mitte des April habe ich ihn mehrmals im Prachtkleide erhalten, mit noch weissen Federn auf brauner Kehle untermischt, und bei Untersuchung der Fleisch - Seite des Balges zeigte es sich, dass die weissen alte, die rothbraunen neue Federn waren.

Naumann bemerkt l. c. S. 443: „So oft man an den schleswig-holstein'schen Küsten den Vogel auch im Spätherbst ankommen sah, so wenig konnte man dort seinen Rückzug bemerken" und Boje in seiner Reise S. 157 bemerkt dasselbe. Dies beruht wahrscheinlich darauf, dass er im Frühjahre nicht in die Häfen hinein kommt, sondern sich an der Mündung derselben aufhält, wo er dann Nahrung genug vorfindet. Hier habe ich im Frühjahre in jedem Jahre seinen Rückzug beobachtet, aber nur wenige erhalten, weil der Vogel dann scheu ist, und nicht dorthin kommt, wo die Netze der Fischer stehen. Ber Rückzug geht rasch vor sich, doch sieht man Ende März und Anfang April noch manche mit heller Kehle, obwohl die mit dunkler Färbung häufiger sind.

\section{Collymbus arcticus}

ist hier viel seltener, doch habe ich genug Exemplare dieser Art in den verschiedenen Trachten erhalten, um behaupten zu kön- 
nen, dass die Mauser ähnlichen Regeln unterworfen ist, als die der vorhergehenden Art. Da der Vogel jedoch später im Herbste zu uns kommt, als die vorhergehende Art, und derselbe gleichfalls auf der Wanderung niausert, so trägt er sein Prachtkleid auch länger in den Herbst hinein, und ich habe selbst im December Vögel der Art erhalten, bei denen die Mauser nicht gerade sehr weit vorgeschritten war. Naumann hat selbst ein Exemplar erhalten, an welchem sich noch im Januar einzelne schwarze Federn an der Kehle fanden, und nimmt an, dass dies der Beginn der Frühjahrmauser oder der Uebergang in's Prachtkleid sei, welches nach ihm (l. c. 426) der Vogel schon vom October bis in den December erhält. Ich habe manche Vögel der Art im Fleische untersucht und gefunden, dass in diesen Monaten die grauen Federn die neu hervorkeimenden waren, die Federn des Prachtkleides dagegen die alten verschlissenen sind. Ein Exemplar, im November oder December 1844 im Netze gefangen, habe ich vor kurzem Herrn Prof. Na umann übersandt; es ist zum grössten Theil noch im Prachtkleide, aber überall am Hinterhalse keimen die grauen, an der Kehle die weissen frischen Federn des Winterkleides hervor und verdrängen die Federn des Prachtkleides*), denen man das Abgenutztsein deutlich, besonders den verlängerten, mit den viereckigen Flecken versehenen, Schulter- und Oberrückenfedern ansieht; an diesem Exemplar waren die hervorkeimenden grauen und nicht die schwarzen Federn des Prachtkleides sogenannte Blutfedern**). Im Januar habe ich die meisten erhalten, alt und jung, aber stets im reinen Winterkleide. Der vorige Winter war besonders reich an diesen Vögeln; ich erhielt vom Nọvember bis Februar, ausser dem obenerwähnten, 5 Stück sämmtlich im Winterkleide oder Jugendkleide, von welchen ein sehr altes Männchen mit fast ganz bleischwarzem Schnabel und ungewöhnlicher Grösse noch in meiner Sammlung steht; es wurde ge-

*) Man darf die schwarzen Federn des Prachtkleides nicht wegen des eigenthümlichen Glanzes, den sie nicht leicht verlieren, für neue halten.

**) Nach dem Ausfallen der Federn eines mausernden Vogels allein kann man nicht bestimmen, ob dies alte oder neue Federn sind; nimmt man einen mausernden Vogel in die Hand und streicht das Gefieder, so fallen die alten gerade lose sitzenden Federn heraus; hat man ihn aber abgebalgt und macht dasselbe Experiment, so sieht man einen Theil der neuen Federn am leichtesten ausfallen, besonders wenn der Vogel fett war, da diese, so lange sie Blutfedern sind, weniger fest in der Haut, als dem darunter liegenden Zellgewebe sitzen. 
gen Ende Januar geschossen, und ist in ganz reinem Winterkleide, ohne eine schwarze Feder an der Kehle.

Im Frühjahre habe ich den Vogel nicht bemerkt, was aber bei seiner grossen Seltenheit nicht zu verwundern ist.

Der auffallende Grössen-Unterschied ist von mir auch stets bemerkt: so erhielt ich in diesen Tagen ein junges Weibchen von so kleinen Dimensionen, dass es an Grösse nicht einen Colymbus septentrionalis mittlerer Grösse, selbst nicht am Schnabel, erreicht. Ein ähnlicher sehr alter Vogel im reinen Prachtkleide steht in meinerSammlung, kleiner als ein neben ihm stehender $C$. septentrionalis, doch aber mit stärkerem Schnabel. Ich glaube jedoch im Allgemeinen bemerkt zu haben, dass die kleinsten junge Vögel, besonders Weibchen waren, und scheint mir der Unterschied verhältnissmässig nicht bedeutender, als zwischen einem alten Männchen der Anas clangula und einem jungen kleinen Weibchen derselben Art oft statt findet; daher die Trennung in 2 Species ohne Auffinden anderer Merkmale, nach der Grösse allein, wohl hinreichenden Grundes entbehrt. 



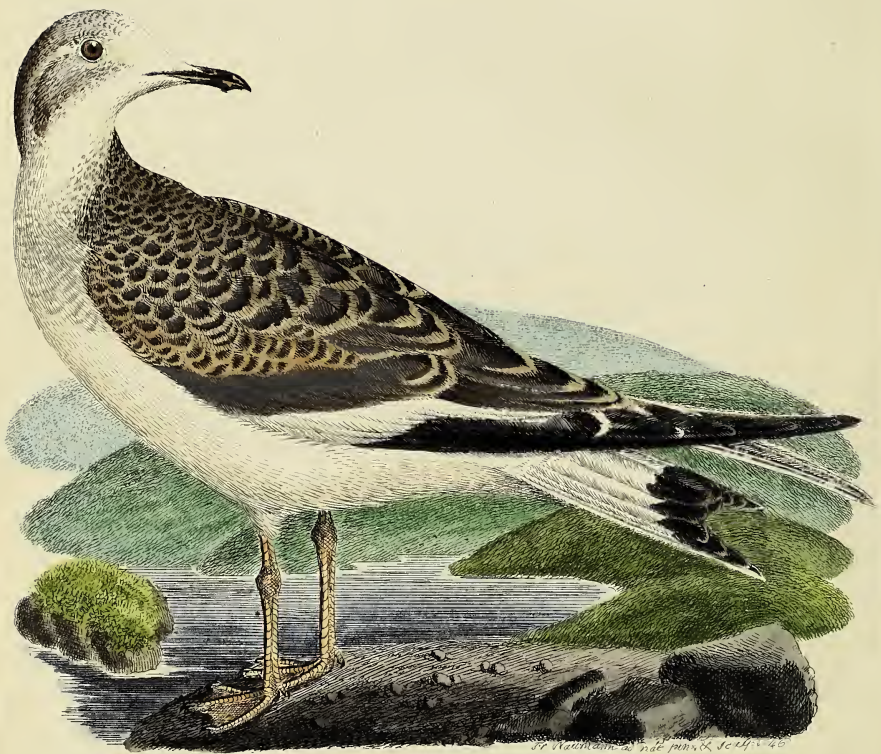

(5/12 der matriol. Grojse.,

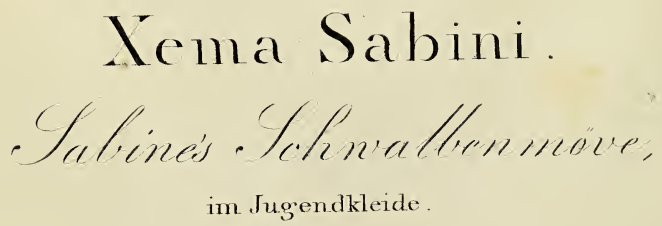




\section{ORNITHOLOGISCHER BEITRAG}

ZUR

FAUNA GROENLANDS

voN

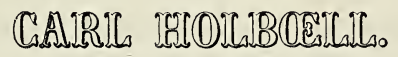

UEBERSETZT UND MIT EINEM ANHANG VERSEHEN

VON

J. H. PAULSEN,

Neue Ausgabe.

LEIPZIT,

ERNST FLEISCHER.

1854. 


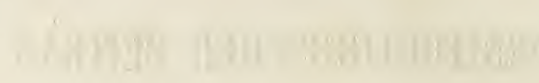

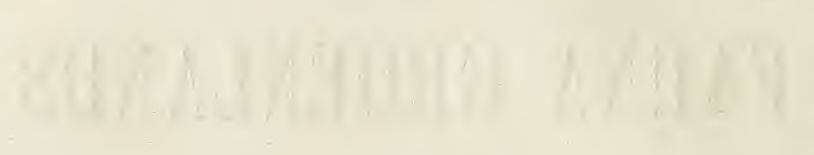




\section{Vorwort des Uebersetzers.}

Diese kleine Schrift wurde von dem Verfasser im Jahre 1840 an die Königl. dänische Gesellschaft der Wissenschaften eingesandt, von dieser mit der Silber - Medaille gekrönt, und für würdig erklärt, nach einigen Veränderungen, welche der Verfasser mit derselben bereitwillig vornahm, unter die Schriften der Gesellschaft aufgenommen zu werden. Da der Verfasser diese Aufnahme zu bewerkstelligen durch 'seinen Aufenthalt in Grönland verhindert wurde, zog er es vor, seine Schrift in der Zeitschrift für Naturwissenschaften 'Bd. IV. Heft 4. bekannt zu machen, aus welcher sie wiederum besonders abgedruckt wurde.

Obschon hierdurch der nächste Zweck erreicht, und dieselbe den Freunden der Ornithologie in Dänemark bekannt wurde, so hat sie doch, ausser diesem Kreise, eine so geringe Verbreitung erhalten, dass es mir selbst nicht gelingen wollte, dieselbe durch den Buchhandel zu erlangen.

Diese Abhandlung enthält aber, bei geringem Umfange, eine so grosse Menge gründlicher Untersuchungen, zuverlässiger Beobachtungen und neuer Thatsachen, dass die Kenntniss des Inhaltes gewiss jedem Ornithologen höchst wünschenswerth sein wird. Dieselbe schliesst sich den bekannten Schriften eines Faber, Boje und Graba an, und bildet gleichsam den Schlussstein zu diesem Cyclus von Beobachtungen, wodurch die Kenntniss von dem Vorkommen, der Ver- 
breitung und Lebensweise der nordischen (besonders nordwestlichen) Vögel unseres Welttheils bekannter und sicherer gestellt wird, als dies an den südlichen Gränzen desselben der Fall ist; wenn auch hier in neuerer Zeit (so durch die ausgezeichnete Schrift des Grafen v. d. Mühle über die Vögel Griechenlands) Bedeutendes geleistet wurde. Wie viele irrige Voraussetzungen über die Vögel Grönlands durch diese Arbeit berichtigt werden, brauche ich nicht näher anzuführen, ich bemerke nur hier die eine Thatsache, dass der grosse Ornitholog Temminck in seinem Manuel von dem Larus Sabini sagt: „,trés commun au Groenland, ou il niche etc.“, während unser Verfasser in $\mathbf{1 8}$ Jahren, bei allen Hülfsmitteln seiner Stellung, nur Ein junges Exemplar auftreiben konnte.

Um das Hinderniss, welches die Sprache der grösseren Verbreitung dieser Schrift entgegen stellt, zu beseitigen, habe ich, nach Rücksprache mit dem Verfasser, die Uebersetzung in's Deutsche übernommen, und bitte um nachsichtige Beurtheilung. Eine Abbildung des in Grönland so seltenen Larus Sabini, welche ich im Jugendkleide von dort erhielt, wird dem Leser gewiss angenehm sein, zumal die ihm bekannte Meisterhand Naumann's es übernommen den Vogel zu zeichnen und zu stechen.

Ueber den Verfasser bemerke ich nichts, da sein Name bereits den meisten Ornithologen Deutschlands bekannt ist, aber die ausgezeichnete Gelegenlheit, welche dem Verfasser, theils durch einen 18jährigen Aufenthalt, theils durch seine Stellung, zur Erweiterung der Naturgeschichte dieser starren Zone zu Theil wurde, muss hier hervorgehoben werden, und es verdient Anerkenning, dass die dänische Regierung bei Besetzung dieses Postens eine Wahl traf, welche ihr auch in andrer als amtlicher Beziehung zur Ehre gereicht.

Noch muss ich bemerken, dass ich die Schrift des Verfassers ganz unverändert wiedergegeben, obschon dieselbe ursprünglich für einen Leserkreis bestimmt war, der mit den 
in derselben vorkommenden Persönlichkeiten, so wie den Lokal - Verhältnissen des Landes, worüber sie handelt, bekannt ist. In dieser Beziehung führe ich an, dass dem hiermit weniger bekannten Leser der Gegensatz vielieicht auffallen wird, den man stets zwischen den Buchten (Fjorden) und den Inseln aussen vor findet. Dies rührt daher, dass das Innere Grönlands fast gänzlich unbekannt und unbewohnt ist. Nur die weite Küstenstrecke der Westseite Grönlands ist bekannt und bewohnt, und die Beobachtungen beziehen sich zum grössten Theıl nur auf diese. Diese Küste ist aber theils mit vielen, zum Theil tief in's Land sich erstreckenden Buchten (Fjorden) versehen, in oder an welchen die einzelnen Colonicen der Europäer oder Hütten der Grönländer liegen, während ein grosser Theil derselben mit einer Reihe zahlreicher Inseln besetzt ist. Die Communikation zwischen den verschiedenen Colonieen findet regelmässig zu Wasser statt, und nur ein kleiner Theil des Innern wird von den Grönländern, wenn sie sich auf die Rennthierjagden begeben, besucht; übrigens sind auch nur die Küstengegenden reich mit Vögeln versehen.

Die Communikation mit Europa, oder eigentlich mit dem Mutterlande Dänemark, findet nur durch die grönländische Handels - Compagnie in Kopenhagen statt, indem der Handel mit Grönland ein Monopol der Regierung ist, welches sie durch die erwähnte Compagnie ausübt. Kein Schiff irgend einer Nation, selbst kein dänisches, darf Grönland anders als im Nothfall besuchen. Ein Mal im Jahr besuchen die Königlichen Handelsschiffe sämmtliche verschiedene Colonieen, bringen die nöthigen Lebensbedürfnisse und Waaren dorthin, und führen die grönländischen Export-Artikel wieder nach Kopenhagen zurück *).

$W_{0}$ in der Schrift schlechtweg vom Königl. Museum die

*) Grönland wird in 2 Inspektorate, Nord - und Südgrönland, getheilt; beiden hat unser Verfasser als oberster Beamter vorgestanden. 
Rerle ist, bezieht sich dies auf das Königl. Museum zu Kopenhagen.

Einige Beobachtungen, welche vielleicht dem Leser von Interesse sein werden, habe ich als Anhang hinzugefügt. Sie waren theilweise für ein naturwissenschaftliches Journal bestimmt; da sie jedoch hauptsächlich von den in der Schrift vorkommenden Vögeln handeln, so glaubte ich, dieser Ort wäre zur Bekanntmachung eben so geeignet. Möchten sie nicht für ganz werthlos gehalten werden.

Apenrade, den Isten Februar 1846.

Dr. Paulsen. 


\section{1 w $\mathbf{c}$}

Die Fauna Grönlands ist früher, als die irgend eines andern, gleichen ungünstigen Verhältnissen unterworfenen, Landes bekannt geworden. Grönland ist so isolirt gelegen, dass man dort von allen litterarischen Hülfsmitteln, welche man nicht selbst mitbringt, entblösst ist, ja die Communikation mit der civilisirten Welt ist so dürftig, und beschränkt sich auf ein einziges Mal im Jahre, dass es zur reinen Unmöglichkeit wird, ein Buch zu leihen. Um so mehr ist es anzuerkennen, dass mehrere der früheren Missionäre und selbst einige der dortigen Handels - Beamten einen so grossen Eifer für die Naturwissensehaften gezeigt haben, als dies wirklich der Fall ist.

Unter diesen vortrefllichen Männern zeichnet sich jedoch 0 tto Fabricius so sehr aus, dass er alle anderen in Schatten stellt, und jeder, der selbst nur wenig mit dem Lande und den Schwierigkeiten, dort Gegenstände aus den Naturreichen zu sammeln, bekannt ist, muss in Wahrheit über das erstaunen, was er geleistet. Später verstrich eine lange Zeil, in welcher die Naturwissenschaften in Grönland wenige Verehrer fanden, theils, weil die Fauna Groenlandica Fabrizii als ein abgeschlossenes Ganze, keiner Verbesserung fähig angesehen wurde, wobei man übersah, dass $\mathbf{F}$ abrizi u s nur an einer Colonie war, und sich nur wenige Jahre in Grönland aufgehalten hat; theils lag der Grund dieser Lauheit darin, 
dass sich damals auch in Dänemark kein besonderes Interesse für diese Wissenschaft zeigte.

Es ist zunächst der Eifer des Herrn Etatsrath Reinh ard $\mathbf{t}$ für die Erweiterung des Königl. Museums in Kopenhagen, dem man es zu danken hat, dass das Interesse für Naturgeschichte hier im Lande wieder geweckt wurde, und dieser Gelehrte wurde durch mehrere günstige Umstände in diesem Bemühen unterstützt. Zuvörderst wurde das Land in den letzten Decennien von mehreren gebildeten Reisenden besucht, von denen einige die Naturgeschichte zu ihrem Hauptzweck gemacht hatten; dann gaben auch die gegenwärtig häufigen Reisen der Oberbeamten nach und von Grönland (welche in mehrerer Beziehung günstigen Einfluss äussern) den Naturforschern in Kopenhagen Gelegenheit, die Aufmerksamkeit jener auf naturhistorische Gegenstände zu lenken; endlich darf ich auch voraussetzen, dass mein Aufenthalt von 18 Jahren in Grönland (welches ich in dieser langen Zeit in keinem Sommer verlassen habe) einen günstigen Einfluss auf die Sammel-Lust geäussert hat, welche sich jetzt in dem Grade im Lande vorfindet, dass schwerlich auf der ausgedehnten Küstenstrecke von Julianehaab bis Upernevik irgend ein seltenes Säugethier, Vogel oder Fisch gefangen werden möchte, welche nicht für die Wissenschaft acquirirt würden.

Von meiner ersten Jugend an habe ich stets grosses Interesse für die Naturgeschichte empfunden; doch waren es hauptsächlich die Vögel, die mich besonders anzogen, und einer meiner liebsten Wünsche war es, ein Polarland zu besuchen, um Beobachtungen in dieser Richtung anzustellen. Dieser Wunsch wurde erfült, indem ich aus dem Fond ad usus publicos im Frühjahre 1822 Unterstützung zu efner Reise nach Grönland, um für das Königl. Museum zu sammeln, erhielt. Mein Aufenthalt dort verlängerte sich bis zum Herbst 1824, und in dem darauf folgenden Frühjahre wurde ich allergnädigst zum Inspektor über den Handel und Wall- 
fischfang in Nordgrónland ernannt, von wo ich 1828 nach Südgrönland versetzt wurde. Für die Zwecke der Ornithologie sind an sich schon die Amtswohnungen der Inspektoren günstig gelegen, und dazu kommt noch, dass dies Amt häufige Reisen mit sich bringt, die immer in offenen Fahrzeugen längs der Küste unternommen werden.

Auf diese Weise habe ich wiederholt die ganze Küste von Julianehaab unter dem $60^{\circ}$ bis Upernevik unter dem 72 $3 / 4^{0}$ N. B. bereist. Nach besten Kräften habe ich diese seltne Gelegenheit, welche mir zu Theil wurde, benutzt, um Grönlands Fauna, besonders die Ornithologie, zu studieren und ich hoffe, man werde mit dem, was ich als Sammler geleistet, zufrieden sein.

Seit 1832 habe ich mehrere Winter in Kopenhagen zugebracht, wo ich das Glück hatte, mich des freundschaftlichen und lehrreichen Umganges mit mehreren tüchtigen Naturforschern *) Dänemarks zu erfrenen, welches in hohem Grade mein Interesse für das Studium der Naturwissenschaften steigerte. Aber hierdurch erkannte ich auch sehr den Mangel, dass keiner, der sich längere Zeit in Grönland aufgehalten (allein mit Ausnahme von F abrizius), seine Beobachtungen über das Vorkommen, die Verbreitung und Lebensweise der Thiere bekannt gemacht hat, so wie ich zugleich die Ueberzeugung erlangte, dass dasjenige, was durch Fabrizius geleistet wurde, uns schon zu wichtigen Schlüssen über die Veränderungen, die seit seiner Zeit in dem Vorkommen und der Verbreitung sowohl der höheren als niederen Thiere stattgefunden, berechtigt.

Die Ueberzeugung dass der Standpunkt, welchen ge-

*) Ich benutze diese Gelegenheit, öfTentlich dem Herin Etatsrath Re in h a r d t, Fitter etc. meinen wärmsten Dank für die wichtigen Aufklärungen auszusprechen, wodurch er mich in den Stand setzte, bedeutende Verbesserungen mit dieser $\mathrm{Ab}$ handlung vorzunehmen. Gleichfalls danke ich Herrn $\mathrm{Hage}$ sehr für seine Bemerkungen, die an mehreren Stellen benutzt sind. 
genwärlig die Naturgeschichte im Kreise der Wissenschaften einnimmt, mehr als ein blosses Namens - Verzeichniss mit Beschreibung der Thiere erforderte (und dies ist doch alles, was unsere geehrten Gelehrten beim besten Willen und mit den besten Kräften daheim über Grönlands Thiere liefern können) und die Aufforderung, welche mir von mehreren Seiten zu Theil wurde, sind die Veranlassung, dass ich das Misstrauen in meine Kräfte überwand, und versuchen will, so gut als dies meine Kräfte gestatten, diesen Mangel, in so fern er die Thierklasse, welche ich am besten kenne, betrifft, zu beseitigen. Sollte diese Abhandlung über die Vögel Grönlands, welche ich hiermit der Oeffentlichkeit zu übergeben wage, eine wohlwollende Aufnalıme bei Sachkundigen finden, so werde ich es mir zu einer angenehmen Pflicht machen, in einigermassen gleicher Art mehrere Thierklassen nach einander zu behandeln, zu welchem Zwecke ich in den letzteren Jahren fleissig die Materialien gesammelt habe.

Godthaab in Grönland im März 1840. 


\section{Von den Vögeln Crönlands.}

\section{$\mathbf{S}_{0}$ viel mir bekannt, giebt es kein vollständiges Verzeichniss}

der in Grönland vorkommenden Vögel, daher ich der Meinung bin, ein solches werde hier an seinem Platze sein.

Diejenigen Arten, welche als brütende Vögel in Grönland beobachtet wurden, sind ohne Abzeichen vor der Nummer aufgeführt. -

Dagegen bedeutet ein Stern (*) vor der Nummer, dass ich vermuthe, der Vogel brüte in Grönland, obschon dessen Brütplatz noch nicht entdeckt ist.

Zwei Sterne (**) zeigen an, dass der Vogel ofters in Grönland gefunden wurde, und daher zur Fauna dieses Landes gerechnet werden muss, obgleich ich nicht glaube, dass er daselbst brüte.

Die mit drei Sternen (***) bezeichneten Arten sind nur ein einziges Mal in Grönland getroffen, wesshalb ich ihr Vorkommen dort für zufällig ansehe. -

Ein Stern (*) hinter dem Namen der Species zeigt an, dass ich den Vogel selbst nicht in Grönland gesehen habe, dass er aber aufgenommen ist nach Etatsraths Reinhardts Ichthyologischen Beiträgen (Icht. B.) oder nach Fabricii Fauna Groenlandica. -

Eine Null $(0)$ endlich bedeutet, dass der Vogel früher dort gebrütet hat, jetzt aber nicht mehr dort gefunden wird.

Mit einem $\mathbf{E}$ habe ich die europäischen, mit einem A die amerikanischen Vogelspecies versehen, welche in Grönland vorkommen. Z bezeichnet, dass der Vogel beiden Welttheilen gemeinschaftlich zukommt. Die eigentlichen Grönländischen Species, deren anderweitiges Vorkommen, als von dort ausgehend, angenommen werden muss, sind unter $G$ verstanden, und endlich be- 
deutet ein grosses 0, dass der Capt. Graah den Vogel auf der Ostküste Grönlands antraf. -

1. Aquila albicilla. Z. 0.

* 2. - ossifraga. Z. 0 .

3. Falco islandicus. Z. 0.

4. - peregrinus. Z.

5. Strix nyctea. Z.0.

** 6. - brachyotus. $\mathrm{Z}$.

7. Corvus corax (var. littoralis, mihi). G. 0.

**** 8. Sylvia mexicana? A.

*** 9. Troglodytes palustris. A.

10. Saxicola oenanthe. E.

11. Anthus ludovicianus, Lichtenstein. Alauda rufa, Wilson. A.

*** 12. Alauda cornuta. A.

13. Emberiza nivalis. Z. 0.

14. - calcaruta. Z. 0.

* 15. Fringilla leucophrys. A.

16. Linota linaria. Z.

17. - Hornemanni, mihi; canescens, auctorum. $\mathbf{G}$.

*** 18. Hirundo americana. A.*

19. Tetrao Reinhardtii (Brehm. lagopus, auctor.). G. 0.

20. Calidris arenaria. Z. 0.

21. Charadrius hiaticula. Z.

** 22 . - phuvialis. Z.

** 23. Vanellus melanogaster. $\mathrm{Z}$.

*** 24. - cristatus. E.*

25. Strepsilas collaris. Z.

** 26. Numenius phaeopus. E.

** 27. - hudsonius. A.

** 28. Tringa variabilis (T. alpina, Fauna Groenl.). *A.

** 29. Schinzii.

30. - maritima. $\mathrm{Z}$.

31. - - islandica. $Z$.

** 32. Limosa melanura. Z.

** 33. Scolopax grisea. A. *

** 34. - gallinago, Z.*

**** 35. Rallus carolinus. A.

*** 36. Podiceps cornutus. Z.*

*** 37. - rubricollis. Z.*

38. Phalaropus hyperboreus. Z.0. 
39. Phalaropus platyrhynchus. Z.

40. Sterna arctica. Z. 0.

41. Xema Sabini. Z.

42. Larus glaucus. Z. 0

43. - marinus. $\mathbf{Z}$.

44. - leucopterus. Z.G.

45. - eburneus. Z.

** 46. - brachytarsus mihi. G.

47. - tridactylus. Z.

** 48. Lestris catarractes. E.

49. - pomarina. $\mathrm{Z}$.

50. - parasitica (L. Schlepii Br.). Z.O.

51. - Buffonii. E.

52. Procellaria glacialis. Z. 0.

* 53. Thalassidroma Leachii. $\mathbf{Z}$.

* 54. Puffinus cinereus. $\mathrm{Z}$.

*** 55. - anglorum. Z.*

** 56. Cygnus melanorhynchus. E.

57. Anser hyperboreus. Z.

58. - albifrons. Z.

** 59. - leucopsis. $\mathrm{Z}$.

60. - bernicla. $\mathbf{Z}$.

61. Anas boschas. $\mathrm{Z}$.

** 62. - acuta. Z.

** 63. - crecca. Z.

64. Clangula glacialis. Z. 0 .

65. - histrionica. Z.0

66. - Barrowii. A.

*** 67. - ? albeola. A.

68. Somateria mollissima. Z. 0.

69. - $\quad-\quad$ spectabilis. Z. 0.

** 70. - perspicillata. Z. 0.

71. Mergus serrator. $\mathbf{Z}$.

72. Carbo cormoranus. Z.O.

** 73. Sula alba. E.

74. Colymbus glacialis. Z. 0 .

75. - septentrionalis. Z. 0 .

76. Uria grylle. Z. 0.

* 77. - troile. $\mathrm{Z}$.

* 78. - leucopthalmos, Faber. (lacrymans, auctorum.) 
79. Uria Brünnichii. G.Z. O.

80. - alle. Z. 0.

81. Mormon fratercula. Z.

82. Alca torda. Z.

$083 . \quad$ - impennis. $\mathbf{Z}$.

*** 84. Loxia leucoptera. Z.0.*

In den Jahren 1840-42 sind die zufällig vorkommenden Vögel noch durch 3 amerikanische und eine europäische Art vermehrt worden:

*** 85. Muscicapa villica Lichtenstein. A.

*** 86. Sylvia (Sylvicola) coronata. A.

*** 87. Icterus frenatus Lichtenstein. A.

*** 88. Gallinula porzana. E.

Folgende mit einem Stern vor der Nummer versehene Arten, als :

Fringilla leucophrys,

Larus eburneus,

Puffinus cinereus,

Thalassidroma Leachii,

Uria troile,

- leucophthalmos

halte ich für nistend in Grönland selbst oder in unmittelbarer Nähe an dessen Küste, obgleich ihre Brüt-Plätze noch nicht auf. gefunden sind:

1) weil man von diesen Arten Individuen in jedem Alter findet, und mit Ausnahme von Fringilla leucoplirys und den 2 Uria-Arten in ziemlicher Menge, ja von Puffinus cinereus in grosser Menge;

2) weil man die alten Vŏgel in grosser Menge in der Brützeit antrifft, und man annehmen darf, dass die Vögel sich in dieser Zeit nicht weit vom Brütplatz entfernen. Dies ist zwar nicht der Fall mit Fringilla leucophrys und den Uria-Arten, aber ersteren schoss ich unter Verhältnissen, welche zienılich sicher schliessen liessen, dass der andere Gatte oder die Jungen in der Nähe waren, und von letzteren habe ich Uria troile einmal mit deutlichem Brutfleck erhalten.

Anders verhält es sich mit den vor der Nummer mit zwei Sternen bezeichneten Vögeln, welche mir aus folgenden Gründen nicht in Grönland zu nisten scheinen: 
1) Weil nur wenige Individuen dort angetroffen werden, worin alle übereinstimmen.

2) Einige wurden ausschliesslich nur während der Zugzeit bemerkt, z. B. die Arten von Anser etc.

3) Andre wurden nur auf dem Meere an den Küsten Grönlands gesehen, wie Lestris catarractes und Sula alba.

4) Andre wurden nur als junge Vögel gefunden, z. B. Anser hyperboreus.

5) Wiederum kommen andre zwar in verschiedenen Alterstrachten vor, z. B. Charadrius pluvialis, Vanellus melanogaster, $\mathrm{Nu}$ menius phaeopus, aber an Orten und unter Verhältnissen*), die es unwahrscheinlich machen, dass die Erlegten brütende Vögel sein sollten. Dies trifft zu bei allen diesen Individuen, welche ich während der Brützeit erhielt und über deren Acquisition ich genaue Auskunft erhalten konnte; sie wurden nämlich unmittelbar bei den Colonieen, oder auf den alleräussersten Inseln erlegt, woraus man schliessen kann, dass sie nicht haben brüten wollen; ausserdem waren alle sehr scheu, während das Gegentheil an den Brütplätzen statt findet.

6) Endlich kann man sich mit ziemlicher Sicherheit auf die Aussagen der Grönländer verlassen, da sie die Vŏgel ihres Landes sehr gut kennen; und der Preis, den sie für seltne Vögel an den Colonien zu erwarten haben, erzeugt noch grōssere Achtsamkeit bei Leuten, die für alles Lebende einen scharfen Blick haben, und deren Herumschweifen, sowohl bei ihrem gewöhnlichen Fang, als auf den Rennthierjagden ihnen die beste Gelegenheit darbietet, die Vögel, welche wirklich im Lande brüten, an den Brütplätzen aufzufinden. Hıerzu kommt, dass die Vegetation an den Bergseen, gleich wie die Anzahl der sich dort aufhaltenden Vögel, so unbedeutend ist, dass diejenigen, welche dort brüten, schwerlich der Aufmerksamkeit der Grönländer, selbst wenn diese geringer wäre, als ich mit Grund annehme, entgehen würde. Es bedarf kaum noch der Erinnerung, dass manche, selbst alte, Sumpfvögel, die nicht brüten oder frühzeitig in der Brützeit ihre Gatten verloren, weit von den Brütplätzen abzustreifen pflegen; das Vorkommen solcher Vögel in Grönland wäre somit sehr erklärlich. Ich will indessen nicht behaupten, dass nicht einzelne dieser Vŏgel, z. B.

*) Das Nähere darüber findet sich bei den einzelnen Arten. 
Tringa Schinzii*), die Scolopax-Arten, Vanellus melanogaster der Achtsamkeit der Grönländer entgangen sein konnten; warum sollte dies aber nicht ebensowohl mit Anthus und Calidris der Fall sein **); letzterer gehört offenbar zu den seltneren Vögeln Grŏnlands.

Folgende Vögel, deren Vorkommen in Grönland ich als zufällig bezeichnet habe, da von jedem derselben nur ein einziges Individuum bisher vorgekommen, möchten am passendsten zusammen, unter Angabe der Zeit wann, und des Ortes wo sie getroffen wurden, aufgezählt werden:

Alauda cornuta: Godthaab, October 1835.

Loxia leucoptera: Ostküste, Zeit unbekannt.

Vanellus cristatus: Fiskenaesset, Januar.

Troglodytes palustris: Fiskenaesset, October 1820.

Hirundo americana oder rufa: Juni 1830.

Rallus carolinus: Sunnertop, October 1822.

Podiceps cornutus: Nenortalik, November.

- rubricollis: Julianehaab, November 1839.

Puffinus anglorum: Julianehaab.

Clangula (P) albeola: Godthavn, October 1827.

Muscicapa villica (Licht.): Nenortalik, 24. Aug. 1840.

Sylvicola coronata: Fiskenaeset, 21. Mai 1841 und wiederum

1844 bei Frederickshaab nach schriftlicher Mittheilung des

Verfassers.

Icterus frenatus: Nenortalik, 2. September 1840.

Gallinula porzana: Goodthaab, 28. September 1841.***)

Werden diese 14 Arten von dem Verzeichniss abgezogen, so bleiben noch 74 Arten zurück, die zu Grönlands Fauna gehören, da sie öfter im oder am Lande angetroffen wurden. Von diesen

*) Tr. Schinzii brütet nach einer schriftlichen späteren Mittheilung des Verfassers an mich gewiss dort. Auch babe ich dieselbe wiederholt unter den Sendungen, die ich von Grönland erhielt, sowohl alt als jung und selbst aus den nördlicheren Colonieen Grönlands erhalten.

Anmerkung des Uebersetzers.

**) In dieser Beziehung hedaure ich, dass mir die Gelegenheit fehlte, mehrere der Buchten Nord-Grönlands zu bereisen, welche im Ganzen am wenigsten von mir erforscht sind.

***) $\mathrm{Zu}$ diesen kommen noch Anthus pratensis, den ich im Herbste 1844, und Turdus iliacus, die ich im vorigen Jahre aus Grönland erhielt.

Anmerkung des Uebersetzers. 
sind 18 Arten nicht als brütend gefunden, und ferner muss Alca impennis abgezogen werden, welcher sicher nicht mehr im bekannten Theil des Landes nistet, so dass also 55 Vogelarten übrig bleiben, welche nach dem Vorstehenden in Grönland nisten.

Fabricius führt in seiner Fauna groenlandica 53 Arten auf, aber 2 von diesen: 1) Falco rusticulus und fuscus (unter einer Nummer aufgeführt) und 2) Anas glaucion sind bekanntlich nur junge Vögel andrer, in demselben Werke genannter, Arten, und 5 andre, Pelecanus cristatus, Larus cinereus, Ardea cinerea, Mergus merganser und Parus bicolor, welche Fabricius nicht selbst gesehen, sondern nach der Beschreibung der Grönländer aufgenommen hat, sind seitdem nicht in Grönland beobachtet, und müssen aus der Liste der grönländischen Vögel gestrichen werden; es bleiben also 45 Arten zurück, welche Fabricius bekannt waren, und die später wieder vorgekommen sind, obgleich nicht alle den in der Fauna groenlandica angeführten Namen entsprechen.

Grönland hat eine so bedeutende Ausdehnung und liegt so isolirt, dass man schon daraus schliessen kann, seine Fauna habe ihren eigenthümlichen Charakter, und dies zeigt sich auch an allen Thierklassen, die hier im Lande gefunden werden. Bei den Vögeln ist das besonders Hervortretende eine, wenn ich so sagen darf, boreale Tendenz. Diese zeigt sich nicht allein daran, dass die grösste Menge der im Lande vorkommenden Vögel beständig nordwärts strebt, dort nistet, und insofern sie aus Standvögeln besteht, sich nur ungern durch Eis oder Dunkelheit nach Süden drängen lässt, so dass es nicht allein, wie auch in andern borealen Ländern, weit mehr Individuen im Norden als im Süden giebt, sondern besonders daran, dass die eigentliche Brützone derselben bedeutend nördlicher in Grŏnland, als in andern Ländern beginnt. Daher kommt es, dass alle Vügel, deren Nester man in Südgrönland fand, auch in Nordgrönland (ausgenommen allein Clangula Barrowii*)) brüten, während unter den oben als

*) Doch ist die Nestzone dieses Vogels auch weit nördlicher in Grönland, als anderswo. Nach Richardson hört derselbe mit $\mathbf{5 7 ^ { \circ }}$ auf. Hier fängt sie erst mit $64^{\circ}$ an, und erstreckt sich ungefähr $1 / 2$ Breitengrad nördlicher. 
in Grönland brütend angeführten Vögeln 13 Arten von den 46, deren Nester wirklich gefunden wurden, nur in Nordgrönland, oder bestimmter: nördlich vom 66sten Breitengrad brüten und 3 andre, welche nicht südlich vom $63^{1 / 2} 2^{\circ}$ N. B. brüten. Nimmt man an, dass der 66ste ${ }^{\circ}$ N. B. Nord - und Süd-Grönland scheide, so hat Nord-G. 46, Süd-G. nur 33 Arten. Nichtsdestoweniger giebt es unter den Vögeln, die allein in Nordgrönland brüten, nicht wenig Arten, deren Brützone sich in andern Ländern weit südlicher erstreckt.

Betrachtet man die Vögelarten mit Rücksicht auf die Zahl der Individuen, so ist dies Phänomen noch mehr auffallend, da zur Brützeit die Zahl der Individuen innerhalb der arktischen Zone ausserordentlich viel grösser ist, als in Südgrönland. Nach meinen Beobachtungen nisten folgende Vögel hier nicht südlicher, als unter dem hinzugefügten Breitengrad, als:

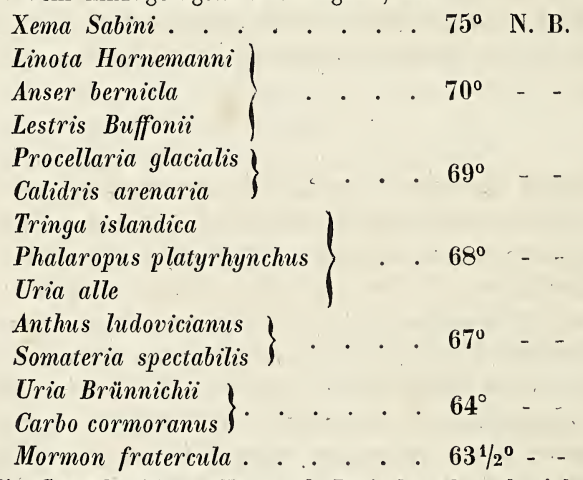

Durch die Güte des Herrn Etatsrath Reinhardt sehe ich mich in den Stand gesetzt, eine Liste hinzuzufügen, wie weit nördlich einige boreale Vögel in Nordamerika brüten (nach Richardsons Beobachtungen):

Falco islandicus . . . bis zum $74^{\circ}$ N. B.

- peregrinus . . . - $-74^{0}-$

Strix brachyotus . . . - $-67^{0}-$

Alauda cornuta . . . . - $-69^{\circ}-$

Emberiza nivalis . . . - - $75^{\circ}-$

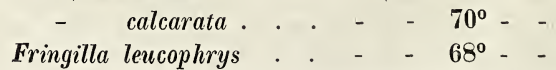


4 Arten Hirundo . . . bis zum $60-68^{\circ}$ N. B.

Tetrao rupestris . . . - - $75^{\circ}-$

Vanellus melanogaster . - $\quad 70^{\circ} \ldots$

Tringa alpina

Sterna arctica

Phalarcopus hyperboreus

Larus leucopterus

platyrhynchus

- glaucus

Lesțis pomarina

- parasitica

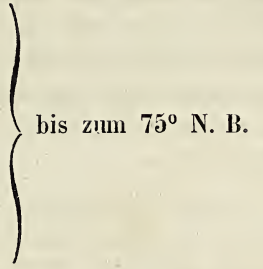

Obgleich nun aber manche Arten ganz im Süden des Landes brüten, z. B. Somateria mollissima, andere ziemlich südlich, als: Uria Brünnichii, Carbo cormoranus, so ist dies doch nur der Fall mit einer so unbedeutenden Zahl Individuen dieser Arten, dass die eigentliche Brützone für diese weit nördlicher zu setzen ist, und dies findet auch bei manchen andern Arten statt.

Die Ursachen zu der Thatsache, dass die Vögel in Grönland so weit nach Norden ihre Brütplätze suchen und überhaupt es vorziehen, im nördlichen Theile des Landes sich aufuhalten, anzugeben, möchte wohl unmöglich sein, bis man bessere Kenntnisse über das Vorkommen der niedern Thierklassen hat, da man annehmen muss, dass die Nahrung eines der wesentlichsten Momente dabei ist. Allerdings kann auch die Lage des Landes darauf einen grossen Einfluss äussern. Nordgrönland liegt näher an Amerika, woher Grönland seine meisten Zugvögel bekommt, der Weg über das Meer ist also weniger lang. Ausserdem hat Nordgrönlands Clima mehr den Charakter eines borealen Festlandes, das Wetter im Sommer ist mehr beständig, die mittlere Wärme in den Sommer-Monaten höher als in Südgrönland, welches gänzlich den Charakter eines borealen Küstenlandes hat, mit viel Regen und Nebel.

Freilich fehlt ein Theil der Zugvögel, welche im Frühjahre sehr selten bei den Colonieen in Südgrönland angetroffen werden, dort nie im Herbste, z. B. Anthus, Anser albifrons und bernicla etc.; dies lässt sich aber leicht erklären, wenn man die Gestalt des Landes ansieht und sich erinnert, dass alle diese Vögel von und nach dem Festlande von Amerika ziehen; längs mit dessen Küsten ziehen die Vögel nach Norden, und gelangen so erst zu dem 
Breitengrade, wo sie ihre Brutplätze suchen, bevor sie quer über die Davisstrasse fliegen, wodurch der Weg über's Meer abgekürzt wird. Im Herbste folgen sie südwärts ziehend dagegen Grönlands Küsten, und indem sie den Flug über's Meer so lange als möglich aufschieben, sieht man dieselben an der ganzen Südküste. Bei Nenortalik, welches in der Nähe der Südspitze Grönlands liegt, sammeln sich daher die Vögel, sowohl von der West-als 0stküste, daher dieser Strich auch zur Herbstzugzeit am reichsten an Vögeln ist.

So reich Nordgrönland *) im Sommer an Vögeln ist, eben so arm ist es in dieser Beziehung im Winter. - In der Zeit, wo die Sonne unter dem Horizonte ist, sieht man von Landvögeln nur: Corvus Corax var. littoralis, Tetrao Reinhardtii, ausnahmsweise Falco islandicus und Strix nyctea; von Seevögeln nur: Uria Brynnichï, Alle und Grylle nebst jungen Vögeln der SomateriaArten. Aeusserst selten bemerkt man einen Larus, nie eine Procellaria, obgleich zuweilen das Meer nicht besonders mit Eis bedeckt ist. Weiter in dem Winter, in der kältesten Zeit, gegen Ende Februar und im März, sieht man auf den Felsen im Innern des Landes Emberiza nivalis und Linota Hornemanni stets in Schaaren, und dort findet man gewöhnlich auch viele Schneehühner. - Gegen Ausgang des April beginnt das Frühjahr, und sobald das Eis aufgeht, ist das Meer auch sogleich bedeckt imit Seevögeln, besonders Uria Brïnnichii, Alle und Grylle. Der letztgenannte Vogel ist unter allen Seevögeln der letzte, welcher sich durch das Eis vertreiben lässt.

Nordgrönland besitzt zwar im Sommer eine weit grössere Anzahl Vögel, sowohl mit Rücksicht auf die Arten als auf die In dividuen, doch giebt es einzelne Vögel, welche Südgrönland eigenthümlich sind, und zwar folgende:

\section{Fringilla leucophrys, \\ Puffinus cinereus, \\ Thalassidroma Leachii, \\ Uria troile, \\ Uria leucophthalmos,}

*) Indem ich von Nordgrönland spreche, beziche ich mich besonders anf Godhavn $\left(69^{\circ} 14^{\prime}\right.$ N. Br. und $43^{1 / 2}$ W. L. von Greenwich), wo ich 3 Jahre mich aufhielt. 


\section{Lestris catarhactes und}

Cygnus melanorhynchus.

Als eigenthümlich für Nordgrönland betrachte ich alle die Vögel, deren Brützone sich nicht weiter südlich, als zum $66^{\circ} \mathrm{N}$. B. erstreckt; aber fast alle diese Vögel wandern entweder im Winter nach Südgrönland, oder werden doch dort in der Zugzeit gesehen.

Nur wenige der Vŏgel, die in Nord- und Südgrönland brüten, werden zur Brützeit häufiger in Süd - als Nordgrönland gefunden, diese sind:

Larus marinus,

- leucopterus,

- tridactylus,

Lestris parasitica,

Clangula histrionica,

Colymbus glacialis und

Corvus Corax var. littoralis.

Alle andern Species sind durchschnittlich weit zahlreicher in Nord - als Südgrŏnland.

Eine andre Eigenheit der borealen Vögel ist die constante Farben-Verschiedenheit an einer und derselben Art, welche, so weit mir bekannt, noch nicht gehörig beachtet ist. Diese Verschiedenheit dauert bei manchen Arten das ganze Leben hindurch, als bei Falco islandicus, Lestris parasitica und pomarina, Procellaria glacialis. Als eigenthümlich für Grönland führe ich an, dass dieselbe bei gewissen Arten nur in der Jugendtracht stattfindet, wie bei Larus glaucus und leucopterus, welche in zwei ganz verschiedenen Farbenkleidern die Jugendzeit durchmachen, doch so, dass, wenn sie brutfähig werden, sie die regelmässigen Farben der Art annehmen.

Als Besonderheit der Fauna Grönlands verdient noch die grosse Menge zufälliger Vŏgel einer Erwähnung, und, wenn man will, das Vorkommen einer Menge Arten, welche nicht jährlich eintreffen, obschon sie öfter gesehen wurden, und welche nie, oder sehr selten dort nisten. - Von erstern sind nemlich 14 Arten bemerkt, von letztern 18, also im Ganzen 32 Arten (von 84), welche nicht jährlich in Grönland eintreffen. Der Grund dieser Erscheinung liegt wohl an verschiedenen Umständen. Der hauptsächlichste ist wohl, dass Grönlands Küsten stets mehr oder weniger mit Eis umgeben sind, und dass das Meer in weiter Entfernung vom Lande nie der Eisberge ermangelt; dazu kommt der 
Nebel, der oft längere Zeit anhält und die Vögel verwirrt, die auf den Eisschollen und Eisbergen Ruheplätze und Wasser, ja die Sumpfvögel selbst Nahrung vorfinden. Die geringe und niedrige Vegetation des Landes gewährt dem ankommenden Vogel keinen Schutz, so dass er bald entdeckt und von dem Sammler acquirirt wird. Hierzu kommt noch die genaue Kenntniss der Grönländer mit den Vugeln des Landes, wesshalb sie gleich auf einen ihnen unbekannten Vogel aufmerksam werden, und denselben erlegen, und der ziemlich hohe Preis, der für solchen ungewöhnlichen Vogel bezahlt wird, ermuntert sie, den Europäern den Fang zu bringen.

Endlich verdient als charakteristisch für die Fauna Grönlands die auffallende Armuth sowohl an Arten als Individuen der Grallatores, welche in andern Ländern der borealen Zone häufig brüten, bemerkt zu werden. -

Wie bekannt, besitzt Grönland einen Theil Zugvögel, welche sowohl in Europa als Amerika gefunden werden, und es möchte nicht ohne Interesse sein, zu erfahren, von welchem dieser grossen Continente Grönland seine Zugvŏgel erhält. Meine sechs Reisen nach Grönland machten es mir möglich, in dieser Beziehung einige Untersuchungen anzustellen, und, insofern diese ein einigermassen zuverlässiges Resultat geben, erhält Grönland nur 5 Arten seiner Zugvögel von Europa, nemlich:

\section{Saxicola oenanthe, \\ Falco peregrinus, \\ Strix brachyotus, \\ Numenius (phaeopus?) und \\ Cygnus melanorhynchus.}

Die Reise nach Grönland trifft gewöhnlich zur Zugzeit der Vögel ein, und der Weg geht über das Atlantische Meer, sũdlich von den Färöern und Island. Wenn man auf diesem Wege nach Westen die westlichste Spitze von Island passirt ist, so glaube ich annehmen zu dürfen, dass alle Vögel, die man dann antrifft, auf dem Wege nach Grönland sind. Auf allen diesen sechs Reisen sah und fing ich dort häufig Saxicola oenanthe, zwei mal erhielt ich Falco peregrinus, einmal Strix brachyotus und bemerkte zweimal einen Numenius und Cygnus, alle auf dem Zuge nach Grönland, wenn die genannten Bedingungen Grund genug geben, die Richtung des Zuges zu bestimmen. - Gelangt man dagegen westlich vom Cap Farvel (der Südspitze Grönlands) und hinein in die Davis-Strasse, so erscheinen ganz andere Zugvŏgel.', Dann 
kommt Emberiza nivalis und calcarata, Anthus ludovicianus und Linota linaria (nie Hornemanni) gewöhnlich mit Nebel und Sâdwind, oft in grosser Menge am Bord der Schiffe. Gleichfalls sieht man kleine Schaaren Charadrius hiaticula*), und zuweilen grosse Schwärme der Phalaropus-Arten, theils fliegend, theils schwimmend zwischen dem Eise. Ich nehme an, dass diese Vögel auf dem Zuge von dem Festlande Amerikas nach Grönland begriffen sind. -

Grönlands Meer, ohne Zweifel eins der fischreichsten im Norden, ist gleichermaassen angefüllt mit Weichthieren, Crustaceen und andern Thieren der niedern Ordnungen. Hieraus lässt sich vielleicht schon der grössere Vogel-Reichthum (an Individuen), woran die Küsten Grönlands die andrer Länder übertreffen, erklären. Da ein grosser Theil derselben gesellschaftlich leben, hat Grönlands Westküste eine Menge Vogelberge **), welche, da dic Volksmenge unbedeutend und der Preis, welcher für Federn bezahlt wird, gering ist (jetzt werden sie nicht mehr aufgekauft), wenig gestört werden. Von den Vogelbergen sind vielleicht Inujuatub in dem Godthaaber Fjorde (Meerbusen) (hauptsächlich bewohnt von Larus tridactylus, leucopterus und glaucus) und Karsarsoak bei Upernevik (besonders besetzt mit Uria Brünnichii) die merkwürdigsten, wegen ihrer Ausdehnung und der unberechenbaren Menge Vögel, welche auf ihnen nisten***). Ich habe Gelegenheit gehabt, eine grosse Anzahl Vogelberge zu sehen, sie bieten alle mögliche Situationen dar: einige liegen weit hinein in die Meerbusen, z. B. Inujuatub gewiss 10 Meilen in dem Godthaaber Fjorde hinein, andere liegen an der offenen See, als Karsarsoak, Godhavn's Scharben- und Blaufelsen, besetzt mit Procellaria glacialis; sie sind gegen alle Himmelsgegenden gerichtet, und haben nur eine Eigenschaft gemeinschaftlich: nemlich die Leich-

*) Obgleich die Amerikan. Ornithologen das Vorkommen von Charadrius hiaticula in Amerika nicht zugeben, muss ich doch annehmen, dass wir den Vogel von dort erhalten; denn nicht allein habe ich denselben im Atlant. Meere gesehen, sondern auch oft auf dem Fluge quer über die Davisstrasse bemerkt. Gewiss ist es jedoch, dass alle die Individuen, welche ich erhielt, von der europäischen Art sind.

**) Doch giebt es nur wenige im südlichen Theil des Landes.

***) Ich bin aufgefordert worden, die Vogelberge genauer zu beschreiben, und werde desshalb Materialien sammeln, um eine solche Beschreibung in einer Zeitschrift zu geben. 
tigkeit, dem Vogel und den Jungen Nahrung während der Brutzeit zu verschaffen, besonders in der ersten Zeit, "nachdem die Eier ausgebrütet. Die meisten Vogelberge, welche ich kenne, liegen nämlich ganz in der Nähe solcher Stellen, wo Mallotus arcticus ans Land kommt, um den Rogen zu streichen. Die übrigen liegen an Stellen, wo das Meer zur Brutzeit (zu andrer Zeit erinnere ich mich nicht, dort gewesen zu sein) gleichsam mit Crustuceen und Weichthieren (besonders Clio borealis und Limacina arctica) angefïllt ist. Bei Karsarsoak ist das Meer so mit Crustaceen angefüllt, dass man nicht durchs Wasser sehen kann, und die Excremente der Vögel beweisen hinreichend, dass jene ihre Nahrung ausmachen, wie ich auch keine andre in der Speiseröhre der erlegten fand. Ich nehme daher an, dass die Sorge für Nahrung das einzigste Motiv ist, welches auf die Wahl der Nistplätze an den sogenannten Vogelbergen influirt, insofern diese Felsen dann passende Localitäten dafür darbieten.

Das von Faber an den isländischen Vogelbergen beobachtete höchst interessante Phänomen, dass es dort immer auch ungepaarte Vögel giebt, und dass diese das Ausbrüten der Eier und die Ernährung der Jungen übernehmen, deren Versorger umkamen, habe ich nicht in Grönland entdecken können. Bei ganz kleinen Vogelbergen glaube ich beobachtet zu haben, dass es keine übercompleten Exemplare gebe; bei den grösseren macht die ungeheure Menge der Vŏgel es unmŏglich, in dieser Beziehung eine Ansicht zu haben. Ich habe öfter die Vögel von einzelnen freiliegenden Nestern weggeschossen, in keinem Falle aber wurden die Eier bebrütet; aber ich habe nur Gelegenheit gehabt, diese Versuche mit Alca torda und mit Larus tridactylus anzustellen, welcher letztere indessen einer der Vögel ist, die Faber nennt. Dieser Mangel an Uebereinstimmung wäre merkwürdig genug, da, wie bekannt, Landt dieselbe Bemerkung auf den Färöern gemacht hat, als Faber auf Island, wenn die Verhältnisse von diesen den grönländischen gleich wären, welches aber keinesweges der Fall ist. Ich habe schon früher bemerkt, dass die grönländischen Vogelberge wenig gestört werden, so dass die alten Vŏgel, Junge und Eier, welche hier von Menschen vernichtet werden, im Ver. hältniss zu der Menge der Vögel gleich Null zu rechnen sind. Wenn aber meine an den Vogelbergen hier angestellten Beobachtungen zu Schlüssen berechtigen können, dürfte es vielleicht nicht zu kühn sein, anzunehmen, dass der bedeutende Vogelfang auf 
Färröe und Island dies Vikariiren der ungepaarten Vögel sowohl nothwendig als möglich macht.

Faber führt in seinem Prodomus S. 108 an, dass, ungeachtet man auf Westmannöe jährlich wenigstens 20,000 Junge der Procellaria glacialis wegnimmt, doch die Zahl dieser Vögel an dieser Stelle zunimmt. $0 b$ diese Zunahme auch an den andern Vogelbergen stattfindet, wird nicht bemerkt, aber nach den Nachrichten, welche ich mir über die Ausfuhr der Federn aus Island habe verschaffen können, hat die Anzahl der Vögel nicht abgenommen.

Hier in Grönland, wo die Vögel und Vogelberge so wenig beunruhigt werden, kann man keine Zunahme bemerken, nur an einzelnen der kleinern Vogelberge findet sich die Zahl der Vögel zuweilen Veränderungen unterworfen, indem dieselben bei dem einen Vogelberge zunehmen, bei einem andern abnehmen.

Wie bekannt, wird der Eidervogel in Island geschont und gehegt, aber der Export der Dunen hat, so weit ich habe erfahren können, nicht zugenommen, also auch nicht der Vogel selbst. Hier in Grönland wird der Eidervogel auf die schändlichste Art behandelt. Man nimmt nicht allein die Eier ohne Schonung weg, sondern fängt und schiesst auch die alten Vögel bei den Nestern, und verfolgt und fängt die kleinen Entchen, sobald sie ins Wasser kommen etc. Ausserdem wird nicht allein eine grosse Menge Eidervŏgel auf dem Zuge geschossen, sondern die Grönländer fangen auch eine Masse in den Monaten Januar bis April, da dieselben nicht selten in dieser Jahreszeit die Bedingung zur Existenz der Grönländer an mehrern Stellen Südgrönlands ausmachen, indem ihr Fleisch, nebst dem einiger Alken und Dorschen (Cottus bubalis, Seebull), die einzigen Nahrungsmittel derselben sind.

Trotzdem ist keine Abnahme zu bemerken, wenigstens wenn man nach der ungeheuren Anzahl, welche im Herbste manche Stellen der Meerbusen förmlich bedeckt, urtheilen will. Gleichfalls hat die Produktion der Dunen nicht abgenommen; dies sollte jedoch im allerletzten Jahre der Fall sein, welches indessen durch ganz andre Ursachen als die Abnahme der Vögel bewirkt ist *).

*) Leider muss ich jetzt (1842) berichten, dass die Menge der Eidervögel an Grönlands Küsten in den letzten Jahren bedeutend abgenommen; aber dies ist plötzlich geschehen, indem nach mehreren sehr feuchten Sommern, unter deren Einfluss die meisten Jungen umkamen, im Jahre 1836 ein sehr früher Winter mit 
Wenn sonach die Anzahl der in Grönland gewöhnlichen Vögel keinen bedeutenden Veränderungen unterworfen ist, so findet ein andres Verhältniss mit den Vögeln statt, welche hier nie in grosser Anzahl waren, sondern die nur Grönland besuchen.

So weiss man mit grosser Bestimmtheit, dass Alca impennis an mehreren Stellen gebrütet hat, - jetzt kann derselbe als gänzlich verschwunden in Grönland angesehen werden. Aehnlich verhält es sich mit dem Schwan *), der jetzt nicht mehr in dem bekannten Theile Grönlands brütet. Charadrius pluvialis ist früher viel allgemeiner als jetzt gewesen, da er nicht allein von Fabrizius als brütender Vogel aufgeführt, sondern von andern auch als gemein genannt wird, während ich in 18 Jahren nur einige Exemplare gesehen habe.

Dagegen nehmen natürlich auch andre Vogelarten zu. Es ist fast unglaublich, dass ein so ausgezeichneter Beobachter, als Fabrizius, den Falco peregrinus **) und Anthus ludovicianus übersehen haben sollte, wenn diese Vögel denn damals, wie es jetzt der Fall ist, jährlich an den meisten Colonieen Südgrönlands, und namentlich bei Frederickshaab, wo Fabrizius wolnte, gesehen wurden.

Vanellus melanogaster und die Numenius-Arten waren vor 18 Jahren so sehr selten, dass ich in 3 Jahren nur ein Exemplar von Vanellus und einen Numenius erhielt, und auch keine Individuen weiter sah, obgleich ich damals häufiger die Fjorde besuchte als jetzt; aber in der spätern Zeit habe ich in jedem Jahre mehrere Exemplare gesehen. Gleichfalls meine ich, dass die Phalaropus-Arten und Tringa islandica im Zunehmen sind. Von andern Vögeln muss man annehmen, dass sie sich periodisch in grösserer Menge zeigen, darunter Strix brachyotus, welche ich im Jahre 1826 an mehreren Colonieen erhielt, die aber seitdem mir nicht vorgekommen. So ist auch Lestris Buffonii, wenigstens zur Zugzeit, ein solcher periodisch sich zeigender Vogel.

In der Fauna groenlandica des Fabrizius finden sich gewiss sehr gute Beobachtungen über Lebensweise und Vorkommen

ungewöhnlich früher Eisdecke eintrat, wodurch der Eidervogel zu Millionen in Nordgrönland unterging.

*) Ausführlicher hierüber bei dem Speciellen dieser Vögelarten.

**) Seitdem hat H. Hage mich aufmerksam gemacht, dass die Beschreibung von Fabrizius Falco rusticolus recht gut zum jungen Falco peregrinus passt. 
eines Theiles der Vögel Grönlands, und der Etatsrath Reinhardt hat, sowohl in seiner Zeitschrift für Naturwissenschaften, als in den Ichthyologischen Beiträgen gleichfalls über das Vorkommen derselben Aufklärungen gegeben; dennoch glaube ich, dass man bisher nirgends ausführliche Nachrichten über die Verbreitung der Vögel besitzt, sowie die Lebensweise mehrerer Arten von dem ausgezeichneten Beobachter Fabrizius nicht angeführt werden konnte, weil der Vogel sich im. Sommer nicht bei der Colonie zeigte, wo Fabrizius wohnte. Ich wage es daher mit dem Versuche bervorzutreten, diese Lücken durch die Erfahrungen, welche ich mir erworben, auszufüllen.

\section{A q $\mathbf{~ i l} \mathbf{~ a . ~}$}

\section{A Q U I A A L B I C I L L A}

ist im Sommer gleichhäufig in Nord - und Südgrönland, wohin im Winter alle ziehen, und im Frühjahre zu unbestimmter Zeit wieder nach Norden. Er horstet nicht selten auf zugänglichen Felsen, und legt 2 Eier spät im April. Er lebt sowohl von Seehunden, als Vögeln und Fischen, und da er zuweilen in SeehundsNetzen, welche nicht nahe an der Oberfläche des Wassers stehen, gefangen wird, taucht er auch: als Stosstaucher. Den Eidervogel fängt er, indem er sich vor Tagesanbruch auf einen Felsen oder eine Eisscholle in der Nẳhe des Tauchplatzes dieses Vogels setzt. Sobald eine Schaar dieser Vögel untergetaucht ist, fliegt derselbe über die Stelle hin, und sucht sich, wenn die Vögel heraufkommen, ein Männchen aus, wahrscheinlich, weil dessen weisse Farbe am besten im Wasser zu sehen ist, und indem er dasselbe verhindert, zum Athemholen hervorzukommen, ermattet der Adler es in dem Grade, dass es ihm leicht zur Beute wird. Uebrigens raubt er junge Vögel aus den Vogel-Felsen *) und nimmt vorlieb mit Aas jeder Sorte.

\section{A Q U I L A O S S IFRA GA.}

Unter diesem Namen glaube ich den langschwänzigen grösse-

*) Während die Larus-Arten zu Junujuatub Junge haben, sieht man täglich Adler und Falken über den Felsen schweben und ganz ruhig die Jungen aus den Nestern holen. 
ren Adler aufstellen zu müssen, welcher sich sowohl hier (in Dänemark?) als in Grönland findet, und sicher nicht A. leucocephala ist, welcher schwerlich in Grönland vorkommt, da man hier nie Adler mit vollkommen weissem Kopfe und Halse sieht. Erst in den letzteren Jahren bin ich auf den Unterschied zwischen diesen beiden Adler-Arten aufmerksam geworden, und bemerke nur, dass ich sicher bin, Aquila ossifraga horste in Grönland, da ich von dort sowohl junge als alte Individuen erhielt. In der Lebensweise stimmt er mit A. albicilla überein, und nach meinen Be obachtungen der letzten 2 Jahre: ist er eben so häufig in Nordals Süd-Grönland.

\section{10 .}

\section{F A L C O IS L A N D I C US.}

Dieser ist der gemeinste Falke Grönlands und gleich häufig Im Süden und Norden. Er ist sehr verschieden an Farbe, vom Weissen mit einzelnen dunkeln Flecken, bis zum fast einfarbigen dunkeln Blaugrau. Ohne Zweifel hat das Alter einigen Einfluss auf diese Verschiedenheit, denn man findet fast keine weisse junge; allein es ist doch Unterschied in der Farbe, nicht allein bei den Nestjungen, sondern auch bei den brütenden Vögeln, von denen angenommen werden muss, dass sie dasjenige Kleid haben, welches sie durch's ganze Leben behalten.

Ich habe mehrere brütende Paare gesehen, von denen der eine Vogel hell war, der andre dunkel, und sowohl hellgefärbte als dunkle Männchen beim Neste erlegt. Nur ein einziges Mal erhielt ich ein Falkennest mit 4 Jungen, von denen das eine blaugrau, fast ohne Abzeichen, die andern dagegen sehr hell mit hellbraunen Streifen waren. Ferner habe ich viele junge Falken selbst erlegt, oder erlegt gesehen, welche dieselbe Farben-Verschiedenheit darboten, und unter den hellen sowohl Männchen als Weibchen gefunden. Die, freilich wenigen, Male, dass ich dergleichen Beobachtungen anstellen konnte, veranlassen mich zur Annahme, dass die weisse Farbe in Nordgrönland vorherrscht, wo das erwähnte Nest ausgenommen wurde, während in Südgrönland mehr dunkle Falken ausgebrütet werden. Mit diesem Punkte wäre ich also wohl im Reinen. Anders verhält es sich mit den schönen gelben Beinen 
und der gelben Wachshaut, welche einzelne, stets sehr helle, Falken haben; diese sind nicht nothwendig, um den Vogel brutfähig zu machen, ja ich muss gestehen, dass alle die Falken, welche ich beim Neste erhielt, mehr oder weniger hell blei-blaue Wachshaut und Füsse besassen. Gleichwohl glaube ich nicht, dass der gelbbeinige Falke eine eigne Species ist, da ich durchaus keinen standhaften Unterschied in der Bildung des Schnabels oder der Zeichnung auffinden konnte. Vielleicht ist der Falke mit den gelben Beinen etwas kleiner, und die weisse Farbe etwas mehr rein; aber dies wäre auch der ganze Unterschied. Unter 14 alten Falken, die ich gegenwärtig in meiner Sammlung habe, ist nur einer mit den erwähnten gelben Füssen. *)

Die jungen Falken mausern, wie es scheint, ununterbrochen, den ganzen Winter hindurch, und gegen das Frühjahr wird keiner ohne Abzeichen gesehen. Ich besitze ein junges Weibchen, geschossen den 4. Jan. 1840, welches am Kopfe und Halse in starker Mauser begriffen ist, und durch die ausgewachsenen Federn an dieser Stelle ein weissgestreiftes Aussehen erhalten hat. Der Eierstock desselben war sehr ausgebildet, und da ich nach der Untersuchung der Fleischseite des Balges annehmen muss, dass der Vogel zum. Frühjahre eine Zeichnung, wie bei den brutfähigen Vögeln, erhalten haben würde, scheint es mir nicht unwahrscheinlich, dass Falco islandicus schon im ersten Jahre, nachdem er ausgebrütet, sich fortpflanzt. **)

Der grönländische Falke legt im Juni 4 Eier von derselben Farbe, als die des Schneehuhns, aber doppelt so gross und mehr abgestumpft; er baut seinen Horst gewöhnlich auf unzugänglichen Felsen.

Er lebt in Grönland besonders von Schwimmvögeln, obschon er gerne Schneehühner raubt, und sucht seinen Horst in der Nähe der Vogelberge anzulegen, um mit Bequemlichkeit aus denselben die jungen Vögel holen zu können. Ich habe gesehen, wie er 2 junge Larus tridactylus auf einmal in seine Fänge nahm, und auf gleiche Weise 2 Tringa maritima, nemlich eine in jeder Klaue.

*) Durch Einsammlung einer grossen Menge Falken im Winter 1840-4l und 42 habe ich die Ueberzeugung erlangt, dass ein Theil, wenn nicht alle, die erwähnte hübsche gelbe Wachshaut erhalten, da ich mehrere Individuen gesehen habe, an denen der Uebergang von dem Bleiblauen deutlich zu sehen war.

**) Dieser Schluss des Verfassers möchte wohl gewagt sein, da der Vogel ja einige Jahre alt sein' konnte.

A nm. d. Uebers. 
Seine Flugfertigkeit kann nicht besonders ausgezeichnet sein. Ich habe in mehreren Jahren Tauben gehalten, und nur 2 Junge verloren, welche der Falke im Sitzen nahm; gleichwohl wurden die alten Tauben im October und November fast täglich von den Falken gejagt, ohne eingeholt zu werden. Der Falke wurde oft geschossen, während er die Tauben bis zum Hause verfolgte. - Er ist nicht besonders scheu; und lässt sich leicht innerhalb Schussweite locken, wenn man ein Schneehuhn oder einen andern Vogel aufwirft.

Falco islandicus lebt im Sommer in der Tiefe der Buchten (Fjorde) und bäut seinen Horst am liebsten auf unzugänglichen Felsen, ganz nahe an den Vogelbergen. Im September fängt er an, sich an die Seeküsten zu begeben, in der Regel südwärts ziehend. Dieser Zug dauert bis in den November. Dann ist er nicht selten, und fliegt gerne bei den Wohnungen der Dänen umher, wo man ihn oft mit den Raben streiten sieht. Der Zug nach Norden im Frühjahre ist nicht so regelmässig, oder man sieht ihn dann nicht so häufig bei den Hăusern der Europäer. Ausser diesem jährlichen Zuge hat der Falke in der Zeit, wo man ihn bei den Häusern sieht, einen täglichen Zug, indem er gewöhnlich Morgens südwărts und Abends gen Norden fliegt.

\section{FAL C O PEREGRINUS}

ist nicht selten und horstet sowohl in Nord- als Südgrönland, unter andern selbst in der Nähe der Colonie Fiskenaesset. Er kommt in der zweiten Hälfte des Mai an und verlässt das Land im October; er verfolgt besonders Emberiza nivalis.

Obgleich ich nicht behaupten kann, dass der nordamerikanische Falco anatum sich in Grönland nicht vorfinde, bemerke ich nur, dass die Individuen, welche ich erhielt, vollkommen mit dem europäischen Falco peregrinus übereinstimmen. Hr. Hage, welcher sowohl aus der Benick'schen Sammlung, als von mir Exemplare vom alten und jungen Vogel erhielt, hat diese meine Meinung bestätigt. 


\section{S 1 i $x$.}

\section{S T R I X N Y G T E A.}

Diese Eule findet sich überall in ganz Grönland, von Upernevik bis Julianehaab, aber im Sommer häufiger im Norden, als im Süden. Ihr Nest ist zwar in Grönland nicht gefunden worden; ich habe jedoch zweimal in den ersten Tagen des Juni Junge derselben erhalten, welche unverkennbar nur wenige Tage das Nest verlassen hatten; es ist also gewiss, dass sie dort brüten. Die Jungen sind von viel dunklerer Färbung als die Alten. Ganz weisse Individuen habe ich nie gesehen.

Während der Vogel noch im Fleische ist, bilden einige wenige Federn auf beiden Seiten des Kopfes über dem Auge eine Art Horn *), so dass die in Temminck man. d'ornithol p. 83 als schlecht angegebene Rudbeck'sche Zeichnung gewiss nichts weniger als schlecht, sondern vollkommen naturgetreu ist.

Strix nyctea jagt sowohl am Tage, als am Abend, und scheint, wenigstens im Winter, am meisten des Abends thätig zu sein. Ich brachte einmal eine solche Eule dahin, mir fast eine Viertelmeile im Mondschein zu folgen, indem ich meine Mütze in die Luft warf; wãhrend ich aber ins Haus ging, meine Flinte zu holen, war sie fortgeflogen. Wenn sie gesättigt ist, ist sie sehr scheu, aber, während sie ihre Beute verzehrt, kann man sich ihr leicht nähern.

\section{S T R I X B R A G H Y O T U S.}

Ich habe diesen Vogel lebend hier im Lande nicht gesehen, aber auf der Ueberreise, wie auch von mehreren. Colonieen in einem und demselben Jahre erhalten, jedoch nicht nördlicher als $65^{\circ} 30^{\prime}$. Die Wenigen, welche ich sah, waren alte Vögel im Mai geschossen.

Strix brachyotus scheint periodisch vorzukommen. So erhielt ich dieselbe 1826 von Julianehaab und dem Rikkertop, und habe sie später nicht wieder gesehen, bis zum Jahre 1842, wo ich Individuen von Fiskenaesset und Julianehaab erhielt; auch wurde in demsel-

*) Der Königl. Arzt an diesem Orte, Hr. Bloch, hat sowie ich diese Beobachtung gemacht, und ich hoffe, es könne diese Bildung noch an einem Balge bemerkt werden, den ich an das Museum geschickt habe. 
ben Jahre ein Exemplar an Bord der Brigg Egedesminde, im Mai, nalıe an Grönlands Südspitze gefangen.

\section{I y แ}

\section{C. CORAX VAR, LITTORALIS. Mihi*).}

Wenn ich auch nicht zugeben will, dass man allein nach der Ausmessung der absoluten Grösse eines Vogels die Verschiedenheit als Art bestimmen darf, so kann dies doch schwerlich auf die rélativen Maasse ausgedehnt werden, und da diese, nach den geringen literärischen Hülfsmitteln, die mir zu Gebote stehen, beim Raben in Dänemark und Grönland verschieden sind, so kŏnnte der grönländische Rabe wohl als eigne Art aufgeführt werden. Ich halte es indess für zureichend, denselben als constante Varietät anzuführen.

Nach Prof. Nilss ons Fauna Scandinaviae (das einzige Handbuch von denen, die ich besitze, welches die relativen Maasse angiebt) sind die Artzeichen von Corvus corax: Schwarz mit Purpurglanz, Schwanz stark abgerundet, Schnabel und Tarsus gleiche Länge, Länge 2 Fuss und darüber. - Dagegen möchten die Artkennzeichen von Corvus corax var. littoralis sein: schwarz mit Purpurglanz, Schwanz keilförmig, Schnabel 1/4 länger als Tarsus, welcher 2 bis $2^{1 / 2}$ Zoll beträgt, Länge $2^{\prime} 2^{\prime \prime}-2^{\prime} 3^{\prime \prime \prime}$. Die übrigen wichtigen Maasse sind: Länge $2^{\prime} 2^{\prime \prime}$, Flügelbreite $4^{\prime} 5^{1} \mathbf{2}^{\prime \prime}$, Schwanz 10" 6"', die mittelste Schwanzfeder länger àls die äusserste $4^{\prime \prime}$, Länge des Kopfes vom ersten Halswirbel zur Schnabelwurzel 2" $2^{\prime \prime \prime}$, mit dem Schnabel 5" 6"'. Schnabel vom Mundwinkel zur Spitze in grader Linie $3^{\prime \prime}$. Höhe des Schnabels an den Nasenlöchern $1^{\prime \prime} 3^{\prime \prime \prime}$, Breite daselbst $1^{\prime \prime} 1 / \mathrm{z}^{\prime \prime \prime}$.

Der grönländische Rabe weicht ausserdem sowohl im Habitus, als in der Lebensweise, vom dänischen Raben ab, welcher besonders im Sitzen sehr gedrungen aussieht, während der grönländische von schlanker flüchtiger Gestalt ist. Sein Schnabel scheint

*) Obgleich man mich aufmerksam gemacht hat, dass der europäische Rabe einen eben so grossen Schnabel als der grönländische hat, so scheint mir doch, als ob seine verschiedene Lebensweise und Aussehn ihm einen Platz als Varietät vindiciren. 
mir auch weniger stark, als der des dänischen Raben zu sein. In der Lebensart ist er von diesem ganz verschieden. Er ist nicht allein am wenigsten scheu von allen grönländischen Vögeln, sondern auch ein ausgemachter Küstenvogel, welcher, ungeachtet die Grönländer auf ihren Rennthierjagden im Gebirge grosse Mengen Fleisch liegen lassen, doch nur ausnahmsweise im Innern des Landes gesehen wird, während er sich sowohl im Winter als Sommer an den Küsten aufhält. Im Winter ist er ein vollkommner Küstenvogel, der sogar nicht selten grade in die Häuser geht, um dort zu stehlen. Ausserdem ist er ein vollständiger Raubvogel, welcher Schneehühner jagt und zuweilen fängt, und ein böser Räuber der Eier der kleinern Möven und der Eier und Jungen der Eidervögel. An meine Tauben schien er sich gewöhnt zu haben; nur in den ersten Tagen, wenn sie im Frühjahre ausflogen, wurden sie vom Raben verfolgt, später liess er sie unbeachtet.

Der Rabe sucht besonders seine Nahrung am Strande; diese besteht aus Fischen, Weichthieren und Muscheln, welche er aus der Höhe auf die Klippen fallen lässt, um sie zu zerschellen. Ausserdem verzehrt er Aas und Abfall aus den Häusern der Dänen und Grönländer. Man-sieht ihn nicht selten in grossen Schaaren von 100 und darüber auf den grönländischen Misthaufen sitzen; ausser der Brutzeit ist er sehr gesellig, wodurch er sich auffallend von dem europäischen Raben unterscheidet, welcher gewöhnlich einzeln gesehen wird.

Er ișt viel hăufiger in Süd-- als Nordgrŏnland, weil hier die grŏnländischen Hunde allen Abfall der Häuser, und Alles was sich bei niedrigem Wasserstande am Meerufer findet, verzehren. Die See tritt dort auch viel weniger zurück als in Südgrönland oder Mittelgrönland. - Er baut auf den Klippen, und hat schon Ende April Eier, die ganz denen des dänischen Raben gleichen.

\section{Saxicola Denanthe.}

Ich habe in der Einleitung zu beweisen gesucht, dass wir diesen Vogel aus Europa*) erhalten, und dass el wenigstens theil-

*) Wie bekannt hat Amerika nicht einmal das Genus Saxicola. 
weise die Reise nach Grönland über das atlantische Meer macht, ohne Island zu berühren. Der Vogel kommt ungefähr zur selbigen Zeit in Südgrönland, als in Island an, nemlich in den ersten Tagen des Mai.

Zu Godhavn kommt er einen Monat später an, und doch zuweilen $\mathrm{zu}$ früh, indem der Schnee noch Alles bedeckt, und die Wärme die Fliegen und Insekten, von denen er sich nährt, noch nicht hervorgelockt hat. Man trifft ihn weit in den Polarkreis hinein, bis zum $73^{\circ}$ und darüber hinaus. Im September zieht er in vollständiger Wintertracht fort.

\section{Anthus ludovicianus. (Lichtenstein.)}

\section{A N T H US R UFUS. (WILSON.)}

Dieser, der einzige Anthus *) Grönlands, ist in Etatsrath Reinhardt's Icht. B. unter dem Namen Anthus aquaticus mit der Bemerkung aufgeführt, dass der Vogel von dem europäischen verschieden sei, indem Reinhardt, Richardson und Bonaparte folgte, welche Alauda rufa = Anthus aquaticus benannten. Später hat B on naparte in seinem 1832 herausgegebenen Namensverzeichniss der europäischen und nordamerikanischen Vögẹl seine frühere Meinung dahin geändert, dass er die Art untẹr dem ersten der obengenannten Namen aufstellt.

Der Vogel weicht sowohl im Ganzen als in den einzelnen Dimensionen von Anthus aquaticus (obscurus Tem.) ab. Der grösste, den ich ausgemessen, betrug $\left.5,5^{\prime \prime * *}\right)$, der kleinste $5,2^{\prime \prime}$, die meisten 5, 3"; die Breite 8" (während die Handbücher, welche ich besitze, Anthus aquaticus angeben: lang 6, 5", breit 11"7. Der Nagel der Hinterzehe ist kürzer, als die Zeh, nemlich der

*) Ich habe schon früher bemerkt, dass ich ein Exemplar von Anthus pratensis aus Grönland 1844 im Herbst erhielt.

Anmerkung des Uebersetzers.

**) Diese Maasse sind nach Decimalen angegeben, da ich sie so in meinem Tagebuche aufgefübrt habe und dieselben sich nicht genau auf Linien reduciren lassen. 
Zeh selbst 0, 27", der Nagel 0, 2" und nur wenig gebogen. Der Schwanz ist 2", der Tarsns 0, 7", der schwache Schnabel bis zum Mundwinkel 0, 52".

Es ist gleichfalls einiger Unterschied in der Farbe; soll derselbe jedoch in Worten wiedergegeben werden, so möchte vielleicht nur die Farbe des grönländischen Anthus mehr ungefleckt sein, als die des Anthus aquaticus (obscurus T.).

Bevor ich die erwähnte Abhandlung Reinhardt's kennen lernte, meinte ich, dieser Anthus sei unbeschrieben, und nannte denselben Anthus Reinhardtii, unter welchem Namen derselbe nach England gesandt ist. Sein grönländischer Name ist Kussecktarnak.

Auf dem Herbstzuge zeigt er sich bei allen Colonieen in Südgrönland, nistet jedoch nicht südlicher als in der Gegend von Holsteinborg, unter $66^{\circ} 50^{\prime}$, und soll an Nordgrönlands Meerbusen häufig 'sein. Das einzige Nest, welches ich gefunden, war in der Nähe von Godhavn, und enthielt im Anfange des Juli 4 Eier. Am Nestorte singt das Männchen mehr schrillernd als angenehm, indem dasselbe laut und durchdringend dieselbe Strofe wiederholt (welche quivit quivit quivit lautet), sich dabei in einer Spirallinie erhebend, und dann plötzlich grade niederstossend. Dieser Anthus ist kein Klippenvogel, wie nach $\mathrm{Nilsson}$ Anthus aquaticus, sondern hält sich im Sommer auf den Gras-Wiesen in der Nähe der Meerbusen, und zur Zugzeit bei den Häusern auf, wo er sich von Fliegenlarven nährt. Das Weibchen, welches ich beim Neste schoss, hatte Phalänen-Larven im Schlunde. An der Meeresküste habe ich denselben seine Nahrung suchend nie gesehen.

Seine Ankunft in Südgrönland findet in der Mitte des Mai statt, einen Monat später in Nordgrönland, und der Wegzug mit dem ersten Schneefall, also früher oder später im September.

\section{am b e i $\mathbf{z a}$.}

\section{E I B E R I Z A N I V A L I S}

ist sehr weit verbreitet über das ganze Land. Während auf Island die meisten überwintern, und nur wenige fortziehen, ist das Verhält- 
niss in Grönland ungekehrt, indem die meisten von àa wegziehen, nur eine geringere Anzahl im Lande zurückbleibt, und von diesen noch mehr in Nord- als in Süd-Grönland, vermuthlich wegen des hier grössern Schneefalles. Während die Sonne unter dem Horizonte steht, habe ich denselben in Nord-Grönland nicht bemerkt. Die ankommenden Vögel zeigen sich zu Godthaab in den ersten Tagen des April, zu Godhavn einen Monat später. Diese ankommenden Vögel, so auch diejenigen, welche ich auf der Herreise am Bord der Schiffe beobachtete, sind in voller Sommertracht, während die überwinternden Vögel hier im Süden gegen Ende des April oft noch in fast completer Wintertracht gefunden werden. Fine merkwürdige optische Täuschung ist es, dass die jungen Vögel, welche nach meiner Ansicht auswandern, grösser als die alten aussehen.

Die jungen Vögel, deren Winteracht ganz verschieden von der Tracht derer, welche in Grönland überwintern, ist, haben die Rückenfedern, den Schwanz ind Schwungfedern von derselben Farbe, als im Sommer, doch alle Federn besetzt mit graubraunen Kanten, Kopf und Hinterhals grau mit bräunlichem Schein, auf der Mitte des Kopfes fast schwarz, Kehle, vordere Halsseite und Kropf bleich und aschgrau, am Kropfe ein rostbraunes Band. Die Seiten und der ganze Vogel sehen von unten weiss, mit aschoder braungrau angelaufen, aus, Schnabel gelb mit schwarzer Spitze. In dieser Tracht befinden sich alle die Vögel, welche Ende August, im September und October in Schaaren an den Colonieen und längs der Küste gesehen werden. Sie sind dann gewöhnlich sehr fett und wohlschmeckend. Wenn der Schnee den Boden ganz bedeckt, wandern sie aus. Als ich im October des Jahres 1834 Grönland verliess, sah ich Schaaren so gezeichneter Vögel nach Westen ziehen.

Sowohl Männchen als Weibchen überwirtern in Grönland. Bei dem Männchen sind dann die Federn am Kopfe, die im Sommer rein weiss sind, mit rostbraun gekantet; alle die Federn, welche im Sommer schwarz sind, haben dagegen breite weisse Säume, so dass der Vogel ein ganz weisses oder weissliches Aussehn erhält. Die Weibchen haben gleichfalls dieselben Farben als im Sommer, aber alle Federn mit breiten weissen Säumen, doch sehen diese nicht völlig so hell aus, als die Männchen. In dieser Tracht sieht man dieselben im Herbste nie an der Küste, wohl aber im Innern des Landes auf den Gebirgen. In sehr ge- 
linden (nie in harten) Wintern kommen sie in dieser Tracht einzeln an die Colonieen, werden aber desto häufiger von den Rennthier-Jägern im Innern des Landes gesehen, ,wo sie sich in Schaaren auf den Bergen umhertreiben. Als ich 1826 im Februar über Land von Ritenbenk nach Omanak reiste, sahe ich eine kleine Schaar $E$. nivalis nebst einer Schaar Linota Hornemanni auf den höchsten Gebirgen.

Emberiza nivalis nährt sich sowohl von Saamen und den Beeren von Empetrum nigrum und Vaccinüu, als von Insekten und deren Larven, mit welchen sie vorzugsweise die Jungen füttert.

Der Uebergang zum Sommerkleide geschieht, selbst bei dem jungen Vogel, dessen Tracht ich beschrieben, allein durch $\mathrm{Ab}$ scheuern der Kanten, welches ich an Vŏgeln, die ich im Bauer überwinterte, beobachtet habe, obgleich diese immer etwas von der Zeichnung der jungen Vögel behalten und nie den rein weissen Kopf, welcher dem ausgefärbten Männchen eigenthümlich ist, bekommen.

\section{E M B ERIZA CAL C A PA T A}

ist allgemein im Innern der Meerbusen (Fjorde), sowohl in Südals Nordgrönland, doch sahe ich ihn nicht bei den nördlichsten Colonieen Omanak und Upernevik; die Fjorde dieser letzteren habe ich indess nicht bereist.' Zu Godthaab kommt er an Anfangs Mai, einen Monat später zu Godhavn (ich bemerke, dass ich die Zeit der Ankunft der verschiedenen Vögel nach den ersten Tagen, an welchen ich die Vögel bemerkte, bestimmt habe). Der Zug, sowohl vom Lande weg als zum Lande, geschieht nicht zu einer Zeit; so sieht man z. B. bei Godthaab den ganzen Mai hindurch Emberiza calcarata ankommen. Er bleibt in Südgrŏnland bis Ausgang September, ja länger, wofern ihn der Schnee nicht vertreibt. Da man denselben nie auf den Schiffen sieht, bevor man in der Davisstrasse ist, so nuss man annehmen, derselbe komme von Amerika nach Grönland.

Der grönländische Name: Narksamatak (Bewohner der Ebene) ist sehr bezeichnend, da der Vogè sich nur auf den Niederungen im Innern der Buchten aufhält, wo er sein Nest, wie die Lerchen, ins Gras oder zwischen Lichen-Arten baut. Seine 5 Eier von schmutziger Olivenfarbe mit braunen Flecken sind etwas kleiner als die der Emberiza nivalis. Der Gesang des Männchens, welchen es, entweder sich etwas in die Luft schwingend oder 
sich auf einem Zweige wiegend, hören lässt, ist sehr klar und melodisch, desshalb heisst er auch die grönländische Nachtigall.

Seine Nahrung besteht meist aus Saamen, und sucht derselbe nicht so sehr nach Insektenlarven an den Häusern der Grönländer als $\boldsymbol{E}$. nivalis.

In der Wintertracht gleichen alle Vögel dem Weibchen in der Sommertracht, nur sieht man am Männchen das Schwarze an den Kopffedern durchscheinen.

\section{Fi n g i 1 a.}

\section{F R I N G I L L A L E U G O P I R Y S}

Obschon ich diesen Vogel nur ein Mal*) in Grönland gesehen habe, glaube ich doch mit Grund anzunehmen, dass er im Innern des Landes nistet, da ich am 12. August das alte Männchen geschossen habe, welches im Königl. Museum aufgestellt ist, und abgezeichnet in den Icht. B. Tab. 1. fig. 2. Dies war 10-12 Meilen im Innern der Fjorde Amaraglik**); ich hörte hier seinen klaren Lockton, und vermuthete desshalb, dass er sein Weibchen oder Junge in der Nähe habe. Im Herbste desselben Jahres 1823 wurde wenigstens eine kleine Schaar bei Neuherrnhut bemerkt $\left(64^{\circ}, 10^{\prime}\right.$ N. B. $)$.

Einzelne Grönländer, denen ich die Zeichnung vorzeigte, erzählten mir, dass sie den Vogel im Innern von Amaraglik gesehen zu haben glaubten; allein ich habe, obschon ich gute Bezahlung anbot, später keinen erhalten. Vielleicht geht es mit diesem Vogel wie mit Clangula Barrowii, dass sein Aufenthalts-Ort sich auf eine sehr kleine Strecke des Landes beschränkt.

*) 1841 ist er im Herbste in der Nähe von Fiskenaesset geschossen.

**) In der Nähe von Godthaab. 


\section{Ti n t a.}

\section{L I N 0 T A L I N A R I A.}

Dieser Vogel ist in Grönland sehr verbreitet, und kommt dort zur selben Zeit oder einige Tage später an, als $\boldsymbol{E}$. nivalis, aber stets in der ersten Hälfte des April. Dessen ungeachtet habe ich denselbén in den ersten Tagen des Juni am Bord der Schiffe gefangen, obgleich wir nicht nördlicher als Godthaab waren. $\mathbf{E r}$ kommt aus Amerika nach Grönland, welche Ansicht dadurch bestätigt wird, dass er in Island selten, aber häufig in Grönland ist.

Im Juni trifft man ihn im Innern der Fjorde bei seinem Neste, wo er ganz gegen die Natur andrer Vögel sehr wild ist, während er das ganze Jahr hindurch sonst sich äusserst dummdreist zeigt.

Das Männchen verliert in dieser Zeit seine schöne carmoisinrothe Brust, und ähnelt vollkommen dem Weibchen; er ist alsdann viel weniger prachtvoll, als in der Wintertracht. Derselbe baut ein kleines Nest in Birken, Ellern oder Weiden, und legt gewöhnlich 5 blauweisse Eier mit hellbraunen Flecken. Gegen Ende August und im September sieht man denselben in kleinen Schaaren bei den Colonieen. Das Männchen hat wieder seine schöne rothe Brust und sowohl Alte, als Junge sind äussert dummdreist. Die Individuen dieser Art, welche ich am Bord der Schiffe fing, wurden gleich völlig zahm, obgleich die Brütezeit, in welcher Zeit sich der Vogel selten an den Käfig gewöhnt, sehr nahe war; ja schon am 2lsten Tage ihrer Gefangenschaft hüpften sie auf meine Hand, und kämpften selbst um Platz auf derselben, um den Hanfsaamen aufzulesen, obschon sie hinlänglich mit Grützund Kernfutter versehen waren, hei welchem Futter ich sie Jahre lang erhalten habe. Ihre Nahrung besteht ausschliesslich aus Saamen und den Spitzen der Lichen-Arten. Im Anfang October verschwindet derselbe aus Grönland, und wird nie im Winter gesehen. In der Grösse variirt er sehr; in der Länge von $\mathbf{4}^{3 / 4}$ " $-5^{1 / 4} "$ und in der Breite von 7" bis $8^{\prime \prime}$. 


\section{L. HORNEMANNI, Mihi*) L. CANESCENS, Auctorum.}

lch kann nicht annehmen, dass dieser Vogel, obschon er einige Aehnlichkeit mit Linota linaria hat, eine Abart dieser Species sein sollte, und zwar aus folgenden Gründen: Diese Art hat 1) einen stärkeren und viel breitern Schnabel, 2) ganz andre Farben in jedem Alter, 3) eine bedeutendere Grösse, 4) eine ganz andre Lockstimme, 5) eine andre Lebensweise als Linota linaria, der ausserdem immer das Land verlässt, während Linota Hornemanni Standvogel ist. 1824 sandte ich eine Sendung Voggel an Herrn T e mminck, unter dieser L. Hornemanni. Herr Justitiarius Boje, welcher bei dem Auspacken der Sendung zugegen war, hat mich versichert, dass sowohl er als Herr Temminck sogleich den Vogel als eigene Art erkannten**); da der Vogel indessen nicht in Temminck's Supplement angeführt ist, muss derselbe seine Meinung verändert haben, vielleicht weil er den jungen Vogel und das Nähere über die Lebensweise nicht kannte.

\section{Art-Kennzeichen:}

Der Schnahel stark, eben so breit als hoch, mehr als zur Hälfte bedeckt mit borstenartigen Federn, der Oberschnabel überragt den untern mit einer herabgebogenen Spitze. Länge $5^{3 / 4}$ Zoll.

\section{Beschreibung:}

Das alte Männchen in vollständiger Wintertracht hat eine schwarzbraune Kehle, der Raum zwischen dem Schnabel und Auge von derselben Farbe, die borstenartigen Federn auf dem Schnabel dunkelgrau. Ueber den Augen läuft auf beiden Seiten ein veisser Strich, die hellgrauen rostgelb angelaufenen Ohrfedern bilden eine ohrähnliche Figur, um diese ein heller Streif, der Hals unter dem dunkeln Kehlfleck und an den Seiten rostgrau, diese letzteren gegen

*) Ich habe schon vor langer Zeit diese Linota als eigene Species erkannt, und nach dem secl. Etatsrath Hornemann genannt, welcher von Kindesbeinen an meine Lust für die Naturwissenschaften geweckt hat und welcher ohne Zweifel grosse Verdienste um den Eifer für diese Wissenschaft hat, welche sich vor $\mathbf{3 0}$ Jahren unter meinen Altersgenossen zeigte.

**) Bckanntlich ist im 3. und 4. Bande von T e m min cks Manuel d'Ornithologie dieser Leinfink unter dem Namen Fringilla borealis aufgeführt, vid. l. cit.III.p. 264.

Anmerkung des Uebersetzers. 
den Kropf rosenroth angelaufen. Der Kropf und die Federn über dem Bürzel weiss und mit schönem Rosenroth angelaufen. Der übrige Theil des Rumpfes weiss, doch so, dass alle Federn gegen den Körper zu unten dunkelaschgrau sind, aber mit breiten weissen Säumen, welche den dunkeln Theil der Federn so decken, dass der Vogel völlig weiss aussieht. Hinter der carmoisinrothen Kaputze sind die Federn des Kopfes, Halses und Rückens grau in der Mitte, mit breiten weissen Säumen, welche dem Vogel das Ansehn geben, als wäre er in die Länge gestreift. Steuer-und Ruderfedern schwarzgrau mit breiten weissen Säumen. Auf den Flügeln 2 breite weisse Streifen. Der gespaltene Schwanz und die ausgebreiteten Flügel sehen von unten so hellgrau aus, dass sie fast weiss erscheinen. Der Oberschnabel hornschwarz, der Unterschnabel gelb, die Beine schwarz, stark und mit stark gekrümmten Nägeln versehen.

Die Sommertracht unterscheidet sich rom Winterkleide nur dadurch, dass die Federn einen grossen Theil der weissen Säume durch die von Nilsson sogenannte "partielle Mauserung“ verlieren, durch welche auch das schöne Rosenroth am Halse und Kropfe verschwindet. Der ganze Schnabel ist hornschwarz, nur am Unterschnabel findet sich am Mundwinkel ein gelblicher Schein. Der Schnabel ist sehr stark, eben so breit als hoch. Der Oberschnabel ragt über den untern bedeutend hervor und ist von oben wenig eingedrückt. Länge $5^{3} / 4^{\prime \prime}$, Breite $8^{3} / 4^{\prime \prime}$, Schwanz $2^{\prime \prime} 5^{\prime \prime \prime}$, Tarsus $71 / 2^{\prime \prime \prime}$.

Das alte Weibchen in der Wintertracht und das junge Männchen nach der ersten Mauser unterscheiden sich von dem alten Männchen in der Wintertracht nur dadurch, dass ihnen das Rosenroth am Kropfe und über dem Bürzel gänzlich fehlt, und dass sie weniger weiss sind, indem sich einzelne graue Streifen an den Seiten zeigen. Im Dunenkleide sind die Jungen einfarbig grau, ohne Schwarz an der Kehle; der Schnabel bildet ein gleichseititiges Triangel, und der Vogel kann also nicht einmal in dieser Tracht, in welcher er doch am meisten dem jungen $L$. linaria gleicht, mit ihm verwechselt werden, da der Schnabel dieses stets von geringerer Breite als Höhe ist.

L. Hornemanni lebt im Sommer im höchsten Norden und nistet nicht südlicher, als unter dem 69sten Breitengrade. Er ist dann in Nordgrönland häufiger als L. linaria, welcher im hohen Norden selten wird, während L. Hornmanni selbst bei $73^{\circ} \mathrm{N}$. B. 
noch häufig vorkommt. Er baut sein Nest ebenso wie $L$. linaria ins Gebüsch und die Eier desselben gleichen ganz denen von $L$. linaria. Seine Lockstimme, welcher $L$. linaria nicht folgt, ist trillernd, und der des Seidenschwanzes nicht unähnlich. Er ist ein wirklicher Standvogel und hält sich im Winter in Schaaren auf den Gebirgen im Innern auf, doch von dem $66^{\circ} \mathrm{N}$. B. gegen Norden hin zahlreicher, als nach Süden. Im Februar 1826 sah ich mehrere Schaaren desselben auf den Gebirgen zwischen Ritenbenk und Omanak, und auf der Reise, welche der Kaufmann Kjelds on 1830 im stärksten Winter in's Innere des Landes von Holsteinborg aus unternahm*), zeigten sich grosse Haufen dieses Vogels, der auch von den Rennthierjägern häufig gesehen wird, wenn sie im Winter sich tief ins Land hinein wagen. In Südgrönland findet er sich im Sommer nie, und überhaupt selten. In sehr gelinden Wintern kann er jedoch zuweilen in ziemlich grosser Anzahl sich bei den Colonieen einfinden, wie im Winter 1828-29 und 1837-38 geschah. In den folgenden 2 Wintern wurde er nicht bei Godthaab gesehen, so wie man ihn in harten Wintern überhaupt nie an den Küsten bemerkt. Im Frühjahre und Herbste zeigen sich zuweilen einzelne.

\section{T e t r a}

Obschon mir Gelegenheit wurde, eine grosse Anzahl dieser Vögel zu untersuchen (die, so zu sagen, zu unserem täglichen Brodte gehören) und ich eine grosse Verschiedenheit in der Grösse und dem Bau des Schnabels und der Zehen gefunden habe, glaube ich doch, dass Grönland nicht mehr als eine Art besitzt. T. saliceti habe ich nie gefunden, obschon Temminck sie als grönländisch aufführt. Anführen muss ich jedoch, dass ich im Winter 1827-28 einige Schneehühner in Nord - Grönland erhielt, die so bedeutend kleinere Dimensionen hatten, dass ich nicht mit Sicherheit behaupten kann, dass diese nicht zu einer zweiten Art gehörten; ich nahm mir desshalb vor, sie in der Sommertracht aufzusuchen, um darüber Gewissheit zu erhalten, aber in demselben Jahre wurde ich nach Südgrönland versetzt, und verlor dadurch die Gelegenheit dazu.

*) Beschrieben in der dänischen Wochenschrift vom Dr. Pingel. 
Wenn auch das grönländische Schneehuhn nicht ganz oder vollkommen dem isländischen und norwegischen Felsen-Schneehuhne gleicht, so kann man, da die Abweichungen zu unbedeutend sind, doch schwerlich dasselbe als eigne Spezies aufstellen, und halte ich dasselbe für Tetrao lagopus, den Brehm'schen Namen hinzufügend.

\section{T. LAGOPUS, auctorum (REINHARDTII, Brehm.).}

Ich sehe mich ausser Stand gesetzt, eine genaue Beschreibung dieses Vogels zu geben, da dieselbe ohne sorgfältige Vergleichung mit dem isländischen und norwegischen Schneehuhn ungenügend sein würde, und beschränke mich desshalb darauf, folgende Maasse anzugeben: Männchen: Ganze Länge 15", Flügel-

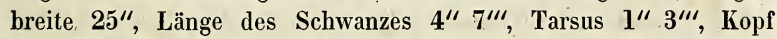
vom Halswirbel zum Schnabel 2" $1^{\prime \prime \prime}$, Schnabel in grader Linie vom Mundwinkel zur Spitze 9"', derselbe im Bogen von dem Anfang der Befiederung bis zur Spitze $4^{\prime \prime \prime}$. Die Maasse sind vom alten Männchen genommen; das Weibchen ist $13 \frac{1}{1}{ }^{\prime \prime}$ lang, mit $23^{1 / 2}$ " Flügelbreite Es wäre wünschenswerth gewesen, dass Prof. Reinhardt das grönländische Schneehuhn in seinem Beitrag zur Naturgeschichte Grönlands abgezeichnet hätte.

In der Lebensweise gleicht das grŏnländische Schneehuhn durchaus dem isländischen, indem es sich den ganzen Sommer über im flachen Lande oder tiefen Gebirgsthälern aufhält, ja nicht wenige Paar nisten selbst auf den Inseln längs der offnen See. Dagegen finden sich auch einzelne Schneehühner brütend auf dem Gipfel mittelhoher Berge, wo man auch die meisten Schneehühner, welche nicht vereinzelt brüten, im Sommer antrifft. Schon in den letzten Tagen des April sieht man die Schneehühner gepaart, und das Männchen ist stets in der Nähe des Weibchens, bis die Eier ausgebrütet sind; dann zieht es fort in die höchsten Gebirge, wo es die wärmste Zeit des Sommers zubringt. Im Frühjahre sind die Schneehühner am Tage still; man sieht sie dann gegen Sonnenaufgang oft hin und her ziehen und auf Felsenspitzen sitzen. Das Männchen lässt jetzt oft sein schnurrendes arrr-r hŏren, welches das Weibchen mit seiner hellen Lockstimme beantwortet. Im Winter findet man das Schneehuhn, sobald es Tag wird, mit der Nahrung beschäftigt, und selten sieht man es, wenn es nicht aufgejagt wurde, vor Nachmittag fliegen, dann aber gewöhnlich in kleinen Schaaren ziehen, in der Regel von den 
Bergen herunter und gegen die See zu; gegen Abend zieht es zurück. Bei strenger Kälte gräbt es sich in den Schnee, wenn derselbe nur einigermassen weich ist.

Gegen den Herbst, wenn die Jungen vollständig ausgewachsen sind, ziehen die Schneehühner volkweise auf die Berge, wo sie sich den ganzen Winter über aufhalten; nur in sehr milden und schneearmen Wintern findet man dieselben auch überall in den Thälern. Ist sehr viel Schnee oder Eisschlag gefallen, dann streifen sie überall umher, kümmerlich ihre Nahrung suchend. Im Winter findet man dieselben sowohl im Innern der Buchten, als auf den Inseln. Obschon man das Schneehuhn einen Standvogel nennen kann, so wandert doch ein grosser Theil im Winter südwärts, am liebsten mit starkem Nordwinde; im Winter ist das Schneehuhn viel häufiger in Süd - als Nordgrŏnland, obgleich doch immer dort einige bleiben, selbst während die Sonne unter dem Horizonte ist.

Ich habe mehrmals bemerkt, dass das Schneehuhn nicht allein im Nothfall schwimmen kann*), sondern zuweilen selbst ohne solchen Grund schwimmt, und dies gar bei starker Kälte. Im September 1825 sah ich zum erstenmal ein Schneehuhn schwimmen; ich lag damals mit einer Galeasse auf der sogenannten Südostbucht, wir hatten einige Tage Nebel, und mehrere Schneehühner kamen auf's Schiff. - Eins dieser flog so gegen ein Segel, dass es ins Wasser fiel. Ich liess, da es fast stilles Wetter war, ein Boot aussetzen, in der Meinung, es werde mir leicht zur Beute werden; aber mit grosser Leichtigkeit erhob es sich vom Wasser, und flog unbeschädigt davon. Im Winter darauf sah ich im December bei $10^{\circ}$ Kälte 2 Schneehühner von dem UdkigsFelsen bei Godhavn herabfliegen, und sich ganz ruhig auf's Wasser setzen. Gleichfalls habe ich Schneehühner in einem kleinen Gebirgswasser sich baden und auf selbigem herumschwimmen gesehen.

Die Mauserung des Schneehuhns bietet in Grŏnland einige merkwürdige Erscheinungen dar, indem dieser Vogel nicht allein in Südgrönland während des kurzen Sommers 3 mal mausert, sondern auch an den nördlichsten Orten, wo ich ihn beobachtete, zwischen 72 und $73^{\circ}$ N. B., zum wenigsten das Männchen mit der Frühjahrs-Mauserung nicht fertig wird, bevor die WinterMauserung im Herbste beginnt.

*) Herr Hage hat mir erzählt, dass er dasselbe beim gemeinen Rebhuhn beobachtet hat. 
Im April fängt das Weibchen an, seine Wintertracht mit der Sommertracht zu vertauschen, und hat vollständig ausgemausert, bevor es Eier legt. Das Männchen fängt später an zu mausern, mausert auch länger, so dass es gewöhnlich erst im Juli in vollständiger Sommertracht erscheint, und dies selbst nur in Süd-Grönland. In Nord-Grönland geschieht diess noch später, und bei Upernevik (unter $72^{\circ}$ N. B.) habe ich die Männchen selbst im August in noch nicht vollständigem Sommerkleide gesehen, welches sie auch schwerlich ganz erhielten. Das Weibchen trägt die Sommertracht fast 3 Monate hindurch, denn im August findet man die meisten, wo nicht alle, brutfähigen Weibchen in voller Mauserung, durch welche sie ein völlig verschiedenes Aussehen bekommen, und es ist möglicherweise diese Mauserung, welche $\mathbf{F}$ a b e r zu der irrigen Annahme veranlasste, dass das Schneehuhn sein Winterkleid durch Abbleichen der Federn erhielte.

Durch diese Mauserung, welche vollständig ist (d. h. wo die Schwung - und eigentlichen Schwanzfedern auch gewechselt werden), behalten diese ihre gewöhnliche Farbe. Die Brust, welche während des Brütens völlig nackt war, wird weiss, alle übrigen Theile des Vogels, welche im Sommer bis dahin schwarzbraune Federn mit breiten gelben Flecken und Bändern hatten, werden nun mit gelb - oder rothbraunen Federn bekleidet, welche ganz fein im Zickzack mit Schwarzgrau gezeichnet sind, so dass der Vogel in einiger Entfernung aussieht als wäre er einfarbig braungrau. Jede einzelne Feder hat indessen diese Färbung nur zur Hälfte ihrer Länge, indem der innere Theil weiss ist. Die Herbstmauser beginnt am Rücken, dann folgen die Seiten und zuletzt Hals und Kopf, dessen Federn braunröthlich sind. Ich habe noch nie einen Vogel gesehen, bei dem die erwähnte Mauserung am Kopfe fertig war*).

In wie weit das Männchen an dieser Mauserung Theil nimmt, habe ich bisher nicht entdecken können, da ich erst seit den letzten 2 Jahren diese Herbstmauserung des Weibchens kenne, und die Männchen in dieser Jahreszeit sètten zu erhalten sind. Doch nehme ich an, dass diese Mauserung gleichfalls beim Männchen statt finde, ja selbst bei den Jungen desselben Jahres, worüber ich jedoch während meines erneueten Aufenthaltes hier in Grŏnland

*) Das zweifache Sommerkleid beobachtete auch Naumann (s. VI, S. 407 u. f.) am Schneehuhn der Schweizer-Alpen, u. a.

Anmerkung des Uebersetzers. 
Gewissheit zu erlangen suchen werde*). Von dieser Herbsttracht geht durch die gewöhnliche Mauserung das Schneehuhn über ins reine Winterkleid, welches es bereits im October vollständig trägt.

Das grönländische Schneehuhn ist sehr einfältig und wird leicht erlegt, es aber in der Gefangenschaft am Leben zu erhalten, hat mir nicht glücken wollen.

Ich habe nicht mehr als 12 Eier in einem Neste gefunden, doch hat man mir erzählt, dass dasselbe zuweilen bis gegen $\mathbf{1 6}$ Eier enthalte. Die kleinen Jungen habe ich in den ersten Tagen des Juli gesehen; sie sind im August ausgewachsen, doch ist es auffallend, von welcher verschiedenen Grösse man diese Jungen zur selben Zeit bei den verschiedenen Paaren findet. Das Schneehuhn nährt sich von den Blättern und Knospen der Gebüsche, aber im Winter machen die Beeren von Empetrum nigrum und den Vaccinium-Arten einen bedeutenden Theil seiner Nahrung aus.

Herr Justitiarius Boje hat mich mit der Stimme des norwegischen Schneehuhns bekannt gemacht; diese ist aber von der des grönländischen bedeutend verschieden. Das Männchen schreiet auch nicht wie das isländische : orrr! sondern deutlich arrr! und die Lockstimme des Weibchens hat keinesweges, wie die des isländischen, Aehnlichkeit mit der Stimme der Emberiza nivalis, sondern die Lockstimme derselben ist viel höher und klangvoller, doch weiss ich Nichts, mit dem ich dieselbe vergleichen könnte.

\section{Calidris aremaria}

gehört zu den seltnen Vögeln Grönlands, wird aber jedes Jahr auf Disco bemerkt, wo derselbe brütet. In Südgrönland habe ich den Vogel nicht selbst gesehen, aber bei Nenortalik ist er öfter geschossen, und ich glaube, dass er nicht südlicher, als unter dem $68^{\circ} \mathrm{N}$. B. brütet. Ich habe die Eier desselben nicht gesehen, sie sind mir aber beschrieben als von gleicher Farbe und Grōsse, wie die der Tringa maritima; die 4 Jungen desselben im Dunenkleide fand ich auf einer kleinen Wiese etwas ostlich von Godhavn im Monat Juli. Nach der Zeit, zu welcher er zu Nenortalik geschossen wird, zu urtheilen, verlässt er das Land Ende September.

*) lch habe dem Königl. Museum Schneehuhn-Weibchen in dieser Feder Tracht übersandt. 


\section{Ch h r a d r i u s.}

\section{C H A R A D R I U S H I A T I C U L A}

findet sich überall in Grönland, aber nirgends in Menge. Man sieht ihn bei Godthaab Anfangs Mai, trifft ihn aber im Herbste selten. Er hălt sich auf und sucht seine Nahrung bei kleinen Landseen und in Mooren. An solchen Stellen findet man das Nest zwischen kleinen Steinen und Grant.

\section{CHARADRIUS PLUVIALIS}

ist nach meinen Beobachtungen sehr selten. In 18 Jahren erhielt ich diesen Vogel nur 3 mal. Es wunderte mich daher, in den Icht. B. S. $11 \mathrm{zu}$ lesen, dass er an einzelnen Stellen in Schaaren gefunden würde. Ich glaube nicht, dass er im Lande brütet.

\section{Vanellus melanogaster}

gehört zu den Vŏgeln, deren Vorkommen nach meiner Ansicht im Zunehmen ist; ich habe ihn sowohl in Nord - als Südgrönland gesehen, doch gehört er bis dahin zu den seltneren Vögeln Grönlands. $1840 \mathrm{im}$ September wurden 3 bei Nenortalik geschossen. Ich habe denselben im August bei Amaralik erlegt.

\section{Strepsilas collaris}

ist, ohne gerade gemein zu sein, doch auf den Inseln nicht selten, wo er sowohl in Süd- als Nordgrönland brütet. Er gehört zu den am spätesten ankommenden Vŏgeln, wird erst gegen Ende des Mai gesehen und verlässt das Land im September. Seine Nahrung bilden kleine Univalven, Bivalven und Crustaceen. 


\section{No me n i us.}

Es wurde in der Vorrede angeführt, dass man gegenwärtig Vŏgel dieses Genus häufiger, als vor 18 Jahren sieht. Wenn man dieselben in Grönland antrifft, sind sie ausserordentlich scheu, wesshalb man nur selten genau die Species erkennt. Dieser Umstand beweist übrigens auch, dass sie nicht in Grönland brüten, da dieselben zur Brutzeit sehr zahm sein sollen.

\section{NUMENIUS PHAEOPUS.}

Die Exemplare, welche ich erhielt, im Ganzen 5, waren zwischen Mai und September geschossen, und habe ich den Vogel sowohl von Nord - als Südgrönland erhalten.

\section{NUMENIUS HUDSONIUS}

ist zweifelsohne noch seltner, als der vorhergehende. Ich habe im Ganzen nur 3 Exemplare gesehen, nemlich von Julianehaab, Fiskenaesset und Godthaab.

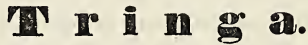

\section{T R I N G A I S L A N D I G A.}

Dieser Vogel ist in Süd-Grönland sehr selten, aber in Nord Grönland wird derselbe oft angetroffen, und hat seine Brütplätze in den Buchten, wo er 4 Eier legen soll, die ich zwar nicht gesehen habe, aber dagegen mehrmals die Jungen desselben im Dunenkleide erhielt. Er muss in Nordgrönland gleich nach der Brütezeit sich auf die äussersten Inseln begeben, denn im Herbste habe ich ihn nie bei Godhavn bemerkt, dagegen bei Godthaab denselben in Wintertracht erhalten, und zwar im September. Erst im Juni kommt er im Sommerkleide zu Godhavn vor; kurz vor dieser Zeit sieht man ihn auf den äussersten Inseln unter $64^{\circ}$ in Südgrönland, wo er sich in der Zugzeit in jedem Frühjahre zu zeigen pflegt. Nach der Meinung der Grönländer, übereinstimmend mit meinen Beobachtungen, ist sein Erscheinen im Zunehmen; dieselben verwechseln ihn indessen zuweilen mit Phaluropus platyrhynchus und benennen ihn eben so: Kajok oder Kajordlik. 


\section{T R I N G A MAR I T I MA.}

Im Winter ist dieser Vogel sehr gemein so weit nach Norden, als das Meer nicht mit Eis bedeckt ist*). In dieser Jahreszeit hält er sich in grossen Schaaren zusammen, die desto zahlreịcher werdên, jemehr der Winter zunimmt und mehrere Vŏgel zwingt südwärts zu ziehen. Er nistet überall im Lande. Anfangs Juni verschwindet der Vogel von der Küste und zieht nach den Bergebenen, wo er sich kurze Zeit in kleinen Schaaren aufhält; bald darauf geht er paarweise an die Brütstellen, welche stets auf den Ebenen vom Meere $a b$, aber doch nie weit im Innern gefunden werden. Er legt 4 Eier, und ist um seine Jungen sehr besorgt. $\mathrm{Zu}$ keiner Jahreszeit ist er scheu, schwimmt nicht selten von einem Ufer zum andern, ja taucht selbst angeschossen. Seine Nahrung besteht aus kleinen Weichthieren mit Schaalen und Crustaceen, welche dem Fleische wahrscheinlich den nach meinem Dafürhalten unangenehmen Geschmack geben. Seine Frühjahrs Mauser findet Ende April statt, zu welcher Zeit sich der Vogel auf den Inseln in Haufen schaart, und die Paarzeit anfängt. In dieser Periode lässt er seine schrillernde Stimme ununterbrochen hören, besonders des Nachts.

\section{T R I N G A VAR I A B I L I S **).}

Ich sahe den Vogel nie in Grönland, führe ihn daher bloss auf Fabrizius und Reinhardt's Auctorität als grönländisch hier an.

\section{T R I N G A S C H I N Z I I, Bonap. ***).}

Ich habe den Vogel selbst in Grönland nicht gesehen, und führe desshalb nur an, dass das Museum 3 Exemplare 1841 von

*) Es ist merkwürdig, dass Capt. Gra a h diesen Vogel nicht an der Ostküste von Grönland antraf; auch ist kein Name angegeben.(Gr a a h's Reise pag. 195), welcher vermuthen lässt, dass dieser Vogel gemeint sei.

**) Ich habe mehrmals den Vogel im Jugend - und Herbstkleide aus Grönland, jedoch nie im reinen Sommerkleide erhalten.

Anmerkung des Uebersetzers.

***) Nach schriftlicher Mittheilung des Herrn Verfassers vom vorigen Jahre brütet dieser Vogè sicher im Julianehaab-District, wo Capt. Holböl in den letzteren Jahren im August-Monat stets kleine Schaaren, junge und alte Vögel zusammen, angetroffen hat.

Anmerkung des Uebersetzers. 
Nenortalik erhielt (woher auch Herr Hage 1835 ein so junges Exemplar bekam, dass er annimmt, es müsse in Grŏnland ausgebrütet sein) und wiederum 1840 ein Individuum im Uebergange zur Wintertracht.

\section{Limosa melanura.}

Ich habe nur ein einziges Exemplar dieses Vogels erhalten, mit einer Kugel auf den Kok-Inseln, aissen vor Godthaab, erlegt.

\section{Scolopax grisea?*).}

Fast in allen Sommermonaten sahe ich eine Scolopax-Art bloss fliegend, konnte aber dieselbe nie schussrecht erhalten, da diese Vögel sehr scheu waren; jedoch dies nur in Südgrönland.

\section{Pha la o p us.}

Dies Genus enthält die niedlichsten Schwimmvögel, welche man sich denken kann. Sie schwimmen mit Grazie und Leichtigkeit, selbst in der aufgeregtesten see und unter den schwersten Stürmen, während welchen ich dieselben mitten in der Davisstrasse schwimmend angetroffen habe. Es ist bekannt, dass das Weibchen sowohl grösser als schöner ist, als das Männchen, und dass dieses Brütflecke hat, jenes nicht. Trotzdem behauptet $\mathrm{F} \mathrm{a-}$ ber in seinem Prodromus, dass sowohl Weibchen als Männchen brüten und die Jungen begleiten. Dass ein Seevogel ohne Brütflecke brüten sollte, ist gegen alle Analogie, und ich war der Meinung, bis die erwähnte Schrift herauskam, dass das Weibchen nie brüte. Beide Arten sind in Grönland nicht selten, ich habe

*) Im Herbste 1845 erhielt ich eine Scolopax gallinago aus Südgrönland, und möchte es wohl zweifelhaft sein, ob die in Grönland vor'ommenden Scolopax nicht der gewöhnlichen Heerschnepfe angehören, die man ja auch in Island und auf Ferroe häufig antrifft. Anmerkung des Uebersetzers. 
viele Nester gefunden, aber nicht ein brütendes Weibchen; ja dies ist in der Nähe des Nestes so selten, besonders Ph. platyrhynchus, dass ich unter 11 dieser Vögel, welche ich in der Nähe 5, von mir aufgefundener Nester schoss, nur I Weibchen erhielt. Ich vermuthe daher, dass Faber (dem ich meine Beobachtungen über diese Vögel mittheilte und der mir sagte, dass $P$ h. hyperboraeus nur selten brüte) den Vogel auf dem Neste getroffen habe, grade als er sein letztes Ei legte; auf andre Weise kann ich mir diesen Mangel an Uebereinstimmung nicht erklären.

\section{PH. H YBERB O RAEUS}

kommt in den letzten Tagen des Mai an die Küste, schwimmt eine Zeit lang an den Inseln umher, und findet sich an den Brutplätzen zu Ende des Juni. Diese sind stets im Innern der Fjorde, am Ufer kleiner, in Thälern oder Mooren befindlicher Seen, nie an Gebirgs-Seen. Das Weibchen legt stets 4 Eier, die $10^{\prime \prime \prime}$ lang, hell olivengrün mit vielen braunen Flecken sind. Die Jungen laufen, wie die einer Tringa, im Grase umher und schwimmen nicht im Dunenkleide. In der Zeit, während welcher der Vogel sich hier aufhält, lebt er hauptsächlich von Insektenlarven, welche er in den kleinen Süsswasser-Seen fängt, oder aus dem Moose am Ufer hervorsucht. Jedoch zieht der alte Vogel am Abende hinaus auf die Fjorde, wo man ihn umherschwimmen und kleine Thiere verzehren sieht; $\mathrm{zu}$ welcher Thierklasse diese indessen gehören, habe ich, da sie sowohl sehr klein als gleich sehr zerdrückt sind, nie beobachten können.

Im August ziehen Alte und Junge hinaus zu den Inseln, wo sie in ungeheuren Schaaren umherschwimmen. Anfangs September sind sie in Wintertracht, und in dieser Zeit, in welcher sie selten an's Land kommen, sind sie so fett, dass es fast unthunlich ist, das Fell zum Ausstopfen abzustreifen. Am Ende des Septembers verlassen sie die Küsten ganz.

\section{PH. PLA T Y R H Y N G U S}

ist der Vogel, welcher unter allen am spätesten in Grönland ankommt, nämlich Anfangs Juni. In diesem Monate sieht man ihn oft in der Davisstrasse und dann in grossen Schaaren; so traf es sich, als ich im Frühjahre 1835, 18 Tage hindurch, während der Hinreise nach Grönland, vom Eise eingeschlossen war. So 
lange wir vom Eise eingeschlossen waren, sahen wir stets diesen Vogel zwischen den Eisstücken herumschwimmen. In Südgrönland sieht man den Vogel äusserst selten, und nur auf dem Zuge nach Süden trifft man bei den äussersten Inseln oft kleine Schaaren an; aber in Nordgrönland, vom $68^{\circ} \mathrm{N}$. B. nach Norden, ist er sehr häufig und nistet dort fast auf allen Inseln, welche kleine Teiche besitzen. Dagegen nistet er nie im Innern der Fjorde, und unterscheidet sich hierdurch von $P h$. hyperboraeus, welcher nie auf den Inseln aussen vor der Küste brütet. Im Uebrigen gleichen beide Arten sich in der Lebensweise. Im August sind die Jungen flügge, und im September sieht man sie in Gesellschaft mit den Alten, sämmtlich in Wintertracht, bei den äussersten Inseln herumschwimmen, wo sie besonders die Scheeren aufsuchen, in deren Brandung sie sich sehr gern herumtummeln. In dieser Zeit kommen sie noch seltner an's Land, als Ph. hyperboraeus, und sind eben so fett. Sie verlassen die Küsten gegen Ende des September, und in dieser Zeit, besonders nach Sturm, trifft man kleine Haufen derselben aussen vor den Inseln in Südgrönland. Die Eier, stets 4, gleichen völlig denen der vorhergehenden Art, sind nur etwas grōsser.

\section{Sterna arctica.}

Schon im April sieht man diese Meerschwalbe in der Davisstrasse, Anfangs Mai kommt dieselbe jedoch erst an die Küste, ungefähr gleichzeitig mit Phoca groenlandica. Sie ist sehr gemein gleich von Capj Farvel an bis Upernevik, mit Ausnahme der Strecke von Kangamiut $65^{\circ} 38^{\prime}$ bis Rummelpotten $67^{1 / 2^{\circ}}$. Auf dieser Küstenstrecke, die sehr mit Inseln versehen ist, und scheinbar einladende Brutplätze für Meerschwalben enthält, findet man sie nie, selbst nicht in der Zugzeit, so dass die Grönländer von Holsteinborg sie nur dem Namen nach kennen. Diese erwähnte Küstenstrecke, an welcher die Meerschwalbe nicht brütet, ist der Lieblings - Aufenthaltsort der Somateria mollissima, welche hier besonders nistet. Doch ist es keinesweges diese, welche die Sterna vertreibt, denn von dieser Küstenstrecke sowohl nord- als südwärts brütet die Sterna und der Eidervogel auf denselben Inseln in grösster Eintracht. Es wäre nicht ohne Interesse, den Meeres- 
grund auf dieser Strecke zu untersuchen, und da ich gegenwärtig im Besitz der nothwendigen Instrumente bin, werde ich dies bei erster Gelegenheit ausführen.

Die Meerschwalbe ist der einzige Vogel, welcher sich zuweilen an den Brütplätzen zeigt, ohne die Tracht der alten Vŏgel zu haben; aber diese jungen Vögel haben keine Brütflecke. Dess halb ist es auch nur der Geselligkeits-Trieb, welcher sie an die Brütplätze führt. Auch ich habe junge Vŏgel nur äusserst selten gesehen, und möchte lieber annehmen, eine verspätete Mauser habe die Schuld. Die Stirn ist dann weissgefleckt, der Schnabel sowohl als die Füsse schmutzig-carmoisinroth.

Die Meerschwalbe nistet sowohl auf den vor der Küste gelegenen Inseln, als in den Meerbusen und an den Süsswasserseen. Ihre liebste Nahrung sind kleine Fische und Themisto arctica, doch verzehrt sie auch viele Clionen. In den letzten (ersten?) Tagen des October verlässt sie die Küste, und wird bei Sturmwetter einzeln den ganzen Monat hindurch angetroffen.

\section{I $\mathbf{a}$ u $\mathbf{s}$.}

Faber sagt im „Leben d. hochnordischen Vögel" S. 85., dass Männchen und Weibchen dieses Genus gleich gross seien. Dies ist in Grönland nicht der Fall, wo das Männchen stets grösser als das Weibchen ist. Aber die Möven variiren an Grösse so sehr, dass man gewiss ein grosses Weibchen finden kann, welches eben so gross, als ein kleines Männchen derselben Art wäre, aber gewiss nicht mit diesem gepaart.

Alle die Mŏven, welche man in Grönland antrifft, so auch Sterna arctica, Lestris parasitica*) und pomarina sind Stosstaucher, da ich ohne Ausnahme alle diese Arten von den Grönländern in Schlingen, welche 2-3 Fuss unter die Oberfläche des Wassers gestellt werden, habe fangen sehen. Als Lockmittel braucht man entweder frische Mallotus arcticus oder man bildet einen Streifen aus Seehundspeck, welcher sehr deutlich im Wasser zu sehen ist.

*) Lestris parasitica wird in Schlingen von den Grönländern in jedem Jahre, und recht häufig besonders im August gefangen. 
Es ist wohl schwer auszumachen, ob Larus marinus, glaucus und leucopterus theilweise vom Lande ziehen; ich bezweifle, dass die Erste dies thue, und möchte annehmen, dass von den zwei andern Arten auch nur sehr wenige im Winter die grönländische Westküste verlassen. Dagegen ist dies bestimmt der Fall mit den Möven dieser Arten, welche an der 0stküste leben, wo das Meer gewöhnlich mit Eis bedeckt ist; diese Möven ziehen vermuthlich nach dem nicht fernen Island, wo Faber Larus leucopterus im Winter antraf, aber nicht im Sommer; doch zweifle ich nicht, dass diese Möve zuweilen auch dort nistend vorkomme.

Die angeführten drei Arten ziehen dagegen längs der Küste im Herbste südlich, im Frühjahre nördlich, aber die Zugzeit lässt sich nicht genau angeben, da sich dieselbe nach dem Belege mit Eis und dem Wetter richtet. Die Möven ziehen am liebsten im Sturm und gegen den Wind *). Ausser diesem jährlichen Zuge haben die Möven, wenigstens diejenigen, welche in den Fjorden sich aufhalten und brüten, einen täglichen Zug, indem sie am Morgen theils längs der Küste, theils in der Mitte der Meerbusen in diese hineinziehen, und des Nachmittags oder Abends fast immer in der Mitte und oft sehr hoch in der Luft hinausziehen. $* *$ )

\section{L. M A R I N U S.}

Aus dem grönländischen Larus marinus hat Hr. Brehm die Art Larus maximus gebildet, deren Art-Verschiedenheit gewiss aber auf sehr schwachem Grunde ruht; doch glaube ich anführen zu müssen, dass drei junge Grönländer, welche 1837 mit mir aus ihrer Heimath reisten, am Habitus den europäischen Larus marinus, welchen wir zuerst an den Hebriden und später an den dänischen Küsten sahen, durchaus nicht wieder erkennen konnten. Sie bemerkten mit Recht, dass nicht allein der Flug verschieden sei, sondern dass auch die Flügel dieser sowohl schmäler als spitzer seien, als die der grönländischen Mantelmöve.

Larus marinus ist im ganzen Lande gemein, doch häufiger in Süd-als Nordgrönland, am häufigsten vielleicht in der Mitte Winde.

*) Die Somateria-Arten ziøhen am liebsten bei gutem Wetter und mit dem

**) Siehe bei Somateria mollissima. 
zwischen $63^{\circ}$ und $66^{\circ} \mathrm{N}$. Br. Diese Möve ist der bestimmteste Standvogel, den Grönland besitzt, denn ein Theil derselben bleibt das ganze Jahr hindurch in der Nähe der Inseln, wo sie brüten. Sie legt ihr Nest gewöhnlich auf Inseln aussen vor der Küste, oder auf ziemlich hohen Felsen an der Mündıng der Meerbusen an. Trotzdem entfernt sie sich von allen Möven am wenigsten weit vom Lande, so dass die Schiffer es für ein sicheres Zeichen ansehen, dass das Land nur einige Meilen entfernt sei, wenn $L a-$ rus marinus sich zeigt.

Obgleich sie selbst fischt und ein guter Stosstaucher ist, ist sie doch ein wahrer Raubvogel, da sie Eier und Junge stiehlt, wo sie nur ankommen kann. Sie nährt sich auch von Aas, aber da sie viel scheuer als Larus glaucus ist, findet sie sich nicht, wie diese, bei der Zerstückelung der gefangenen Wallfische ein. Anfangs Mai legt sie ihre Eier, und obgleich es am 6. Mai 1824 $12^{\circ}$ fror, hatte ich doch schon am 3. Mai die Eier derselben gefunden.

\section{L. G L A U G U S}

ist häufiger als die vorerwähnte Art, deren Grŏsse sie in einzelnen Individuen erreicht. Im Sommer ist sie zahlreicher in Nordals Südgrönland, wohin fast alle im Winter ziehen. Aus dieser Art hat Hr. Brehm seinen L. medius gebildet, von der man vorausgesetzt hat, dass sie sich in Grönland finden sollte; aber durch das Ausmessen einer grossen Anzahl dieser Vögel habe ich die Ueberzengung erlangt, dass es hier in Grönland nur eine Art giebt, die dahin gezählt werden kann, welche aber, was die Grösse betrifft, so sehr variirt, dass man gerne drei oder mehr Arten daraus bilden könnte. Das Mittel einer grossen Menge Ausmessungen giebt folgende Maasse:

Länge $2^{\prime} 5^{\prime \prime}$, Flügelbreite $5^{\prime} 6^{\prime \prime}$. Der grösste Vogel, den ich ausgemessen, ein Männchen, war $2^{\prime} 7^{\prime} 1 / 2^{\prime \prime}$ lang und $6^{\prime}$ breit; der kleinste, ein Weibchen, war $1^{\prime} 11^{\prime \prime}$ lang und zwischen den Flügeln $4^{\prime} 6^{\prime \prime}$. Dieser letzte nähert sich mit Rücksicht auf Grösse sehr dem Larus leucopterus, und kann nur dadurch von demselben geschieden werden, dass die Flügel nur ganz wenig den Schwanz überragen, während sie bei Larus leucopterus in zusammengelegter Lage über denselben 2 bis $21 / 2$ Zoll hinausreichen.

Larus glaucus und leucopterus haben das gemeinschaftlich, 
dass sie vom Neste an zwei ganz verschiedene Trachten durchmachen, oder, wenn man will, es giebt unter diesen zwei Arten, so lange die Vögel jung sind, zwei verschiedene Varietäten, welche dasselbe Kleid anziehen, sobald sie brutfähig werden. Diese Variation ist bei beiden Arten ganz gleich und die Beschreibung der einen Species gilt ebenso für die zweite. Wenn man in einem Neste Junge von dieser verschiedenen Zeichnung findet, so ist die eine, welche ich mit Nr. 1 bezeichnen will, von der Färbung, in welcher die betreffende Mövenart im Nestkleide gewöhnlich beschrieben wird; die andre, welche ich mit Nr. 2 bezeichnen will, ist von hellerer Färbung.

\section{N. 1 .}

Am Halse mehrere Streifen im Zickzack; der Unterleib dunkelgraubraun; Rücken, Flügel und Schwanz weissgrau, auf welchem Grunde ein dunkles Graubraun und Lichtbraun Flecken und Bänder bilden.

Durch eine partielle Mauserung im ersten Herbste wird das Nestkleid fast gar nicht verändert.

Im ersten Frühjahre mausert der Vogel die Kopf- und Halsfedern, wodurch diese Theile dieselbe Farbe erhalten, welche Nr. 2 im Neste hatte; derselbe unterscheidet sich in diesem Alter von Nr. 2 durch den dunkelgraubraunen Unterleib.

Im zweiten Herbste mausert der Vogel alle Federn, und erhält "dann den Schivanz, die Flügel und den Unterleib hellgrau mit bräunlichen Flecken und Strei-
N. 2.

Es fehlt überhaupt die dunkle graubraune Farbe, so dass die ganze Zeichnung einen sehr hellén Ton erhält, und der Vogel dem ersten Augenschein nach einfarbig aussieht. Am Halse fehlt die Zeichnung fast gănzlich. *)

Ebenso.

Nach der ersten FrühjahrsMauserung wird Kopf und Hals einfarbig weissgrau, die übrigen Theile verändern sich nicht.

Im zweiten Herbst, wo alle Federn gewechselt werden, wird Nr. 2 überall schmutzigweiss, ausser am Kopf und Halse, wo er Nr. 1 gleicht, und am Unter-

*) 1824 brachte ich von Grönland zwei lebende junge Möven (Lar. glaucus) in dieser Farbentracht mit, welche von verschiedenen Ornithologen gesehen.wurden. Bei meiner Zurückreise nach Grönland schenkte ich sie meinem Freunde dem Apotheker S te e nberg in Helsingör. 
fen, so dass der Vogel viel heller aussieht als in ersten Jahre. Am Kopfe und Halse ist diese Zeichnung fast völlig übereinstimmend mit der des alten Vogels in der Wintertracht, aber die Grundfarbe ist hellgrau, nicht wie beim alten weiss, der Schnabel helffleischfarbig mit dunkler Spitze.

Im zweiten Frühjahre erhält Nr. 1 die Farbe des alten Vogels auf Kopf und Hals, aber das Weisse ist nicht so blendend als beim alten Vogel, das Uebrige bleibt unverändert.

Im dritten Herbste erhält der Vogel die Wintertracht des ausgefärbten Vogels. leibe, wo er einige bleichhellbraune Schmitze oder Streifen erhält.

Im zweiten Frühjahre wird der Vogel mit Ausnahme der erwähnten einzelnen Schmitze und Streifen einfarbig weiss, doch ist diese Farbe nicht von der blendenden Weisse, welche dem alten Vogel eigenthümlich ist, sondern das Weisse ist mit äusserst bleichem Grau angelaufen *). In diesem Kleide ist es Bennecke's Larus glacialis.

Im dritten Herbste erhält $\mathrm{Nr}$. 2 dieselben Farben, als der alte Vogel in Wintertracht, doch ist vielleicht das Mövenblau des Rükkens etwas weniges heller.

Die unter Nr. 2 beschriebene Varietät ist in Nordgrönland die häufigste **), während es von $\mathrm{Nr}$. 1 am meisten im Süden giebt. Von 11 Jungen, die ich an einem Tage bei Godhavn erhielt, waren 8 wie Nr. 2, 3 wie Nr. 1 beschaffen. - In Südgrönland mag das Verhältniss umgekehrt wie $3-1$ sein, so dass man am meisten von Nr. 1 findet.

Larus glaucus ist ein nicht völlig so schlimmer Räuber, als Larus marinus, aber doch ein kühner Eierdieb. Sie unterstützt die Lestris-Arten in der Bekämpfung der kleineren Arten, zwingt sie aber in der Regel, ihre Beute abzugeben. Sie ist sehr gie-

*) In dieser Farbentracht habe ich den Vogel an's Königl. Museum nach Hanse gesandt, wo er sich aufgestellt vorfindet.

**) Wieder ein Beleg zu dem schon beim Falco islandicus bemerkten Vorwalten der weissen Farbe in höheren Breitegraden.

Anm. d. Uebers. 
rig nach Aas und desshalb beim Aufhauen der Wallfische sehr zudringlich, doch nicht so sehr als Procellaria glacialis. Sie fängt mehrere Arten Fische, z. B. Cyclopterus lumpus, Cottus bubalis etc., aber nährt sich im Nothfall auch von Seegras, und verzehrt eine Menge Beeren von Empetrum nigrum *), von denen die Excremente oft blau werden.

Sie brütet stets auf den Felsen, am liebsten in Gesellschaft mit andern Vögeln; doch sind einzelne Berge auch allein mit $\boldsymbol{L} a$ rus glaucus besetzt, wie Najartut, etwas südlich von Godthaab. Am meisten brütet sie in Gesellschaft mit Larus leucopterus und tridactylus. Larus glaucus duldet keinen Vogel über sich im Berge, und brütet daher in oberster Reihe, dann folgt Larus leucopterus, endlich Larus tridactylus in gleicher Höhe mit Alca torda, wenn dieser im Berge ist; zu unterst Uria grylle, die niemals in solchem Vogelberge fehlt.

Larus glaucus ist die einzige Möve, die man zuweilen, aber äusserst selten, im Winter in Nordgrönland antriftt; sonst hält sie sich in dieser Jahreszeit an den äussersten Inseln bis zum Februar auf, wo sie im Süden in die Buchten zu ziehen beginnt, đann fângt die Frühjahrs-Mauser an. Man sieht sie nicht selten sehr weit vom Lande ab.

\section{L. L E U G 0 P $T$ E R U S.}

Es ist merkwürdig, dass ein so ausgezeichneter Beobachter, wie Fabrizius, diese so gewöhnliche Möve übersehen hat, um so mehr, da Glahn in seiner Recension der Cranz'schen Schrift Larus leucopterus mil dem grönländischen Namen Najangoak aufführt.

Diese Mŏve ist nach Larus tridactylus die häufigste im Lande, doch ist sie zu jeder Jahreszeit häufiger in Süd-als Nordgrŏnland, welches sie im Winter ganz verlässt.

Sie variirt bedeutend an Grösse, und kann daran allein nicht

*) Diese Beeren spıelen überbaupt eine wichtige Rolle in der Ernährung der Thiere in Grönland. Nach den Excrementen zu urtheilen, fressen fast alle Thiere und Vögel im Herbste diese Beeren, selbst der Fuchs. Auf den Inseln, wo die Wallrosse im Herbst ans Land gehen, sind alle Beeren bald verschwunden, also wahrscheinlich von den Wallrossen verzehrt. Die Grönländer essen die frischen Beeren unmässig, und bewahren sie in Thran eingemacht auf, als Desert ims Winter. 
von Larus glaucus unterschieden werden, aber stets sind die Flügel länger als an dieser, und der Schnabel verhältnissmässig sowohl dünner als niedriger. Die Mittelgrösse ist 'in der Länge $\mathbf{l}^{\prime}$ $10^{\prime \prime}$, in der Flügelbreite $5^{\prime} 6^{\prime \prime}$. Sie erreicht aber zuweilen eine Länge von $2^{\prime} 1^{\prime \prime}$; wogegen unter den kleinsten mir eine vorgekommen, welche nur $l^{\prime} 7^{\prime \prime}$ maass.

In Grönland will man zwei Arten dieser langfügeligen Blau Möve unterscheiden, und behauptet, dass die kleinere auf den Inseln brüte, die grŏssere auf den Felsen. Ich kann das Factum nicht bestreiten, dass die Individuen, welche ich auf den Inseln und da fast immer nur in einzelnen Paaren brütend antraf, auffallend klein waren; aber die Maasse dieser und jener laufen so in einander, dass man daraut allein unmöglich irgend eine Artverschiedenheit gründen kann; ein andrer Unterschied, ausser dass die Flügel verhältnissmässig etwas länger scheinen, ist nicht bemerklich.

Schon im Vorhergehenden ist gesagt, dass Larus leucopterus dieselben verschiedenen Federtrachten in der Jugend durchmacht, als L. glaucus. Das Verhältniss zwischen der hellen und dunklen Varietät ist gleichfalls ein solches wie bei Larus glaucus.

Es ist sehr merkwürdig, dass man hie und da Individuen dieser Mövenart findet, welche dieselbe Zeichnung an den Flügelspitzen, jedoch von ganz blassgrauer Farbe haben, als Larus argentatus, während sie bei dieser schwarz ist. *) Dies hat schon Capt. Sabine bemerkt, und aus diesem Grunde wollte er Larus leucopterus nicht als eigne Art anerkennen. Ich habe drei so gezeichnete Exemplare erhalten. Es könnte also scheinen, als wenn diese Möve ein Albino von Larus argentatus sei, aber dieser Zweifel kann leicht gelöst werden, wenn man an lebenden Individuen und nicht an getrockneten Bälgen untersuchte, ob bei Larus argentatus die Flügel in der Ruhe den Schwanz eben so weit überragen, als bei Larus leucopterus, welches sie nach Temminck nicht sollen.**)

Larus leucopterus (wie schon bei $L$. glaucus erwähnt) baut gewöhnlich in den Vogelbergen, doch habe ich nie einen Berg mit dieser Möve allein besetzt gesehen. Dagegen findet man sie zuweilen einzeln oder in ganz kleinen Vereinen auf den Inseln

*) Etwas Aehnliches zeigt Larus glaucescens, gegenüber von $L$. glaucus und marinus. S. N a u man $\mathrm{n}, \mathrm{X}$. S. $35 \mathrm{l}$.

Anm. d. U ebers.

- **) Larus argentatus möchte ausserdem stets einen stärkern gedrungenern Körper und kräftigeren Schnabel haben.

Anm. d. Uebers. 
brütend*); auf diesen bauet dieselbe, nicht wie in den Vogelbergen, am steilen Ufer, sondern auf der Oberfläche. Ihre Eier, 3, 2, 4 an der Zahl, sind von gleicher Grösse und Farbe, als die der Larus argentatus und möchten schwer von diesen zu unter scheiden sein. Sie legt Eier vom 10. bis 16. Juni.

Ihre liebste Nahrung ist Mallotus arcticus, doch verzehrt sie auch viele Gadus agilis (Reinh.), nimmt aber auch mit selbigem Futter vorlieb, als L. glaucus. In Nordgrönland habe ich sie im Winter nie bemerkt, dagegen sieht man sie weit hinaus in die Davisstrasse, aber nicht im atlantischen Meere.

\section{L. T R I D A G T Y L U S.}

Wer noch nie einen Vogelberg, besetzt mit dieser Vogelart, sah, kann sich eben so wenig einen Begriff von der eigenthümlichen Schönheit, als von der Menge dieser Vögel machen. Man könnte einen solchen Mövenberg vielleicht mit einem gigantischen Taubenschlage, besetzt mit Millionen gleichgefärbter Tauben, vergleichen. Der Berg Inujuatuk ist eine Viertel Meile lang, und der ganzen Länge nach, mehr oder minder stark, mit verschiedenen Mövenarten besetzt, und dies bis zu einer Höhe, dass man die obersten Vŏgel nur als kleine weisse Punkte erkennen kann. Zu den Zeiten, als ich den Berg besuchte, habe ich stets mehrere Adler und Falken, die unter den Mövenjungen fouragirten, angetroffen, und diese Räuber haben auch ihre Horste ganz in der Nähe des Vogelberges.

In der Zeit,. wenn Larus tridactylus Eier und kleine Junge hat, ist der Meerbusen hier im Godthaaber Distrikt, in der Nähe der Vogelberge, gleichsam angefültt mit Massen von Mallotus arcticus und die Seehunde, welche diesen Fisch von unten verfolgen, verhelfen den Vögeln zu einem leichtern Fang. So wie die Jungen der Letztern heranwachsen, und längere Zeit Futter und mütterliche Erwärmung entbehren können. muss jenes weiter weg gesucht werden, und gegen Ende Juli sieht man Schwärme dieser Vögel, nach der Richtung zu urtheilen, von Inujuatuk (10 Meilen weiter landeinwärts von Godthaab) kommend, aus und mit Futter einziehen, besonders Morgens und Abends.

L. tridactylus ist unser erstes Frühjahrszeichen. Zwischen

*) Es wurde schon bemerkt, dass diese Individuen stets sehr klein sind. 
dem 8. und 20. März kommt diese Möve in Schaaren an, oft mit strenger Kälte und östlichem Winde. Sie zieht gleich an die Vogelberge, wo sogleich ihr betäubendes Geschrei erschallt, und zeigt sich besonders unruhig und stark schreiend, wenn die Brut. plätze mit starkem Schnee bedeckt sind. Im November verlässt sie die Fjorde, hält sich aber zum Theil in der Davisstrasse, wo man bei Sturm, besonders aus Süden, dieselbe oft an der Küste, und zuweilen in ziemlicher Anzahl antrifft. Sie ist ein Ocean-Vogel, welchen man überall im atlantischen Meere erblickt.

Ihre Nahrung besteht aus Fischen, besonders Mallotus arcticus *) und Gadus agilis (Reinh.), jedoch auch aus Crustaceen, besonders Themisto arctica.

\section{L. E B U P N E U S.}

Ich habe zu jeder Jahreszeit diese liebliche Möve erhalten, nur nicht im Monate April, und stets in derselben Farbentracht. Wenn dieselbe also auch eine doppelte Mauser hat, so verändert sie doch nicht die Farben. An den Exemplaren, welche ich im Februar und März erhielt, konnte ich keine Mauserung bemerken, freilich waren dies junge Vögel.

Während und nach schweren Stürmen, besonders im Herbste und Winter, zeigt sich Larus eburneus zuweilen in Menge, und ist dann sehr einfältig und leicht zu fangen. Es liegt am Tage, dass dieselbe nicht die Gefahr kennt, welche mit der Annäherung an das räuberischste aller Raubthiere, den Menschen, verbunden ist. So ist es notorisch, dass man dadurch, wenn man ein Stück Speck an eine Schnur bindet, und dies in's Wasser wirft, den Vogel oft so nahe an sich lockt, dass man ihn mit Händen greifen kann; ja ein Grönländer, welcher mir ein schönes Exemplar eines jungen Larus eburneus brachte, erzählte mir, er habe dasselbe dadurch an sich gelockt, dass er seine Zunge hervorstreckte und bewegte, worauf der Vogel so nahe herangekommen sei, dass er ihn mit seinem Kajak**)-Ruder erschlagen habe. Alle die In-

*) Dieser Fisch findet sich an manchen Orten in ungeheurer Menge, und dient im Herbste und Winter den Seehunden und Vögeln zum bedeutendsten Theil der Nahrung. Der Zug desselben ist noch nicht hinlänglich beobachtet.

**) Kajak ist das Boot, welches die Grönländer auf der See gebrauchen. Sehr leicht gebaut, an beiden Enden spitz, ist es von oben dicht und hat nur in der 
dividuen, welche ich secirt habe, hatten das Futter in der Speiseröhre so verzehrt, dass ich nur erkennen konnte, dass Ueberreste von Fischen darunter seien.

Larus eburneus scheint sich mehr westlich in der Davisstrasse aufzuhalten, wo man sie stets, wenn man sich mehr der Küste Amerika's als Grönlands nähert, von den Schiffen aus erblickt.

\section{L. BRACHYTARSUS. Mihi.}

Diese seltne Möve steht in demselben Verhältniss zu Larus eburneus, als Sterna arctica zu St. hirundo, denn sie hat dieselben Farben als $L$. eburneus, unterscheidet sich aber von dieser:

1) durch den sehr kurzen Tarsus, welcher nur 1 Zoll lang ist,

2) durch die Länge der Flügel, sowohl durch die absolute als relative,

3) durch die Bildung der Federn im Flügel und

4) durch die noch stärker ausgeschnittene Schwimmhaut.

Art-Kennzeichen:

Tarsus 1"; die zusammengelegten Flügel reichen $21 / 2^{\prime \prime}$ über den Schwanz hinaus; Farbe: schneeweiss oder schneeweiss mit dunkelbraunen Flecken. Länge $\mathbf{1}^{\prime} 5^{\prime \prime}-\mathbf{1}^{\prime} \mathbf{6}^{\prime \prime}$.

Larus brachytarsus gleicht in der Zeichnung in jedem Alter L. eburneus, und ist gleich gross oder etwas kleiner.

Der Schnabel ist gelb mit dunkler Spitze. Die besonders langen Flügel unterscheiden sich von denen aller andern Möven dadurch, dass die 4 ersten Schwungfedern derselben von ausserordentlicher Breite sind. Füsse und Schwimmhaut schwarz, letztere sehr stark ausgeschnitten.

Ich habe drei Exemplare dieser Möve besessen, deren Dimensionen fast ganz gleich waren, so dass ich eine vergleichende Zusammenstellung der Maasse dieser beiden, einander so nahe stehenden, Möven geben kann.

Mitte ein Loch, in welches der Grönländer sich hinein setzt, und eine am Rande desselben befindliche Fellbekleidung um seinen Leib befestigt; es kann also kein Wasser hineindringen und dasselbe nicht sinken; doch verliert mancher Grönländer sein Leben durch Umschlagen desselben.

Anm. d. Uebers. 


\section{L. brachytarsus.}

Länge . . . . . . $1^{\prime} 5^{\prime \prime}-1^{\prime} 6^{\prime \prime}$ Flügelbreite . . . . . $\quad 3^{\prime} 4^{\prime \prime}$

Aeusserstes Flügelglied m. d. Vorderschwingen . . . . . . . $\mathbf{l}^{\prime} 2^{\prime \prime}$

Schwanz . . . . . . $6^{\prime \prime} 2^{\prime \prime \prime}$

Tarsus . . . . . $1^{\prime \prime}-1^{\prime \prime} 1^{\prime \prime \prime}$

Mittelzeh . . . . . $1^{\prime \prime} 9^{\prime \prime \prime}$

Breite der äussersten Schwinge, 4" v. der Spitze . . . . . . . $1^{\prime \prime} 3^{\prime \prime \prime}$

Die zusammengelegten Flügel überragen den Schwanz um . . . $2^{\prime \prime} 6^{\prime \prime \prime}$ Schnabel v. Mundwinkel in graderLinie $1^{\prime \prime} 10^{\prime \prime \prime}$

Von diesen drei Exemplaren waren zwei von Nordgrŏnland, das eine von Godthaab. In der Lebensweise scheint sie Larus eburneus zu gleichen. Leider sind alle diese Exemplare zu Grunde gegangen, so dass nicht einmal das Königl. Museum eins von mir erhalten hat. In den letzteren Jahren habe ich mich bemüht, mehrere zu erhalten, aber bisher vergebens.

Anm. Larus Rossi habe ich nie gesehen und bin auch nicht im Stande gewesen, über selbige einige Nachricht oder Auskunft zu erhalten.

\section{$\mathbf{X}$ ma $\mathbf{S}$ a b i n i.}

Ich habe nur ein verstümmeltes Exemplar dieses Vogels, das Museum ein zweites von Major Fasting erhalten. Beide diese waren junge Vŏgel. Die Grönländer von Kangek, einem Aussenposten westlich von Godthaab, welche das erwähnte Exemplar überbrachten, erzählten, dass sie zuweilen den Vogel sähen, wenn sie weit in der See hinaus auf Fang gewesen. Obgleich Upernevik nur 35 Meilen südwärts von dessen Brutplatz liegt, kannten die dortigen Grönländer doch nicht den Vogel nach der Zeichnung, welche ich ihnen zeigte.*)

Unter allen bekannten Vögeln erstreckt sich die Brutzone dieser Möve gewiss am wenigsten südlich vom Pole.

*) Unsere Abbildungivor dem Titel ist nach einem grönländischen Exemplare entworfen.

Anm. d. Uebers. 


\section{Hestio.}

Dieses Genus hat eine doppelte Mauser, durch welche die Farbe unbedeutend und nur am Unterlialse sich verändert; dies beweist ein Exemplar, welches ich im Anfange des März erhielt, und das in voller Mauserung stand, jedoch nur am Halse und Kopfe. Die Wintertracht ist am kenntlichsten an Lestris pomarina und zeigt sich dadurch, dass sie mehr oder fast nur blaugraue Federn am Unterhalse bekommt. Bei Lestris parasitica findet kaum eine Veränderung statt. Ich glaube, dass dies Genus gleich im nächsten Frühjahre ausgefärbt ist; denn nicht allein sieht man keine jungen Vögel nach Grŏnland kommen, sondern auch, weil ich bei meinen Reisen hierher den Vogel nur in dem Kleide, in welchem er hier an's Land kommt, gesehen habe. Es sind wahre Ocean =Vögel, die ich alle, mit Ausnahme von Lestris Buffonii, im Atlantischen Meere gesehen habe.

\section{L. CA T A RA C T E S}

muss mit eben so grossem Rechte zu den grönländischen Vögeln gerechnet werden als Sula alba. Zweimal habe ich den Vogel in der Nähe der Südküste von Grönland gesehen, und ohne Zweifel kommt er zuweilen zwischen die Inseln hinein.

\section{L. P O M A INA *)}

ist die gewöhnlichste Lestris in Nord-Grönland. Sie kommt zu Godhavn in der Mitte oder gegen Ende Mai an, und zieht im September fort. Die Jungen sieht man, nachdem sie flügge sind, selten länger als 14 Tage an der Küste. Sie brütet stets in Gesellschaft, am südlichsten bei Bjornenaesset, etwas südlich von Egedesminde, nördlicher auf einer Ebene an der Lachself bei Godhavn und an andern Orten. Sie kann allerdings fischen**), aber lebt doch noch ausschliesslicher als Lestris parasitica von dem andern Vögeln abgejagten Raube; und dies kann sie um so leich-

*) Nach späterer Mittheilung des Verfassers hat $L$. pomarina angefangen, weiter nach Süden zu brüten, indem sie 1844 als brutender Vogel im Holsteinborger Distrikte angetroffen wurde. Anm. des Uebers.

**) Ich habe sie in Mövenschlingen fangen sehen, welche 3 Fuss unter der Oberfläche des Wassers standen. 
ter, da sie sowohl stärker als die genannte ist, als auch gewöhnlich im Vereine mit mehreren Arts-Genossen ihre Angriffe ausführt. In Südgrönland ist sie selten, und man sieht sie hier nur im Frühjahre an den Küsten und im Herbste auf dem Zuge. Die dunkle Varietät ist selbst in Nordgrŏnland selten, wird aber doch zuweilen angetroffen. Sie legt 2 Eier von derselben Farbe und Länge als $L$. parasitica, aber bedeutend stumpfer und dicker.

\section{L. PARASITICA (L. SGHLEPII. Brehm.).}

Brehm hat die grönländische $L$. parasitica als eine von der isländischen verschiedene Art aufgestellt. Faber, welcher bei meiner Heimreise von Grönland 1824 meine gesammelten Vögel musterte, erklärte beim ersten Anblick, dass die grönländische $\boldsymbol{L}$. parasitica nicht mit der jsländischen identisch sei. Ich sandte Herrn Temminck Männchen und Weibchen mit dieser Bemerkung; da er sie aber nicht als eigne Art aufgenommen hat, muss ich annehmen, dass $\mathbf{F}$ aber sich geirrt habe. Der Unterschied soll in dem bedeutend stärkeren Schnabel und in den grösseren Dimensionen des Vogels liegen. Da es auch dieses ist, welches L. parasitica von $L$. Buffonii unterscheidet, will ich die vergleichenden Ausmessungen dieser beiden Arten, von 2 frisch erlegten Vögeln (zwei Männchen) hergenommen, aufführen:

L. parasitica.

Ganze Lănge mit den verlängerten Schwanz-

federn

Ganze Länge ohne diese . . . . . . $1^{\prime} 5^{\prime \prime}$

Tarsus . . . . . . . . . . . . $1^{\prime \prime} 9^{\prime \prime \prime}$

Mittelzeh . . . . . . . . . . . $1^{\prime \prime} 9^{\prime \prime \prime}$

Aeusserste Zeh . . . . . . . . . $\mathbf{l}^{\prime \prime} 5^{\prime \prime \prime}$

Innerste Zeh . . . . . . . . . . $1^{\prime \prime} 3^{\prime \prime \prime}$

Hinterzeh . . . . . . . . . . . $2^{\prime \prime \prime}$

Oberschnabel von den Federn bis zur Spitze

im Bogen gemessen . . . . . . . $\mathbf{l}^{\prime \prime}$

Länge des Schnabels vom Mundwinkel bis zur Spitze

Hŏhe des Schnabels über dem Nagel . .

Breite des Schnabels an der Basis . . . 1"

Der Oberschnabel überragt den untern . 1/2"'

Länge des Kopfes

Breite des Kopfes über den Augen . . . 1" $5^{\prime \prime \prime}$
L. Buffonii

$1^{\prime} 10^{\prime \prime}$

$1^{\prime} 1^{\prime \prime}$

$1^{\prime \prime} .5^{\prime \prime \prime}$

1" $9^{\prime \prime \prime}$

$1^{\prime \prime} 3^{\prime \prime \prime}$

$11^{\prime \prime \prime}$

$3{ }^{1 / 2} 2^{\prime \prime \prime}$

$10^{\prime \prime \prime}$

I" $^{\prime \prime} 9^{\prime \prime \prime}$

$41 / 2^{\prime \prime \prime}$

7"'

$1^{1 / 4} \mathbf{4}^{\prime \prime \prime}$

1" $5^{\prime \prime \prime}$

$1^{\prime \prime} 2^{\prime \prime \prime}$ 
Da die grönländische $\boldsymbol{L}$. parasitica sich durchaus nicht von der europäischen an Farbe unterscheidet, wird man nach dieser Ausmessung allein $\mathrm{zu}$ urtheilen haben, ob die grönländische Lestris parasitica eine eigne Art sei.

L. parasitica ist häufiger in Süd- als Nordgrönland. Sie brütet stets auf Wiesen oder in Mooren, sowohl im Innern der Buchten als auf den Inseln, aber nie in Gesellschaft. Ihre 2 Eier sind ganz, wie F aber sie beschreibt, $3^{\prime \prime}$ lang (2"?), sehr zugespitzt, von dunkelolivengrüner Farbe, mit vielen braunen Flecken. Die Jungen gleichen einander ganz im Neste, und die Varietäten zeigen sich erst beim Uebergange in's brutfähig machende Kleid des Vogels. Die dunkle Varietät, einfarbig dunkel blaubraun, ist nicht das Jugendkleid. Ich kann um so bestimmter dies behaupten, als ich in 3 Jahren dasselbe Paar, brütend auf einer Insel in der Nähe von Godthaab, beobachtet habe. Von diesem Paar war der eine Gatte dunkel, der andre hell. Im dritten Jahre schoss ich den hellen Vogel weg, welcher das Weibchen war; im vierten Jahre brachte das Männchen wiederum èn helles Weibchen, aber in diesem Jahre wurden beide alte Vögel gegen meinen Wunsch getödtet und der Platz nicht wieder besetzt. Man findet sowohl Männchen als Weibchen von der dunkeln Varietät.

In den ersten Tagen des Mai kommt $L$. parasitica an die Küste, scheint aber die Davisstrasse nie ganz zu verlassen, da in starken Stürmen einzelne zu den Colonieen selbst mitten im Winter kommen. Im September verlassen die Alten die Küste, die jungen Vögel schon in der Mitte des August. Diese Art fischt viel selbst, und wird oft von den Grönländern in den für $L$. tridactylus ausgesetzten Schlingen gefangen.

\section{L. B UF F O N I I.}

Diese Lestris, unterscheidet man, selbst in weiter Entfernung, von $\boldsymbol{L}$. parasitica leicht an dem sehr hüpfenden Fluge, der ganz dem der Meerschwalben gleicht.

In Grönland ist dieser. Vogel ein Bewohner des höchsten Nordens, und wird nur selten südlich vom $69^{\circ}$ N. B. gesehen. Der inzige Brütplatz, welchen ich kenne, ist auf einigen Inseln, t $\quad$ ige Meilen südlich von Upernevik, auf circa $72^{\circ} 40^{\prime} \mathrm{N}$. Br. ei $i_{\perp} \quad$ ich bei den Nestern war, waren nur mit Dunen bekleidete Als i darin. Im nächsten Jahre brachte man mir zwei von deren 
Eiern, welche dieselbe Farbe und Bau als die der L. pomarina hatten, aber fast $1 / 2$ " kürzer warẹn. Sie brütet in Gesellschaft, wie man dieselbe auch fast immer in Gesellschaft mit ihren ArtGenossen antrifft. Von den 3 Exemplaren, welche ich erhalten habe, ist eins geschossen am Brütplatze, eins zwischen Holsteinborg und Egedesminde und eins aus einer Schaar, welche sich in der Năhe von Godhavn niedergelassen hatte. Nach einer Mittheilung des jetzt verstorbenen Kaufmanns Merk werden öfter im Herbste Schaaren dieses Vogels an dem West-Eiland im Egedesminder Distrikt gesehen.

Ich habe nie bemerkt, dass $L$. Buffonii andre Vögel verfolgte; dagegen sahe ich selbige sehr eifrig mit dem Stosstauchen, wie die Sterna's, beschäftigt. Im Oesophagus fand ich Ueberreste von Fischen und Crustaceen. Ich habe keine dunkle Varietät bemerkt. Der Tarsus war bei allen, welche ich untersuchte, hellblau, während das Knie, der Fuss und die Schwimmhaut schwarz waren.

\section{Procellaria und Puffinus.}

Mag man auch, um consequent zu sein, wegen des Unterschiedes im Bau des Schnabels *) genöthigt werden, diese Vögel in 2 Genera zu trennen, so herrscht doch zwischen ihnen eine so grosse natürliche Verwandtschaft, dass Faber gewiss sehr Unrecht daran thut, sie im System zu trennen. Wie bekannt begründete Faber diese Benennung allein auf den Umstand, dass er Puffinus Anglorum hat tauchen sehen, aber dies bei Procellaria glacialis nie bemerkt hat. Puffinus cinereus hat Faber nur in einem Individuum gesehen. Ich habe dagegen Puffinus Anglorum bei Grönland nie bemerkt; sollte ich aber Puffinus und Procellaria in 2 Genera trennen, so würden meine Gründe den seinigen grade entgegengesetzt ausfallen, weil ich Puffinus cinereus nie, aber Procellaria glacialis sehr oft habe tauchen sehen. Doch muss ich sogleich hinzufügen, dass die Grönländer, welche oft Puffinus cinereus in grosser Anzahl fangen, berichten, derselbe

*) Müsste man nicht die 2 Phalaropus-Arten aus demselben Grunde trennen? So ist der Schnabel von Tringa islandica auch so verschieden von dem der $T r$. maritima, dass man auch hier 2 Genera bilden könnte, u. d. m. 
tauche zuweilen. Faber hat im ,Leben der hochnordischen Vögel" S. 282 zu beweisen gesucht, dass Procellaria glacialis kein eigentlicher Taucher sei, obgleich er nach Wallisch-Aas untertauche, wenn er es sehen kann, und vergleicht diese Tauchfähigkeit mit der einer Taube, welche sich in's Wasser wirft, um dem Stosse des Falken zu entgehen. In wie weit man diese Gründe gelten lassen will, weiss ich nicht; aber ich habe oft Procellaria glacialis nach Futter tauchen sehen und jeder, der auf dem Atlantischen Ocean reist, kann dasselbe erfahren, wenn Windstille eintritt: Man braucht dann nur, wenn $\boldsymbol{P}$. glacialis in der Nähe ist, ein Stück Speck auszuwerfen, und ohne. Zweifel wird der Vogel danach tauchen, um dasselbe zu erhaschen, bevor es sinkt. Ausserdem hat Herr Etatsrath Reinhardt in der Zeitschrift für Naturwissenschaften $3 \mathrm{r}$ Theil S. 60 anatomisch bewiesen, dass P. glacialis ein Taucher sei.

\section{PR O G L L A I A G A C I A IS.}

Man sieht diesen. Vogel überall in der Davisstrasse, nur nicht ganz in der Nähe des Landes, denn in Südgrönland nähert er sich nur bei starkem Nebel der Küste, und kommt zwischen die Inseln und auf die Fjorde, während er in Nordgrönland sich beständig an den Kủsten und in allen Buchten herumtreibt. Ja ich habe ihn mehrmals aus meinen Fenstern in der InspekteurWohnung zu Godhavn geschossen. Beim Aufhauen der Wallfische ist er sehr zudringlich so, dass man denselben zu Tausenden mit Rudern und Bootshaken todtschlagen kann. Er ist ein wahrer Ocean-Vogel, der gleich von Fairhill an auf dem ganzen Atlantischen Meere angetroffen wird.

Sein südlichster Brüteplatz findet sich einige Meilen nördlich von Godhavn; der einzige, welchen ich ausserdem kenne, ist in der Bucht von Omanak; an beiden findet sich eine grosse Menge brütender Vögel. Sein grosses weisses Ei ist sehr wohlschmeckend, wie auch der Vogel in der Brütperiode.

.Es giebt, wie bekannt, eine dunkle Varietät von Procellaria glacialis, welche mit. Ausnahme eines dunkeln Fleckes am Auge und eines hellern am Flügel, einfarbig und sehr dunkel mövenblau ist*). Diese Varietät ist nicht sehr häufig, wird aber stets

*) Von den Grönländern wird diese Varietät Igarsook d。i. Koch genannt, nach dem gewöhnlichen Aussehn des Schiffskoches. Der helle Fleck am Flügel wird nur bemerkt, wenn man den Flügel ausbreitet. 
unter den übrigen am Vogelberge bemerkt; in wie fern sie aber wechselseitig gepaart sind, kann ich nicht mit Bestimmtheit anlühren. Am Gefieder kann man die flüggen Jungen nicht von den Alten unterscheiden.

Procellaria glacialis trägt seinen Namen nicht mit Recht, denn er scheut zuum wenigsten die grösseren Eismassen. Während der langen Zeit, dass ich in den Jahren 1835 und 1837 mit dem Schiffe vom Eise in der Davisstrasse eingeschlossen war, wurde äusserst selten eine Procellaria bemerkt, und die Schiffsführer halten es für ein sicheres Zeichen, dass sie in der Nähe des offnen Wassers sind, wenn sie, eingeschlossen im Eise, mehrere dieser Vögel sehen. In Nordgrönland findet man Procellaria glacialis im Winter nie, obschon das Meer zuweilen ziemlich frei vom Eise (bis in den Januar hinein) sein kann*).

\section{Thalassidroma Teachii.}

Auf der Reise nach Grönland sieht man stets diesen Vogel gleich von der Südspitze des Landes, bis man zwischen den 64 und $65^{\circ}$ kommt, wo er ganz aufhört. Ist man nicht zu weit von der Küste entfernt, also auf den reichen Fischbänken, so umschwärmt dieser Vogel gewöhnlich das Schiff in den hellen Sommernächten, besonders bei stillem und gutem Wetter, indem er beständig seine pfeifende Stimme, die dem Pfeifen der Mäuse gleicht, hören lässt. Bei den Kock-Inseln vor der GodthaabBucht sieht man ihn am häufigsten, und es sollte mich nicht wundern, wenn man auf einer oder der andern dieser mehrerer hundert Inseln seine Brütplätze fände; denn er ist von Anfang des Mai bis Ende des August in der Davisstrasse anzutreffen. Als ich im October von Grönland abreiste, sahe ich keine Sturmschwalben in jener Strasse, aber ungewöhnlich viele im Atlanter-Meer, woraus ich schloss, dass sie im Winter die Küsten Grönlands verlassen.

Die Sturmschwalbe besitzt jene. Fähigkeit, welcher sie den generischen Namen verdankt, nämlich auf den Wellen mit ausge

*) Herr Brehm hat in der $0 \mathrm{rnis}$ die grönländische Procellaria als eigene Art aufgestellt, doch ist hierzu wohl kein Grund; was derselbe über den Nutzen des Vogels in der grönländischen Haushaltung anführt, ist vollkommen falsch. 
breiteten Flügeln zu laufen. Dies ist ein allerliebstes Schauspiel, wird aber vom Seemann nicht gern gesehen, weil er glaubt und, wie ich meine, nicht mit Unrecht, dass dies einen bevorstehenden Sturm bedeute.

\section{PUFFINUS CINEREUS. *) (PROCELLARIA PUFFINUS Tem.)}

Puffinus cinereus findet sich in grosser Menge in der Davisstrasse, gleich von der Südspitze Grönlands an, his $651 / 2^{\circ} \mathrm{N}$. Br.; hier scheint das Vorkommen desselben zu endigen; aber grade vom 63sten bis $65^{1} / 2^{\circ}$ N. B., wo sich Grönlands fischreichste Bänke vorfinden, ist er am allerzahlreichsten. Tritt im August Nebel ein, so kommt er in solcher Menge in die Fjorde hinein, dass er, so zu sagen, das Meer bedeckt; aber kaum hebt sich der Nebel, so sind plötzlich alle wie durch Zauberei verschwunden. Es ist besonders vom 62 . bis $65^{1} 2^{\circ} \mathrm{N}$. B., dass derselbe auf diese Weise an die Küste kommt, aber vorzüglich ist dies der Fall im Distrikt des Sukkertopp's (Zuckerhuts), wo er mehrfach in jedem Jahre vorkommt, ja selbst ohne Nebel sich dort am Abende zwischen den Inseln zeigt. Im Herbste, wo man ihn in der Regel fängt, ist er so ausserordentlich fett, dass es fast unmŏglich ist, das Fell zum Ausstopfen zu bereiten; dies ist der Grund, wesshalb das Museum nur 2 Exemplare dieses sonst gewöhnlichen Vogels erhalten hat.

Vom Anfange des Mai bis Ende September trifft man ihn in der Davisstrasse; desshalb nehme ich an, dass er seine bisher unbekannten Brütplätze hier, oder an der 0stküste des nördlichsten Amerika habe. Im October 1834 hatte er die Davisstrasse verlassen, wurde aber gleichwohl nicht im Atlanter-Meere bemerkt, wo dagegen Puffinus Anglorum, welcher, wie ich meine, nicht zu den grönländischen Vögeln gezählt werden kann, in grosser Menge gesehen wurde.

$P$. cinereus gleicht im Habitus, wie in der Lebensweise, auffallend der Procellaria glacialis; freilich habe ich denselben nicht

*) Da Herr Etatsrath Reinhardt 1822 nur einen Puffinus von Grönland erhalten hatte, nemlich Pufinnus Anglorum, nahm er an, dass dies Fabrizius Procellaria Puffinus sein müsste. Spätere Beobachtungen und der Umstand, dass man nur einmal Puffinus Anglorum von Grönland erhalten hat, beweisen, dass Fabrizius hinsichtlich der Ortsbestimmung Recht hatte. 
tauchen sehen; aber nach der Aussage der Grönländer taucht derselbe, doch nicht besser als $\boldsymbol{P}$. glacialis. Dagegen ist dieser Vogel im Besitz einer andern Art Tauchfertigkeit. Wenn nämlich im Sturm, oder nach demselben, die See hoch geht, sieht man den Vogel beständig in Bewegung zwischen den hohen Wellen, deren Bewegungen er geschickt zu folgen weiss; wenn er nun in der Welle selbst seine Beute erblickt, fliegt er mit stille gehaltenen Flügeln durch die Woge, doch stets gegen dieselbe an, nie mit derselben.

Er scheut, wie Procellaria glacialis, die grossen Eismassen; während wir vom Eise eingeschlossen waren, habe ich ihn nie gesehen.

\section{Cygnus melanorhynchus *)}

gehört nicht allein zu den grönländischen Vögeln, weil Capt. Gra ah ein Exemplar ganz südlich im Lande geschossen, und ich den Vogel nicht weit von der grönländischen Küste gesehen, sondern hauptsächlich, weil ich mit Grund annehme, dass der Schwan vor geraumer Zeit in Grönland gebrütet hat. Am Godthaaber Fjord ist eine Landstrecke, welche Kuksuk (der grönländische Name des Schwan's) heisst, wo derselbe nach der Tradition der Grönländer gebrütet haben soll. Diese Landstrecke ist angefüllt mit kleinen sumpfigen Seen und Bächen und hat eine für Grönland recht üppige Vegetation sowohl am Lande, als in den Seen.

Die Grönländer erzählen, dass der Schwan dort nistete, aber dadurch ausgerottet wurde, dass man in der Mauser-Periode, wenn der Vogel nicht fliegen konnte, denselben dort mit dem Kujak verfolgte. Den Verfolgungen mit diesen leicht zu rudernden Fahrzeugen zu entgehen, möchte auch, während der genannten Periode, für den Schwan unmöglich sein.

*) Der Verfasser schreibt mir, dass Cygnus melanorhynchus sich in mehreren Exemplaren im Julianehaaber Distrikt gezeigt habe.

Anmerkung des Uebersetzers. 


\section{A s e r.}

\section{ANSER HY PERBOREUS.}

Man sieht diese Gans einzeln in der Herbst-Zugzeit, beson ders nach Sturm, und dann kommt dieselbe öfter nach Nord-als Süd-Gronland, obgleich ich dieselbe auch von Julianehaab erhielt. Es sind indessen nur junge Vögel, welche im Lande geschossen wurden, obschon kein Grund zu der Annahme vorhanden, als seien dieselben hier ausgebrütet, wenigstens nicht, so weit die Rennthierjäger in's Land hinein kamen.

\section{ANSER ALBIFRONS.}

Diese Gans ist nicht selten im Sommer in den Süsswasserseen und Strŏmen zwischen $66-681 / 2^{\circ}$, und wird in der Zugzeit nur südlich von dieser Breite gesehen. Nach den Aussagen der Grönländer legt sie 7-11 Eier und ist am Brütplatze wenig scheu. In der Mitte des Mai sieht man sie paarweise nach Norden ziehen, und im Herbste kommt sie in Schaaren sowohl auf die Inseln, als selbst an die Häuser der Colonieen (z. B. Jacobshavn), um zu weiden. In dieser Zeit ist sie zwar sehr scheu, wird aber doch nicht selten geschossen. Sowohl Alte als Junge werden leicht zahm und dem Menschen sehr zugethan. Vor einigen Jahren erhielt ich eine Junge, die nicht allein so zahm wurde, dass sie mir und meiner Familie überall wie ein Hund aus und ein folgte, sondern, wenn sie, wie dies ŏfter der Fall war, hoch in der Luft flog, augenblicklich herabkam, sobald man sie rief, und ihre Freude mit einem hellen gä́ck, gäck gäck zu erkennen gab. Uebrigens hatte sie sich sehr an eine rothe Kuh attachirt und folgte dieser, sobald sie nicht von ihren Bekannten unter dèn Menschen einige fand, welchen sie folgen konnte. Die Kuh schien auch viel Vorliebe für die Gans zu haben, und liess dieselbe stets auf ihrem Rücken schlafen, wenn sie im Stalle war, auch im Sommer sah man die Gans stets auf dem Rücken ihrer grossen Freundin stehen, wenn diese lag. Die Gans starb in ihrem dritten Jahre an einer Lungenkrankheit.

\section{ANSER LEUGOPSIS}

scheint regelmässig bei Julianehaab in der Herbst-Zugzeit vorzu- 
kommen, da ich sie in den letzten Jahren mehrmals von dort erhielt und dem Museum im Jahre 1837 zugestellt habe.

\section{A N S ER BERNI C L A}

erscheint als Zugvogel an der ganzen Westküste Grönlands, nistet aber erst nördlich von dem $73^{\circ} \mathrm{N}$. B. und brütet nach dem Berichte der englischen Reisenden bis weit gegen den Pol. Nach Godhavn kommt sie gewöhnlich zwischen dem 6ten und 12ten Juni, zieht dann in grossen Schaaren, in ungefähr 12 Tagen, und wird dann zuweilen in grosser Menge geschossen; in dieser Jahreszeit ist sie ziemlich mager. Im September sieht man sie nicht selten in ungeheuren Schaaren an den äussersten Inseln, aber besonders bei Norsoak am Nordende von Waigatt, wo dieselbe in dieser Jahreszeit zuweilen zahlreich erlegt wird. Im. Herbste ist sie sehr wohlschmeckend, aber nicht sehr fett.

\section{A $\mathbf{n}$ s.}

\section{A N A B O S G H A S}

ist die einzige in Grŏnland nistende Art dieser Enten-Familie, und nicht selten sowohl in Nord-als Süd-Grönland; sie baut ihr Nest stets an kleinen Süsswasserseen oder am Ufer der Ströme, führt aber nicht selten die Jungen gleich auf's Meerwasser, wo sie hauptsächlich von kleinen Schaalthieren leben; und ich habe ófter im Oesophagus dieser Jungen Turbo planorbis Fabr. gefun • den, welche sonst schwierig genug aufzufinden ist.

Anas Boschas ist in Grönland derselben doppelten Mauser als bei uns (in Dänemark) unterworfen. Sie verlässt nie die Küsten Grönlands und lebt im Winter ganz wie eine Tauchente einzig von Crustaceen, nach welchen sie auf 2 bis 4 Faden Tiefe untertaucht. Gewŏhnlich findet sich in ihrer Speiseröhre: Margarita helicina, Modiola und Tellinen, weniger häufig Amphipoden. Ihr Fleisch hat im Winter einen sehr herben Geschmack, wahrscheinlich von ihrer Nahrung; doch ist sie in gelinden.Wintern ausserordentlich fett.

Die Membran am Hinterzeh hat eine Breitè von $3^{\prime \prime \prime}$, den Zeh eingerechnet. 


\section{A N A S A C U T A}

verirrt sich zuweilen nach Grönland. Ich habe sie von Fiskenaesset und Julianehaab erhalten, das Museum gleichfalls von Omanak.

\section{A N A S C R E C C A.}

Es verhält sich mit dieser Ente ganz wie mit $A$. acuta; sie wurde, durch Stürme verschlagen, sowohl in Süd - als Nord - Grönland angetroffen.

Beide diese Enten-Arten, so wie Clangula Barrowii; habe ich von den Grŏnländern unter dem Namen Kertlutok piarsuk erhalten, unter welchem Namen Fabrizius A. clangula anführt, so dass es scheint, als ob die Grönländer allen Enten-Arten, welche sie nicht kennen, diesen Namen, zusammengesetzt aus Kertlutok: ,graue Ente“ und piarsuk: „,etwas ähnliches“ beilegen.

\section{C $1 \mathbf{a} \mathbf{n} \mathbf{g} \mathbf{l}$ a.}

\section{C L A N G U L A G L A C I A L I S}

ist häufig sowohl längs der ganzen Küste, als auf den Inseln und den Ufern im Innern der Fjorde. Sie legt 7-11 Eier an kleinen Süsswasserseen, führt aber die Jungen gleich auf's Meer. Ihre. Nestdunen sind schwarz und sehr elastisch und werden für die vorzüglichsten von allen zur Füllung der Oberbetten gehalten.

- In der Mitte des Juni haben sie Eier. Das Männchen hält sich während des Brütens zu dem Weibchen, verlässt es aber, wenn die Jungen ausgekrochen sind; dann fängt es an das Gefieder zu ändern und im August findet man den Vogel nicht mehr in der Sommertracht. Die jungen Vögel halten sich, gewöhnlich in Gesellschaft mit einander, zwischen den Inseln auf. Im Winter, wo Anas glacialis an der ganzen Küste von Südgrönland sehr häufig ist, sind die alten und jungen Vŏgel in demselben Haufen. Sie taucht besonders auf Sandgrund. Ihr Zug ist nicht regelmässig, wie der der Somateria.

Dies ist die einzige Ente in Grönland, deren Männchen die Sommertracht vor der Nestperiode anlegt, also gleichzeitig mit dem Weibchen. Sie taucht bis auf 8 Faden Tiefe und lebt be- 
sonders von Modiola faba, Margarita helicina, Tellinen, Mya arenaria und Amphipoden. Im dritten Sommer ist sie brutfähig.

Weder diese noch eine andre Art des Genus Clangula entfernt sich weit vom Lande, sie dienen daher auch als Kennzeichen von der Nähe des Landes, wenn man im Nebel auf selbiges zusegelt *).

\section{GLANGUL A H I S T R I O N I CA}

ist in Nord - Grönland ein seltner Vogel, während sie zwischen dem 62 und $65^{\circ}$ N. B. sehr gemein ist. Das Nest dieser Ente findet sich stets am Ufer eines sehr reissenden Baches, und ist so gut unter Schirmpflanzen und Weiden versteckt, dass man es nur selten entdeckt. Die Jungen werden gleich in's Meer geführt, doch dauert ihr Aufenthalt in der Nähe dèr Brutstelle länger, als bei der vorhergehenden Art. Sie liebt aufgeregte See, und findet sich deshalb ausser der Brutzeit gewöhnilich bei den äussersten Inseln, wo sie mitten in der Brandung taucht; doch ist ihre Tauchfähigkeit geringer, als bei $\mathrm{Cl}$. glacialis, und sie taucht kaum tiefer, als in 6 Faden Wasser. Die Nahrung ist älnlich der der vorhergehenden Art, doch vielleicht mehr ausschliesslich auf Amphipoden beschränkt.

Sie hat eine doppelte Mauserung. Die Frühjahrs-Mauser des Weibchens, wodurch keine Veränderung im Gefieder entsteht, fängt im April an, und ist beendet vor dem Eierlegen. Das Männchen, welches durch seine kurze Sommer-Mauser einfarbig blau wird, mausert Ende August. Keins der Individuen, welche ich in dieser Periode erhielt, hatte Schwungfedern; der Vogel kann also in dieser Zeit natürlich so wenig fliegen als A. boschas.

\section{C L A N G ULA B A R R O W II.}

Mit den wenigen literarischen Hülfsmitteln, welche ich während meines ersten Aufenthaltes in Grönland mit mir führte, war es mir nicht möglich, diese Ente von Clangula vulgaris zu unterscheiden, obschon der Unterschied beim Zusammenhalten sehr

*) Herr Lector Steenstrup hat mich aufmerksam gemacht, dass es in Island 2 Formen dieser Art gebe; demzufolge habe ich eine Anzahl grönländischer Individuen untersucht, aber keinen derartigen Unterschied in der Grösse oder den Dimensionen gefunden. 
bedeutend ist. Nach Etatsrath Reinhardt besteht er in Folgendem,

1) in der grŏssern Ausbreitung der schwarzen Farbe des Kopfes am Halse herab,

2) dessen Schillern in's Blaue,

3) der triangulären Form des weissen Fleckes zwischen Auge und Schnabel bei $C l$. Barrowii, welcher bei $C l$. vulgaris rund ist.

4) Die verlängerten Kopffedern erstrecken sich bei $C$. Barrowii weiter herab am Hinterhalse, wodurch der Schopf vollständiger, als bei $C l$. vulgaris wird.

Ausserdem ist der Schnabel derselben etwas höher und breiter, und hierzu kommt noch, dass das Männchen der $C l$. Barrowï grösser als das der $\boldsymbol{C l}$. vulgaris ist, während die Grösse beider Weibchen, nach den in den Handbüchern angegebenen Ausmessungen, sich gleich bleibt. Da ich nicht weiss, ob das Weibchen und junge Männchen in einer in Dänemark leicht zugänglichen Schrift beschrieben ist, erlaube ich mir, die Beschreibung dieser nebst einigen vergleichenden Ausmessungen mitzutheilen:

altes M. junges M. altes W.

Länge . . . . . . . . $1^{\prime} 7^{\prime \prime} 6^{\prime \prime \prime} 1^{\prime} 6^{\prime \prime} 3^{\prime \prime \prime} 1^{\prime} 3^{\prime \prime}$ Flügelbreite . . . . . . $2^{\prime} 10^{\prime \prime}-2^{\prime} 8^{\prime \prime}-2^{\prime} 4^{\prime \prime}$ -

Des Schnabels Höhe an d. Basis - $1^{\prime \prime} 2^{\prime \prime \prime}-\quad$ - $9^{\prime \prime \prime}-\quad$ - $10^{\prime \prime \prime}$

- - Breite - - _ - - $11^{\prime \prime \prime}$ - - $81 / 2^{\prime \prime \prime}$ - - $9^{\prime \prime \prime}$

- Länge v. Mund-

winkel . . . . . . . - $2^{\prime \prime}-\quad 1^{\prime \prime} 6^{\prime \prime \prime}-1^{\prime \prime} 8^{\prime \prime \prime}$

Des Schnabels Bogen von den - $1^{\prime \prime} 6^{1 / 2^{\prime \prime \prime}}+1^{\prime \prime} 4^{\prime \prime \prime}-1^{\prime \prime} 3^{1 / 2} \mathbf{2}^{\prime \prime \prime}$

Stirnfedern

Tarsus . . . . . . . - $1^{\prime \prime} 9^{\prime \prime \prime}-1^{\prime \prime} 5^{\prime \prime \prime}-1^{\prime \prime} 6^{\prime \prime \prime}$

Länge des Schwanzes • . - $4^{\prime \prime} 1^{\prime \prime \prime}-3^{\prime \prime} 5^{\prime \prime \prime}-3^{\prime \prime} 2^{\prime \prime \prime}$

Das alte Weibchen hat am Kopfe und obern Theile des Halses ein sehr tiefes Dunkelbraun ohne Glanz, der übrige Theil des Halses ist aschgrau mit wellenartigen Linien von weisser Farbe; der Kropf weiss, die Seiten hell aschgrau mit weisslichen Wellenlinien, der Unterleib aschgrau, gegen die Brust zu heller, gegen den Schwanz dunkler. Der Rücken ist dunkelaschgrau mit hellaschgrauen Querstreifen, Flügel und Schwanz so dunkelaschgrau, dass sie fast schwarz aussehen. Am vordersten Theil der Flügel sind einige Wellenlinien von hellem Aschgrau und in der Mitte ein rein weisser Spiegel. Tarsus und Zehen sind dunkelbraun; 
die Schwimmhaut schwarz, der Schnabel dunkel aschgrau mit einem breiten orangegelben Band auf der Mitte, die Iris gelb.

Das junge Männchen vom Jahr gleicht ziemlich dem Weib chen, es fehlt ihm aber der reine weisse Spiegel auf den Flügeln, wie auch das Braun am Kopf und Hals heller und glänzender als beim Weibchen ist. Die Nackenfedern sind schon lang und beginnen einen Schopf zu bilden. Unter dem Braun des Halses ist ein ziemlich schmales weisses Band. Der Kropf ist schön aschgrau mit wellenförmigen weissen Streifen. Brust und Unterleib weiss, die Seiten hell aschgrau mit wellenförmigen weissen Streifen. Der Rücken, die Flügel und der Schwanz von so dunklem Aschgrau, dass sie schwarz scheinen; gegen den Hals zu hat der Rücken einen Schein von hellem Aschgrau. Die Flügel haben keinen rein weissen Spiegel, sondern es bilden einige weisse $\mathrm{Fe}$ dern 3 unregelmässige weisse Bänder, und hinter diesen endigen sich mehrere Federn mit Weiss, wodurch ein Rhomboid entsteht.

Der Schnabel ist schwarz an der Basis und Spitze, in der Mitte etwas heller; Iris grüngelb; die Füsse, nämlich Tarsus und Zehen, von vorne dunkel orangegelb, von hinten fast schwarz, die Schwimmhaut schwarz.

Die Abbildung des alten Männchens in den Ichthyol. Beiträgen ist sehr genau, nur der Hals von der Schnabelwurzel bis hin unter den weissen Fleck am Kopfe zu dick.

Clangula Barrowii ist ganz beschränkt auf den Godthaaber Busen, und kommt so selten südlich oder nördlich vom Godthaaber District vor, dass die Grönländer sie nicht kennen, ja nicht einmal zu benennen wissen, welches sowohl der von Fabrizius als Graah angeführte Name hinreichend beweist. Der richtige grönländische Name ist Niakortok, ,grossköpfige Ente," welcher besonders für das Männchen sehr bezeichnend ist, welches, wenn es schwimmt, allerdings einen auffallend grossen Kopf zu haben scheint. Sie hält sich besonders im Innern der Fjorde auf und verlässt dieselben nicht, bevor alle kleinen Buchten mit Eis belegt sind. Sie kann nicht auf tieferem Wasser tauchen, als $\mathrm{Cl}$. histrionica, ja ihre Tauchfertigkeit ist wohl noch geringer. Ihre Nahrung besteht besonders aus Modiola faba, Margarita helicina und Amphipoden*).

*) Herr Missionär Jorgensen, welcher sich mehrere Jahre hindurch in Julianehaab aufhielt, und manchen wichtigen Beitrag zur grönländischen Fauna ge- 
Ausser der Brutzeit sieht man dieselbe in Familien, aber sie ist der scheueste Vogel unter allen in Grönland, so dass es ohne ganz besondere Vorsicht unmöglich ist, sich ihr auf Schussweite zu nähern. Meine Schützen pflegten in mondhellen Abenden sich in der Nähe der Orte verborgen aufzustellen, wo der Vogel zu tauchen pflegt, und erhielten auf diese Art zuweilen einige. Im Frühjahre erscheint sie paarweise; sie fliegt dann sehr hoch, und es ist noch schwieriger, bei ihr zum Schuss zu kommen. Ich selbst habe sie oft gesehen, aber mich ihr nie so nähern kŏnnen, um sie zu schiessen. Der einzige bekannte Brütplatz ist im Grunde eines der tiefsten Arme des Godthaaber Busens, auf einer Felsen-Insel, mitten in einem nicht unbedeutenden Wasserfall, welcher die Insel unzugänglich macht. In der Nähe dieses Ortes erhielt ich ein ziemlich erwachsenes Junges in der ersten Hälfte des August. Nach der Aussage der Grönländer trifft man Cl. Barrowii nie in den Buchten nördlich oder südlich von dem BaalsRevier (dem Godthaaber Fjorde) an, so dass ihr Aufenthalts-Ort sich hier auf die Strecke zwischen $63^{\circ} 45^{\prime}$ und $64^{\circ} 30^{\prime}$ N. B. einschränkt.

Da ich den Vogel nie im Sommer erhalten konnte, kann ich nichts Bestimmteres über die Sommer-Mauserung angeben, als dass das Männchen seine Farben nicht vor der Brützeit ändert, und dass die langen Federn am Kopfe kürzer zu sein scheinen, als im Winter, welches ich durch den Tubus bemerkt zu haben glaube.

Anm. Clangula vulgaris habe ich nie in Grönland angetroffen, wo sie nach meiner Meinung nicht vorkommt.

\section{S m a t e r i a.}

Die 2 Arten dieses Genus, S. mollissima und spectabilis, machen nicht allein an den 3 Colonieen, wo die Dunen ein wichtiger Handels-Artikel sind, den hauptsächlichsten Reichthum der Grönländer aus, sondern es besteht auch bei mehreren Colonieen in den Monaten.Februar und März die einzige Nahrung derselben in dem Fleische dieser Vögel. Ausserdem tödten die Grönländer den Eidervogel zu jeder Jahreszeit und unter allen Verhältnis-

geben, theilt mir mit, dass C. Barrowii anch zwischen Nenortalik und Sydpröven nistet, wo ihre Lebensweise gleich wie im Godthaaber Busen sich verhält. 
sen, so dass es wirklich unbegreiflich ist, dass die Menge dieser Vögel nicht bedeutend abgenommen; wenigstens glaube ich nicht, dass, trotz solcher. Misshandlung, diess der Fall ist, so lange Europäer in Grönland gewohnt haben. Der Handel mit den Dunen hat bis vor wenigen Jahren durchaus nicht abgenommen. Die grŏsste Quantität unreiner Dunen, welche von Südgrŏnland in einem Jahre abgesandt wurde, betrug 5807 Pfund. Nord-Grönland sandte wohl halb so viel zurück. Man rechnet die Dunen von 12 Nestern auf ein Pfund, also wurden 104,520 Vögel in dem genannten Jahre ihrer Dunen beraubt, und zugleich, wenigstens dem grössten Theile nach, auch ihrer Eier; denn äusserst selten lässt ein Grönländer diese liegen, wenn sie auch schon halb ausgebrütet wären.

Dass der Eidervogel in solcher Menge gefangen wird, und zwar zu jeder Jahreszeit, hat mich in den Stand gesetzt, seiner Mauserungs-Geschichte sehr' genau zu folgen, und ich erlaube mir darüber Folgendes festzustellen:

Erst wenn der Vogel das zur Fortpflanzung fähig machende Gefieder bekommen hat, wozu für beide Geschlechter gleich lange Zeit, nemlich 2 volle Jahre gehören, erst dann tritt die doppelte Mauser für beide ein, aber zu sehr verschiedener Zeit, indem das Weibchen schon im April in voller Mauserung ist, und dieselbe vor dem Eierlegen beendet hat, während das Männchen erst zu mausern beginnt, wenn es das Weibchen verlassen hat, welches nicht eher, als bis die Eier ausgebrütet sind, statt findet.

Die Sommer-Mauserung des Weibchens beschränkt sich auf die Federn am Kopf, Hals und einem Theil des Rückens, welche Theile eine hellere Farbe, die bei recht alten Vögeln vollkommen hellgrau (Mausegrau) ist, erhalten, bei jüngern Vŏgeln aber mehr in's Hellbraune fältt. Wie es die ältern Vögel sind, welche durch diese Mauser die hellern Farben erhalten, so sind es auch diese, bei denen die Mauser zuerst beginnt; doch ist sie bei allen vor dem Eierlegen, also vor dem 12. Juni beendet. Im angeführ ten Kleide sieht man die Weibchen gewöhnlich bis in den August, wo die totale Wintermauser eintritt, durch welche der Vogel seine gewöhnliche Wintertracht erhält. Einzelne Weibchen mausern indessen viel früher, wovon später.

Die Sommer-Mauser des Männchens findet dagegen erst statt, nachdem dasselbe das Weibchen verlassen, welches geschieht, wenn die Eier ausgebrütet sind; denn, wie bekannt, begleitet das 
Männchen nicht die Jungen, obschon es das brütende Weibchen nicht verlässt. Durch diese Mauser wird das Männchen nicht dem Weibchen gleich, sondern der Theil der Federn, welcher der Veränderung unterworfen ist, erhält eine Farbe, welche der des jungen Männchens gleicht, und einfarbig blaugrau*) ist. Durch diese Mauser, welche total ist und in erstaunenswerther Kürze zu Stande kommt, verändern die Flügel ihre Deckfedern und der Schwanz nicht die Farbe, während der ganze Vogel im Uebrigen mit den erwähnten blaugrauen Federn bedeckt wird; ein Gefieder, welches dem Vogel oft ein wunderlich fremdartiges Aussehn giebt, indem man z. B. bei S. spectabilis den hübschen hellfarbigen Schnabel mit dem grossen apfelsinengelben Auswuchs sieht, und die zierlich gekrümmten Flügeldeckfedern, welche das alte Männchen charakterisiren, und das andere sonst helle Gefieder ganz jene blaugraue Farbe angenommen hat; doch sind die Federn am Kopf und der Kehle dunkler. In der Regel kŏnnen die Männchen während dieser Mauser-Zeit fliegen.

Aber es sind nur wenige Tage, dass man das Männchen mit diesem Gefieder, vollständig ausgebildet und ohne Beimischung von ausfallenden, oder nachwachsenden Federn der Wintertracht antrifft, und im Anfange des October sind fast alle Mànnchen in vollständiger Wintertracht.

Aber eben so wenig als die Weibchen beginnen alle Männchen ihre Winter-Mauser zur angeführten Zeit.

Faber hat im „Leben d. hochnordischen Vögel" S. 101-105 geäussert, dass man während der Zeit, in welcher die Vŏgel regelmässig beim Neste sein sollten, oft alte Vögel weit von den Brütplätzen entfernt antrifft. Dies ist auch der Fall bei den $S_{0-}$ materia-Arten; aber wenn ich meinen Beobachtungen trauen darf, kommt dies Phänomen hauptsächlich daher, dass diese Vögel nach der Paarung oder vielleicht nach dem Eierlegen ihren Gatten verloren. Diese Individuen paaren sich in demselben Jahre schwerlich auf's neue: sondern begeben sich gleich rom Nestplatze an die Orte, wo sie sich ausser der Brütezeit aufzuhalten pflegen.

Meine Gründe für diese Behauptung bestehen darin, dass diese Schaaren alter Voggel, in welchen jedes Geschlecht sich vom andern getrennt hält, und welche die Grönländer nach ihrer in der Regel

*) Sollte wohl heissen ,braungrau ?"، Wie überhaupt an melirern Stellen das ,blaa" des Originals die Bedeutung von ,braun" zu haben scheint.

Anmerkung des Uebersetzers. 
sehr bezeichnenden Art "Schaaren von Wittwen und Wittwern" nennen, stets grŏsser werden. Man sieht also zu Anfang der Brüt-Periode nur wenige dieser ungepaarten Vögel, aber im Verlaufe der Zeit nehmen sie allmählig zu, sowohl mit Rücksicht auf die Zahl der Haufen, als der Individuen; doch will man beobachtet haben, dass es besonders die Haufen der Männchen sind, welche im Juni und Juli (nie späler) zunehmen; und auch giebt es stets mehr sogenannte ungepaarte Männchen als Weibchen. Viel allmähliger vergrössern sich die Haufen der Weibchen, und diese Zunahme dauert auch viel länger, als bei den männlichen Haufen, sehr erklärlich, dưrch Vögel, welche ihre Jungen verloren, und nach diesem Verluste sich in die Gesellschaft der Ungepaarten begaben.

Sollte diese Auseinandersetzung über das Vorkommen jener ungepaarten Vögel sich nicht bestätigen, obschon sie mir so viel Wahrscheinlichkeit, als diese Dinge nur haben können, für sich zu haben scheint, so ist es zum wenigsten gewiss, dass diese Schaaren einen grossen Theil des Sommers hindurch im Zunehmen sind, und dass die Vögel, sobald sie zu diesen Haufen hinzukommen, die ersterwähnte Mauserung beginnen, und man oft alle Nüancen dieser doppelten Mauserung in einem Haufen findet. Daher lässt es sich auch erklären, dass man zu jeder Jahreszeit Männchen im vollständigen Winterkleide antrifft; denn die Mauser findet bei den ungepaarten Vögeln mit derselben überraschenden Schnelligkeit statt, als bei den Vögeln, welche zur gewőhnlichen Zeit die Mauserung beginnen, und manche Vŏgel haben auf diese Weise ihren Feder-Wechsel beendet, ehe derselbe bei den brütenden Vögeln beginnt.

In einer andern Hinsicht ist die Sommer-Mauser bei Somateria verschieden von der, welcher das Sub-Genus Anas und zum Theil Clangula unterworfen ist, indem bei diesen die Vögel wäh rend der Mauser nicht fliegen können, während Somateria*) nie seine Flugfähigkeit verliert.

Die jungen Vögel haben nicht diese doppelte Mauserung, aber

*) Ein altes Männchen der Somateria spectabilis erhielt ich vor reichlich einem Jahre aus Upernevik, in voller Sommer - Mauser begriffen. Bei diesem waren alle Schwungfedern ausgefallen und im Begriff, durch die nachwachsenden ersetzt zu werden, so dass es gewiss nicht fliegen konnte; es war angeblich im August erlegt und befindet sich gegenwärtig im Besitz des Prof. Naumann zu Ziebigk bei Köthen.

Anm. des Uebers. 
die jungen Männchen mausern fast ununterbrochen den ganzen Winter hindurch, so dass es äusserst schwierig ist, zwei junge Mănnchen von vollkommen gleicher Zeichnung zu bekommen; und dieser Umstand in Verbindung mit der, bis vor wenigen Jahren gänzlich unbeachteten, Sommermauser haben wahrscheinlich die Ornithologen zu der Annahme veranlasst, dass der Eidervogel viel längere Zeit bedürfe, um zur Fortpflanzung fähig zu werden, als dies wirklich der Fall ist.

Im Sommer bleichen die Federn der jungen Vögel $a b$, und zwar nicht durch eine partielle Mauser, wie bei Emberiza, sondern durch Einwirkung der Sonne und Luft. Sie erhalten dadurch ein helleres oder abgebleichtes Aussehen.

Durch die Untersuchung der Häute bei einer grossen Anzahl Individuen habe ich die Gewissheit erlangt, dass dies nicht durch Mauserung geschehe, und diese Ueberzeugung wird dadurch bestätigt, dass auch die Federn im. Schwanze und den Flügeln auf diese Art abbleichen.

Um nicht später wieder von den jungen Vögeln reden zu müssen, bemerke ich hier, dass sie im Sommer sich in den Fjorden und zwischen den Inseln aufhalten, wo das Wasser nicht zu tief, höchstens 6-8 Faden ist, und hier ausserordentlich fett werden. Obschon man in Südgrönland am meisten Somateria mollissima findet, findet man doch auch in denselben Haufen Somateria spectabilis.

Indem ich eine grosse Anzahl junger Vŏgel beider Arten verglichen habe, bin ich zu völliger Gewissheit gelangt, dass sie beide 2 volle Jahre bedürfen, um völlig ausgewachsen zu werden, so dass die Jungen, welche im Jahre 1840 aus den Eiern krochen, im Herbste 1842 ausgewachsen sind und im October vollständige Wintertracht erhalten haben*). Diese Zeit ist für beide Geschlechter gleich. Die Weibchen sind im ersten Jahre ganz grau, ohne das weisse Band im Flügel zu haben, und erhalten im zweiten Jahre fast dieselbe Färbung als die alten Vögel, sind aber stets von diesen durch den Mangel des weissen Bandes im Flügel unterschieden.

Noch ein Phänomen habe ich in Betreff der Weibchen beider Arten anzuführen: nämlich, dass sie zuweilen eine Tracht erhal-

*) Doch will ich gerne einräumen, dass diese allgemeine Regel einige Ausnahmen, durch verspätete Mauser veranlasst, erleidet. 
ten, weiche der des jungen Männchens im 2ten Jahre in so fern gleicht, dass sie mit einem breiten isabellfarbigen Bande am Kropfe geziert sind und zuweilen auch die Zeichnung des alten Männchens am Kopfe zu erhalten beginnen, während der Vogel im übrigen die braune Farbe des alten Weibchens mit weissen Bändern auf den Flügeln behält. Alle die Individuen, welche ich in dieser Tracht gesehen habe, waren bestimmt sehr alte Vögel, und bei einigen fand ich Verhärtungen im Eierstock, welches erwies, dass dieselben zur Fortpflanzung unfähig waren. Ich habe Vögel in dieser Zeichnung dem Königl. Museum zugestellt.

Die Somateria-Arten halten sich in der Regel längs der Küste auf, woran die. Nahrung sie bindet, doch sieht man dieselben nicht ganz selten weit in der Davisstrasse hinaus. Wahrscheinlich wird man dort, wo sich diese Vögel gewöhnlich aufhalten, reiche Fischbänke vorfinden, da diese auch stets von Mollusken bewohnt sind, welche die vorzüglichste Nahrung der Somaterien ausmachen.

\section{S. M O L L I S S I M A}

ist gemein an der ganzen Küste Grönlands und brütet schon in einzelnen Paaren ganz im Süden, jedoch in ziemlicher Menge erst zwischen dem $63^{\circ}$ und $64^{\circ}$. Zwischen dem $65^{1 / 2^{\circ}}$ und $69^{\circ} \mathrm{N}$. B. nimmt die Anzahl der brütenden Vögel noch mehr zu, und es ist in einem Theil dieser Gewässer, die ich unter Sterna arctica genannt habe, wo dieser Vogel (St. arctica) sich nicht findet, obgleich südlich und nördlich von denselben Sterna arctica und $S$. mollissima in gutem Vernehmen mit einander auf denselben Inseln brüten.

Vom $69^{\circ}$ bis $71^{\circ}$ sind fast keine Inseln und hier ist der Eidervogel wieder selten, aber im Uperneviker Distrikt zwischen $72^{\circ}$ und $73^{\circ} \mathrm{N}$. B. ist er wieder sehr häufig, und seine Brütplätze erstrecken sich so weit nördlich, als ich das Land kenne. Der Eidervogel beschränkt seine Brütplätze nicht auf die vor den Küsten liegenden Inseln, sondern findet sich auch brütend weit in den Buchten hinein, wenn diese nur flache Eilande haben; dagegen brütet er nie in Grönlands grossen Bergseen.

Ich habe schon früher darauf aufmerksam gemacht, däss man zuweilen Weibchen antrifft, welche Junge anführen, die zu verschiedenen Zeiten ausgebrütet sein müssen.

Ich zweifle keineswegs, dass $S$. mollissima zuweilen sich 
sich mit $S$. spectabilis fruchtbar verpaart; denn man findet nicht allein öfters Weibchen, deren Schnabel Aehnlichkeit mit beiden Arten hat, sondern ich habe zuweilen auch Männchen von $S$. mollissima erhalten mit der schwarzen lanzettförmigen Zeichnung am Halse, welche das Männchen von spectabilis bezeichnet. Dem Museum habe ich ein solches Individuum zugestellt, ein zweites ist zur Zeit in meiner Sammlung.

Ausser dem täglichen Zuge, auf welchem S. mollissima Abends in die Buchten hinein und Morgens aus diesen heraus zieht, hat der Eidervogel auch einen jährlichen Zug, indem derselbe in den Monaten September und October südlich zieht, und im April und bis Ende Mai wieder zurückkehrt.

Die Bedeutung des täglichen Zuges habe ich nicht ergründen kŏnnen. Weder am Morgen noch am Abende hat der Vogel besonders viel im Kropfe, und was sich vorfindet sind Mollusken, welche sich gemeinschaftlich in den Buchten und dem Meere aussen vor diesen aufhalten. Auffallend erscheint es dagegen, dass die Möven des Morgens hinein- und Abends herausziehen, den Eidervögeln gerade entgegengesetzt.

Auf dem jährlichen Zuge nach Süden fliegt der Vogel nicht in grossen Haufen, sammelt sich aber an gewissen Stellen in ungeheurer Menge. An diesen Stellen giebt es überflüssige Nahrung und der-Vogel bedeckt dann oft das Meer im buchstäblichsten Sinne des Wortes. Ich übertreibe gewiss nicht, wenn ich behaupte, dass diese Schaaren oft aus mehreren Hunderttausenden bestehen. Diese Lieblings - Plätze sind hier im Godthaaber Distrikt solche, welche früh sich mit Eis belegen, und nur einige Faden Wasser über Lehm- oder Sandboden haben.

Auf dem Zuge nach Norden fliegen sie oft in ungeheuren Schaaren, und es ereignet sich dann zuweilen, dass man seine Flinte mehrmals abschiessen und laden kann, ehe die Schaar vorbeipassirt ist, so z. B. in dem sogenannten Sunde, einer schmalen Meerenge nördlich vom Godthaaber Fjord. Bei Fiskenaesset schoss der Kaufmann Heilmann einst 21 Eidervōgel aus einer solchen Schaar auf einen Schuss, ich selbst 13 Stück.

Die Tauchfähigkeit desselben ist sehr ausgebildet, aber bei weitem nicht in dem Grade als bei der $S$. spectabilis, und ich glaube nicht, dass derselbe seine Nahrung in grösserer Tiefe als 25 Faden sucht. Die längste Zeit, welche ich ihn habe untertau- 
chen sehen, war 6 Minuten *), doch ist dies selten. Seine Nahrung besteht gewöhnlich aus Tellina-, Modiola-, Margarita-, Buccinum- und Defrancia-Arten. Ausserdem finden sich Krabben und Echini, seltner Amphipoden und nie Fisch-Ueberreste in seinem Oesophagus, aber wohl Fisch-Rogen **).

\section{S. S P E C T A B I L I S.}

Es ist auffallend, dass diese schöne Ente so selten in Island ist, während sie hier in Grönland sich über das ganze Land verbreitet, obgleich ihre eigentliche Brützone nördlicher liegt, als das Land von Europäern bewohnt wird. Im Winter ist sie sehr gemein, gleich vom Cap Farvel an bis Holsteinborg. Sie kommt nistend, obgleich sehr selten, vom 67sten Breitengrade an vor, aber in einiger Menge brütet sie erst unter dem $73^{\circ} \mathrm{N}$. B. Ihre Eier sind schmaler, aber von derselben Farbe und Länge als die der Somateria mollissima.

An einigen Männchen endigt sich das schöne Blaugrau des Kopfes mit einem sehr dunkeln Rande am Halse.

Den kammartigen Auswuchs am Schnabel findet man entwickelt das ganze Jahr hindurch, derselbe verliert jedoch an Umfang, wenn der Vogel mager ist, und nimmt zu, wenn er fett wird. Da alle Seevögel gegen die Brützeit zu fett sind, ist folglich dieser Kamm beim Männchen der $S$. spectabilis auch zu jener Zeit sehr entwickelt; dass aber ein andres Verhältniss zwischen diesem Schmucke und der Brützeit sei, glaube ich nicht. Einer der grössten Kämme, welchen ich ausgemessen, betrug $1^{\prime \prime} 8^{\prime \prime \prime}$ in der Höhe über dem Schnabel, die grösste Breite war $1^{\prime \prime} 2^{\prime \prime \prime}$,

*) Diese Zeit, stimmt vollkommen mit Faber's Beobachtungen in Island überein, doch bedaure ich, dass die Tiefe der Tauchstelle nicht zugleich angeführt ist. Wo ich die Zeit angeführt habe, wäbrend welcher ich beobachtete, dass der Vogel unter Wasser war, ohne an die Oberfläche, um zu athmen, zu kommen, ist dies stets die höchste, welche ich überhaupt bemerkte. S. mollissima ist gewöhnlich nur 2-3 Minuten, S. spectabilis 4, 5 bis 6 Minuten unter Wasser. Die längste Zeit, welche ein Haufe Seehunde, umstellt von Netzen, unter Wasser zubrachte, war 141/2 Minute, und bei dem einen der Wallfischfänge, dem ich beiwohnte, war das Thier 271/2 Minute unter Wasser, seitdem es die erste Harpune erhalten.

**) Herr Misșionär Jorgensen hat mir mitgetheilt, dass er bei Frederikshaab zuweilen Coltus bubalis in dem Magen des Eidervogels fand. 
am Schnabel war die Breite 9"'. Die Farbe desselben ist schön apfelsinengelb, die der Beine und des Tarsus schmutzig orangegelb.

In der Lebensweise gleicht dieselbe sehr der $S$. mollissima und hat so auch denselben $\mathrm{Zug}$ als diese, fängt aber später im Herbste nach Süden zu ziehen an; ebenso beginnt ihr jährlicher Frühjahrszug später, obgleich sie eine weitere Strecke nach Norden zu fliegen hat, vielleicht weil das Meer, so weit nördlich als sie brütet, früher nicht offen ist.

Man sieht sie nie in so grossen Haufen fliegen, als $S$. mollissima, aber sie liegt nicht selten in eben so grossen Haufen auf der See, jedoch nicht auf denselben Tauchplätzen, weil sie tieferes Wasser aufsucht. Sie zieht weiter seewärts hinaus, wesshalb sie, und weil sie in kleineren Haufen fliegt, weniger oft geschossen wird. Dagegen wird sie von den Grönländern im Kajak in viel grösserer Menge gefangen; denn da sie längere Zeit unter Wasser bleibt, können sich jene leichter der Stelle nähern, wo sie wieder auftauchen wollen. Es ist erstaunlich, welche Menge von diesen Vögeln jährlich in Südgrönland gefangen wird.

Im Herbste werden die jungen Vögel nicht selten ein Opfer ihrer Unlust, weiter nach Süden zu ziehen, indem sie dadurch umkommen, weil das Meer sich überall mit Eis belegt. Ende Juli sieht man bei Godhavn ungepaarte Vögel; sie sind dann in voller Mauser. Hier im Süden ist es schwierig, das Männchen in der Mauserzeit zu erhalten.

Wunderbar ist der Instinkt, welcher den Vogel in den Stand setzt, die Plätze, wo er seine Nahrung suchen kann, aufzufinden. Auf diesen ist stets tiefes Wasser, wo man die alten Vögel selten auf weniger als 30 Faden Tiefe ihrer Nahrung nachgehen sieht. Solche Bänke liegen nur ausnahmsweise in der Nähe des Landes und sind ofters ziemlich schmal. Der Vogel muss dann, wo der Strom stark geht, wie in dem Godthaaber Fjorde, auf einer ganz andern Stelle untertauchen, wenn das Wasser bei der Ebbe fällt, als wenn es steigt, welches ich von den Fenstern meiner Wohnung jetzt gut bemerken kann, da ich genau die Lage und Ausdehnung der Bänke kenne. In der Fähigkeit, auf den Grund unterzutauchen, übertrifft $S$. spectabilis bei weitem alle anderen Vögel Grönlands, und bleibt auch am längsten unter Wasser. Sie taucht auf so tiefem Wasser, als ich nur hier in der Nähe Conchylien gefunden habe, nämlich bis 65 Faden oder 200 Ellen Tiefe. Um so tief zu tauchen, seine 
Nahrung aufzusuchen und wieder an die Oberfläche des Wassers zu gelangen, braucht der Vogel allerhöchst 9 Minuten (denn längere Zeit habe ich sein Verweilen unter Wasser nie beobachtet); aber gewöhnlich bleibt er bei gleicher Tiefe nur 4, 5, 6 Minuten unten. Doch ist zu bemerken, dass nur die alten Vögel diese Tiefe suchen, die Jungen dagegen auf kaum grŏssere Tiefe als 90 Ellen zu tauchen pflegen.

Um unter dem Wasser sich vorwärts zu bewegen, braucht der Vogel seine Flügel, und die wenigen Male, dass ich $S$. spectabilis seiner Nahrung nachgehen sah, führte er dies schwebend, nicht gehend aus.

In der erwähnten grösseren Tiefe finden' sich gerade keine andren Conchylien, als unter niedrigem Wasserstande, nämlich besonders Trophon craticulatum, Turritella polaris, Pecten islandicus, Mitra groenlandica und einige kleine unbestimmte Arten. Dagegen finden sich auf dieser Tiefe eine Menge Ascidien, von denen ich aber keine im Magen der S. spectabilis gefunden habe*). Ich begreife desshalb nicht, wesshalb der Vogel diese grosse Tiefe aufsucht, um so mehr, da es augenfällig ihn sehr anstrengt. Im Magen findet man ausserdem Krabben, Actinien, Ophiuren und bei jungen Vögeln Echinen und Amphipoden, nie Fischüberreste, wohl aber öfter Rogen.

\section{S. P ER S P I G I L L A T A}

zeigt sich zuweilen an der grönländischen Küste, doch habe ich nur 1 Exemplar, nemlich von dem Godthaaber Fjorde erhalten. Capt. Graah sah den Vogel an der 0stküste. Im Schlunde hatte mein Exemplar dieselben Conchylien, welche sich gewŏhnlich bei $S$. mollissima finden.

*) S. spectabilis ist der beste Wegzeiger, den man sich wünschen kann, wenn man Mollusken in tiefem Wasser suchen will; nur Schade, dass man diesen Wegzeiger nur im Winter hat, wo man keine Reisen längs der Küste machen kann, und es ausserdem keine angenehme Arbeit ist, mit dem Schleppnetz zu fischen bei $12-16^{\circ}$ Kälte. Im Sommer muss das Auge die Lage, das. Senkblei das Specielle an den Bänken angeben. Eine kleine Art Ascidia, welche eingehüllt ist durch eine Sandkruste, circa $1 / 2$ " lang, und sich auf 15 Faden Tiefe im Sandboden vorfindet, habe ich zuweilen im Kropfe der $S$. mollissima angetroffen. 
 \\ Mergus serrator}

brütet sowohl in Süd-als Nord-Grönland, und ist, ohne eigentlich irgendwo selten zu sein, nirgends häufig. Seine hauptsächlichste Nahrung besteht nach meinen Beobachtungen in verschiedenen Arten Fischen, besonders Blennius, ausserdem Amphipoden.

\section{Carbo cormoranus}

ist die einzige Scharbe, welche wir in Grŏnland besitzen. Ihr südlichster Brütplatz ist in dem Godthaaber Fjorde, wo nur einzelne Paare brüten; sie nistet übrigens so weit nach Norden, als ich gewesen bin. Ihre Nestplätze sind auf Felsenabsätzen, welche lothrecht gegen das Meer zu stehen, gewöhnlich ziemlich hoch oben, nur selten so weit unten, dass man den Vogel schiessen kann. In Nord - Grönland nistet sie an vielen Orten; an einigen in grosser Menge zusammen. Ihre Eier sind kaum grösser als die der Uria grylle und von unebner Oberfläche. Im Winter ist sie häufig in Südgrönland und hat ihre eignen Schlafstellen dort, welche von den Excrementen weiss gefärbt sind.

\section{S $\mathbf{1} \mathbf{a}$ a 1 ba.}

Ich habe sie einzeln in der Davisstrasse gesehen, und einmal ist eine todt bei Godthaab angetrieben. Ein Exemplar erhielt das Museum von Egedesminde. Doch habe ich sie weder selbst hier gesehen, noch einige Auskunft über ihr Vorkommen in Nordgrönland erhalten können. 1842 erhielt ich ein Exemplar von Julianehaab.

\section{1 y m b u s.}

Obgleich ich mir viel Mühe gegeben habe, die MauserungsGeschichte dieses Genus zu studieren, hat es mir docb nicht glücken 
wollen, einige Resultate zu erlangen; vielleicht weil die Arten desselben zu früh die Küsten verlassen, und im vollständigen Sommerkleide zurückkehren.

\section{C O L Y M B U S G L A C I A L IS}

ist viel häufiger im Süden des Landes als in Nordgrönland, wo der Vogel sehr selten vorkommt. Vielleicht ist der Umstand, dass die Bergseen, deren einziger befiederter Bewohner dieser Vogel ist, oft sehr spät aufthauen, die Ursache dieser Erscheinung; auch sind wohl die Bergseen im Süden fischreicher, als die in Nordgrönland. In der Mitte des Mai kommt er zu Godthaab an, und gegen Ende des October verlässt er Grönlands Küste. Ich habe beobachtet, dass er 8 Minuten unter Wasser war.

\section{COL Y M US SEPTENTRIONALIS}

ist allgemein im ganzen Lande, und findet sich sowohl in den kleineren Bergseen, als in den Seen auf den Inseln und in den Thälern, aber selten weit vom Meere ab, welches er öfter besucht, als $C$. glacialis. Er kommt im Anfange des Mai an und Anfangs November sieht man noch einzelne Individuen in den Buchten umherschwimmen.

\section{U $\mathbf{i} \mathbf{a}$.}

Grönland besitzı alle die Arten dieses Genus, welche in Island vorkommen, aber bei weitem überwiegend der Zahl nach ist $U$. Brynnichii. Die grosse Anzahl Vögel der verschiedenen Arten dieses Genus, welche ich untersucht habe, haben mir die völlige Gewissheit verschafft, dass die Nahrung derselben sich auf Fische und Crustaceen beschränkt; noch nie habe ich in ihrem Magen eine Conchylie, weder Univalve noch Bivalve gefunden.

Die Vŏgel dieses Genus sind allerdings gute Taucher, aber keinesweges kann ich mit Faber (l. c. S. 259 u. 263) annehmen, dass Lria troile und Grylle da bis auf den Grund țauchen können, wo das Wasser 50 Faden Tiefe hält. Da Faber durch seine genauen Untersuchungen sich ein grosses Vertrauen erworben, darf ich, ohne meine Gründe anzuführen, dieser Meinung nicht widersprechen. 
Ich meine, es sei sehr schwer zu bestimmen, wie tief ein Vogel tauche, wenn man nicht genau angeben kann, in welcher Tiefe er seine Nahrung findet. Dies kann man aber unmöglich wissen, wenn es sich um Fische oder Crustaceen handelt. Faber hat desshalb auch seinen Beweis, dass diese Vögel so tief tauchen sollten, daraus hergenommen, dass man sie zuweilen in dem Magen des Scymnus borealis findet, welcher sich selten in geringerer Tiefe als 50 Faden aufhält; aber es ist hinreichend bekannt, dass der Polarhai auch bis an die Oberfläche des Wassers kommt, um seine Nahrung aufzusuchen, welches man z. B. sieht, wenn ein Wallfisch gefangen ist, und unter dem Wasser stirbt. Sobald derselbe sich an die Oberfläche des Wassers hebt, wird man ihn bald von Haien umringt finden; auch werden diese zuweilen in Seehundsnetzen bei 3-4 Faden Tiefe gefangen. Desshalb kann auch die Tiefe, in welcher derselbe gewöhnlich sich findet, durchaus keinen Maasstab für die Tauchfähigkeit der Vögel, welche sich in seinem Magen vorfinden mögen, abgeben. Ich kann mittlerweile nur die Aufklärung über die Tauchfähigkeit des Genus Uria geben, dass Uria Brynnichii nie über 3 und Uria Grylle nicht über 2 Minuten unter Wasser geblieben ist, wenn ich sie beobachtet habe.

\section{U R I A G Y L L E.}

Sie ist gemein sowohl in Süd- als Nord-Grōnland, wo sie der letzte Vogel ist, welcher sich durch die Eisdecke zwingen lässt, südwärts zu ziehen.

Zwar ist sie ein geselliger Vogel, findet sich jedoch selten in grosser Anzahl zusammen. Zuweilen ereignet es sich indessen, dass sie sich im Winter, wenn die Fjorde, welche ihren Lieblings-Aufenthalt bilden (z. B. Fiskenaesset-Fjord) sich mit Eis belegen, in ungemein grosser Anzahl in den Oeffnungen zusammenfindet, welche der Strom einschneidet, wo man zuweilen Abends im Mondschein über 40 Stück mit einem Schusse tödten kann.

Man findet sie stets in der Nähe des Landes, und sie unterscheidet sich in dieser Hinsicht von den andern Arten des Genus Uria, welche wahre Oceanvögel sind, und sich überall im atlantischen Meere vorfinden.

Sind Faber's Beobachtungen richtig, betreffend die lange Zeit, welche Uria Grylle in Island (Prodromus S. 40) bedarf, um zeu- 
gungsfähig zu werden, so ist die isländische Art von der grönländischen verschieden, da letztere dazu nicht mehr als 2 Jahre bedarf.

Uria Grylle variirt besonders häuîg sowohl in der Grōsse als im Bau des Schnabels, aber diese Verschiedenheiten laufen so in einander, dass ich für meine Person überzeugt bin, dass es nur eine Art in Grönland giebt. Ich habe sowohl eine ganz weisse Varietät gesehen, als eine, die völlig schwarz aussah, indem der weisse Spiegel fehlte.

\section{URI A T R O I L E.}

Sie ist selten, und hat so grosse Aehnlichkeit mit Uria Brünnichii, dass sie erst von mir hier bemerkt worden ist.

Da ich ein Mal Uria troile in vollständigem Sommerkleide mit fast nacktem Brutflecke erhalten habe, nehme ich an, dass sie zwischen $U$. Brünnichii brüte. Ich erhielt dieselbe zwar nur bei Godthaab, glaube aber den Grund davon darin zu finden, dass man dieselbe bei den andern Colonieen nicht genau beobachtet oder unbeachtet gelassen habe. Ich sandte 2 Individuen an's Kŏnigl. Museum ein.

\section{URIA LEUGOPHTHALMUS. (Faber, lacrymans Auct.)}

Ich habe nur $2 \mathrm{Mal}$ diese Uria erhalten, welche in Grönland sehr selten sein muss.

\section{UR I A BR UEN N I CH I I}

ist zweifelsohne die zahlreichste unter allen Vögeln Grönlands; denn man trifft sie fast überall in der Davisstrasse, zu jeder Jahreszeit, selbst in der Brützeit, in grossen Schaaren weit von den Brūtplätzen an. und ich glaube desshalb, sie brüte nicht im ersten Lebens - Jahre.

Ihr südlichster Brütplatz ist $2 \frac{1}{2}$ Meile im Westen vom Godthaaber Fjord, wo vielleicht ein hundert Paar brüten. Obgleich man mehrere Berge im Distrikt des Sukkertopps und in Nordgrönland mit diesen Vögeln besetzt findet, ist doch Kassarsoak, eine Meile im Süden von Upernevik, der Platz, wo die meisten im Vereine brüten. Dieser Fels, gewiss $3 / 4$ Meilen lang und einer der höchsten in Grönland, ist besetzt mit Nestern, so weit man sehen kann, so dass die obersten Vögel wie Fliegen ausse- 
hen, wenn sie aus - und einfliegen. Ich kann wahrlich nur ein schwaches Bild von der Menge dieser Vögel geben. Die beste Vorstellung kann man sich vielleicht machen, wenn man sich den Felsen, so lange die Vögel nicht beunruhigt werden, als einen Bienenstock vorstellt, wenn die Bienen schwärmen. Fällt da ein Schuss, wodurch doch nur ein sehr kleiner Theil der Vögel anf. geschreckt wird, so wird im eigentlichsten Sinne des Wortes die Sonne von ihnen verdunkelt, und die Zuschauer förmlich bedeckt von den Excrementen der Vögel. In kürzerer Zeit als einer Stunde habe ich selbst von diesen Lummen eine ganze Ladung für eine gewöhnliche Schiffsschaluppe geschossen, und mit einem Schuss wurden 22 Stück niedergestreckt; so sah ich auch, dass eine einzige Büchsenkugel 12 Stück tödtete.

Sie kommen bei diesem Felsen an, bevor das Eis aufgebrochen ist, und bringen dort die kurze Nacht schlafend zu. Dies giebt den Grönländern Gelegenheit, auf eine eigne Art die Vögel zư fangen. Sie begeben sich nämlich so still als möglich, gewöhnlich mehrere zusammen, unter den Berg; dort angekommen erschrecken sie die Vögel, indem sie plötzlich schreien und schiessen; die armen Vŏgel bedenken im Augenblicke nicht, dass unter ihnen das Meer noch mit Eis bedeckt ist, sondern stürzen sich köpflings herab und brechen meistens am Eise das Genick oder werden doch den Grönländern zur leichten Beute, die dann gewöhnlich ihre Schlitten mit den so gefangenen Vögeln beladen können.

Nächst dem Seehunde macht Uria Brünnichii das Hauptnahrungsmittel der Grönländer in mehreren Colonieen in Südgrönland aus, und wenn dieser Vogel sich nicht in Menge einstellte, würde ofter, als jetzt der Fall ist, Hungersnoth unter diesen wenig kultivirten Menschen, denen man bis jetzt noch nicht beigebracht hat, anders als von einem Tage zum andern zu leben, eintreten. Sie werden zuweilen in solcher Menge gefangen, dass sie für eine grönländische Familie auf mehrere Tage ausreichen. Hauptsächlich wird er bei kaltem Wetter, wo der Vogel sehr ungern fliegt, dem Grönländer, welcher ihn aus seinem Kajak mit dem Pfeile erlegt, eine leichte Beute.

Die Nahrung derselben besteht sowohl in Fischen (besonders Mallotus arcticus und Gadus agilis) als in Crustaceen, mit denen man oft den Schlund angefüllt findet. In den bei Kassarsoak geschossenen Vögeln fand ich nur diese. 
Obschon man sie das ganze Jahr hindurch an den Küsten Südgrönlands antrifft, so ist es doch besonders im September, von wo an die Anzahl derselben fortwährend zunimmt, bis gegen den Mai, wo sie die Südküste verlassen, um sich an die Vogelberge zu begeben. Wie bereits erwähnt, bleibt indessen eine nicht geringe Anzahl zurück.

Uria Brünnichii variirt nicht selten in der Farbe: man findet einfarbig schwarze, andre von hell aschgrauer und auch blass rothgrauer Farbe. Die schwarze Varietät habe ich im Ganzen 3 Mal erhalten, 2 Exemplare bei Godthaab, eins am Sukkertopp, stets in Winter.

\section{URIA A L L E}

gehört als brütender Vogel ausschliesslich Nordgrönland an, zieht aber nach Süden, wenn der Winter sich einstellt. An den Küsten Südgrönlands findet man dieselbe vom December bis in den April hinein, und in harten Wintern in ungeheurer Menge.

Sowohl unsere eignen Grönlandsfahrer, als die englischen Wallfischfänger haben dem Vogel den Namen „Eisvogel“ beigelegt, weil sein Vorkommen in Menge gewöhnlich die Nähe grosser Eismassen andeutet. Zweimal bin ich vom Eise eingeschlossen gewesen, und beide Mal sah ich zahllose Vögel dieser Art stets in grossen Haufen nach Norden ziehen. Auf den andern Ueberreisen sah ich nur wenige dieser Vögel und nur in kleinen Schaaren. Seine Nahrung besteht ziemlich ausschliesslich aus Amphipoden, doch finden sich zuweilen Ueberreste von Fischen im Magen.

Man findet dieselben Varietäten als bei Uria Brünnichii, mit Ausnahme der ganz schwarzen; die rothgraue ist nicht selten.

\section{Mormon fratercula}

ist nirgends in Grönland häufig und hat seinen südlichsten Brütplatz unter $63^{\circ} 30^{\prime}$. Er brütet stets auf Inseln in der Nähe der offnen See, und ist häufiger, je weiter man nach Norden kommt; doch habe ich ihn nicht bei Upernevik getroffen, und kann aus meinen Bemerkungen nicht ersehen, ob ich die Grönländer dort über sein Vorkommen befragt habe. Ich nehme mit Faber an, dass er sowohl, als Alca torda, schon im ersten Jahre ausgewachsen ist, nicht allein, weil man durchaus keine jungen Vögel an 
den Küsten antrifft, sondern weil man im Atlantischen Meere und der Davisstrasse im Frühjahre nie andre als alte Vögel dieser Art bemerkt. Seine Nahrung besteht nach den Untersuchungen aller Individuen, die ich geöffnet, ausschliesslich aus Fischen, besonders Ammodytes dubius Reinh.

\section{A 1 a.}

\section{A L G A T}

ist weder in Süd- noch Nordgrönland selten. Er ist ein Zugvogel, welcher in Südgrönland Ende April ankommt und die Küste im August verlässt, früher als irgend ein andrer Vogel, zugleich mit seinen Jungen, beide in der Sommertracht. Er ist der einzige mir bekannte Vogel, welcher die Küste vor der Mauser verlässt. Im August sieht man ihn in der Davisstrasse, und er hält sich auf Grönlands grossen und reichen Fischbänken auf. Seine Nester hat er in Gesellschaft mit Larus tridactylus und Uria Grylle. Seine Nahrung besteht während seines Aufenthaltes hier im Lande ausschliesslich aus Fischen und Crustaceen.

\section{A L G A I M P E N N I S}

ist an Grönlands Küsten seit 1815 nicht gefangen worden, wo Kaufmann Heilmann ein Exemplar bei Fiskenaesset erhielt.

Man hat mir erzählt, dass er im Norden des Sukkertopps gesehen worden sein soll; da ich aber 20 Thaler für ein Exemplar geboten habe, ohne eins zu bekommen, zweifle ich an der Richtigkeit der Aussage und fürchte, dass man den Vogel nicht mehr an den Küsten dieses Landes, wo er vor 80 Jahren nicht selten war, antreffen werde. Die Aussagen der Grönländer äber seine früheren Brütplätze sind sehr verwirrt; indem einige ihm Brütplätze im Innern der Fjorde anweisen, behaupten andre, er trage die Eier unter den Flügeln, und wieder andre, er brüte an den alleräusserst gelegenen Inseln, was ich für das wahrscheinlichste halte. 
A n h a n g. 



\section{Aquila ossifraga.}

Da diese Adler-Art, die von den meisten nordischen Naturforschern (so z. B. Nilss on ornith. suec. I. p. 14.) für eine eigne Species gehalten wird, sich selbst in den meisten Schriften bewährter Ornithologen (z. B. S chle gel, krit. Uebersicht der Vögel Europa's S. 28) keine rechte Anerkennung verschaffen kann, so ist es sehr zu bedauern, dass der Verfasser der vorstehenden Schrift nicht die Art-Kennzeichen genau angegeben, und durch vergleichende Ausmessungen an frischen Exemplaren beider Arten die Verschiedenheit dargethan hat; wenn gleich auch so das Urtheil eines so gründlichen Beobachters, der die beste Gelegenheit zu dergleichen Untersuchungen hatte, nicht zu übersehen ist. Ich habe unter den vielen alten und jungen Adlern, die ich von Grönland erhielt, bisher nur einen Balg eines $\boldsymbol{A}$. ossifraga (junges Weibchen, das ich noch liegen habe) erhalten. Dasselbe ist durch ungewŏhnliche Grössen-Verhältnisse, auch des Schnabels und der Fänge, einen sehr langen Schwanz (die mittlere Feder misst $1^{\prime} 2^{1} / 2^{\prime \prime}$, die äusserste $l^{\prime} 1^{\prime \prime}$ pariser Maass) und eine sehr dunkle Färbung (fast schwärzlich) des ganzen Gefieders ausgezeichnet. Es übertrifft an Grösse die alten Weibchen der gewöhnlichen Art, die ich aus Grönland erhielt; allein solche Bestimmungen, von Bälgen hergenommen, haben allerdings keinen so grossen Werth, als vergleichende Ausmessungen frischer Vögel.

Anm. Es verdient vielleicht Erwähnung, dass ich den Uebergang vom Jugendkleide in's ausgefärbte bei einem gefargenen gewöhnlichen Seeadler beobachtet habe. Im vollständigen Jugendkleide wurde derselbe flügellahm geschossen und eingefangen. 
Im dritten Jahre nachher erhielt er bei guter Pflege und Kost und keinesweges geräumigem Bauer den weissen Schwanz und gelben Schnabel zu gleicher Zeit; es war ein Männchen.

\section{Aquila leucocephala.}

Es ist merkwürdig, wie schwierig es ist, die Resiltate einiger falschen Behauptungen und Beobachtungen aus der Wissenschaft wieder auszumerzen. Nach den gründlichen Untersuchungen Schlegel's, theils im Susemihl'schen Kupferwerk, theils in seiner Kritik, durfte es wohl als ausgemacht anzusehen sein, dass A. leucocephala in Europa nicht vorkomme. Hier erfahren wir nun gar bestimmt, dass er nicht einmal in dem Amerika so nahen Grönland angetroffen wird. Boje hat durch seine Bemerkungen in seinem Tagebuche wohl am meisten dazu beigetragen, diesen Vogel als europäisch festzuhalten. Sollte es sich vielleicht mit dem Unterschied zwischen Podiceps cornutus und arcticus auf ähnliche Weise verhalten? Schinz verwirft bereits die Verschiedenheit beider Arten, Naumann (IX. S. 756) kann keine festen Unterscheidungszeichen auffinden, Schlegel scheint die Verschiedenheit zu bezweifeln, indem er den Podiceps arcticus auch cornutus arcticus nennt. Sieht man Boje's Reise S. 308 durch, auf dessen Auctorität hauptsächlich wohl die Art aufgestellt ist, so hat er dieselbe nach einem am 30. August geschossenen Weibchen aufgestellt; und zwar giebt er als Hauptunterscheidungszeichen den gänzlichen Mangel einer Haube an; konnte aber dieser Hochzeitsschmuck nicht schon am 30. August ausgefallen sein? zumal da angegeben wird (l. c. S. 309) dass die Oberbrust hell rostfarben, mit weissen Federstrahlen untermischt, gewesen sei, was wohl das beginnende Herbstkleid andeuten möchte. Das Männchen erhielt Boje nicht, und gleichfalls nicht die bei Brekeide bemerkten, zu dieser Art gezählten Vŏgel. Fernere Untersuchungen mŏgen hier entscheiden; mir hat es nicht glücken wollen an den Bälgen, die ich gesehen, einen dauerhaften Unterschied zu erkennen *).

*) Dass F aber ihn mit $P$. auritus verwechselte, würde doch auch wohl zu bedenken sein?

Anm. des Uebersetzers. 


\section{Aquila naevia.}

Da Schleg.el (l. c. S. 25) zu neuen Untersuchungen über diese Art auffordert, so darf ich den, wenn gleich geringen, Beitrag, welchen ich geben kann, nicht vorenthalten. Der Schreiadler brütet bekanntlich in Schleswig-Holstein; es ist diess die Art, welche Schinz S. 120 Aquila pomarina nennt und Boje in der Isis beschrieben hat. 4 alte Exemplare, welche ich erhielt, gleichen vollständig dem im Susemihl'schen Kupferwerk Taf. 20 abgebildeten alten Vogel; sie waren grösstentheils im Frühjahre geschossen. Ein junges im September 1844 erhaltenes Exemplar aus Holstein gleicht genau dem an selbigem Orte Taf. 21 abgebildeten jungen Schreiadler. Im Mai des Jahres 1845 erhielt ich ein an demselben Neste geschossenes altes, wirklich gepaartes Paar. Das bedeutend grŏssere Weibchen mit grossem Brutfleck gleicht genau dem alten Vogel im erwähnten Werke, das zur selben Zeit am selben Orte geschossene Männchen, mit dem es gepaart gewesen, ist offenbar im Uebergange aus dem Jugendkleide in's Alterskleid und verdient eine nähere Beschreibung.

Von oben gesehen hat es so ziemlich dieselben Farben, als der im Susemihl'schen Werke abgebildete Vogel; Kopf, Oberrücken, Schulterfedern, Flügel wie beim alten Vogel, allein im Nacken findet sich noch der hellsemmelfarbige Fleck (an derselben Stelle als bei der alten männlichen Kornweihe) und die hintern Schwung- und Flügeldeckfedern sind noch sparsam mit tropfenförmigen semmelfarbigen Flecken versehen, zum Theil diese Flecken verschlissen. Die obern Deckfedern des Schwanzes fast einfarbig semmelgelb, diese Farbe und Flecken sich auf den Unterrücken hinauf erstreckend, und mit Braun gemischt bunt aussehend. Die Untertheile vom Halse an nach Brust und Bauch zunehmend mit tropfenartigen Flecken ähnlicher semmelgelber Farbe, die Unterschwanzdeckfedern einfarbig, etwas heller. Die Befiederung der Beine bunt: braun und semmelgelb. Die Hosen einfarbig gelblich. Schwanz einfarbig dunkel-schwarzbraun mit schwachem, von oben kaum bemerkbarem Saum. Es möchte sich wohl aus diesem ergeben, dass das Gefleckt- und Ungeflecktsein der Schreiadler keine Art-Verschiedenheit bedingt, sondern nur Alters-Verschiedenheit ist. Auch geht hieraus offenbar hervor, dass der Schreiadler zeugungsfähig wird, ehe er das Alterskleid ganz 
vollständig angelegt hat. Dazu bemerke ich noch, dass ein zuverlässiger, mit der heimischen Ornithologie vertrauter, Forstbeamter mir bestimmt versichert hat, dass er aus dem Neste ungefleckter Schreiadler ein geflecktes Junges selbst genommen und längere Zeit am Leben erhalten habe. $0 \mathrm{~b}$ es aber eine grössere, dem Aquila fulva näher stehende, Art giebt, die mehr einfarbig dunkel-kaffeebraun mit Goldglanz gefärbt ist, und sich vielleicht mehr östlich aufhält, mögen spätere Beobachtungen entscheiden; es scheint, als ob die Anmerkung in der kleinen Schrift des Grafen v. d. Mühle S. 19 u. 20 darauf hindeute. Alle alten Schreiadler, welche ich von hier erhielt und sah, waren sowohl im Herbst als Frühjahr ganz gleich gefärbt: Rücken, Schwanz, Schulterfedern dunkel mit Glanz, Flügel, besonders der obere Theil hell und matter gefärbt, Grösse bis auf den Geschlechtsunterschied bei allen ziemlich gleich, Schnabel und Zehen schwach.

\section{Falco islandicus.}

Die Bemerkungen des Verfassers im Vereine mit den gründlichen Untersuchungen Schlegel's in seiner Kritik möchten wohl hinreichen, den Falco candicans, islandicus und groenlandicus (Brehm) als eine und dieselbe Species wieder zu vereinigen. Ich habe eine ganze Reihe grönländischer Falken aus den verschiedenen Colonieen Grönlands unter den Händen gehabt, deren Musterung die Resultate dieser Naturforscher nur bestätigen. Das Vorwalten der weissen Farbe scheint theils ein Resultat des höheren Alters, hauptsächlich aber auch des Aufenthaltes in höheren Breitengraden zu sein; dagegen ist das Erscheinen der gelben Fänge und Wachshaut wohl allein ein Resultat des Alters. Solche gelbfüssige Falken erhält man nur selten aus Grönland; unter $\mathbf{1 0}$ weissen grönländischẹn Falken verschiedenen Geschlechts erhielt ich nur einen solchen, und dieser war nicht einmal so weiss als mehrere mit blauen Fängen und Wachshaut, die ich aus den nördlichsten Colonieen erhielt. So erhielt ich unter andern aus Nordgrönland ein beim Nest geschossenes altes Weibchen, an dem Kopf, Schwanz und alle untern Theile, ausser einigen freien Streifen, rein weiss waren. Rücken und Flügel waren auf weissem Grunde mit einzelnen dunkeln Längsstreifen (nicht Querbinden 
oder herzförmigen Flecken) versehen; es war so frisch, als ich es im October erhielt, dass die lebhaft bleiblauten Fänge noch vollständig biegsam waren.

Es ist also gewiss, dass dieser Falke (wie ich auch bei $\boldsymbol{F}$. naevius bemerkte) nicht das vollständig ausgefärbte Kleid zu erhalten braucht, um fortpflanzungsfähig zu werden, und lässt sich auch ohne Annahme einer Artverschiedenheit erklären, warum auf Island wenig weisse Falken brüten.

\section{Falco peregrinus.}

Ich erhielt aus Grönland ein altes Männchen, bei dem der rein weisse Fleck am Halse sich sehr weit auf die Brust herab erstreckt, und besonders an den Seiten mit blassem Rosenroth angelaufen ist; der Kopf fast schwarz mit sehr breitem Backenstreif, an den untern Theilen nur sparsame herzförmige Flecken auf weisslichem und weissröthlichem Grunde. Er scheint sich dem Falco anatum zu nähern, obschon die Abtrennung dieser Art wohl auf schwachen Gründen beruhen mag.

\section{Cinclus aquaticus.}

Mit Rücksicht auf Schl egel (l. c. S. 70) scheint mir die Bemerkung nicht überflüssig, dass alle Cinclus, die ich in der von mir bewohnten Gegend erhielt oder sah, zu der als Cinclus melanogaster aufgestellten Art (oder nach der Localität verschiedenen Varietät) gehörten, und ohne Rücksicht auf Alter, Geschlecht oder Jahreszeit stets einen einfarbigen Unterleib hatten. Schwanzfedern waren stets 12 vorhanden. Sie gleichen völlig einem alten Männchen, welches ich in diesen Tagen aus Lappland durch den Hrn. Prof. Naumann erhielt, nur sind an den hier erhaltenen, selbst im Herbste geschossenen, Exemplaren fast keine weisslichen FederSäume am Unterleibe zu bemerken, und sind dieselben vielleicht etwas grösser, doch täuscht dies bei Bälgen bekanntlich sehr. 


\section{Sterna anglica.}

Wenn Temminck im Manuel Tom. IV. p. 460 anführt, dass die Sterna aranea Wilson nach den Amerikan. Beobachtern von unserer Sterna anglica verschieden sei durch: „une légère différence dans les formes totales et une disparité trés-marquée dans leur genre de vie etc.", so kann ich dies zwar, was den ersten Unterschied betrifft, nicht bestimmt widerlegen, da mir zur Vergleichung Exemplare der amerikanischen Art abgehen; da aber dieser Unterschied légère sein soll, die zweite, von der Lebensart hergenommene, bedeutendere Verschiedenheit bei der hier vorkommenden Sterna anglica bestimmt wegfällt, so wird entweder Sterna anglica und aranea synonym sein, oder die hier vorkommende Sterna anglica gehört zu der amerikanischen Species, da sie nicht von Fischen lebt.

In der Nähe meines Wohnortes ist ein grosser See, welcher 2 Inseln enthält, auf deren einer Sterna anglica bisher jährlich in ziemlich grosser Anzahl brütete; und ich sehe mich daher in den Stand gesetzt, einige zuverlässige Nachrichten über selbige zu geben.

Sterna anglica stellt sich nach meinen Beobachtungen ziemlich früh am Brütplatze ein, da ich sie schon zu Ausgang April in Schaaren dort bemerkt habe, während Sterna hirundo und arctica hier erst in der ersten Hälfte des Mai sich zeigen. Sie macht bald Anstalten zum Brüten, und zu Anfang des Juni habe ich schon stark bebrütete Eier gefunden. Ihre Nester sind nicht so kunstlos wie die der hirundo und arctica, sondern bestehen aus einer mit trocknen Grashalnen reichlich belegten, und mit etwas erhöhter gleichfalls aus trocknem Grase bestehenden Rändern umgebenen Vertiefung, die sie gewöhnlich am Ufer über der Gränze anlegt, welche der höchste Wasserstand des Sees durch Aufspühlen von Schilfstückchen u. s. w. zurückgelassen. Auf dem Grante zwischen diesem Rande und dem Wasser, wo zuweilen die Sterna hirundo und Charadrius hiaticula (die einzeln diese Inseln bewohnen) ihre Nester anlegen, habe ich sie nie gefunden. Ich habe selbst eine Sterna anglica geschossen, welche im Schnabel einige trockne Grashalme zum Nestbau vom festen Lande zur Insel herüber trug. Federn habe ich nie in den Nestern bemerkt. Die Nester fand ich besonders an dem südlichen und westlichen 
Ufer, oft dicht zusammenstehend. In dieselben legt sie 2-4 Eier von so verschiedener Färbung und Form, dass ihre Beschreibung schwierig sein möchte, doch haben sie etwas Uebereinstimmendes, und sind überhaupt von Naumann gut beschrieben. In einem Neste fand 'ich 7 Stück, wahrscheinlich hatten 2 zusammen gelegt. Sie scheint auch am Tage zu brüten, denn zur Eierzeit sieht man stets eine ziemliche Menge auf der Insel sitzen, während eine noch grössere Anzahl über derselben schwebt. Năhert man sich aber derselben im Boote, so fliegen sie alle auf, und umgeben dasselbe mit ihrem einem Hohngelächter ähnelnden Geschrei; und nach dem ersten Schusse sind sie so scheu, dass selbst am Neste sie sich stets ausser Schussweite halten.

Obgleich der Meeresstrand kaum eine Meile von dem genannten See entfernt ist, so ist es doch eine grosse Seltenheit, dort eine zu erblicken, während ich sie 1/2 Meile weit vom Brütorte in's Land hinein hinter dem Pfluge habe gehen sehen. Der erwähnte See ist von baumlosen Ufern umgeben, die theils in trocknem, steinigem Ackerland, theils in Haide mit einigem Moorwasser bestehen.

Obschon der See fischreich ist, habe ich sie nie dort fischen sehen, und bei keiner der geoffneten Ueberreste von Fischen vorgefunden. Sehr häufig habe ich sie dagegen (auf meinen Berufsreisen) ihrer Nahrung nachgehen sehen und gefunden, dass sie dieselbe hauptsächlich auf dem Lande sucht. Wenn im Frühjahre zur Buchwaizen-Saat gepflügt wird, so sieht man sie stets hinter dem Pfluge, vermischt mit Larus ridibundus, einhergehen und Engerlinge auflesen. $\mathrm{Zu}$ andern Zeiten sah ich sie über das trockne Land hinstreifen, plötzlich (wie die andern Sterna) rüttelnd stillhalten und sich jählings gegen das Land herabstürzen, dabei aber stets ganz nahe über der Bodenfläche sich in einem flachen Bogen wieder aufschwingen; ihren Flug muss sie also sehr in ihrer Gewalt haben. Sehr häufig habe ich sie auch gegen die stillen Moorwasser herabstürzen sehen, aber nie ins Wasser selbst; da nun diese Wasser keine Fische enthalten, müssen es wohl Insekten sein, welche sie erhascht. Auf dem See habe ich sie nie fischen sehen, obgleich derselbe fischreich ist, sondern stets beobachtet, dass sie vom Lande gerade über den See zum Brütplatz flog, und denselben auch so verliess; über der Insel sieht man aber stets eine grosse Schaar kreisen.

Die von mir geöffneten hatten sämmtlich den Schlund voll 
von Maikäferlarven, nur eine hatte eine grosse grüne zerstückelte Eidechse im Oesophagus.

Die zweite Insel war, als ich sie besuchte, von Larus ridibundus bewohut, und war in solcher Menge von Eiern, nackten und ausgewachsenen Jungen bedeckt, dass ich, um nicht mit jedem Fusstritt mehrere zu vernichten, dieselbe schleunig verliess.

Leider muss ich hinzufügen, dass dieser interessante Brütplatz bald eingehen wird, da die Landleute den See, um Land zu gewinnen, etwas abgelassen und Knaben dadurch eine Fuhrt aufgefunden haben, wo sie zur Insel hin waten können. Im vorigen Frühjahre 1845 stellte sie sich zahlreich, wie gewöhnlich, ein, als ich aber zu Anfang August mich hinbegab, um wo möglich einige Vögel im Jugendkleid zu erhalten (während des Brütens hatte ich sie nicht stören wollen), fand ich nicht eine vor und erfuhr, dass ruchlose Knaben die ganze Brut zerstört hatten; unter andern hatte man am Ufer einen ganzen Haufen zerschlagener Eierschaalen gefunden. Ich habe die Jagdbeamten ersucht, diesem Unwesen wo möglich zu steuern.

\section{I $\mathbf{a}$ u s.}

Der Verfasser der vorstehenden Schrift macht an verschiede nen Orten auf den täglichen Zug aufmerksam, den man bei diesem Genus finde, ohne den Grund anzugeben. Bei den auf unsern Ostseehäfen sich aufhaltenden und überwinternden Möven (Larus marinus, argentatus, canus, ridibundus) findet genau dieselbe Erscheinung statt; sie hat aber bestimmt nur ihren Grund darin, dass dieselben sich auf ihre Schlafstätten begeben, welche sie nicht in den Häfen haben, sondern vielleicht auf einzelnen Steinriffen, unbewohnten Inseln, oder schwimmend auf offner See. Dies abendliche Verlassen der Häfen theilen mit den Möven fast alle übrigen Winterseevŏgel, und es hat etwas ganz Interessantes, gegen Abend am Ausgange der Fjorde dies zu beobachten. Da erscheint bald ein Zug Colymb. septentrionalis im schwerfälligen gerade ausgehenden Fluge, jeder für sich, vom nachfolgenden weit getrennt; bald dicht gedrängt mit läutendem Flügelschlag hoch in der Luft ein Haufe Anas clangula oder dicht an der Wasserfläche Anas glacialis mit melodischem Ruf. Wiederum streichen 
mit schwirrendem Fluge, dicht am Wasser hin, stets einzeln, Alca torda und Uria troile und endlich erscheint in unregelmässigen Haufen, gewöhnlich in der Mitte des Meerbusens, ziemlich hoch in der Luft die Mövenschaar bunt durcheinander, und in grosser Hast, während einzelne: am Ufer denselben Weg langsamer ziehend, vor dem Schlafengehen sich noch eine Mahlzeit zu erspähen suchen. Kaum aber haben alle den Hafen verlassen, so erscheinen wieder von aussen her (wo ich sie oft am Tage haufenweise auf offner See habe herumtreiben sehen) hereinziehend die Süsswasser-Enten, besonders Anas boschas, im Frühjahre Anas tadorna und mit heiserem Rufe der Reiher, die verlassenen Ufer einnehmend. Am Morgen ziehen mit den übrigen Wintervögeln die Mŏven wieder in die Häfen hinein, langsam dem Ufer folgend und unter beständigem Fischen. In der Mittagsstunde halten sie gewöhnlich auf irgend einem Sandriffe, alle Arten zusammensitzend, doch Larus marinus immer etwas gesondert, Ruhe. Da die $\boldsymbol{S}_{0-}$ materia-Arten ihre Futterplätze, wie wir gesehen haben, ziemlich weit hinaus in die See haben, so wäre es vielleicht möglich, dass ihr den Möven entgegengesetzter abendlicher Zug in Grönland dieselbe Bedeutung hätte, und dass sie in den Fjorden auf ruhigem Wasser etwa in der Mitte einen sicheren gemeinschaftlichen Schlafplatz fänden.

\section{Anas glacialis.}

Mit Beziehung auf die doppelte Mauser dieser Ente sehen wir in vorstehender Schrift den geehrten Verfasser auf die Seite $\mathbf{F a -}$ ber's und F. Boje's treten, der Meinung Naumann's in der Naturgeschichte Deutschlands XII. S. 225 entgegengesetzt. Naumann sagt, es liege ein Irrthum zu Grunde, wenn man behauptet hat, dass sie das Fortpflanzungs-Geschäft erst betrieben, wenn sie das braune Kleid völlig angelegt hätten, und Holbőll sagt, diese Ente sei in Grönland die einzige, deren Männchen das Sommerkleid vor der Brütperiode anlege. Ohne über die Bedeutung des einen und andern Kleides zu streiten, erlaube ich mir meine Beobachtungen hier anzuführen, da diese Ente sich auf unserm Hafen vom October bis April, ja selbst Anfang Mai, und zwar in 
In grosser Menge, aufhält, nur nicht wenn derselbe, was jedoch selten der Fall ist, zufri, i.

Wie bemerkt, kommt hier Anas glacialis im October an, und hält sich in grossen Haufen zuerst an den Sandbänken aussen vor dem Hafen auf, gegen das Frühjahr weiter hineinziehend. Diese Haufen sind aus Männchen und Weibchen gebildet und zuweilen auch aus Jungen, doch halten diese sich gern gleich anfangs gesondert, gewōhnlich näher dem Lande liegend *). Männchen und Weibchen sind den ganzen Winter über gepaart, welches man deutlich bemerkt, wenn ein Haufe auffliegt, wo man stets Männchen und Weibchen zusammen fliegen sieht. Trifft man ein einzelnes Paar, so fliegt das Männchen stets zuletzt auf, dem scheueren Weibchen folgend. Ungepaarte trifft man natürlich auch stets den ganzen Winter über an, und ich habe eben so oft an schönen Herbst - als Frühlingstagen mehrere Männchen ein Weibchen mit lautem Gesange verfolgen sehen. Im März beginnt durchweg die Mauser, und es scheint der Vogel während derselben gar nicht zu leiden, sondern ist stets munter; nie habe ich bemerken können, dass die Flügelfedern ausgefallen waren, noch weniger, dass die Männchen in dieser Zeit nicht fliegen können, wie Naumann dies l. c. angiebt. Vor einigen Jahren hörte ich in der Stadt in den Ostertagen den lauten Gesang dieser Ente vom Hafen her; Nachmittags begab ich mich im Boote hinaus, und fand 2 grosse Schaaren, jede aus einigen Hunderten bestehend, bei ganz stillem Wetter; so weit ich sehen konnte, waren alle Männchen in der Mauserung. Sobald die Schaar bei Annäherung der Boote fortflog, fand ich auf der Stelle, wo sie gelegen, eine ganze Menge durch die Mauserung ausgefallener Federn des Winterkleides. Ein altes Männchen, welches ich schoss, hatte bereits das Sommerkleid theilweise an, unter andern waren die gekrümmten Schulterfedern schon durch dunkle ersetzt, und am Halse der Vogel in starker Mauser. Als ich nach mehreren Tagen mich wieder hinausbegab, waren alle fortgezogen, bis auf 4 Stück, 2 Paar, von denen ich wiederum ein Männchen schoss, das auch zum Theil das Sommerkleid angelegt hatte. Nicht ganz selten trifft man auch völlig ausgefärbte Vögel der Art im Sommerkleide

*) So wurden hier im December 1845 IIunderte von Anas glacialis gefangen, die fast nur aus jungen Vögeln bestanden; ich sah selbst 14 Stück in einem Netze sitzen. 
hier an, aber die meisten begaben sich während der Mauserung mit ihren Weibchen fort. Dass malig (S. Naumann l. c.) im Mai und selbst Anfangs Juni alte Männchen im Winterkleide sieht, will ich gerne einräumen, und ist sehr erklärlich, da die Mausernden *) stets gepaart nach Norden ziehen und so die ungepaarten Männchen, deren Mauser sich durch unbekannte Ursachen verspätete, zurückbleiben. Diese Erfahrungen werden auch durch Capt. Holb öll's Bemerkungen bestätigt, indem derselbe sagt, dass das Männchen die Sommertracht vor der Brützeit anlege, und hauptsächlich dadurch, dass nach seinen am Brütorte gesammelten Erfahrungen das Männchen gleich nach dem Ausbrüten der Eier (also schon im Juli) wieder die Wintertracht anlege und schon im August nicht mehr im Sommerkleide angetroffen werde. Es ist Schade, dass der Verfasser nicht bemerkt, ob bei dieser Sommermauser die Schwungfedern ausfallen, welches ich im Frühjahre nie habe finden können, vielmehr scheint mir die Frühjahrsmauser mehr mit der der Uria-, Alca- und Colymbus-Arten (s. unten) nebst Möven zu correspondiren, bei welchen erst in der Herbstmauser Schwung- und Schwanzfedern gewechselt werden.

\section{C $\mathbf{y} \mathbf{m}$ b u s.}

Ich hatte gehofft, als ich die IIolböll'sche Schrift zuerst in die IIand nahm, dass ich darin eine Bestätigung meiner Erfahrungen über die Mauser dieses Genus finden würde. Leider sagt der Verfasser aber, dass es ihm nicht geglückt sei, in dieser Beziehung einige Resultate erlangt zu haben**). Ich sehe mich daher genöthigt, mit meinen Beobachtungen ohne diese Stütze hervorzutreten, obgleich ich dies mit einigem Zagen thue, da ich einer so bedeutenden Auctorität, als Naumann ist, entgegentreten muss.

*) Dass die nordischen Seevögel ihre Reisen nicht ungewöhnlich während dẹ Mauser vornehmen, werden wir spăter beim Colymbus septentrionalis bestätigt sehen.

**) Sollte dieser Umstand nicht selbst für meine Ansicht sprechen und die Colymbi ihr nordisches Vaterland im Prachtkleide verlassen, in dem sie dort ankommen? 
Naumann sagt XII. S. 386, dass die Colymbi ihr Prachtkleid im August ablegen und in den Wintermonaten wieder anlegen, dass man namentlich in den Monaten October, November und December alte Vögel im Uebergange zum Prachtkleide fände.

Ich bin der Meinung, dass die Colymbi ihr Pracht- oder Sommerkleid im März und April anlegen und wieder mit dem unscheinbaren grauen oder Winterkleide in den Herbstmonaten, September bis Ausgang December vertauschen, eben so wie die Alken, Teisten und Lummen, nur etwas später, denen auch $\mathrm{Nau}$ mann diese Mauserung beilegt; (s. l. c. XII. 457, 468, 485, 514, $530,540,614$.)

Zuvörderst muss ich bemerken, dass meine Beobachtungen sich nur auf Colymb. arcticus und septentrionalis beziehen, da C. glacialis hier zu selten vorkommt, um Schlüsse ziehen zu können, und mache ich auch ausserdem darauf aufmerksam, dass einzelne entgegenstehende Beobachtungen nichts gegen die allgemeine Regel entscheiden. So erhielt ich in den ersten Tagen des Januar 1846 ein altes Männchen der Uria grylle im vollkommenen Sommerkleide und eben so von Alca torda einen alten Vogel mit halb vermauserter Kehle, während man oft zu Anfang Mărz alte Alca torda schiesst, die noch einen rein weissen Vorderhals haben, und hier kann zwischen Alt und Jung keine Verwechselung stattfinden; so erhielt ich ferner am 24sten Decemher 1845 ein altes schŏnes Männchen der Larus fuscus*) im reinen Sommerkleide, da es doch bekannt genug ist, dass die Möven 2 Mal jährlich, im Frühjahre und Herbste, mausern.,

Was zuerst Colymbus septentrionalis betrifft, so beginnt die Herbstmauser, die vollständig ist, und durch welche die alten Vögel ihr Prachtkleid mit dem grauen unscheinbaren Herbstoder Winterkleide vertauschen, vielleicht bereits schon im August, dauert aber bestimmt bei einer nicht geringen Anzahl bis in den October und selbst November hinein und alte Vögel, die man in diesen Monaten mit noch vorhandenem zimmtbraunen

*) Ich halte die Bemerkung nicht für überflüssig, dașs Larus fuscus hier zu den seltensten Erscheinungen gehört, Der erwähnte Vogel ist der einzige der Art, den ich in 8 Jahren gesehen oder erhalten habe. Ein Freund von mir, welcher bereits 20 Jahre und darüber sammelt, hat sie nie hier erhalten, - Larus marinus ist dagegen eine tägliche Erscheinung. 
Kehlstrich antrifft, sind im Uebergange in's graue und nicht in's Prachtkleid begriffen*), da der braune Kehlstrich am letzten verschwindet, wie er auch zuletzt im Frühjahre erscheint. Das Pracht- oder Sommerkleid zieht der alte Vogel erst wieder im Mărz und April an, und begiebt sich während der Frühjahrsmauser wieder nach Norden zurück.

Es hat allerdings etwas Auffallendes, dass der Vogel grade wăhrend seiner Haupt-Herbstmauser wandert, allem die Beobachtungen, die ich darüber habe anstellen können, sind so zahlreich, dass ich darüber nicht im Zweifel sein kann. Der Colymbus septentrionalis gehört in unsern Ostseehäfen zu den allerge. wöhnlichsten Erscheinungen, und wird den ganzen Winter hindurch zu Hunderten geschossen und in Netzen gefangen, so dass ich den Vogel in jedem Monate und jeder Tracht, welche er in der Zeit seines Hierseins hat, dutzendweise labe untersuchen können.

Schon im September hört man gewöhnlich hoch in der Luft, besonders bei kaltem Wetter, die lautschallende Stimme des Vortrabs; im October, November und December nehmen die Schaaren zu, dann wird er, namentlich bei hartem Winter, selten (in gelinden überwintert ein grosser Theil) und im Mărz und April kehrt die ganze Menge in raschem Zuge zurück.

Die alten Vögel, welche man im September und October, und einzelne davon, die man im November erhält, haben noch Spuren des Prachtkleides an sich, namentlich einen zimmtbraunen Streif an der Kehle, während die obern Theile alle das graue Winterkleid zeigen. Nur zwei mal erhielt ich früh im Herbste Vögel in fast vollständigem Prachtkleide, doch fing bei diesen auch schon die Mauserung auf den obern Theilen an. Einmal habe ich einen auf dem Kieler Hafen (im Vereine mit noch lebenden Zeugen) gejagt, der durchaus nicht fliegen wollte; wiederholt verwundet und auf seichtes Wasser gejagt, wusste er zuletzt vor dem schnellrudernden Boote keinen andern Ausweg, als auf's Land sich zu schieben, wo er lebend ergriffen wurde. Bei der Untersuchung zeigte es sich, dass es ein alter Vogel in der Mauserung war, der alle Schwungfedern abgeworfen hatte und nicht fliegen konnte; es war, wenn ich nicht irre, im October. Vom

*) N a umann I. c. S. 440 . 
December an bis in den Februar habe ich nur Vögel im reinen Winterkleide gesehen. Im December 1844 sah ich mehrere Tage einen grossen Haufen von gewiss 4-500 Stück unsern Hafen umkreisen, wie es schien, ungewiss, ob er weiter ziehen sollte; wenn mir die Schaar über den Kopf flog, konnte ich deutlich genug die weissen Hälse aller unterscheiden, da sie nie ge drängt, sondern stets weit aus einander fliegen; ich bemerkte nicht einen darunter mit dunkelm Halse. In diesen Tagen (Ende Januar 1846) sahe ich den Vogel täglich an den Stangen der Fischer hängen, neben den Fischen, mit denen er sich zugleich gefangen; noch heute den 26sten Januar musterte ich 3 Stück, von welchen einer gewiss ein sehr alter ungewöhnlich grosser Vogel war; alle hatten sie die rein weisse Kehle dè Winterkleides. Wenn, wie Naumann l. c. 440 meint, das Prachtkleid bei den Alten in der Regel im Januar vollendet ist, müsste ich bei dieser Menge doch einen der Art in diesen Monaten antreffen. Erst im März sieht man alte Vögel und in der Mitte des April habe ich ihn mehrmals im Prachtkleide erhalten, mit noch weissen Federn auf brauner Kehle untermischt, und bei Untersuchung der Fleisch - Seite des Balges zeigte es sich, dass die weissen alte, die rothbraunen neue Federn waren.

Naumann bemerkt l. c. S. 443: „So oft man an den schleswig-holstein'schen Küsten den Vogel auch im Spätherbst ankommen sah, so wenig konnte man dort seinen Rückzug bemerken" und B oje in seiner Reise S. 157 bemerkt dasselbe. Dies beruht wahrscheinlich darauf, dass er im Frühjahre nicht in die Häfen hinein kommt, sondern sich an der Mündung derselben aufhält, wo er dann Nahrung genug vorfindet. Hier habe ich im Frühjahre in jedem Jahre seinen Rückzug beobachtet, aber nur wenige erhalten, weil der Vogel dann scheu ist, und nicht dorthin kommt, wo die Netze der Fischer stehen. Der Rückzug geht rasch vor sich, doch sieht man Ende März und Anfang April noch manche mit heller Kehle, obwohl die mit dunkler Färbung häufiger sind:

\section{Colymbus arcticus}

ist hier viel seltener, doch habe ich genug Exemplare dieser Art in den verschiedenen Trachten erhalten, um behaupten zu kön- 
nen, dass die Mauser ähnlichen Regeln unterworfen ist, als die der vorhergehenden Art. Da der Vogel jedoch später im Herbste zu uns kommt, als die vorhergehende Art, und derselbe gleichfalls auf der Wanderung mausert, so trägt er sein Prachtkleid auch länger in den Herbst hinein, und ich habe selbst im December Voggel der Art erhalten, bei denen die Mauser nicht gerade sehr weit vorgeschritten war. Naumann hat selbst ein Exemplar erhalten, an welchem sich noch im Januar einzelne schwarze Federn an der Kehle fanden, und nimmt an, dass dies der Beginn der Frühjahrmauser oder der Uebergang in's Prachtkleid sei, welches nach ihm (l. c. 426) der Vogel schon vom October bis in den December erhält. Ich habe manche Vögel der Art im Fleische untersucht und gefunden, dass in diesen Monaten die grauen Federn die neu hervorkeimenden waren, die Federn des Prachtkleides dagegen die alten verschlissenen sind. Ein Exemplar. im November oder December 1844 im Netze gefangen, habe ich vor kurzem Herrn Prof. Na uman n übersandt; es ist zum grössten Theil noch im Prachtkleide, aber überall am Hinterhalse keimen die grauen, an der Kehle die weissen frischen Federn des Winterkleides hervor und verdrängen die Federn des Prachtkleides*), denen man das Abgenutztsein deutlich, besonders den verlängerten, mit den viereckigen Flecken versehenen, Schulter- und Oberrückenfedern ansieht; an diesem Exemplar waren die hervorkeimenden grauen und nicht die schwarzen Federn des Prachtkleides sogenannte Blutfedern**). Im Januar habe ich die meisten erhalten, alt und jung, aber stets im reinen Winterkleide. Der vorige Winter war besonders reich an diesen Vögeln; ich erhielt vom November bis Februar, ausser dem obenerwähnten, 5 Stück sämmtlich im Winterkleide oder Jugendkleide, von welchen ein sehr altes Männchen mit fast ganz bleischwarzem Schnabel und ungewöhnlicher Grösse noch in meiner Sammlung steht; es wurde ge-

*) Man darf die schwarzen Federn des Prachtkleides nicht wegen des eigenthümlichen Glanzes, den sie nicht leicht verlieren, für neue halten.

**) Nach dem Ausfallen der Federn eines mausernden Vogels allein kann man nicht bestimmen, ob dies alte oder neue Federn sind; nimmt man einen mausernden Vogel in die Hand und streicht das Gefieder, so fallen die alten gerade lose sitzenden Federn heraus; hat man ihn aber abgebalgt und macht dasselbe Experiment, so sieht man einen Theil der neuen Federn am leichtesten ausfallen, besonders wenn der Vogel fett war, da diese, so lange sie Blutfedern sind, weniger fest in der Haut, als dem darunter liegenden Zellgewebe sitzen. 
gen Ende Januar geschossen, und ist in ganz reinem Winterkleide, ohne eine schwarze Feder an der Kehle.

Im Frühjahre habe ich den Vogel nicht bemerkt, was aber bei seiner grossen Seltenheit nicht zu verwundern ist.

Der auffallende Grössen-Unterschied ist von mir auch stets bemerkt: so erhielt ich in diesen Tagen ein junges Weibchen von so kleinen Dimensionen, dass es an Grösse nicht einen Colymbus septentrionalis mittlerer Grŏsse, selbst nicht am Schnabel, erreicht. Ein ähnlicher sehr alter Vogel im reinen Prachtkleide steht in meinerSammlung, kleiner als ein neben ihm stehender $C$. septentrionalis, doch aber mit stärkerem Schnabel. Ich glaube jedoch im Allgemeinen bemerkt zu haben, dass die kleinsten junge Vögel, besonders Weibchen waren, und scheint mir der Unterschied verhältnissmässig nicht bedeutender, als zwischen einem alten Männchen der Anas clangula und einem jungen kleinen Weibchen derselben Art oft statt findet; daher die Trennung in 2 Species ohne Auffinden anderer Merkmale, nach der Grösse allein, wohl hinreichenden Grundes entbehrt. 






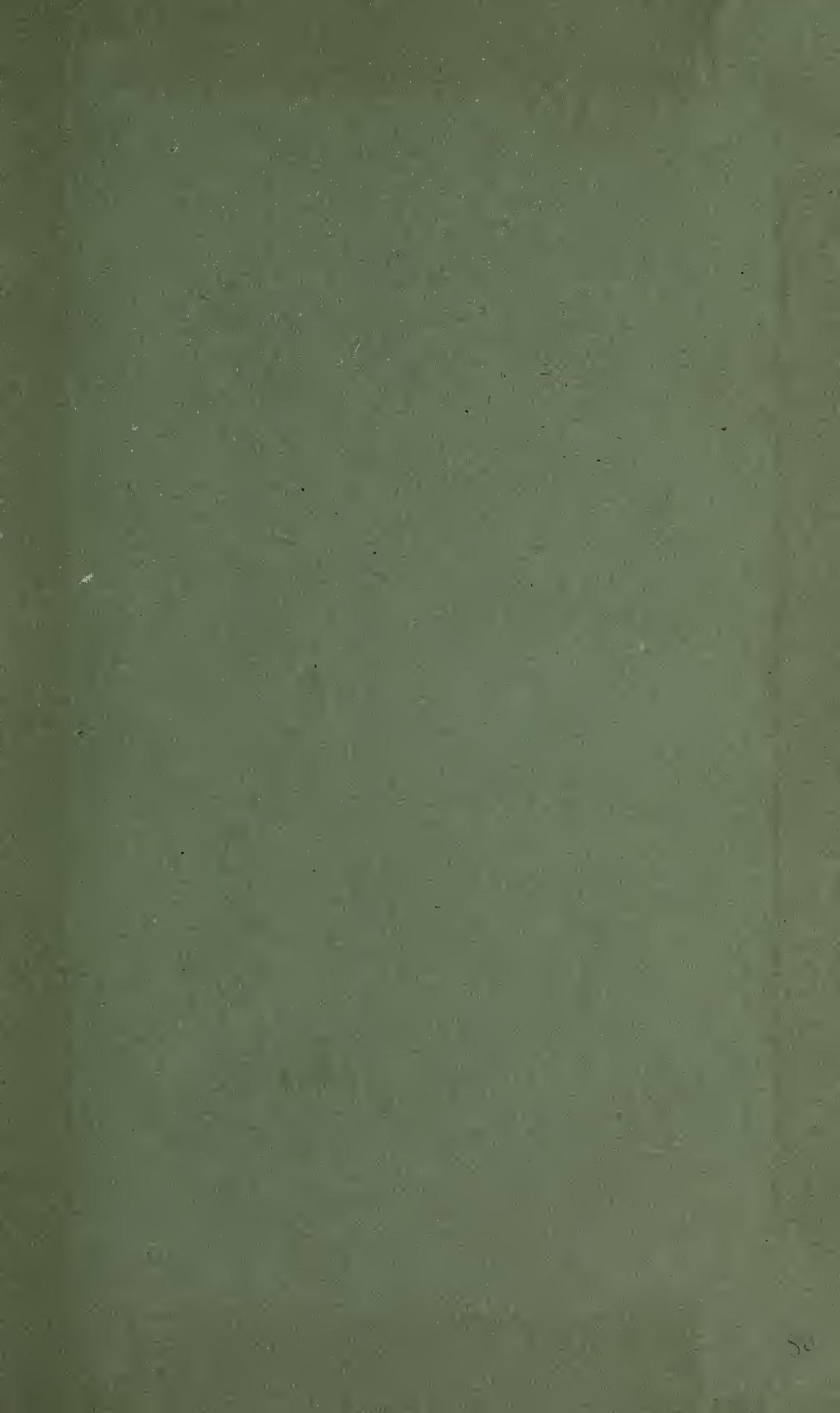


